United Nations University Press is the publishing arm of the United Nations University. UNU Press publishes scholarly and policy-oriented books and periodicals on the issues facing the United Nations and its peoples and member states, with particular emphasis upon international, regional and transboundary policies.

The United Nations University was established as a subsidiary organ of the United Nations by General Assembly resolution 2951 (XXVII) of 11 December 1972. The United Nations University undertakes a wide range of activities focused on knowledge generation (basic and applied research, and foresight and policy studies), education and capacity development (developing human and organizational capabilities), and knowledge transfer and sharing (communications, dissemination and outreach). The University operates through its institutes and programmes located throughout the world, and its planning and coordinating centre in Tokyo. 
EU enlargement and Turkish labour migration 



\section{EU enlargement and Turkish labour migration}

Gönül Oğuz

United Nations
University Press

TOKYO • NEW YORK • PARIS 
(C) United Nations University, 2012

The views expressed in this publication are those of the author and do not necessarily reflect the views of the United Nations University.

\section{United Nations University Press}

United Nations University, 53-70, Jingumae 5-chome,

Shibuya-ku, Tokyo 150-8925, Japan

Tel: +81-3-5467-1212 Fax: +81-3-3406-7345

E-mail:sales@unu.edu general enquiries: press@unu.edu

http://www.unu.edu

United Nations University Office at the United Nations, New York

2 United Nations Plaza, Room DC2-2062, New York, NY 10017, USA

Tel: +1-212-963-6387 Fax: +1-212-371-9454

E-mail: unuony@unu.edu

United Nations University Press is the publishing division of the United Nations University.

Cover design by Maria Sese-Paul

Printed in the United States of America

ISBN 978-92-808-1206-0

Library of Congress Cataloging-in-Publication Data

Oğuz, Gönül. EU enlargement and Turkish labour migration / Gönül Oğuz. p. $\mathrm{cm}$.

Includes bibliographical references and index.

ISBN 978-9280812060 (pbk.)

1. Foreign workers, Turkish-European Union countries. 2. Turkey-Foreign economic relations-European Union countries. 3. European Union countriesForeign economic relations-Turkey. 4. European Union-Turkey. 5. European Union-Membership. I. Title.

HD8378.5.T8O48 2012

$331.6 ' 256104-\mathrm{dc} 23$ 


\section{Endorsements}

"Migration-related issues in the context of Turkey's prospective EU membership have attained growing salience in public, policy and academic debates in the EU, because they have unique and multi-faceted implications for the economic, social, political and demographic structures and processes of the EU. Debates about Turkey-related migration to Europe involve a variety of issues: For instance, many politicians in Europe frequently speak of the 'invasion' of migrants from Turkey, when they publicly debate Turkish EU membership. Moreover, the commonlyaccepted view that Turkish immigrants who are already in Europe face integration difficulties, together with intensifying Islamophobia on the continent, have made Turkey-related migration issues a topic of critical debate in European circles. However, proponents of Turkey's EU membership argue that Turkey's EU membership is in the Union's interest because it would reduce demographic pressures on the labour market by bringing workers into the Union. In this volume, Gönül Oğuz critically examines the issues of Turkey-related migration in the context of European enlargement, and provides stimulating answers to many questions fundamental to an understanding of these burning issues."

Ahmet İçduygu, Professor of International Relations and Director of the Migration Research Program, Koç University 
"This provocative book argues that Turkish accession to the EU is more likely to be associated with a test-the-waters migration hump rather than an ongoing wave of Turkish migrants to EU member states."

Philip Martin, Professor in the Department of Agricultural and Resource Economics, University of California, Davis, and Chair of the University of California Comparative Immigration and Integration Program

"This is a timely book. It brings together in an informed and well-organized way some of the key issues relating to European labour migration, particularly in the current uncertain economic conditions. Its main intellectual strength is its use of the important Turkish example as a lens through which to view the evolution of migration in the continent as a whole over several decades. It identifies and scrutinizes many of the key issues facing EU and national policymakers as well as those confronting Turkey itself. It is surprising, given the longevity of migrant flows from Turkey into Western Europe, that there has so far been no similar text and the author is to be congratulated on taking on the job. The arguments presented are well-supported by empirical data and by an extensive bibliography. It is clearly written and will be a welcome addition to the bookshelves of academics, policymakers and other interested parties."

John Salt, Emeritus Professor of Geography and Director of the Migration Research Unit, University College London 


\section{Contents}

Endorsements $\ldots \ldots \ldots \ldots \ldots \ldots \ldots \ldots \ldots \ldots \ldots \ldots \ldots \ldots \ldots, \quad \mathrm{v}$

Figures $\ldots \ldots \ldots \ldots \ldots \ldots \ldots \ldots \ldots \ldots \ldots \ldots \ldots \ldots \ldots \ldots$ viii

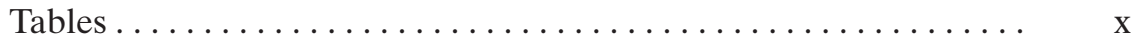

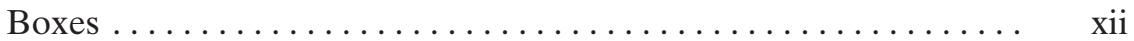

Abbreviations $\ldots \ldots \ldots \ldots \ldots \ldots \ldots \ldots \ldots \ldots \ldots \ldots \ldots \ldots \ldots \ldots$, xiii

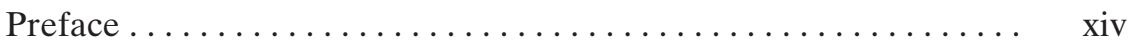

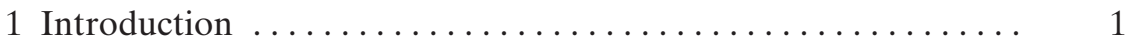

2 Turkish labour mobility in the European Union ........... 25

3 Past enlargement experiences...................... 59

4 The European Union's overall strategy for the movement of

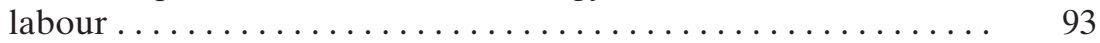

5 The impact of Central and East European accession on the movement of Turkish labour .................... 116

6 Concluding remarks $\ldots \ldots \ldots \ldots \ldots \ldots \ldots \ldots \ldots \ldots \ldots$

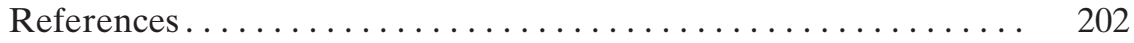

Index $\ldots \ldots \ldots \ldots \ldots \ldots \ldots \ldots \ldots \ldots \ldots \ldots \ldots \ldots \ldots \ldots \ldots \ldots \ldots, 215$ 


\section{Figures}

1.1 Annual flows of Turkish workers to West European host countries, 1961-2008

1.2 Annual flows of Turkish workers to other countries, 1961-2008

3.1 Stock of immigrants from Spain in the UK and Germany, relative GDP per capita and relative employment rate, 1985-1997

3.2 Stock of immigrants from Portugal in the UK and Germany, relative GDP per capita and relative employment rate, $1985-1997 \ldots \ldots \ldots \ldots \ldots \ldots \ldots \ldots . \ldots 6$

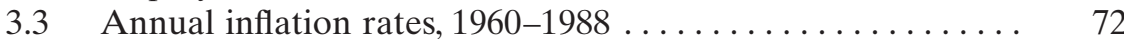

4.1 Reasons for admitting Central and East European countries ............................... 101

5.1 Youth education attainment level, $2006 \ldots \ldots \ldots \ldots \ldots \ldots . \ldots 124$

5.2 Employment by sector, $2007 \ldots \ldots \ldots \ldots \ldots \ldots \ldots . \ldots 126$

5.3 At risk of poverty after social transfers, persons aged 65 years and over, $2005 \ldots \ldots \ldots \ldots \ldots \ldots \ldots \ldots \ldots \ldots \ldots$

5.4 Total public expenditure on education, 2004 ........... 143

5.5 Number of hospital beds per 100,000 inhabitants, 2005 . . . 144

5.6 Number of practising physicians per 100,000 inhabitants,

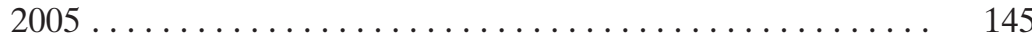

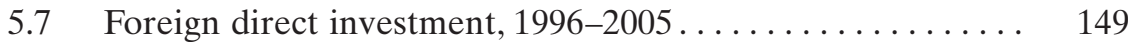

5.8 Inequality of income distribution, $2005 \ldots \ldots \ldots \ldots \ldots \ldots$ 
5.9 Proportion of secondary school pupils learning foreign languages, by language, $2005 \ldots \ldots \ldots \ldots \ldots \ldots \ldots$

5.10 Convergence of CEEC income levels towards the EU-15 . . 176 


\section{Tables}

1.1 Annual inflows of Turkish workers to European host countries, 1961-2008

1.2 Annual inflows of Turkish workers to other countries, 1961-2008 .................................. 17

$3.1 \quad$ GDP per capita, $1985 \ldots \ldots \ldots \ldots \ldots \ldots \ldots \ldots \ldots \ldots \ldots \ldots$

3.2 Unemployment rates, $1975-1987 \ldots \ldots \ldots \ldots \ldots \ldots \ldots . \ldots 6$

3.3 Characteristics of the labour market, $1987 \ldots \ldots \ldots \ldots \ldots .70$

3.4 Increase in gross domestic production, 1970-1987 . . . . . . 71

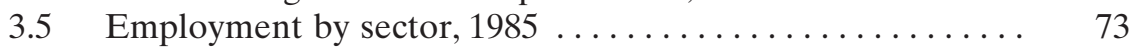

3.6 Composition of GDP by sector ................ 74

3.7 Total expenditure on education and the proportion of the adult population with upper secondary education ....... 75

$3.8 \quad$ Indicators of living standards, $1985 \ldots \ldots \ldots \ldots \ldots \ldots \ldots . \ldots \ldots$

3.9 Population, $1970-1985 \ldots \ldots \ldots \ldots \ldots \ldots \ldots \ldots \ldots \ldots \ldots$

3.10 Population by age group, $1985 \ldots \ldots \ldots \ldots \ldots \ldots \ldots \ldots$

4.1 Evolution of the EEC labour market in terms of new work

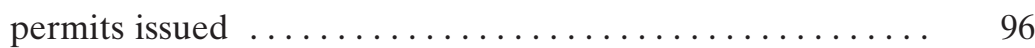

5.1 Selected macro-analytical model-based calculations ...... 118

5.2 CEEC employment rates in the EU-15 member states, by

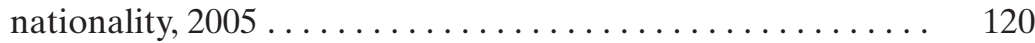

$5.3 \quad$ Unemployment rates........................ 122

5.4 Students in tertiary education, $2006 \ldots \ldots \ldots \ldots \ldots \ldots .6 \ldots$

5.5 The minimum wage in the EU-27 and Turkey, 2007 ..... 132

5.6 GDP per capita: PPP ....................... 133 
5.7 The number of Turkish workers in foreign countries, 2006 .. 136

5.8 Expected destinations of Turkish migrants in the EU, based on numbers in EU countries in 1999 ............... 137

5.9 Preferred destination countries of Turks for short trips ... 139

5.10 Estimated contributions and receipts for the candidate

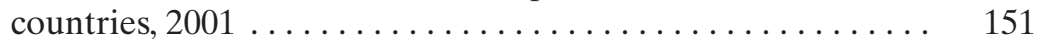

5.11 Total populations in Europe, 1997-2007............. 158

5.12 Naturalization of Turks in some EU countries ......... 169 


\section{Boxes}

1.1 The determinants of migration $\ldots \ldots \ldots \ldots \ldots \ldots \ldots \ldots$. 5

4.1 An overview of the transitional period $(2+3+2) \ldots \ldots \ldots \ldots .103$ 


\section{Abbreviations}

CEE Central and Eastern Europe

CEEC Central and East European country

EC European Community

EEC European Economic Community

EU European Union

ECJ European Court of Justice

JHA Justice and Home Affairs

FDI foreign direct investment

OECD Organisation for Economic Co-operation and Development 


\section{Preface}

This book is based on my $\mathrm{PhD}$ thesis, which was completed in September 2010 at the University of Reading. The last two waves of enlargement of the European Union (EU) in May 2004 and July 2007 have refuelled the debate about Turkey's admission to the Union. The key issue in the enlargement debate has centred on labour migration, with complex and sometimes contradictory implications for Turkey. With this book, I hope to resolve the debate about the potential need for Turkish workers in the post-enlargement period. At a time when the EU has grown in size through the accession of new member states, while its legitimacy regarding the addition of policy areas is ever more contested, employmentrelated migration seems to me to be of the utmost importance, not only for students of European politics but for the public in general. Its impact on Turkish labour migration is evident and crucial. I am hoping to make a contribution to this debate, as well as highlighting relevant policies and instruments.

This book is about the Eastern enlargement and its link with Turkish labour migration in the EU. The likelihood is that, if significant labour movement takes place from these new accession countries to the EU, severe, even unbearable, strains will be imposed on Turkey, because its population continues to expand unchecked without the necessary growth of the national economy to prevent massive unemployment. I therefore examine the effects of the Southern enlargement and (more recently) the Eastern enlargement of the EU on the free movement of Turkish labour. At the same time, the European Community's experiences with past en- 
largements to integrate economies that had much in common with Turkey can serve as an indicator of what would happen if Turks were granted free access to the EU. The book demonstrates that, before the Southern enlargement, there were fears within the old members of the Community that there would be massive waves of migration from the new member states, but that these failed to materialize to the extent predicted. A detailed comparison of demographic, social, economic and educational data suggests that the same would hold true if Turks were allowed free movement into the EU, notwithstanding persistent cultural (especially religious) differences.

Hence, the book covers the most important aspects of how the demand side of Turkish labour migration has been shaped largely by changing trends in demand in the European economies and of the size of future migration in the face of the EU enlargements. Having said this, the book presents a detailed review of the literature describing why restrictions were applied throughout West European countries in the period 19612008. Based on past enlargement experiences, the book focuses on the more negative externalities to the extent that the inclusion of Greece, Spain and Portugal created difficulties for the integration of Turkey with a possibly large number of migrants - into European labour markets in the 1980s. The book assesses the EEC/EU's legal framework as well as the different policy regimes of the individual member states, which are closely associated with the historical and future Turkish flow rate. Finally, the book provides a very detailed and thorough evaluation of the factors that are key to the potential of future Turkish labour flows in the EU in the context of the Eastern enlargement.

I would like to thank my PhD supervisor Professor D.B.G. Heuser for responding promptly and enthusiastically to my many requests to review the drafts of my work. I am grateful for her understanding and kindness. I am also indebted to my former supervisor, Professor Christopher Lord, whose wholehearted approval of my research proposal first gave me the confidence and courage without which this book would probably never have been written. During the first three years of my research he was a sounding board for many of the ideas in this book. My support network extends to the academic examiners. Indeed, I am extremely grateful to Dr Jonathan Golub, who provided much-needed advice and criticism that undoubtedly improved the book at a number of points. A special debt of gratitude is owed to Professor Bülent Gökay for his comments after reading the whole text. 

1

Introduction

\section{The EU enlargement process}

On 1 May 2004, the European Union (EU) reached the end of a long process of enlargements that extended membership to eight new Central and East European countries (CEECs) - Hungary, Poland, the Czech Republic, Estonia, Slovenia, Slovakia, Latvia and Lithuania - plus Cyprus and Malta. Two more countries, Romania and Bulgaria, joined the EU on 1 July 2007. These Central and East European countries are referred to as the CEEC-10, even though they in fact exhibit considerable heterogeneity. The EU guarantees the free movement of workers to all its citizens and eventually to the citizens of the accession countries - the European agreements have already guaranteed the citizens of the CEECs the right to work. EU citizens are to be free to move anywhere within the expanded EU to look for work.

As with the Southern enlargement, concerns arose in some older member states regarding the impact of complete liberalization on their labour markets. In response to this fear, the EU added "transitional arrangements" to the accession treaties, which gave the member states the option of delaying the implementation of the right to full free movement of workers for up to seven years. Most EU countries imposed restrictions on workers from the eight Central European accession countries after the 2004 enlargement, although workers from Malta and Cyprus can move freely across the EU member states. Only the UK, Sweden and Ireland fully opened their doors immediately. The transitional arrangements

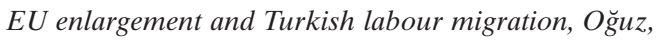

United Nations University Press, 2012, ISBN 978-92-808-1206-0 
that applied for the first two years ended on 30 April 2006. Germany, France, Italy, the Netherlands, Belgium, Austria and Luxemburg then applied a three-year (phase two) transitional period. From May 2011, full freedom of movement applied throughout the EU, but the free movement of workers from Romania and Bulgaria will be delayed until 30 June 2014.

The issue of the proposed free movement of workers from the CEECs is not without precedent in the history of the Union. The common position of the countries of the European Economic Community (EEC) in the Association Agreements signed in 1963 and the Additional Protocol in 1973 between the Community and Turkey envisaged progressive stages of movement between 1976 and 1986. The 1960-1973 period saw considerable Turkish labour migration to West European countries, and these legal instruments reflected a cautious approach to this issue. Labour shortages in some countries induced openness and even an active recruitment policy. For example, Germany established a guest worker programme by means of a recruitment treaty with Turkey. At the end of 1973, recruitment of foreign labour was abruptly stopped owing to the saturation of the labour market in the Community. Caution recurred with the accession of the South European countries, notably Greece (1981), Spain and Portugal (1986), when the introduction of free movement with the labour-sending countries was expected to instigate large migration flows. Later still in the integration process, labour migration from the newest EU members remains a controversial issue for the EU-15 countries as the key variable in determining the probable scale of international labour migration.

Enlargement is expected to bring significant labour flows. Much of the debate has centred on whether there are disadvantages for the EU in granting Turkish workers greater access to European labour markets. The key question is whether the Turkish labour flow rate is likely to fall sharply as a result of the Eastern enlargement. Indeed, the effect of EU enlargement is already being felt, as the old EU member states started to recruit from the new entrants. On the face of it, the prospect of largescale labour flows from the CEECs to the EU is of considerable concern. How pressing is this concern? This study will try to provide an answer to this question.

\section{Overview of the literature on theories of migration}

Mobility and migration constitute complex phenomena, and their analysis proves increasingly to be interdisciplinary (Borjas et al. 1996: 279). In the literature, there is no clear differentiation between the terms "mobil- 
ity" and "migration". In some cases, they are even used synonymously. Nevertheless, the two terms should be differentiated as follows. The spatial (interregional) mobility of workers is, in general, any movement of labour from one region to another. The spatial movement of labour together with a simultaneous change of residence is migration. Thus, "migration" has the connotation of permanence. If the spatial movement of labour does not involve a change of residence, it entails commuting (Hönekopp and Werner 2000: 2). Thus, "labour mobility" is taken literally to mean any change that alters one's work or geographical location.

Hence, the term "labour migrant" is usually reserved for those who migrate for work reasons, but this is a very diverse group. It includes: contract labour migrants recruited in groups for specific projects; individual contract workers, often for indeterminate periods; highly skilled professional, managerial and technical workers on secondment, short-term assignments or in joint ventures; seasonal workers; au pairs; domestic servants; restaurant/bar staff; entrepreneurs. Other migrants do not move primarily for work reasons, but subsequently enter the labour market and become part of the immigrant workforce - family members rejoining a primary labour migrant; foreign students who work temporarily during their courses or stay on permanently after qualification; asylum seekers who enter the labour market unofficially before acceptance, and stay and work illegally despite rejection of their claim; refugees who enter the labour market legally after being granted the right to stay; and those who come as tourists, stay beyond the legal period of presence as tourists and enter the labour market, even though they may intend eventually to return to their country of origin (Salt 1992: 1079).

In economic theory, there are two hypotheses regarding the movement of workers within integrated markets. According to integration theory, the creation of a common market leads to increased economic welfare if workers are allowed to move to an area where their productivity is greatest and the wages they can earn are, hence, also the highest. This assumes movement away from less productive to more productive workplaces in the integration area. This process continues until marginal productivity and, at the same time, wages (for the same work) reach equilibrium throughout the area. The underlying assumptions are, of course, that the workforce is mobile, that information about available employment is easily accessible to all and that there are no obstacles to migration such as legal barriers (residence permit, work permit), non-recognition of qualifications or cultural and linguistic differences (Hönekopp and Werner 2000: 4).

According to classical foreign trade theory, the gains from trade are modified by the existence of production factors, such as the state of technology, labour and natural resources. The opportunity cost ratios are 
different in each country. This means that beneficial trade is possible that raises prosperity. Each country is more efficient than the others in the production of particular commodities so that it has a comparative advantage. This emphasizes the division of labour generated by foreign trade in accordance with the comparative cost advantage. Prosperity is conditional on increasing the volume of trade between the countries. On the other hand, it is very possible that increasing specialization yields disadvantages with respect to labour mobility. From this standpoint, labour migration is unnecessary. For most, increased trade between countries is considered to be a more favourable movement than labour.

A theory of migration highlights those factors that are important for migration to occur, namely the pull factors and push factors for foreign labour that are inherited in the economic structure of contemporary advanced societies. This idea was first put forward by Everett Lee (1966), who provided a general explanation of the causes of migration. Ever since Lee's contribution, a number of negative (push) factors in the country of origin that cause labour migration, in combination with a number of positive (pull) factors that attract migrants to a receiving country, are repeatedly proposed and both are necessary to get started. The push factors include such elements as the lack of employment prospects, unemployment or low income in the home country, while the pull factors comprise geographical and cultural proximity and the comparative advantages of the destination country, including higher wages, the availability of jobs or better working conditions.

In order to encourage workers to move, the labour market situation needs to be fully transparent. The largest migration flows result from legal entitlements (for example, family reunion), in the sense that a legally permissible labour market entails a high degree of mobility (illegal migration is not considered). The ensuing flows are regulated by legislative and administrative procedures - work permits or residence permits that limit access and the duration of stay. In any case, more attention than hitherto should be paid to other barriers, such as the lack of familiarity with other foreign languages, removal costs and cultural differences, all of which are assumed to be barriers to international mobility in general.

Migration theory also stresses the importance of networks. Migration networks can be defined as sets of interpersonal relations that link migrants or return migrants with relatives, friends or fellow compatriots at home. They convey information, provide financial assistance, facilitate employment and accommodation, and give support in various forms. In so doing, they reduce the costs and uncertainty of migration and therefore facilitate it (Arango 2000: 284). The existence of networks is determined by the direction of migratory flows, but networks can also intensify existing movements, such as those of the Turks to Germany (joining one's 
Box 1.1 The determinants of migration

(i) The neo-classical approach considers the migration decision as an individual's decision. The most important determinants of migration for this school of thought are:

- The costs of migration, including transport costs, income losses during migration and psychological costs suggest that migration can be interpreted as an investment, since the present costs have to be paid off in the future. Costs are therefore negatively related to the probability of migrating.

- The expected income from work is a function of obtainable wages and the probability of getting a job. Therefore, even if the probability of getting a job is small, an individual may migrate if the wage differential is sufficiently high.

- The existence of social security systems means that unemployment does not necessarily equate to no income.

- Information/search costs may be a function of the distance from the receiving country and "network" effects, i.e. the connection between individuals in a host country and friends and relatives left at home.

- The age of an individual: the probability of migration has been found to decrease with age.

- Skill levels: strong demand for particular skill groups may encourage migration.

- Expected developments in home and receiving countries: it may be disadvantageous to migrate if developments are positive in the home country or negative in the target country.

(ii) The "new economics of migration" considers the household as the core decision-maker:

- Individual family members migrate because this reduces dependence on the labour market situation. However, singles still make up a higher proportion of immigrants than family members.

- Individuals' relative income position within a society is important. Migration is influenced by income inequality in the home country: there is a higher incentive to emigrate if one is poor among the rich, rather than poor among the poor.

Source: Fertig and Schmidt (2002).

family) or Algerians to France (colonial history). Geographical proximity, which is defined as the distance between the country of origin and the country of destination, is likewise important. For Germany's neighbour Poland, such considerations are certainly significant, although they scarcely apply to another neighbour, the Czech Republic. In 1998 there 
were 69,000 Poles working in Germany. This accounted for almost twothirds of all Polish workers in the EU (Hönekopp and Werner 2000: 4). Networks, it should be noted, are cumulative in nature. This means that every move creates a resource for those who stay behind and facilitates further moves that widen the networks and the probability of their further expansion as a result.

To a greater extent, theories have focused on the question of why people move, or a variant of the same question, such as what determines the volume of migration, even though the vast majority of people do not migrate. Why people stay in the home country is usually ignored by the theories. It is only recently that there are signs of increasing interest in them. Generally, decisions to stay are influenced by social structures, social system, family ties and kinship. A similar consideration can be relevant to the cultural dimension, particularly on terms of adequate skills and education, but it goes beyond that, including the cost of cultural adaptation. Every individual evaluates the returns and costs in a different way, depending on personal characteristics such as age, gender and schooling. For example, individuals with higher education should exhibit a higher migration probability, because the greater ability to collect and process information gained through higher education reduces the risks that accompany migration (Bauer and Zimmermann 1999: 15).

Additionally, the relevance of political dimensions should not be underestimated. There are rules for admission in order to support efforts to integrate migrants into the host society. Given the powerful impact of admission restrictions, such an account is incomplete without incorporating processes, determinants and selectivity as essential ingredients in models. In some of the more developed regions, where movement is becoming less important relative to admission policies, labour migration tends to be severely curtailed. Yet admission policies that restrict migration are far from being inconsequential, even if they are no longer relevant within the context of freedom of movement regulations in the EU, including border controls and legal barriers (residence and work permits). However, this does not necessarily imply a complete removal of barriers even after the realization of the single European market in 1992. There are still obstacles to labour mobility within the EU in terms of administrative, tax or social benefit systems.

\section{Assumptions in the existing theoretical literature}

Before the Eastern enlargement took place, many Europeans expected that it would produce the largest ever wave of immigration to the EU-15. This fear arose from the fact that, until then, the existing member states 
allowed migrants from the accession countries to enter their countries without restrictions. For our purposes, the question concerns the extent to which the EU would prioritize the new CEEC members over Turkey in granting the right to free movement in the medium or long term. The debate about this is important because of political, socioeconomic and cultural trends that seem to undermine the legal basis of Turkish labour migration. In this vein, a number of claims in the literature are worth noting:

- the Eastern enlargement is very different from the previous enlargements in terms of its effect on the movement of Turkish labour;

- the Eastern enlargement will hinder the movement of Turkish labour;

- each round of enlargement roughly coincides with a change of attitude by the EU towards Turkish labour;

- labour flows from Turkey to the EU are controlled by the immigration policies of the EU;

- the movement of Turkish labour tends to be restricted by the EU because of factors such as social and economic conditions, demographic trends and cultural differences.

The Eastern enlargement is very different from the previous enlargements in terms of its effect on the movement of Turkish labour

Although many countries joined the EU at the same time, the total population of the CEEC-10 was about the same as that of the Southern states that joined the EU in the previous enlargement as a percentage of the EU population that they were joining (at around 20 per cent) (Heinz and Ward-Warmedinger 2006: 9).

The degree of development of a market economy is different in the two groups of accession countries. Greece, Spain and Portugal had all been market economies before their accession; by contrast, the CEECs started their conversion into market economies only at the beginning of the 1990s. The income gaps for the CEEC-10 are greater relative to the EU than those of Spain, Greece and Portugal. Despite wage and income differentials between the CEEC-10 and the EU-15, the magnitude of these differentials relative to the cost of migration may be smaller. This is an important determinant promoting labour flows in the short run.

Geographical distance is mentioned as a third difference in the Commission's Enlargement Paper (CEC 2000). Greece and Portugal have no common borders with the EC-9 countries, and the Spanish regions bordering France have an income much above the already high national average. By contrast, half of the CEECs have a common border with Austria, Germany or Italy, which makes commuting feasible, especially 
because the border regions are relatively densely populated (CEC 2001a: 9).

What seems to have happened is that movement from the CEECs was instigated via flexible transitional arrangements following the bilateral treaties. This might be read as a controlled experiment, since a common European market demands unimpeded cross-border movement for workers. The European Commission was acutely aware of this sensitivity when it recently announced that it would move to impose permanent curbs on Turkish workers migrating to parts of the EU, despite the legal instruments of 1963 and 1973 that might eventually allow this freedom.

Hence, the Eastern enlargement may easily serve to impede any further Turkish migration as the existing members struggle to come to terms with the first waves of workers. Some commentators have advised free movement of labour within the Union but a policy of restriction towards Turkey as a result of this freedom. Particular concern was expressed by the EU Enlargement Commissioner, Günter Verheugen; and his successor, Olli Rehn, indicated that a permanent safeguard clause to prevent "instability" in other European labour markets should be inserted into the EU treaties or regulations (Gow 2004: 1). Expected labour flows from the CEECs may sooner or later lead to a situation in which fear of additional migrants from Turkey may become relevant.

\section{The Eastern enlargement will hinder the movement of Turkish labour}

It is hard to say whether or not Turkey's relations with the European Community have changed for the better as a result of the Association Agreement of 1963 as the core legal instrument. Since the inception of the EEC, much of the discussion in the Community has bemoaned how little labour mobility has actually been taking place. Of particular relevance to this consideration is the rather stringent EU policy, which in practice has led to a permanent curb. The need to secure freedom of movement in the European labour markets is reflected in the launch of accession discussions within the EU in a nod to public opinion. For example, the European Council stated that "these negotiations are an openended process, the outcome of which cannot be guaranteed beforehand". The Council concluded that "the negotiations could be suspended if Turkey backtracks on reforms" and raised the possibility of permanent curbs on labour movement even after accession (Council of the European Union 2005: 8).

According to the logic of enlargement, there must be a preference for the nationals of the CEECs over other non-EU nationals. Being free 
from any restrictions points to an increasingly close partnership between new and old member states. It is argued that the existing member states will be a magnet for workers from the CEECs, who have just gained the freedom to travel abroad. This concern was highlighted in an article by David Gow (2006):

Germany and ... Austria are among the EU countries most afflicted by "enlargement fatigue", notably concerns that entry of new members from poor countries in the Balkans - and Turkey - would bring an unmanageable influx of migrant workers... The commission plans to issue a strategy paper on enlargement or "absorption capacity" on October 24.

This picture can be overstated, but it is obvious that the phrase "enlargement fatigue" does suggest a significant shift from conventional accounts of previous enlargements. A study by the European Integration Consortium (2002) concluded that the numbers of foreigners from the CEEC in the EU would increase annually by around 335,000 immediately after the introduction of the free movement of people. A further dimension to the "Big Bang" enlargement lies in the significant proportion of Europeans, particularly the unemployed and those in the lower income groups, who openly express deep unease about labour flows. The spectre of an invasion of "Polish plumbers" is a clear indication of the prevailing mood (European Report 2005: 2).

Given the considerable resurgence of migration pressures during the post-enlargement period, growing concern has been expressed that the EU cannot take on Turkish membership, which would bring more inflows of labour. In the UK, the General Secretary of the Trades Union Congress, Brendan Barber, said that "the free movement of goods, capital and services within the EU should be matched by freedom for European workers to take jobs anywhere in the EU" (Seager 2004: 2), implying whatever the defects - that priority should be given to workers from the new accession countries.

The effects of enlargement on additional migration from the new accession countries have been avoided for a time through the imposition of long transition periods. In the long run, such effects must take account of labour flows from Turkey. Anxiety in the EU over whether the European Commission will move to impose permanent curbs on labour movement from Turkey is a key part of any agreement to admit Turkey to the EU. In fact, "clauses may permanently be available as a basis for safeguard measures" (Council of the European Union 2005: 7).

The current enlargement may make a difference to Turkish migration if the EU faces a wave of labour flows from the CEECs. At the very least, the view of future enlargement to include Turkey is that it will exclude 
Turkish workers from ever accessing the European labour markets. This is called a "third-class ticket" to Europe, which gives Turkey a status below that of the former Communist countries Poland, Slovakia and Romania as far as enlargement is concerned (Reuters News 1998: 2). For many observers, the practical tone of recent summit meetings on migration and enlargement was the reason for devising a new criterion - "the Union's capacity to absorb new members". It is more likely that priority will be given to the nationals of the CEECs, but, against this, one has to bear in mind the socioeconomic and demographic outlook of these countries. The basic assumption of these factors is a relatively moderate increase in migration flows, but much will depend on labour shortages in the EU-15.

\section{Each round of enlargement roughly coincides with a change of attitude by the EU towards Turkish labour}

The history of relations between the EU and Turkey suggests that a curb has been considered in any enlargement since 1973. This was when Turkish labour migration reached its peak. By the end of the 1970s, the EC's low-key approach to immigration issues became less moderate. The accession of Greece, Spain and Portugal helped greatly to give prominence to such issues. Because the accession of the South European countries is often taken to be most similar to the 2004 enlargement in particular, the pressure for a review of the EU policy on labour migration has arisen from the experience of the past two decades. In the 1980s, the process of integrating Turkey, which has been pre-eminent in each round of the enlargement process since 1973, invariably ran into problems owing to the persisting disparities.

Each successive enlargement of the EU has been accompanied by prolonged problems of "digestion". It may well be reasonable to assume that enlargement is reaching its limits. In 2006, the European Commission's strategy on enlargement (CEC 2006a) called for the EU to continue enlargement, but to take into account its "integration capacity", which refers both to applying rigorous conditionality with respect to candidate countries and to completing institutional reforms and financing arrangements to sustain the EU's ability to function. The strategy also called for the EU to honour its current commitments with prospective members but to remain "cautious" about assuming any new commitments (Archick and Kim 2008: 5). In other words, the enlargement strategy demonstrates that the Union is on the verge of being overstretched. Its absorption capacity is likely to come increasingly into the spotlight, since making the EU able to absorb Turkey will be a difficult task with regard to the movement of labour. 
The issue gained more momentum with the current enlargement to the CEECs. The inclusion of these countries is unprecedented in terms of both the numbers and their levels of economic development. In order to calm the situation, the EU has tended to give priority to the economic and social policies of the CEECs. In the meantime, the EU-15 countries are extremely anxious about mass migration from Turkey under a free movement regime. The movement of Turkish labour has, therefore, been a hot issue not only in the past but particularly in the context of the Eastern enlargement.

\section{Labour flows from Turkey to the EU are controlled by the immigration policies of the EU}

The free movement of workers within the EU involves the abolition of legal barriers to intra-Community labour migration. It is directed at national practices that control immigration by restricting the entry and the movement of foreigners into the labour market, and giving preference to their own nationals (Goedings 1999: 10). A safeguard clause (see Council of the European Union 2005: Ch. 2) allows the normal application of the acquis communautaire but permits member states to impose effective restrictions when and where the labour market becomes distorted (CEC 2001b: 19). This definition illustrates that movement is subject to limitations if the member states experience serious unemployment through substantial increases in the number of migrant workers. In principle, they must give workers from the new member states priority over workers from third countries in terms of access to jobs, as set out in the accession treaties.

The predicted outflows from the CEECs are expected to lead to problems regarding the movement of Turkish labour in the future. A pessimistic view is that, as the EU continues to grow in size, it will adopt a "Fortress Europe" type of policy towards Turkey. A typical comment appeared in a letter to the Guardian on 27 September 2004:

Free movement in labour works between countries with comparable income and welfare levels. The vast gulf between the EU and demographically exploding Turkey is unbridgeable by any realistic economic development over any realistic timescale. Turkey should be given associate membership, 95\% of the package but not freedom of movement of labour.

Yet the pressure for, and the commitment to, the reduction in barriers to Turkish labour migration has become increasingly important. Considering the obstacles to movement from the CEECs under the transitional arrangements, one may assume that workers from Turkey will be subject to restrictions for many years after its entry. 


\section{The Movement of Turkish labour tends to be restricted by the EU because of factors such as social and economic conditions, demographic trends and cultural differences}

Many commentators repeatedly emphasize the need to analyse Turkey's social and economic situation as the underlying basis for the fact of mass movements. For instance, it has been shown by Gros (2005) that economic convergence in Turkey will take a long time and lead to continuing pressure for workers to migrate from the poor regions of Turkey to different parts of the EU. It is the large number of Turkish citizens "who have been firmly established for some time in the EU and their concentration in one country in particular (Germany)" that gives rise to the most concern (Gros 2005: 1). Similarly, a Commission report in 2008 (CEC 2008g) underlined that the general level of socioeconomic progress in Turkey was below that of the EU, despite considerable efforts. It also acknowledged continuing problems, including the size of the population, declining labour force participation and very problematic social security schemes, as current trends.

Other commentators have focused on a fundamental rethink of the whole concept of Turkey's identity, which appears to be crucial for the EU's policy. The debate revolves around the assumption that labour is not just a factor of production. It comprises human beings who have different cultures and different languages (Kelly 2003: 3). The scepticism about Turkey's Europeanization follows through into the mass migration of Turks to West European countries from the 1960s onwards. This trend can actually be observed in opinion polls in some of the EU-15 member states, which suggest that most Europeans perceive further labour migration from Turkey as a threat to their identity.

\section{The factual background: Turkish labour flows}

To obtain quantitative data about labour migration, several sources are typically used to measure flows and stocks. Many diverse sources are consulted to generate migration data. These sources are not necessarily always accurate and, indeed, the available data may not always be objective. Although migration data for Turkey remain difficult to obtain, the Turkish Employment Institution provides a relatively reliable and detailed account of the numerical trends in Turkish workers in foreign countries.

Turkish migration to West European countries began with the signing of a recruitment agreement between Turkey and Germany in 1961. Turkey signed similar agreements with Austria in 1962 and with Belgium, France, the Netherlands and Switzerland in 1963. These agreements con- 
tained some provisions for the social security of the Turkish migrants and their family members. It was expected that the agreements would increase the recruitment of Turkish workers in Western Europe, especially of young people, but the number would depend on the availability of workers and the remaining barriers to their entry.

The migration potential of Turkish workers varied depending on the host country: the individual member states have their own socioeconomic, historical and cultural differences that influence their attitudes to immigration. This affects both the likely pattern of demand for immigration from third countries and the ability of each member state to absorb migrants from different parts of the world. According to the official emigration figures produced by the Turkish Employment Institution the total labour force abroad in the period 1961 to 2008 numbered a little over 2.2 million people. Of these, 847,411 workers emigrated to West European countries, where they were accepted with provisional status. These figures include family unification (the movement of spouses and children).

Table 1.1 and Figure 1.1 clearly illustrate the situation for the six major countries - Germany, Austria, Belgium, France, the Netherlands and Switzerland - in the 1961-2008 period. From the early 1960s, Germany hosted the biggest immigrant group $(693,157$ workers, or around 81 per cent of inflows), followed by France (59,606 workers, or 7 per cent of all workers), Austria, the Netherlands, Belgium and Switzerland. In aggregate terms, the 1961-1973 period was characterized by an increasing willingness to employ Turkish migrant workers, but their proportion decreased by 71 per cent in 1974 .

This emigration continued until recent times. This often took the form of family reunion, since workers already in the host countries could get their employers to request immigration permission for a spouse (Castles 2006a: 3). In terms of the annual number employed under the family unification scheme, a downward trend was recorded between 1974 and 1981 in Germany (by 98.5 per cent), Austria (by 85 per cent), Belgium (by 95 per cent), France (by 83 per cent), the Netherlands (by 93 per cent) and Switzerland (by 70 per cent). The number of workers who immigrated to these countries was markedly the lowest in the period 1982-1991, when the proportion of workers accounted for only 0.39 per cent of the total number of entrants for the 1961-1981 period. It is also interesting to note that labour migration remained constant throughout this period.

In the period 1991-2008, flows in four countries fluctuated in the following ways. In Austria, the numbers of workers dropped sharply until 1997, bringing the number down to 1 from 315, and picked up from 2001 onwards. In Belgium, the lowest numbers were observed from 1991 to 2005, but a slight recovery was recorded between 2006 (when 6 workers in total were admitted) and 2007 (66 workers). In France, flows had been 
Table 1.1 Annual inflows of Turkish workers to European host countries, 19612008

\begin{tabular}{|c|c|c|c|c|c|c|c|}
\hline & Germany & Austria & Belgium & France & $\begin{array}{l}\text { Nether- } \\
\text { lands }\end{array}$ & $\begin{array}{l}\text { Switzer- } \\
\text { land }\end{array}$ & Total \\
\hline 1961 & 1,476 & - & - & - & - & - & 1,476 \\
\hline 1962 & 11,025 & 160 & - & - & - & - & 11,185 \\
\hline 1963 & 23,436 & 937 & 5,605 & 63 & 251 & 36 & 30,328 \\
\hline 1964 & 54,902 & 1,434 & 6,651 & 25 & 2,958 & 193 & 66,163 \\
\hline 1965 & 45,572 & 1,973 & 1,661 & - & 2,181 & 122 & 51,509 \\
\hline 1966 & 32,580 & 469 & - & - & 1,208 & 153 & 34,410 \\
\hline 1967 & 7,199 & 1,043 & - & - & 48 & 215 & 8,505 \\
\hline 1968 & 41,409 & 673 & - & - & 875 & 97 & 43,054 \\
\hline 1969 & 98,142 & 973 & - & 191 & 3,404 & 183 & 102,893 \\
\hline 1970 & 96,936 & 10,622 & 431 & 9,036 & 4,843 & 1,598 & 123,466 \\
\hline 1971 & 65,684 & 4,620 & 583 & 7,897 & 4,853 & 1,342 & 84,979 \\
\hline 1972 & 65,875 & 4,472 & 113 & 10,610 & 744 & 1,312 & 83,126 \\
\hline 1973 & 103,793 & 7,083 & 265 & 17,544 & 1,994 & 1,109 & 131,788 \\
\hline 1974 & 1,228 & 2,501 & 555 & 10,577 & 1,503 & 770 & 17,134 \\
\hline 1975 & 640 & 226 & 59 & 25 & 32 & 229 & 1,211 \\
\hline 1976 & 2,101 & 672 & 72 & 6 & 98 & 281 & 3,230 \\
\hline 1977 & 2,413 & 583 & 45 & 15 & 83 & 246 & 3,385 \\
\hline 1978 & 1,333 & 54 & 41 & 13 & 48 & 326 & 1,815 \\
\hline 1979 & 933 & 23 & 27 & 11 & 40 & 406 & 1,440 \\
\hline 1980 & 764 & 944 & 35 & 21 & 32 & 549 & 2,345 \\
\hline 1981 & 274 & 184 & 13 & 6 & 31 & 379 & 887 \\
\hline 1982 & 75 & 12 & 2 & 9 & 2 & 163 & 263 \\
\hline 1983 & 43 & 7 & 2 & 4 & 4 & 209 & 269 \\
\hline 1984 & 17 & 2 & 3 & - & 5 & 69 & 96 \\
\hline 1985 & 23 & 16 & 7 & 4 & 5 & 110 & 165 \\
\hline 1986 & 17 & 52 & - & 3 & 12 & 137 & 221 \\
\hline 1987 & 27 & 74 & 2 & 4 & 18 & 83 & 208 \\
\hline 1988 & 85 & 34 & 1 & 6 & 19 & 96 & 241 \\
\hline 1989 & 51 & 142 & 3 & 7 & 21 & 38 & 262 \\
\hline 1990 & 62 & 423 & 15 & 14 & 31 & 64 & 609 \\
\hline 1991 & 49 & 315 & 2 & 33 & 22 & 66 & 487 \\
\hline 1992 & 1,685 & 239 & 7 & 21 & 21 & 52 & 2,025 \\
\hline 1993 & 1,999 & 82 & 2 & 8 & 12 & 32 & 2,135 \\
\hline 1994 & 2,032 & 10 & 1 & 17 & 12 & 13 & 2,085 \\
\hline 1995 & 2,246 & 16 & 1 & 13 & 13 & 18 & 2,307 \\
\hline 1996 & 2,443 & 5 & 2 & 16 & 5 & 31 & 2,502 \\
\hline 1997 & 1,800 & 1 & 2 & 9 & 2 & 13 & 1,827 \\
\hline 1998 & 1,734 & 1 & - & 33 & 1 & 10 & 1,779 \\
\hline 1999 & 2,350 & 1 & 1 & 25 & 2 & 5 & 2,384 \\
\hline 2000 & 2,135 & 1 & 1 & 87 & 1 & 1 & 2,226 \\
\hline 2001 & 2,437 & 5 & 1 & 202 & 2 & 1 & 2,648 \\
\hline 2002 & 3,367 & 2 & - & 341 & 131 & 2 & 3,843 \\
\hline 2003 & 3,366 & 11 & 2 & 422 & 431 & - & 4,232 \\
\hline 2004 & 2,197 & 22 & - & 530 & 1 & - & 2,750 \\
\hline 2005 & 1,074 & 23 & - & 593 & - & - & 1,690 \\
\hline
\end{tabular}


Table 1.1 (cont.)

\begin{tabular}{lrrrrrrr}
\hline & & & & & $\begin{array}{l}\text { Nether- } \\
\text { lands }\end{array}$ & $\begin{array}{l}\text { Switzer- } \\
\text { land }\end{array}$ & Total \\
\hline 2006 & 708 & 2 & 6 & 377 & - & - & 1,093 \\
2007 & 2,022 & 120 & 60 & 488 & 90 & 50 & 2,830 \\
2008 & 1,398 & 77 & 35 & 300 & 61 & 34 & 1,905 \\
Total & 693,157 & 41,341 & 16,314 & 59,606 & 26,150 & 10,843 & 847,411 \\
\hline
\end{tabular}

Source: Turkish Employment Institution, 2008.

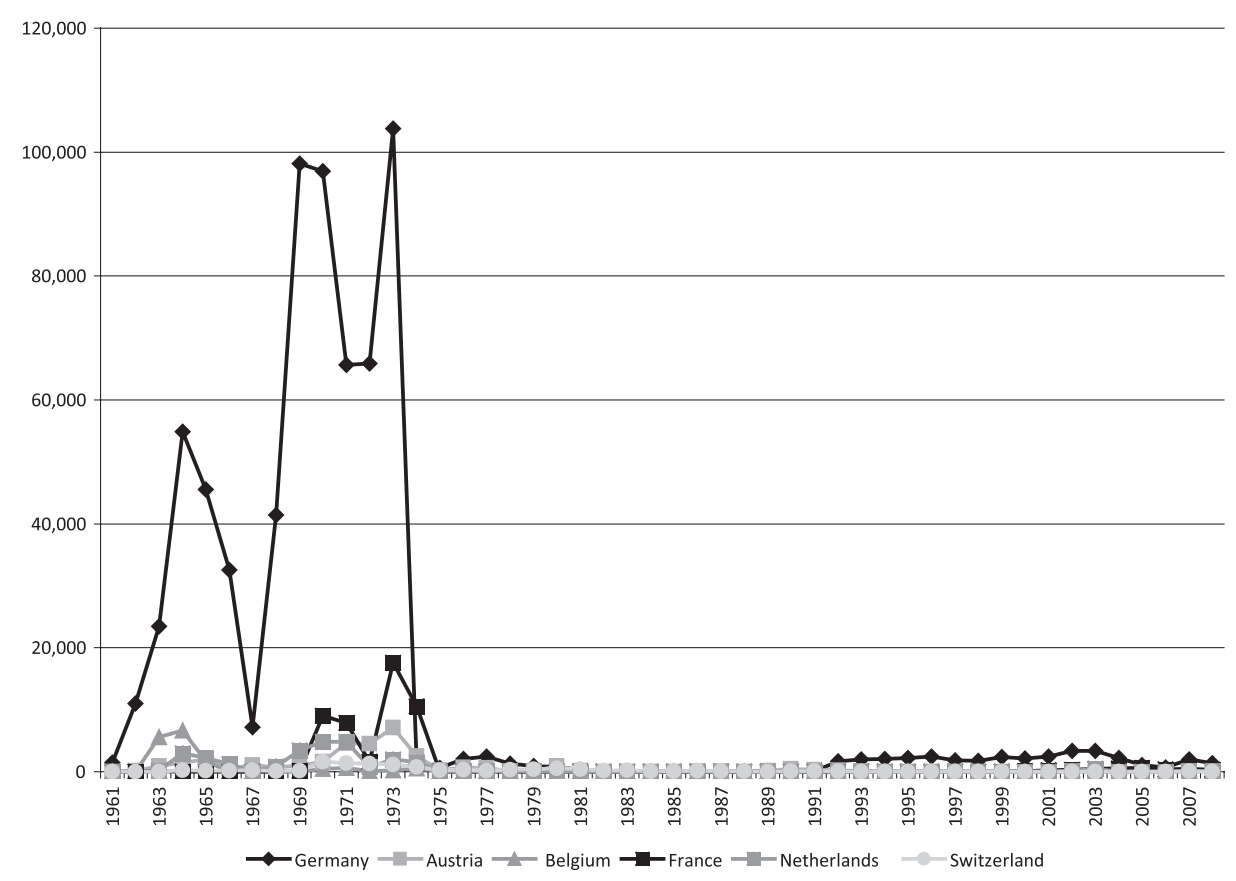

Figure 1.1 Annual flows of Turkish workers to West European host countries, 1961-2008.

Source: Turkish Employment Institution, 2008.

broadly stable at a low level and rose steadily from 9 in 1997 to 488 in 2007. And in the Netherlands the numbers continued to decline until 2000 , with a ceiling of 1 worker, and increased significantly by 131 workers in 2002; no movements were recorded in 2005 and 2006, but flows recovered in 2007. There were notably higher levels of workers in Germany from 1991 to 2003. Although the number of workers dropped to 708 in 2006 from 2,197 workers in 2004, it peaked in 2007 with 2,022 workers. In the case of Switzerland, a decreasing trend continued until 2002. No 
movement was recorded between 2003 and 2006, but an upswing was observed in 2007 . The most significant general trend increase was in the total number of workers, which rose from 487 in 1991 to 2,830 in 2007, and then declined by over 32 per cent to 1,905 in 2008. On the whole, these figures can reasonably be assumed to vary depending on both recruitment policies and the EU enlargement.

To complete the picture, Turkish labour flows to other parts of the world (notably, Iraq, Kuwait, Libya, Saudi Arabia, Jordan and Yemen) should be added, although it seems that many Turks were keener to move to Europe. "Other countries", which involved mainly Canada, Australia, Russia and the United States, attracted Turkish workers who were expected to create exceptional economic benefits. Table 1.2 and Figure 1.2 show that the growth of large-scale labour movements from Turkey to these parts of the world, especially to the Middle East, has been impressive: annual flows rose from 4,032 in 1973 to 56,697 in 2008. This level is in stark contrast to the period between 1964 and 1972, when immigration was at its lowest and the number of workers emigrating to this part of the world was around 2.38 per cent of those going to Western Europe. The total number recruited each year was governed by a quota set at 1,368,787 in 2008; although this figure was well above (by 62 per cent) the total flows to West European countries. The largest annual rises in Turkish workers were observed in Libya and Saudi Arabia. Additionally, emigration to Iraq became more significant, despite the number of Turkish workers falling sharply in the 1991-2001 period. Although flows in recent years have increased or remained constant, the total immigrant populations show a declining trend, with 56,697 in 2008 - around 16 per cent less than a year before. Generally, this increase, or the changing route towards the East, is partly related to a fall in the number of workers emigrating to West European countries.

In the absence of free movement, migration pressures may show up in illegal work or in less restricted channels such as self-employment or the importation of services (CEC 2002: 393). The asylum track and undocumented labour migration have become more prominent since the 1980s and 1990s as categories of labour migration flows. However, the dominant form of emigration is still family reunification with Turks living abroad. Marriages of Turkish and European spouses constitute a secondary family reunion. Migration resulting from the marriage of children of migrants (the so-called second generation) is today the main statistical heading in the case of legal entries, with considerably varying proportions of individuals who hold Turkish or another European nationality but are children of Turkish immigrants. In France, a total flow of 8,000-9,000 people represents about 80 per cent of annual entries (Gülçiçek 2006: 10). In short, reunions continue to take place in the countries that have recently 
Table 1.2 Annual inflows of Turkish workers to other countries, 1961-2008

\begin{tabular}{|c|c|c|c|c|c|c|c|c|}
\hline & Iraq & Kuwait & Libya & $\begin{array}{l}\text { Saudi } \\
\text { Arabia }\end{array}$ & Jordan & Yemen & $\begin{array}{l}\text { Other } \\
\text { countries }\end{array}$ & Total \\
\hline 1961 & - & - & - & - & - & - & - & - \\
\hline 1962 & - & - & - & - & - & - & - & - \\
\hline 1963 & - & - & - & - & - & - & - & - \\
\hline 1964 & - & - & - & - & - & - & 13 & 1 \\
\hline 1965 & - & - & - & - & - & - & 11 & 11 \\
\hline 1966 & - & - & - & - & - & - & - & - \\
\hline 1967 & - & - & 92 & 342 & - & - & 8 & 442 \\
\hline 1968 & - & - & - & - & - & - & 150 & 150 \\
\hline 1969 & - & - & - & 87 & - & - & 995 & 1,082 \\
\hline 1970 & - & - & 19 & 1 & - & - & 6,089 & 6,109 \\
\hline 1971 & - & - & 58 & 45 & - & - & 3,360 & 3,463 \\
\hline 1972 & - & - & 86 & 28 & - & - & 1,989 & 2,103 \\
\hline 1973 & - & - & 664 & 4 & - & - & 3,364 & 4,032 \\
\hline 1974 & - & - & 1,015 & - & - & - & 2,062 & 3,077 \\
\hline 1975 & - & - & 2,121 & 251 & - & - & 836 & 3,208 \\
\hline 1976 & - & - & 4,098 & 1,832 & - & - & 1,398 & 7,328 \\
\hline 1977 & - & - & 8,582 & 4,722 & - & - & 2,395 & 15,699 \\
\hline 1978 & - & - & 7,726 & 5,769 & - & - & 3,542 & 17,037 \\
\hline 1979 & - & - & 9,825 & 8,522 & - & - & 3,843 & 22,190 \\
\hline 1980 & - & - & 15,090 & 5,643 & - & - & 5,425 & 26,158 \\
\hline 1981 & 10,467 & - & 30,667 & 14,379 & 251 & - & 2,102 & 57,866 \\
\hline 1982 & 8,906 & 271 & 26,686 & 12,325 & 298 & - & 639 & 49,125 \\
\hline 1983 & 7,367 & 539 & 23,292 & 20,238 & 321 & - & 444 & 52,201 \\
\hline 1984 & 2,430 & 2 & 16,410 & 25,985 & 185 & - & 317 & 45,329 \\
\hline 1985 & 1,612 & 68 & 9,680 & 35,067 & 10 & 390 & 370 & 47,197 \\
\hline 1986 & 2,160 & 50 & 8,381 & 23,771 & 88 & 381 & 600 & 35,431 \\
\hline 1987 & 1,729 & 147 & 10,986 & 27,109 & - & 337 & 589 & 40,897 \\
\hline 1988 & 3,717 & 273 & 13,194 & 34,645 & 27 & 39 & 616 & 52,511 \\
\hline 1989 & 2,549 & 403 & 12,608 & 32,319 & 2 & 308 & 1,646 & 49,835 \\
\hline 1990 & 1,274 & 98 & 8,606 & 33,077 & - & 139 & 4,038 & 47,232 \\
\hline 1991 & - & 189 & 4,728 & 40,782 & 1 & 5 & 6,833 & 52,538 \\
\hline 1992 & - & 465 & 2,432 & 46,467 & - & - & 8,611 & 57,975 \\
\hline 1993 & - & 255 & 2,549 & 35,826 & - & - & 22,479 & 61,109 \\
\hline 1994 & - & 58 & 1,869 & 13,050 & 5 & - & 44,078 & 59,060 \\
\hline 1995 & - & 256 & 1,753 & 14,529 & - & - & 40,638 & 57,176 \\
\hline 1996 & - & 7 & 2,063 & 5,635 & 80 & - & 30,410 & 38,195 \\
\hline 1997 & - & 5 & 1,833 & 7,657 & 15 & - & 21,984 & 31,494 \\
\hline 1998 & - & 5 & 1,032 & 6,821 & - & - & 16,270 & 24,128 \\
\hline 1999 & - & - & 698 & 5,178 & 20 & - & 9,195 & 15,091 \\
\hline 2000 & - & - & 385 & 1,862 & 166 & - & 9,006 & 11,419 \\
\hline 2001 & 37 & 11 & 238 & 4,657 & 203 & - & 12,448 & 17,594 \\
\hline 2002 & 191 & 45 & 1,037 & 6,399 & 234 & - & 15,167 & 23,073 \\
\hline 2003 & 601 & 26 & 2,515 & 6,064 & 368 & 104 & 20,241 & 29,919 \\
\hline 2004 & 4,900 & 230 & 668 & 1,146 & 752 & 23 & 29,729 & 37,448 \\
\hline 2005 & 8,237 & 151 & 986 & 6,452 & 2,241 & 9 & 40,589 & 58,665 \\
\hline 2006 & 7,525 & 596 & 770 & 19,841 & 2,239 & 12 & 49,303 & 80,286 \\
\hline 2007 & 6,696 & 115 & 2,574 & 4,049 & 1,099 & - & 52,661 & 67,194 \\
\hline 2008 & 4,791 & 8 & 5,991 & 7,556 & 351 & 157 & 37,843 & 56,697 \\
\hline Total & 75,189 & 4,273 & 244,007 & 520,132 & 8,956 & 1,904 & 514,326 & $1,368,787$ \\
\hline
\end{tabular}

Source: Turkish Employment Institution, 2008. 


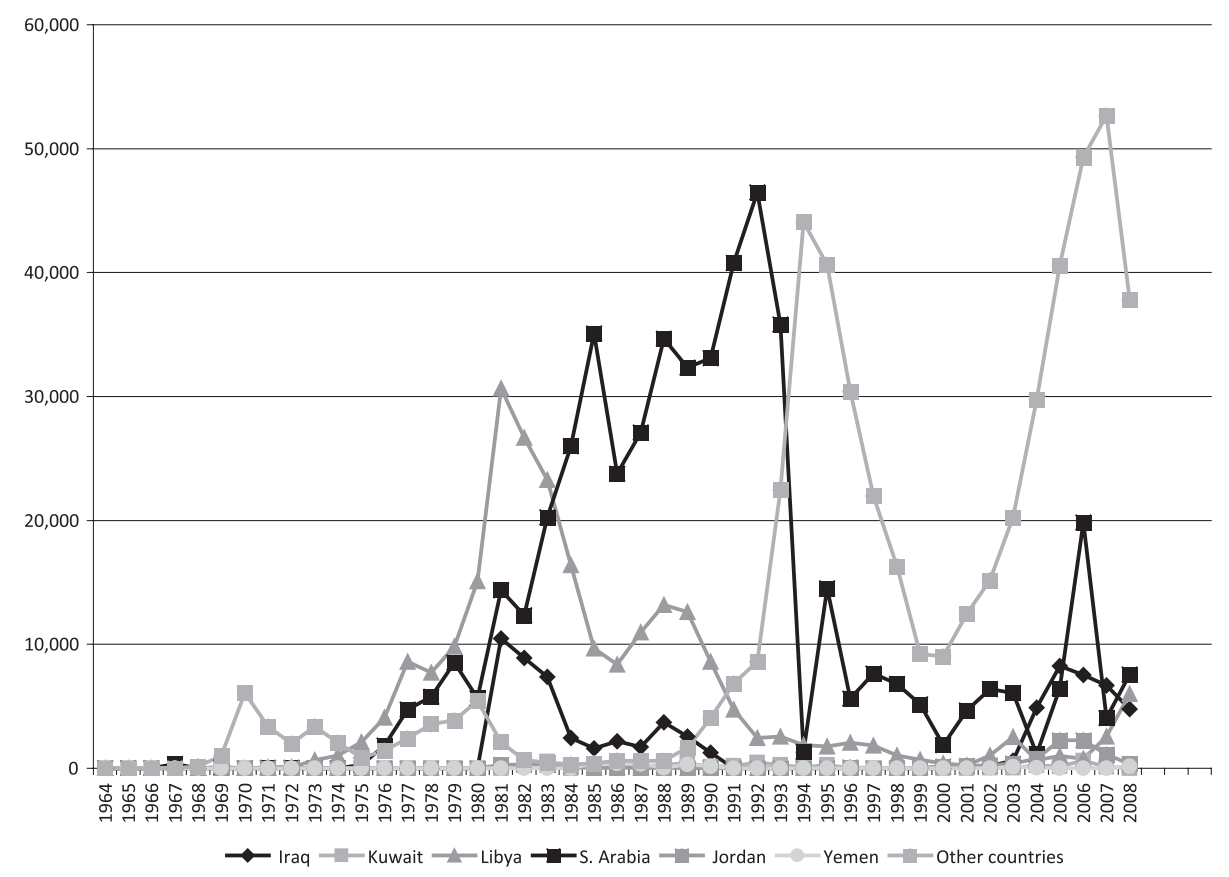

Figure 1.2 Annual flows of Turkish workers to other countries, 1961-2008. Source: Turkish Employment Institution, 2008.

become part of the migration field or, in the case of recent migrations, involving small numbers of individuals.

\section{The empirical literature: Existing case studies and gaps}

There is a voluminous literature devoted to identifying the factors driving international labour migration. Germany is the most important host country purely in terms of the numbers of Turkish migrants received over the years. It admits some workers for companies that specifically require a Turkish labour force. This is why an extensive literature has focused on the most important facts and circumstances of Turkish migrants in Germany.

As regards empirical studies, Faruk Şen's hugely influential work “The Historical Situation of Turkish Migrants in Germany" (2003) analysed current problems and challenges in the concept of integration. In important ways, this approach overlooks the determination of migration flows in terms of a set of possible explanatory factors. An overview of the current situation of migrants' labour market integration in Germany was 
provided by Thomas Liebig (2007), who assessed the relative strength of the pull factors. Admittedly, Liebig's view of the situation of the "second generation" with very low educational outcomes and low skills - leading to the curbing of migration to Germany - is rather unusual, given that many of these "guest worker" immigrants settled and became assimilated into German culture. That might tempt some to assume that Liebig's claim is almost dispensed with by Ali Riza Gülçiçek (2006) in The Turkish Presence in Europe: Migrant Workers and New, European Citizens, since his work is merely concerned with the integration of Turkish residents of the first, second and even third generation, especially in Germany. Although sharing some important basic assumptions with Liebig, Gülçiçek outlined why the strong social and cultural identity of Turkish migrants should not be perceived as a barrier to full integration in relation to Turkey's prospects for accession to the EU. By all accounts, these studies have typically paid too little attention to Turkish migration patterns in the context of the perceived strong impact of EU enlargements, but rather have focused on other issues.

Studies of Turkish labour migration to the West are mostly restricted to the 1960 s or 1970 s. One might expect a large amount of academic research, since the standstill of 1973, to have focused on family unification schemes in relation to permanent settlement. Besides, it has to be conceded that these studies rarely focus on the theoretical aspects of migration. Owing to these theoretical deficiencies, there is some practical difficulty in assessing the forms, intensity and direction of Turkish migration at a particular time. Yet, the problem of the limitations of the available data is similarly beset by a confusing array of approaches. These approaches have focused, to a certain extent, on case studies or merely addressed selected aspects of the theme. The fact that many of these studies are speculative by nature and are not concerned with hard evidence has made it difficult to develop a more precise understanding of the subject.

More generally, there is an extensive literature on the impact of labour migration on the EU labour market. Useful review articles can be found in The Impact of Eastern Enlargement on Employment and Labour Markets in the EU Member States (Boeri and Brücker 2000), "Cross-Border Labour Mobility within an Enlarged EU" (Heinz and Ward-Warmedinger 2006), "EU Enlargement and Future East-West Migration in Europe" (Fassmann and Münz 2002), "The Impact of the EU Enlargement on Migration Movements and Economic Integration: Results of Recent Studies" (Hille and Straubhaar 2001), "Migration Policies in Western Europe and the EU-Enlargement" (Biffl 2001) and "Assessment of Possible Migration Pressure and Its Labour Market Impact Following EU Enlargement to Central and Eastern Europe" (Bauer and Zimmermann 1999). 
However, none of these studies seek to explain the obstacles to Turkish labour mobility in the EU solely from within its own enlargement paradigm. They have provided a much more sophisticated understanding of why and how the EU has shaped, directed and occasionally determined changes in labour movement since 1962. Even if some studies have estimated the future migration potential from Turkey when it joins the EU, the effects of the EU enlargement on Turkish labour flows have been left largely untackled. This gap has yet to attract significant interest on the part of individuals or bodies of empirical research.

In addition to methodological drawbacks, the analysis suggests a number of key points that need to be taken into consideration.

First, there is considerably less Turkish literature on the movement of labour; most of the literature concentrates on the UK. Recently, several Turkish government institutions have attempted to improve the collection and compilation of data on labour migration. This process is yet to be concretized. Having said this, there is one exception: data from the Turkish Employment Institution are used to form the basis of the preliminary assessment of the impact of the new accession countries.

Second, forecasts of possible labour flows from the East to the West in the absence of administrative or legal restrictions vary considerably, depending on the methodology and assumptions used. Model-based studies remain relatively uncertain, often relating to the complexity of the factors influencing migration. Reliance on very long-term forecasts of economic development in the EU and the accession countries may lead to an upward bias in many estimates of future migration owing to the unpredictability of economic growth. This is coupled with imprecise measurement as well as the absence of data.

Third, the majority of studies carried out in Turkey have so far focused on political and economic issues. Social policies have received comparatively little attention. A general problem is the lack of more comparative data to assess the nature and the extent of labour market policies in Turkey. In fact, the lack of comparative data is not unique to Turkey. Most studies of social policy focus on a very limited number of CEECs. In particular, a lack of comparative data from the late entrants, such as Romania and Bulgaria, is common. The incompleteness of data on a number of countries in the Central and East European region (as well as Turkey) has placed limitations on what can be inferred from the overall patterns and trends. In spite of all the problems, there are very useful studies that provide an analytical framework and come up with some salient practical conclusions. In taking into account the approach outlined above, this study will therefore fill gaps in the literature concerning Turkish labour movements into Europe, and will test several assumptions made in the existing literature on this subject. 
Last, but not least, labour mobility has many aspects. Although the scope of this study is political, I shall not restrict my attention to the politics of mobility. That is to say, the other aspects are obviously important. In order to maintain a focus on the politics, this study will allude to the economic, social and legal aspects only where the political content warrants their inclusion. In addition, in assessing future migration potential, it is obvious that labour flows in the context of enlargement are quantifiable. The study involves both quantitative and qualitative analyses of potential migration performance, which may prove to be credible for political argument at least.

\section{About the book}

The purpose of this study is to investigate the impact of EU enlargement on the movement of Turkish labour, with a particular focus on the Eastern enlargements of 2004 and 2007. The past enlargements may provide indications of future migration trends. It is, then, essential to explore whether there has been a variation in the actual numbers of Turkish workers coming into the EU since the early 1960s and, if so, what has caused this variation; in other words, why the restrictions have applied throughout the West European countries. The study seeks to answer two basic questions: whether the volume of Turkish labour flows has been a result of past EU enlargements and to what extent the effects of the Eastern enlargement will contribute to changes in the regulatory setting and therefore in the level of Turkish labour mobility. These questions necessarily involve an examination of the changing national and EU policies governing the flows of Turkish workers. Thus, a detailed understanding of the factors driving workers from the CEECs to the EU and the impacts is especially important in any discussion of Turkish migration. Other factors may play a more important role, so they, too, have to be taken into consideration. An analysis of culture, networks, and demographic and labour market trends is essential, because all these factors may affect the supply of and demand for Turkish labour.

The movement of Turkish labour is thus the dependent variable of this study. The flow of Turkish labour into the EC/EU clearly depends on more factors than the effects of EC/EU enlargement - it would be excessively reductionist and totally unrealistic to try to press it into an analysis with one independent variable and one dependent variable. Other factors ("independent variables", although they might well be interdependent among themselves and there may be a feedback connection with the dependent variable) have to be taken into account in order to establish what impact enlargement - as opposed to all the other factors - has on 
Turkish labour movement. This is reflected in the legal framework, at both the EU and national levels, which has clearly influenced the flow of Turkish labour. Other independent variables include unemployment levels both in the EC/EU as a receiving area and in Turkey, and, again on both sides, wages, average income, social networks, geographical distance and social provision systems (as factors supporting migration effects), as well as trade liberalization and EU funds, return migration, internal inequalities, social and cultural ties, and risk aversion (as factors refuting migration fears). These independent variables are covered by most of the theoretical approaches explaining migration to the extent that they are used to explain the determinants of labour flows from both the CEECs and Turkey. The study examines causality within the expectations. As political and socioeconomic conditions change, so do labour flows, pointing to the significance of this change.

In the specification of these variables, the flow rates are more likely to be simulated with the following characteristics:

- It is plausible to assume that the integration of the CEECs into the EU has been detrimental to immigration from other countries, especially Turkey. Therefore, the possibility of future labour flows will continue to depend on regulatory influences from EU policy as well as that of member states' governments.

- Economic considerations imply that, the lower the economic development in a country, the higher will be the number of people leaving to find work elsewhere. This assumes that labour will move from lowwage to high-wage areas, if it is free to do so. The process of labour inflows to the EU depends not only on the supply of migrant labour, but mainly on the demand for it. In forecasting future trends, the labour market situation in the CEECs and Turkey has to be reviewed to establish whether the EU member states are likely to attract workers, given this assumption about labour flows.

- Changes in the flow rates are often linked to some intervening variables representing political considerations, such as the nature of regimes and individual freedoms. This naturally extends to the implied stability of the political and institutional environments in the CEECs and Turkey. Any unpredictability in these environments may reflect an increase in labour migration when better conditions exist in the host countries.

- Demographic trends are primarily concerned both with the social policy implications of the ageing population of the EU and the CEECs, and with the growing Turkish population.

- Differences and similarities in culture - for example, language and socio-psychological factors - can promote or hold back migration. In view of the homogeneity of the potential members, the EU's method 
of enlargement has been based not only on geographical but also on cultural principles. This is why it is important to have the full facts and to carefully examine the cultural factors that might influence Turkish labour flows.

- Geographical proximity may be a crucial factor in the impact of the CEECs on Turkish labour flows as far as the transport and transaction costs of moving are concerned. This assumes that push migration rises linearly with geographical distance. Conceptually, the matter is neither as simple nor as straightforward as the definition would imply, because other factors come into play.

The analysis is based on recent publications of the European Commission, the Organisation for Economic Co-operation and Development (OECD) and various government institutions in Turkey, including the Turkish Employment Institution the Turkish Ministry of Employment and Social Security and the State Planning Organization, as well as a number of independent studies in this field. My study relies on a number of basic facts and statistics, which are reproduced on the assumption that their meaning is unambiguous. The study will draw upon and test explanatory and interpretative models in the existing literature on migration. Thus, what follows is a short overview of recent theoretical and empirical work, without claiming that this overview is complete.

I have noted the multiplicity of factors influencing Turkish labour movements, and the importance of taking all of them into account when assessing the relative importance of EC/EU enlargement for Turkish labour flows. The book is therefore structured in the following way:

- This introductory chapter has provided the theoretical background to the movement of workers in the context of EU enlargement, with a specific focus on Turkish labour migration trends from 1961 to 2008. The chapter has identified the research questions and the opinions expressed on them in the relevant existing literature, and it has positioned the research within this literature to answer the questions.

- Chapter 2, "Turkish labour mobility in the European Union", on the basis of the existing literature, surveys the historical developments of Turkish migration into the EEC/EU in a wider context and examines how early initiatives stimulated or stymied the movement of Turkish workers. The chapter quantitatively evaluates the migration periods, based on economic, social, political and legal factors in the 1961-2008 period. The circumstances requiring the EU to give Turkish citizens unrestricted immigration rights into the Union are also broadly examined.

- Chapter 3, "Past enlargement experiences", addresses the question of whether past enlargements are a good predictor of how the recent enlargement will affect Turkish labour flows. It does so by surveying the 
effects, predicted and actual, of the previous waves of enlargement on the European labour markets, but also on its pull factors towards Turkish economic migrants.

- Chapter 4, "The European Union's overall strategy for the movement of labour", assesses the EU's evolving policies since the 1960s. Hence, aspects of the EU's migration policy influencing historical flow rates are highlighted. Special attention is paid to the obstacles created to immigration. The chapter explores how these obstacles have been associated with the changing pattern of Turkish labour migration.

- Chapter 5, "The impact of Central and East European accession on the movement of Turkish labour", specifies whether the increasing number of members of the EU has made Turkish workers' access to the EU's labour markets more difficult. The chapter extrapolates from the pull and push factors the different possible developments that can be identified for Turkey in the migration of its workforce to the European labour markets.

- Chapter 6 offers concluding remarks. 

European Union

\section{Introduction}

Although the issue of Turkish labour movement has been invoked in treaties, regulations and decisions since 1963, there have been very few attempts to demonstrate the Community's responsibilities as far as the policy of the European Economic Community (EEC) and then of the European Union (EU) is concerned. From the outset, a main theme for the EEC was to improve the living and working conditions of Turkish migrants and to encourage integration of those migrants into European labour markets, all of which addressed the underlying difficulties. For the most part, the weaknesses of the EEC/EU in dealing with the principle of free movement derive from the implementation of the rules in the member states. The validity of all kinds of arrangements between the EU and Turkey should, therefore, be questioned in relation to the size and nature of migration flows. The aim of this chapter is to provide a comprehensive overview of Turkish migration in the EEC/EU. I first review developments in the Turkish workers' situation and in the migration policy of the EEC/EU. I then present an analysis of a number of distinct migration periods, looking at the interplay of factors during each period. This section draws on the variety of explanations, which are invoked to demonstrate the social, economic, political and legal variables. Finally, I focus on why Turkish citizens should be allowed to move into the EU freely. 


\section{The overall pattern of historical development}

\section{Post-war Turkish migration to Western Europe}

The Turkish labour migration phenomenon traces a direct line of descent back to the establishment of the EEC in 1957. At first, migration began with individual initiatives from 1960 onwards and continued in line with the turnaround in the economic fortunes of West European countries, especially in the 1962-1973 period. During these years, among other reasons, an intense demand for labour, which was targeted mainly towards the Mediterranean countries, had led migration flows from Turkey to the West. Naturally, labour shortages became a driving force for gradually increasing migration (Berksu 1999: 1). The Turks gained the freedom to migrate to the West just when European, especially German, firms were rapidly expanding under Europe's "economic miracle" and were starting to look abroad to recruit foreign guest workers (Gastarbeiter) to staff their assembly lines. The supply of East German migrants had been curtailed by the construction of the Berlin Wall, and thus, in October 1961, Turkey and Germany signed a bilateral labour recruitment agreement that allowed German employers to hire Turks under temporary (oneyear) work permits (Teitelbaum and Martin 2003: 103).

During the same period of expansion of labour migration, the Ankara Association Agreement was signed in 1963 between the EEC and Turkey. The principal aim of the Agreement was to regulate economic, social and financial matters and the Agreement acknowledges the "ever closer bonds between the Turkish people and the people brought together in the European Economic Community". Its role was to allow Turkish workers to move freely in the Common Market. The policy was directed towards the greater social and cultural integration of Turks who live in the Community. The Agreement involved far greater numbers of individuals, including professionals and entrepreneurs. Article 12 stated that "the Contracting Parties agree to be guided by Articles 48, 49 and 50 of the Rome Treaty establishing the Community for the purpose of progressively securing freedom of movement for workers between them". All provisions in the Agreement were originally intended to pave the way for a steady reciprocal lowering of EEC tariffs and, eventually, migrant barriers.

From the outset, Turkey saw the Ankara Agreement as a means, among other economic and political goals, to improve the legal status of Turkish migrant workers in Western Europe, most of whom had already taken up employment in the EEC countries (Aral 1997: 1). The Agreement was the first step towards the creation of an international bargaining structure within which the right to labour movement became a crucial aspect. It 
created the starting point for the negotiations between the contracting parties.

To facilitate cooperation in the area of social policy, the process was strengthened by a further legal instrument. An Additional Protocol was signed between the parties in 1970 and came into force in 1973. The Protocol held an important place in both the economic and the social history of EEC-Turkey relations. First, it envisaged the gradual introduction of free movement of workers between Turkey and the Community in the period 1976-1986; secondly, it provided an immediate equality of treatment of workers by the EEC countries and safeguards of their social security benefits. Article 36 of the Additional Protocol put in place the essential structure to ensure the free movement of Turkish workers. The Community was to assume responsibility for removing barriers to Turkish workers. At the same time, the rules guaranteed equal treatment for workers already in the EEC countries. Additionally, EEC policy was to constantly ensure that the Council of Association acted in accordance with the provisions laid down in Article 36.

Under these legal instruments, the period 1961-1973 was characterized by a very large increase in the number of Turkish workers in West European countries. Evidence from the Turkish Ministry of Foreign Affairs shows that the potential migratory flows from Turkey to the Federal Republic of Germany were initially very small, but increased to 66,000 in 1964. The flow rose to 130,000 in 1970 and then peaked at 136,000 in 1973. Between 1961 and 1975, the number of Turkish workers living in the Federal Republic of Germany, who were officially sent by the Turkish Employment Institution to work abroad, jumped to 805,000. It is estimated that 1.5 to 2.0 million Turks went abroad for employment reasons between 1961 and 1973. This evidence also suggests that the proportion of workers in the EEC was equivalent to 12 per cent of Turkey's workforce and 40 per cent of Turkish males aged 20-39 in 1970.

\section{The end of the guest worker programme}

Germany's "recruitment stop" in 1973 fundamentally reveals the methods and patterns of development when the 1960-1973 period of the guest worker programme, which was characterized by the diffusion of strengths and weaknesses, ended. In 1974, as a result of a slowdown in the economies of Western Europe, a rise in unemployment and the oil crisis, the large labour-importing countries announced a major change of policy: withdrawal from the collective recruitment of foreign labour (European Committee on Migration 1996: 40), and, thus, access was blocked for third countries. The change in economic circumstances and the structure of the labour market forced Germany - the main country for the immigration 
of Turkish citizens - to announce a halt to its policy of inviting guest workers to the country. Similar measures were undertaken by other EEC countries.

As for the oil crisis of 1973, the ending of the recruitment of Turkish labour as a result of economic conditions in the Western European countries was not without some benefit for the Turkish side. The substantial drop in migration resulted in a need for Turkey to review its migration policies, especially for unskilled workers. A logical measure to help address the unemployment problem was for Turkey to export more of its labour force to other countries, given that the West now had little need for the mass migration of those with low skill levels. Similarly, selective policies were being adopted in more distant countries with low population growth and high living standards - most notably the United States, Canada and Australia - where only highly skilled individuals were being encouraged to immigrate. Given these policy changes, Turkish workers seem to have shifted away from European sources to "nearby countries" in the East. Adding to this shift was the fact that, as Kirişçi (2003) has pointed out, recession in the West coincided with an economic boom in the Middle East. Consequently, there was an increase in outflows of Turkish workers to Middle Eastern countries of almost 90 per cent in 1973 compared with 1972, most notably to Iraq, Libya and Saudi Arabia. The scale and pattern of Turkish migration to the East became much greater than what had previously occurred in the West.

\section{An alternative way to promote labour movement}

Although migration had now switched to other parts of world, Turkey continued to press for a role as a provider of migrants to West European countries. It was thought that sending workers to Europe from less developed regions would alleviate unemployment and bring remittances. Perhaps what counted most was that, if migrants had the skills and experience, they would not have difficulty in finding jobs. Workers who returned with new skills were considered to be vital for Turkey's modernization efforts. They were characterized as workers who were, on average, better qualified than the hidden or openly unemployed.

After 1980, new restrictions (that is, visa requirements) by most EEC countries gave incentives to workers to return home, with substantial consequences for an economic downturn in Turkey. For instance, the German government launched a policy of visa application for those categorized as "economic refugees" in October 1980. The policy was not limited to this. Tougher restrictions were in fact introduced for foreign workers in the same period. The most prominent was that husbands or wives were entitled to immigrate to Germany as a "spouse" after three years of marriage. This policy is still in effect. 
The essential demand - free movement - was excluded. Movement was stopped because of the frozen relationship between the EEC and Turkey as a result of the political crisis of 12 September 1980. This was reflected in the flows of Turkish workers, whose situation was completely helpless. The meeting of the EEC-Turkey Association Council that was scheduled for 1 June 1983 did not take place. In the late 1980s, the "democratic deficit", mainly relating to human rights abuses, denoted the negative image of Turkey.

In the meantime, the passing of the Single European Act (SEA) in 1986 signalled significant improvements for the movement of Turkish labour, laying down provisions similar to those of the Association Agreement. The creation of a single European market entailed the integration of national economies and the removal of barriers to trade. This initiative included services, capital and a limited number of sectoral policies, along with the principle of labour movement. As part of the process, the EEC had at least something to offer to meet Turkey's aspirations. The success of Turkey's integration with the Community depended on how it managed the social issues. In the main, it trailed far behind Community members in terms of European values.

At the same time, there were some improvements to the residence and working conditions of Turkish workers living in the EEC. The Association Council reset a target for so-called "new objectives", when it assembled on 24 November 1986, stipulating that:

- the rights were to be given only to those who had worked for three years in one of the member states;

- the principle of second priority was still to be applicable;

- the individual member states were to continue to apply their national legislation for retaining restrictions on the movement of Turkish labour;

- the rules regarding family unification, with a minimum requirement of 18 years of age, would be applied in accordance with the national legislation of each member state.

The significance of these principles was largely symbolic. Despite the major role assigned to the EEC's social policy, the outcome of this meeting showed that the Community members were not willing to commit themselves to the leap of faith demanded by the Agreement. Undoubtedly, this situation would place Turkey in the category of third member. This was unacceptable in that the previous agreements envisaged that Turkey would be given priority for labour movement. This in turn was interpreted by some as a delaying tactic, an idea so outrageous in its audacity that it would become mired in years of debate and argument.

Whatever the debates about how and why the principle of free movement for Turkish labour evolved, 1986 witnessed the failure of the implementation of the free movement provision that might have led to the third 
and final stage of labour movement. The EEC rejected the right to free movement, which was due to commence on 1 January 1986. The Community members even refused to consolidate the existing bilateral agreements with Turkey. The whole situation was characterized as "a question of law" and its jurisdiction was mainly left to interpretation by the European Court of Justice (ECJ), which would, in principle, provide remedies.

\section{Membership application}

It was partly the recognition of the basic inadequacy of the Association Agreement (and of the Association Council decisions) that finally led Turkey to apply for full EEC membership on 14 April 1987. This shifted the problem from the Association Agreement to Turkey's membership application. Turkey's understanding was that its citizens would be able to obtain freedom of movement when it became a full member of the EEC (Duran 2006: 58). Thus, "exporting surplus labour" was one of the main reasons for Turkey's interest in joining the EEC in early 1980.

Yet - at least in retrospect - membership appeared to be just an expediency favoured by Turkish politicians to undermine the principle of labour movement. Following a landslide victory in the country's general election of 1983, the Motherland Party gave a low priority to the issue of labour mobility, instead concentrating more on Turkish membership. This was a clear sign that the discussion of movement of labour would be postponed in return for some concessions from the EEC. This trend continued to be a predominant consideration of Turkish policy in the 1990s, with the labour goal traded off in the hope of expediting accession. However, Turkey's interest in obtaining labour mobility was by no means on the decline. Rather, both issues were now interrelated, as the demand for labour movement became part of its membership aspirations. It was hoped that Community membership would bring free movement regardless of previous legal instruments. Linking issues together in "package deals" could open the door to Turkey by ensuring that differences in social policy could be reconciled by harmonization.

Even so, there was considerable confusion about Turkish labour migration and its economic impact on the Community members when Turkey made its application to the EEC. This confusion could easily be attributed to Turkey's past economic policies. In the 1970s, Turkey pursued an inward-looking, import-substituting economic policy that was completely incompatible with the EEC Association Agreement, whereas the Community quickly retreated into a protectionist shell whenever it felt threatened by Turkish exports and it did not implement the agreed timetable of concessions (Xuereb and Pace 1996: 198). Despite these national policies, it was still felt politically necessary to provide some sort of 
backing for the full membership application at the European level. This could, as many hoped, ease the effects of large-scale unemployment in Turkey.

With its focus on the economic benefits, in the late 1980s a great deal of debate centred on whether the suspension of Turkey's application for membership would increase the unemployment level in Turkey. Of course, this goal was combined with the EEC's social dimension. Many saw the necessity of becoming a part of the European social model as the main motive for labour movement. From this perspective, the newly formed European social model could become a major incentive to improve the situation in Turkey. On 6 June 1990, the European Commission announced the contents of a harmonization programme that put some pressure on Turkey to take appropriate measures in social policy. Consequently, meetings were regularly held between officials of the Turkish Ministry of Social Security and the EEC's implementing bodies to discuss the Community's fundamental social rights. The major emphasis was almost exclusively on the harmonization of Turkey's national standards of social security rights, with a particular focus on working conditions, wages and social insurance. Any progress that could be made on social policy issues would be reported.

At the same time, the protection of the rights of Turkish workers in the EEC became a core issue that the Turkish side often brought up during the Association Committee meetings. In this regard, in April 1993, the Committee meeting reinforced the operational design of the free movement of services and workers, residency rights and the introduction of new instruments for easy job searching in the host country when the effective social integration of Turkish workers into the Community market was addressed as one of the prominent issues. In the main, these measures were seen as crucial steps by both parties to improve the scope and character of Turkey's social policy.

In the mid-1990s, a picture of increasing economic engagement between the EU and Turkey was beginning to emerge on the customs union front. This implied a consolidating democratic reform process in Turkey and greater optimism about financial cooperation. To the extent that full labour mobility could ever be granted to Turkey, the signing of the Customs Union Agreement in 1995 between the EU and Turkey could have potentially been a step in this direction. Unfortunately, the prospect of freedom of movement seemed a dead letter for the period in question.

\section{Turkish labour movement: A waiting game}

In the early 2000s, while the opportunity to migrate to the EU countries in order to find work was seen as the most ambitious project that would 
ever be undertaken by successive Turkish governments, the perceptions of both the public and policy makers in the EU were changing. The prospect of enlargement to Central Eastern Europe raised the issue for some member states that, on accession, citizens of the candidate countries might migrate in huge numbers to the EU to work for wages lower than those that domestic workers might accept (Cini 2004: 222).

Responding to such fears, at the European Summit in Nice in 2000, Chancellor Schröder led the EU in a different direction. He voiced the acute fear of migration and said that Germany could not absorb a sudden wave of economic migrants from the East. The proposal by the European Commission in April 2001 included one important point from the "Schröder formula": "the general transitional period of five years, which was subject to automatic review after two years". During this transitional period, the member states of the Union could either restrict or open their labour markets to the citizens of other member states on a preferential basis, as requested by the German Chancellor (Vaughan-Whitehead 2003: 436). Other EU countries, notably Austria and the United Kingdom, also expressed concerns about the potential impact of migration on their labour markets. Basically, immigration was not acceptable. Concerns of this kind meant that the Eastern enlargement proceeded at a cautious pace, and it raised the possibility of new barriers to Turkish labour movement.

By the time the EU was to decide whether to start accession negotiations with Turkey in December 2004, the situation of Turkish immigrants in European countries and the prospects of further emigration from Turkey had become major issues (Kirişçi 2003: 3). In an economic sense, perceptions that were clearly predicated on the ability of the European labour markets to absorb the expected labour flows from Turkey were questioned. Consideration would also be given to the need to ensure wide acceptance of opening accession negotiations with Turkey.

As a further development, in a draft text of the conclusions of the EU Summit meeting held on 16-17 December 2004, the EU leaders called for the start of talks on 3 October 2005 "without delay". The Summit also envisaged Turkey's entry not occurring before 2014, namely after the expiry of the EU's 2007-2013 long-term financial framework. The major issue of dispute was the attachment of conditions to the future movement of labour, and thus the whole question of "permanent conditions" on Turkish membership. The EU leaders agreed that "Turkey was a candidate state destined to join the Union on the basis of the same criteria as applied to other candidate states" and they subsequently concluded that:

Long transitional periods, derogations, specific arrangements or permanent safeguard clauses, which are permanently available as a basis for safeguard 
measures, may be considered. The Commission will include these, as appropriate, in its proposals for each framework, for areas such as freedom of movement of persons, structural policies or agriculture. Furthermore, the decision-taking process regarding the eventual establishment of freedom of movement of persons should allow a maximum role of individual Member States. Transitional arrangements or safeguards should be reviewed regarding their impact on the competition or the functioning of the internal market. (Council of the European Union 2005: 7)

Interpreted literally, the significance of this declaration is clear. It seems to limit Turkey's access to a key benefit of EU membership: the free movement of labour. The concern in several EU countries that large numbers of Turks would head to Europe in search of work once restrictions on labour movement were lifted is equally important for EU policy. Given the levels of anxiety, the truth is that some EU countries have found a way to keep Turkey out. This situation might be looked upon as a kind of "permanent limbo", implying that the arrangements that were established prior to the 1980s would be maintained, with no sign of an easing of the circulation of Turkish labour. Since the accession of the Central and East European countries (CEECs), many European politicians have been hiding behind the rhetoric of "absorption capacity", even though, initially, the EU-15 member states did not expect that they would have difficulties in handling a large number of the CEECs. This is a way of saying that restrictions on Turkish labour movement will be permanently possible but not permanently applicable.

Whatever measures were taken in EU-Turkish relations, they all fell short of Turkey's expectations, with strict limits being applied to the movement of Turkish labour. There is now a widespread perception in Turkey that these steps were a deliberate move to make special conditions for Turkey that no other candidate country had faced. After all, the decision in October 2005 to open negotiations with Turkey could, as many expected, add a new dimension to the issue of labour movement. But, then again, it is not the first time that both sides entered an uneasy period. Regarding the current and future size of labour movements, the tension - which the EU has to deal with - remains, despite the present focus of the academic literature on the Turkish membership debate.

\section{Explanations of historical flow rates}

\section{Economically motivated migration and the democratic process}

The reconstruction of post-war Europe generated large labour shortages. In response, the government authorities of the countries concerned, firms 
and private agencies actively recruited migrant workers. These major migration movements within Europe and from developing countries contributed to the economic development and unparalleled growth that took place in Europe between 1945 and 1975. European countries experienced strong economic growth supported by the development of the heavy industry, manufacturing, building and public works sectors. Means of production were modernized and trade flows increased. The wave of migrants from Ireland and Southern Europe (Greece, Portugal, Spain and, to a lesser extent, Italy) - all countries that faced stagnating economies and high unemployment rates - at first met the labour market needs of Western Europe. The period 1961-1973 was characterized by an increasing willingness to employ Turkish migrant workers and by a considerable extension of the migration field (made up of all the regions in which Turkish workers and their families settled) since the whole of industrial Europe (Switzerland, Austria, Sweden and the United Kingdom) attracted Turkish workers and workers of other nationalities (Garson and Loizillon 2003: 2-3). The whole situation held the potential to develop into a massive migration.

In the studies of the 1960s and 1970s, the causes of migration pressure (or "push factors") in the sending countries of the post-war migration to Western Europe, in general, and in Turkey, in particular, were explained through traditional concepts such as slow economic and industrial growth, a rapid industrial growth rate, disparities between economic growth and population growth and unemployment (Akgündüz 2008: 1). At the macroeconomic level, access to the European labour markets and effective increases in earning potential were the two key drivers of Turkish migration in this period. An important part of Turkish migration in European countries was the potential workforce.

Certainly, Turks began to form an important component of European migration in the post-1950 period. This was a new phenomenon for Turkey. Many of its migrants were peasants who had already moved from rural areas to the big cities. According to official Turkish estimates, over 200,000 peasants left their villages to take employment in the big cities between 1950 and 1970, and this figure rose to 500,000 on an annual basis in the post-1990s. Therefore, it seems legitimate to conclude tentatively that the growth of the large-scale emigration movement from rural to urban areas was directed abroad.

In the late 1960s, countries that limited themselves to purely economic considerations prohibited such large migration flows. Accordingly, a sharp decline was recorded, and the number of entries fell by almost 75 per cent in 1967 over the previous year to just over 8,505 in total. This decline can be attributed to a situation of close to full employment in West European countries. It appears that the first warning came in 1966, with 
the onset of a recession. In simple terms, it became obvious that labour mobility was sustainable only as long as European countries demonstrated higher economic growth. It was expected that West European countries that had experienced growth would receive migrants. The economic recovery in these countries led them to review their immigration policies. As a result, large numbers of Turkish workers migrated to the West, particularly to West Germany, in 1969-1970.

As indicated in Chapter 1, Turkish labour migration was initially slow, but it rose significantly in 1963 following the signing of the Association Agreement with the EEC. Although economic factors came into play the level of income that could be earned in the potential immigration countries was very high - political explanations of this rise should not be underestimated. To put it differently, while stressing the importance of economic factors in promoting flows, it is important to note that changes in rates of migration in the late 1960s were also associated with political trends. At a practical level, democracy in Turkey was able to operate through stability and predictability with regard to institutions and their roles, reflecting a clear description of the role of governments. More precisely, migration potential had much to do with the lynchpin of liberal democracy, which provided the basis for broader individual freedoms. There can be little doubt that the 1961 Turkish Constitution was closely linked to liberal values and aspirations. On the face of it, there was nothing to prevent the 1961 Constitution from being undemocratic or authoritarian. Yet, it was compatible with European values. In effect, this political variable created a stronger instrument for migration flows. as West European countries showed more enthusiasm for importing a considerable number of workers from Turkey.

However, the democratic process that began with the 1961 Constitution was cut short when the Turkish armed forces assumed direct control of the government in 1971 with the declaration of martial law. The demand for a new form of social democracy - established as the leading form of socialism in the West - to displace capitalism brought the country to the brink of civil war. The new left was an extremely disorganized and inchoate movement that resulted in countless arrests and detentions. The same period witnessed the execution of three young activists, Deniz Gezmiş, Hüseyin İnan and Yusuf Aslan - on 6 March 1972. This particular event, which had nothing to do with European perceptions of human rights and freedoms, caused an enormous outcry at both the domestic and the international level. In the end, the whole situation proved to be very effective in reducing labour migration to the West. There was a clear trend of decreasing numbers of annually employed Turkish workers in West European countries from 123,466 in 1970 to 84,979 in 1971. This markedly lower level of migration fell further in 1972, to 83,126 workers. 


\section{The family unification scheme, labour market rigidities and political tensions}

Although the free movement provisions had no noticeable effect on the EEC countries in the period 1973-1980, the level of movement was fairly high. To a lesser extent, a declining number of migrants can also be seen in this period. There were several factors that determined migration preferences.

With regard to the growing importance of the family unification scheme, the migratory flows were initially very small, but peaked at 131,788 in 1973. Employment-related migration fell dramatically, but the family reunification flows increased significantly, as did other categories of migration entry. For example, the family formation scheme resulted in significant labour movements from Turkey to Germany, accounting for around 24 per cent of earlier movements, although many subsequently returned home. It would be reasonable to assume that this level of movement was largely the result of the restrictive immigration policies. The real trigger was the period between the first proposal for a recruitment stop and its implementation; the Turks were fearful that the doors to Europe would soon close and so rushed to the "promised land".

To some extent, the peak year of 1973 suggests that the flow rate depended on how the EEC countries managed the family unification policies following the end of guest worker programme. In March 1974, the Law of Family Reunification came into effect in the Federal Republic of Germany, setting up the framework allowing Turkish workers to be reunited with their family members in Europe (Koray 1999: 1). It may be no coincidence that a downward slope in the West European countries is clearly evident, with the numbers decreasing from 17,134 in 1974 to 1,211 in 1975. Some commentators have laid the blame for this downward trend at least partially on policy failure in the host countries. According to Duran (2006), this new migration type (family reunification) was not initially welcomed by the national governments. They implemented a number of policies restricting family reunification in order to discourage foreign dependants or family members who arrived to join their families to work and directed them to less saturated cities (Duran 2006: 40). Likewise, Liebig (2007) argued that the labour market integration of immigrant men in Germany was relatively good in international comparison with respect to employment and unemployment rates. The immigrant women, and particularly those of Turkish origin, had very low employment rates. This was partly an outcome of policies that limited spouses' access to the labour market (Liebig 2007: 4). However, most of these legal obstacles were removed under the new Immigration Act in Germany. 
A labour surplus in Turkey seems to be an important factor that helped to stimulate the flow rate. The economic crisis in Turkey at the end of the 1970s led to a considerable decrease in the number of jobs that were available. Between 1977 and 1983, the number of additional jobs required was 1.6 million. Considerable unemployment was caused by the downturn and by the flow of returning migrants, - around 600,000 from West Germany alone (Gümrükçü 1988: 10). Turkey's high unemployment rate and relatively rigid wages caused difficulties in some sectors when the number of low-skilled workers increased dramatically after their return home. The overall labour surplus created a problem. Because of attempts to pace economic growth and job creation, Turkish employment rose by just 210,000 each year in the mid-1980s, including 65,000 annually in manufacturing. This suggests that each 1 per cent increase in gross domestic product (GDP) added about 32,000 employed workers, or each 5 per cent increase in GDP added 1 per cent to net employment. So, growth rates of 10 per cent or more would be necessary to reduce unemployment and underemployment (Martin 1991: 5). It was primarily young and unqualified workers who were affected by this unemployment.

It is worth emphasizing that the migration pressure observed in the 1980s was due to the skill profiles of returning Turkish migrants. Many returning migrants, who had gone abroad at the beginning of their careers, constituted a highly unqualified and linguistically, technically and culturally inflexible labour force. In economic terms, migrants lacked the incentive to promote an economic take-off in Turkey. This specific problem, coupled with the labour market policies of the Turkish government, caused more surplus labour. This issue of labour market rigidities in Turkey is taken up by Şen (2003), who argues that the government policies constituted a major obstacle to returning migrants. Many Turkish workers who planned to return home constantly delayed and eventually a majority chose to settle in their host country. The main reasons for this were that the investment opportunities in Turkey were not as good as they had first appeared. The economic situation at the time would not have allowed a better life in Turkey with their current savings (Şen 2003: 211). Strictly speaking, the structure of the market economy in Turkey was less influenced by ownership than by public regulation. It is more common to refer to this aspect as limiting freedom of choice and enterprise. Inadequate government incentives, together with technical backwardness (for example in agriculture), had made economic activities inefficient. This situation dramatically increased the migration pressure that for some time had derived from the labour surplus.

An equally important issue that is directly related to the fall in migration flows is human rights violations in Turkey. The mid-1970s saw a considerable increase in the number of human rights violations. Perhaps the 
most concrete example was Turkey's invasion of Cyprus in 1974. Since then, human rights abuses as well as the humanitarian problem of missing persons preoccupied European institutions. The European Parliament set up a special committee to examine more closely these issues. A good example is that Turkey was found guilty of repeated violations of the European Convention on Human Rights by the European Commission of Human Rights in 1976 and in 1983. It is no surprise that, at a time of deep political crisis, Turkey's image in the eyes of the West changed drastically, resulting in the blurring of the issue of labour movement. One illustration of this decline is Germany, where the number of Turkish migrants fell by 99 per cent in 1974 compared with 1973. The Cyprus problem has consistently remained on the agenda as one of the policy concerns of the EU ever since Turkey's invasion.

Looking more closely at the implications of the ending of the guest worker programme in 1973, Turkey's numerous problems on the economic front significantly increased the flow rate in 1976-1977. The economic crisis resulted in greater numbers willing to emigrate. This placed further downward pressure on social and living standards in Turkey. The most visible indicator is that, according to the Turkish Employment Institution, at the end of 1977 there were already over 1 million applications for employment abroad. The higher unemployment was mainly a result of returning migrants as well as new entrants to the Turkish labour force, with a negative effect on the economic downturn. Thus, returning migrants affected the Turkish labour market, albeit with little effect on wage levels.

A decrease in the number of migrant workers in 1978-1979 can be partly explained by the stormy relationship between the EEC and Turkey. In fact, much had been made of how Turkey could achieve an input into the Community's policies (trade, agriculture, textiles, etc.). To a certain extent, Turkey successfully complied with and implemented some provisions of the Additional Protocol. This was complemented by the EEC eliminating fiscal barriers to value-added tax on some Turkish goods. On balance, Turkey's bargaining power was very limited, although it did not preclude undertaking such tasks. The Turkish authorities had always been wary of many arrangements such as higher customs duties and taxes on agricultural products; the Protocol, which did not satisfy Turkey in financial terms; and the Community's more favourable treatment of Mediterranean or other third countries under the framework of the Community's Generalized System of Preferences. As a result of these trends, the mutual relationship worsened, and then froze on 21 September 1979 for a period of five years.

Whether these circumstances contributed to the frozen relationship with the West or whether failure had been generated from within EC- 
Turkish relations in general, it is not fair to put the entire blame on Turkey for not doing enough to harmonize its policies, as required by the EEC. The Turkish government willingly undertook a number of measures that were known as the "24 January 1980 Decisions". The decision for more cooperation with the outside world and economic integration with the EEC helped to remove the obstacles that had hindered Turkey's harmonization process (Karluk 2003: 537). There were also other steps to revive the relationship. For instance, in 1980 Turkey launched a stabilization programme aimed at curbing inflation, removing the gap in foreign finance and creating a more outward-oriented or market-based economic system (Emek 2004: 109). These positive steps can be seen as basic drivers for migration. Undoubtedly, they were reflected in the number of migrants, which almost doubled, increasing by over 61 per cent in 1980 compared with 1979.

Once again, some significant political developments towards the end of the 1970s must be considered as migration drivers. Turkey was faced with a series of anarchist outrages and acts of terrorism, the most shocking of which were the several spectacular assassinations across the country that the civilian government proved unable to prevent. On 12 September 1980, General Kenan Evren seized power through a military coup d'état. The military coup had evidently become the principal device for bringing about a governmental transition of power - two coups had already occurred since the Association Agreement. Consequently, EC-Turkey relations were suspended for another 6 years. The coup primarily strained relationships concerning some economically sensitive issues, such as trade and financial aid. The latter was actually blocked in 1981. A significant fall in migrant flows to Western Europe - for the first time dropping to three digits - was seen. The number of entrants decreased from 2,345 in 1980 to 887 in 1981 and remained at a low level throughout the 1980s. The figure even fell to two digits in 1984 with 96 entries - the lowest in the whole period. This decline can be attributed solely to increased political instability in Turkey.

The redirection of flows, growing xenophobia and racism, and a shortfall in demand for foreign labour

Although the flow rate to West European countries in the 1990s was not what it used to be in the earlier decades, there was still a migration pressure. A sequence of political, economic and social events contributed to this pressure.

Economic and social integration with the EU grew in importance in the 1990s. This can be illustrated by the political crises in the Middle East having redirected Turkish labour migration towards the West. Until 1990, 
huge numbers of Turkish workers had been migrating to Iraq to search of jobs and better living standards. Those who had migrated to Iraq returned to Turkey to escape the political turmoil and civil war. It is also worth noting that approximately 600,000 Iraqis (mostly Kurds) poured into Turkey in the period 1988-1991. As the social and economic situation deteriorated in Iraq, human smugglers brought many Iraqis to Turkey, although some of them entered with valid documents and obtained residence permits. When the labour supply exceeded labour demand in Turkey, many more Turks migrated to Western Europe, where there was still demand for foreign labour (Narlı 2002: 2). In short, the number of Turkish workers in Iraq (and, to a lesser extent, in other Arab countries) fell sharply when the 1991 Gulf War broke out. Consequently, migration was diverted to West European countries. This explains why the early 1990s saw a peak in the migration trends, especially in Germany.

However the flow rate is conceived and explained, it increased sharply in the period 1992-1996, ranging from 2,000 to 2,500 entrants each year. This increase was partially reduced by the effects of xenophobia and racism. Over the decades, increasing public hostility in Western Europe to immigration and third world immigrants and the rise of far right antiimmigration and anti-enlargement parties have exacerbated the problems many migrants experienced in integrating into the social and economic life of Western civilization (Duran 2006: 19). The extent of aggressive racist behaviour is reflected in the figures. In 1992 there were 2,584 attacks on foreigners, resulting in 17 deaths, in the Federal Republic of Germany. This was an increase of more than 65 per cent compared with the previous year. In the first seven months of 1993, a total of 1,223 attacks against foreigners were recorded in Germany (Şen 1994: 3). These developments, coupled with a lack of social provision systems for migrants in the EU member states, undermined the Turkish workers' situation. As Europe was confronted with growing xenophobia and racism as well as ethnic conflicts, this argument was used extensively to decrease Turkish labour flows. Thus, only 3,606 employment-based immigrants were admitted in 1997 and 1998, which was less than 33 per cent of the total for the period 1992-1996.

Furthermore, a set of challenges concerning the family unification policies of individual countries played a determining role in the number of migrants in the 1990s. Annual Turkish flow rates to France collapsed in 1975 and remained extremely low until 1997. However, a tendency of increasing net emigration of Turkish workers to France can be observed from the late 1990s onwards. Moreover, in 1999, 20,000 immigrants were granted the "private and family life" card introduced by the Act of 11 May 1998. Holders of this one-year renewable card may apply for a residence card after five years' uninterrupted residence in France (OECD 
2001: 162). These changes in the family unification system were crucial to bringing in more family members. Since then, the annual flows to France have vastly increased. Another important trigger for this upward trend is France's migration policies. The 2001 OECD report indicated that the French government had issued some 5,800 temporary work permits in 1999, up 35 per cent from 1998. It was certainly a major step for France with respect to supporting policies of employment and free movement.

Finally, there is some evidence that changes in demand by themselves were unlikely to require new large-scale labour migration in the late 1990s. In fact, European labour markets needed skilled workers consistent with the wider political and economic strategy. In this context, a new policy drive would be required on labour standards to complement the policy of labour market openness. Salt (1992) argued that the features of changing labour demand interacted with international migration.

New technologies have revolutionized both processes and products, altering the equation between capital and labor. Perhaps of paramount importance is the changing sectoral structure, which has seen major losses of jobs in manufacturing, continuing decline in primary employment, and major growth in the service sector. Associated with these sectoral shifts have been major changes in the nature of demand and working practices. (Salt 1992: 1081)

The reason for this is that the pattern of migration was associated with one particular constellation of economic conditions in each member state. For instance, the relatively low level of annual inflows of Turkish workers in Belgium is primarily attributable to the suppression of economic activity in 1999 and 2000 by the decline in GDP of 2.7 per cent and 4.0 per cent, respectively. The standardized employment rate had declined since 1998, falling from 9.5 per cent to 8.8 per cent in 1999 and 7 per cent in 2000 (OECD 2001: 136). This markedly lower level of employment in the 1990s reflects a decline in the number of Turkish migrants.

\section{The Eastern enlargement and selective migration policies}

Between 1999 and 2004, the total number of Turkish migrant workers increased much more rapidly than in any other period. However, it declined in 2008 to just over 68 per cent of the figure for 2007. Four explanations can be considered for this: the Eastern enlargement, the demand for highly skilled workers, the difficulties of adaptation and the management of migration policies.

It needs emphasizing that the EU's enlargement in 2004 was invoked to explain the decline in the flow rate. The Eastern enlargement is one of the most controversial issues regarding the potential of Turkish labour 
migration to the EU. Hence, the EU faced the question of how it would run effective migration policies, with the completion of enlargement to 27 member states. The policies of the member states are determining factors in the employment of foreign workers in various sectors in the sense that their policies affect and are affected by the Eastern enlargement. At the same time, the member states are questioning the role of migration in the integration process. This means that the management of migration flows is becoming a top priority in light of the Eastern enlargement.

Evidence from the European Commission and from other independent studies indicates that some labour shortages are filled by workers from the CEECs. European companies are unlikely to prefer larger numbers of Turkish workers, and they admit only a few to fill vacancies. This is certainly the dominant perception of the EU's Eastern enlargement. As such, most companies acknowledge that the real problem is the difficulty of choosing between Turkish workers and the nationals of the CEECs, rather than skill shortages. These vacancies, for which it is difficult to recruit European citizens, correspond roughly with the profile and motives of many emigrants from the CEECs. The more recent period of 20052006 has been characterized by a decline in the number of Turkish entrants. This decline was the result of a considerable increase in the employment of CEEC nationals when restrictions were partly removed in the context of transitional arrangements.

Another explanation for a numerical limit is the skill composition. In terms of labour market trends, a particular problem is the lack of skills to meet continuing economic change. Under the guest worker programme, the way that Turkish migrants were distributed in employment was important to the relationship between demand for labour and skill levels. Their employability as cheap labour indicated that Turkish migrants proved valuable in the circumstances of a short supply of unskilled labour domestically. This situation changed in the late 2000s. The effect of the Eastern enlargement on Turkish labour movement has been considerable. It shaped the decisions of European companies to employ East European workers. In simple terms, the nationals of the CEECs possess relatively high educational standards and they are unlikely to specialize in low-skill, low-tech sectors in the medium or long run.

EU policies now place a strong emphasis on highly qualified migrants and international students, although the employment of foreign migrants remains a matter handled by the member states. This contrasts with earlier decades, when many admitted lower-educated migrants. It is equally important to note that the EU faces structural shortages in many sectors, including domestic services, care-giving, hospitality and construction. There is also a lack of adequate skills in engineering, construction and transportation. Since the late 1990s, high-skilled workers such as foreign 
managers, scientists and computer engineers have been recruited in most member states. Thus, the employment-based preference system has favoured the entry of highly skilled workers, precluding the employment of relatively low-skilled Turkish workers.

Many commentators see demand side forces driving international migration. According to the 2001 OECD report, the observed increase in employment-related migration was the result of several factors. One was the intensity of the late 1990s expansion phase and another was that the development of information and communication technology required skilled and highly skilled labour in the EU member states. The increase in employment-related migration also included unskilled foreign labour, especially in agriculture, building and public works, and domestic services (OECD 2001: 5). Nevertheless, unlike in the period of mass migration, demand for unskilled foreign labour fell significantly, owing to the pattern of technological progress. Most European companies look for specific skilled elements in the workforce.

In effect, there is already free movement for highly skilled foreign workers. The importing of foreign labour led to a reduction in Turkish labour flows. Switzerland is traditionally characterized as the least popular destination country for Turks. A declining trend has been observed since 1999, because of developments in the labour market in Switzerland. In principle, access to the labour market is confined to skilled labour. Since 2000, the economic recovery has been reflected in increasing demand for skilled foreign labour in certain sectors and in quotas that are set every year, but the quotas were completely filled in 2008. Although an improvement in Turkish migration has been recorded since 2007, it is still a small recovery. Processing backlogs have held immigrant admissions at lower than expected levels.

The third explanation for the decline in Turkish employment in the EU is that countries resorting to employment-related migration are seeking flexibility, especially adaptability to current labour needs. In reality, it is clear that countries with selective migration policies are reconsidering their strategies by seeking migrants with characteristics that are better adapted to the medium-term needs of the labour market (Garson and Loizillen 2003: 12). This contrasts sharply with past approaches, which focused on the temporary nature of employment-related migration. In parallel to demand for skilled workers in Germany, for instance, it has increasingly become difficult for unskilled Turkish workers to find a job, which is one of the reasons for high unemployment. As official German statistics show, almost half of Turkish workers do not have educational and vocational training.

Here, the question is how one can reconcile the employment-related migration policies of the EU with the structural differentiation of the 
Turkish workforce. It is known, for example, that language skills and qualifications are essential in order for the different types of immigrant labour to respond to changes. To elaborate this further, one of the chief problems that Turkish citizens face in the EU is adaptation. This problem was best highlighted by Murat (2004). His account of adaptation has the evident merit of linking the phenomenon of migration with the process of recruitment. Murat argued that it proved quite difficult for Turkish immigrants, the majority of whom were from rural areas, to adapt to the socioeconomic and cultural environment of European countries. The language issue exacerbated this problem. It was in fact extremely difficult for Turkish citizens to get used to and to communicate in an environment where different languages were spoken. The second and third generations, who had a language advantage over the first generation, experienced different problems. The new generations learned the language of the country in which they lived, but they were unable to speak their mother tongue, which resulted in dialogue difficulties and alienated them from their family and environment. The level of cultural and social erosion got even worse. In the face of this situation, immigrant Turkish citizens established religious, social and cultural associations to prevent further erosion of those values (Murat 2004: 37).

The fourth explanation of the decline in employment is primarily related to policy measures. Some of the changes in national migration policies that are evident in the EU have contributed considerably to the immobility of Turkish labour through the enforcement of restrictive policies. Of particular importance is emigration to Switzerland, which provides a more detailed insight into a non-EU member state. By comparison with the EU member states, the flow rate of Turkish workers to Switzerland represented only 1.5 per cent of total Turkish inflows to Germany and 18.0 per cent of those to France in the period 1961-2008. Theoretically, this figure should be higher because Switzerland is a prosperous country to which more workers are expected to move. It is conceivable that a sharp increase in movements could take place - Switzerland is famous for its wealth. This is proving to be the most encouraging push factor. Its generous social security system and tackling of what some regard as excessive labour market regulation have made it a more attractive country as a migration destination. Also, its tradition of neutrality and its non-aligned stance can be said to lead to a situation in which a broad consensus and a high measure of security promote social stability and personal security. In spite of this, Switzerland has been left in a less favourable position as a destination country. This poor result in terms of the flow rate should be taken into account in the development of migration policy in Switzerland. Traditionally, its migration policies towards third-country nationals are considered to be relatively restrictive - 
limiting access to labour markets, which depends on economic interests and on the long-term chances of integration on cultural grounds.

All four explanations remain current. However, in the 2000s, much of the literature on immigration policies has been devoted to demonstrating how governments are attempting to stimulate labour flows and how the free market can provide whatever is necessary for cheaper labour. As will be examined in more detail in Chapter 5, there is a general acknowledgement of a demand for labour in the post-enlargement period, despite more selective immigration processes. The basic requirement is that the new labour migrants should be highly skilled. This should not be taken to imply, however, that demand for low-skilled workers has waned. It has clearly continued, especially for a certain category of workers, mostly in labour-intensive and low-paying service industries. One cannot help but be impressed by the rate of change in the movement of Turkish labour over the decades since the halt of immigration. This is despite the fact that fewer immigrants have come to Europe than in the period 1960-1970. It is evident, then, that demand for Turkish workers continues, especially for some menial jobs, for example in healthcare, catering and hotels. This has contributed significantly to the inflows of Turkish labour through the enforcement of policies (such as on family formation), although some deficiencies are detected in the EU's immigration policy. Overall, the flow rate has been rising since 1999, with a pronounced slowdown in the second half of the 2000s. The annual number employed under the family reunion scheme is substantial, but the flow rate to Western Europe continues to be relatively small.

\section{Legitimate concerns over flows of Turkish labour}

\section{The role of bilateral agreements}

In principle, the EEC-Turkey Association Agreement established the legal basis for labour movement, and it was later supplemented by the Additional Protocol. Yet, beyond the bilateral agreements that coordinate relations between the EEC and Turkey, no new provisions of this kind have thus far been created (Engeli 1983: 116). Although Articles 12-14 of the Association Agreement provide for progressive stages for securing the free movement of workers residing in the EEC member states, rights concerning the abolition of restrictions on establishment and service provision are brushed aside under Community law. Acknowledging the limits of these rights, Turkish governments have sought to use legal mechanisms, pointing to the relevant articles of the Association Agreement and 
the Additional Protocol as justifications for claims regarding labour movement.

Concerned about misconduct in relation to implementation, the EU member states have focused on the question of how the unwanted sideeffects of these rights can be minimized. From Turkey's perspective, they are, at best, nothing more than recommendations. Therefore, implementation of the treaty provisions is totally reliant on the good-will of individual member states, whose justifications for restrictive measures are based mainly on socioeconomic grounds. This prevents the member states from moving towards a common approach, and individual cases of discrimination continue to find their way to the ECJ.

Equally important, the exact meaning of these agreements is a matter of some controversy, which derives from the fact that the situation of Turks remains diverse. Only those who are legally resident in a member state can refer directly to Community law when asking for a work permit or for the extension of a work permit or a residence permit. For those who are not legally resident, it is left to the competence of the member states to decide upon questions of entry and access to employment (Lichtenberg 2000: 204). Two challenges emerge for the Turkish side. First, the nature of the judicial arrangements means that the relevant rules do not have the same effect in all member states, and thus are applied differently. Secondly, these arrangements trigger deeper questions about legal validity. They may not be relevant because of the time that has elapsed since the signing of the treaties. In spite of the difficult context, movement is a "legitimate" need. Eventually the goal should be cooperation in the political and socioeconomic fields, and this should be maintained.

To this end, the case law of the ECJ has, since 1987, stressed the need to improve the legal status of migrant workers and their family members, with the aim of integrating them into the host society. Accordingly, three decisions of the EEC-Turkey Association Council (2/76, 1/80 and 3/80; see the next section) provide the legal framework concerning the rights of Turkish workers and their family members envisaged by the provisions of the Association Agreement (Çiçekli 1999: 310). Under Articles 9-12 of Regulation (EEC) 1612/68 of 1968, family members were granted access to the labour market, housing and education.

The Court consistently took the same position with regard to Decision 1/80 of the Association Council EEC-Turkey. In a series of judgments, the Court has recalled that the aim of this Decision is the gradual integration of Turkish workers and their family members in the host Member State... [T] he Court did so again in the Abatay judgment on the standstill clauses in the rules of the Association EEC-Turkey [ECJ 21 October 2003 C-317/01 and 369/01 (Abatay), par. 90]. (Groenendijk 2004: 115) 
These rulings demonstrate that the existence of rhetoric on significant rights to movement that are derived from the bilateral agreements can limit Community action on the broader aspect of immigration policy. In a way, they are said to act as a substitute for Community law.

What has been especially interesting about the ECJ's rulings is the extent to which social policy is partly motivated by concerns about the discrimination practices of EU member states, in terms of the right to take up and pursue activities as a self-employed person. Article 41(1) of the Additional Protocol of the EEC-Turkey Association Agreement prohibits member states from applying any new restrictions on the freedom of establishment and the freedom to provide services. Two Turkish failed asylum seekers, who sought to remain in the United Kingdom as selfemployed persons under the EEC-Turkey Association Agreement, succeeded in their claim under a judgment by the ECJ on 20 September 2007 (Judgment of the Court (Second Chamber), Case C-16/05, Tüm and Dar1) (Guild 2007: 1). One claim rejected by the Court was that of two asylum seekers who the United Kingdom alleged might abuse and defraud the system. After the ruling, this perception is likely to shift, even though it may have some basis in reality in other member states. A more significant outcome of this ruling is that the case provides an example of the EEC-Turkey Association Agreement standstill provision on the selfemployed applying for first-time entry. However, the UK government continues to impose a mandatory visa obligation on Turkish nationals, which raises the question of whether this practice is lawful under the provisions of Community law.

With movement towards more integration in the mid-2000s, heated discussions began about the standstill provision as part of the EU legal framework. The most far-reaching of the ECJ rulings is to be found in the case of Soysal, Savatlı and Salkım, who were taking action against Germany (Judgment of the Court (First Chamber), Case C-288/06, 19 February 2009). The case gave a broad interpretation to the standstill provision. In its judgment, the Court emphasized Article 41(1) of the Additional Protocol rules, which obligates member states to refrain from introducing new restrictions on the freedom of establishment and the freedom to provide services. In the wake of the ECJ ruling, Germany announced a partial easing of visa requirements for Turkish citizens on 5 June 2009. It should be noted that the German visa exemption applies to a wide range of employment categories, including Turkish artists, academicians, sports people and drivers, but it does not apply to businesspeople from Turkey. The Court added that the right to enter Germany for such employment groups was applicable on the condition that their place of residence was in Turkey and their stay in Germany did not exceed two months. The Court even concluded that the Schengen visa constituted a further 
restriction owing to its requirement of additional charges and costs. The fact is that the ECJ did not abolish the visa obligation. This insufficient legal backing for visa-free access to EU countries has been criticized by the Turkish authorities and is yet to be resolved by the two sides. It is argued that the outcome of this ruling will create new and serious problems for member states. It remains to be seen whether this judgment will extend to the other EU countries or be binding for all. In order to overcome these problems, the European Commission has already started to prepare clear guidance for member states.

One particular aspect of the legal framework is Title IV of the EC Treaties: visas, asylum, immigration and other policies related to the free movement of persons (Articles 61-68).

The proposal for the Directive on long-term residents was made by the Commission in the summer of 2001 [OJ 2001 C 240E/78]. After two years of negotiations in the Council and its working groups it was adopted in November 2003 [Directive 2003/109/EC of 25 November 2003, OJ 2004, L16/44]... The Directive has three key elements. Firstly, third country nationals with five years of legal residence in a Member State are entitled to a special secure residence status. That status can only be lost or withdrawn on a limited number of grounds, such as fraud, a very serious criminal offence or a long absence from the country [Article 9]. Lack of income is no longer a ground for expulsion. Secondly, persons having this status are entitled to equal treatment as nationals on a whole range of issues such as employment, education, social security, tax advantages, freedom of association and free movement within the country [Article 11]. Thirdly, third country nationals with this status have the right to look for employment, to work and to live in other EU Member States as well [Chapter III: Articles 14-23]. A Turkish citizen having obtained the status after five years of legal residence in Germany may move and work in the Netherlands or an other Member State, but the second Member State may "examine the situation of their labour markets" and apply the national procedures regarding the requirements for filling a vacancy or for exercising economic activities. It is a status with rights comparable but not equal to those of Union citizens. (Groenendijk 2004: 121)

In the main, these changes in the legal landscape are characterized as turning soft law into hard law. All of this is a renewed effort to reinforce the belief that it will be a difficult task for the EU to add further safeguard clauses to the Association Agreement.

It is generally true to say that equal treatment for Turkish workers is not foreseen in the field of social policy. In this regard, the entitlements of Turkish workers have become increasingly important with respect to employment, remuneration and other conditions of work. The provisions applicable to Turkish workers forbid direct and indirect discrimination. The attainment of these objectives requires that the right to movement 
may be exercised in a context of "freedom and dignity". However, there are some obstacles to mobility. For example, problems including access to employment, equal treatment at work, educational services for children of migrant workers living in the host countries, family reunion and the question of priority for Turkish workers over third-country workers for employment continue to be relevant.

\section{The decisions of the Association Council}

In 1973 the Association Council was empowered to take decisions under Article 22/1 of the Association Agreement. The Council was expected to take responsibility for completing the necessary work concerning the right to enter and reside in a member state as well as the free movement of services. According to Article 23/3 of the Association Agreement, decisions by unanimity voting apply to some areas in the Association Council. Moreover, Article 25 of the Association Agreement states that disputes deriving from the treaty provisions should be resolved by the Association Council and the views of the ECJ sought. The case law of the ECJ on the rules of the EEC-Turkey Association could serve as a good example, with regard to both the content of the rules and the systematic approach by the Court (Lichtenberg 2000: 220). Essentially, an effective functioning of the principles laid down in the Association Council decisions will permit economically planned freedom of movement. These principles may become part of the domestic law of member states, but their impact will depend on interpretation by the ECJ.

Pressure to raise the standard of living and quality of life of Turkish citizens in the EU member states derives from the Association Council, in which the fundamental rights of workers have been consolidated. In this context, Decision 1251/70, which set out the principle of the right to continued residence after the end of the employment or during retirement, is considered by many to be a positive development in the history of EEC-Turkey relations over migration. This is particularly true of Decision 2/76, in December 1976, which implied that short-term migration is the only channel and the door can be kept slightly open, despite the restrictive policies. On the basis of Decision 2/76, the Association Council confirmed the principles of implementation for the first stage of freedom of movement in December 1976. Accordingly, four fundamental rights were established:

- "After three years of legal employment in a Member State of the Community a Turkish worker shall be entitled, subject to the priority to be given to workers of Member States of the Community, to respond to an offer of employment, made under normal conditions and registered with the employment services of that State, for the same occupation, branch of activity and region" (Article 2(1)(a)). 
- "After five years of legal employment in a Member State of the Community, a Turkish worker shall enjoy free access in that country to any paid employment of his choice" (Article 2(1)(b)).

- "Turkish children who are residing legally with their parents in a Member State of the Community shall be granted access in that country to courses of general education" (Article 3).

- "This Decision shall not affect any rights or obligations arising from national laws or bilateral agreements existing between Turkey and the Member States of the Community where these provide for more favourable treatment for their nationals" (Article 8).

In fact, the nature of Decision 2/76's objectives would automatically provide the right to free movement. This was combined with both Article 12 of the Association Agreement and Article 36 of the Additional Protocol, which have been used robustly for the integration of Turkish workers into European labour markets. In a similar vein, a proposed European Commission Paper in 1974 on pursuing a common policy and alternative solutions to migration problems had already sought to serve this purpose. In principle, it was expected that such a proposal, as the first initiative of its kind, would eliminate the existing obstacles to labour movement; it clearly did not. Thus, the EU's approach is far too restrained and a solution needs to be found in line with the effectiveness of labour market policies.

In the prevailing climate of disillusion, it is easy to dismiss the equal opportunity principle in the field of social policy. Yet the social rights of Turkish workers are applied in different ways in different member states according to their respective policy regimes. The application of the equal opportunity principle is only possible through new measures prohibiting discrimination against Turkish workers. It is a historical fact that the EEC's social policy has impinged on them. To a lesser extent, however, it was the outcome of Association Council Decision 1/80 in July 1980 that acknowledged the member states' commitments to the equal treatment of Turkish workers. This was confirmation of the second stage, which would expire on 30 November 1983. Significantly, Article 10(1) of Decision 1/80 states:

The Member States of the Community shall as regards remuneration and other conditions of work grant Turkish workers duly registered as belonging to their labour forces treatment involving no discrimination on the basis of nationality between them and Community workers.

Decision 1/80 also laid down a general principle of equal treatment for families and children of workers in the context of social security and employment. It provided the most important rights: 
- a Turkish worker duly registered as belonging to the labour force of a member state is entitled to free access to any paid employment in the same member state after four years of legal employment;

- members of the family authorized to join the worker are entitled to respond to any offer of employment after three years of legal residence (subject to priority being given to Community nationals) and to have free access to any paid employment after five years of legal residence;

- children who have completed vocational training in the host country may respond to any offer of employment in that country, irrespective of the length of residence, provided one of the parents has been legally employed in the member state in question for at least three years;

- in the event of a demand for labour, member states wishing to call on non-Community workers must endeavour to accord priority to Turkish workers;

- children of legally resident Turkish parents are to be admitted to courses of general education and vocational training under the same conditions as the children of the member state concerned.

Further steps provided by Decision 3/80 of 19 September 1980 can be regarded as a new form of instrument specifically to promote the social security rights of Turkish workers and their families living in the EEC. Decision 3/80 contained a significant number of family allowances for migrant workers and their dependants employed in one of the member states. These included social security entitlements in relation to old age, disability, death, work-related accidents and occupational diseases. Other entitlements included the insurance scheme covering unemployment, sickness and maternity, and invalidity benefits. Decision 3/80 implied that further measures could now be adopted across the Community on all these issues.

In a parallel strategy, a question arises of whether the right to movement is no longer restricted, given the decisions of the Association Council. This question does, in fact, reflect a growing doubt as to whether effective labour movement should be allowed. For instance, the debates surrounding the Turkish minority and citizenship in Germany have focused primarily on the question of whether or not long-term residents should be allowed access to all of the rights enjoyed by German citizens. Recently, Green parliamentarians put forward a draft proposal to liberalize citizenship requirements by allowing dual citizenship and granting citizenship to foreigners concerning the second generation if children were born in Germany. This proposal had no possibility of gathering cross-party support, but it did succeed in revealing misconceptions in the political debate on minority rights.

Generally, it is rather paradoxical that the Association Council must take legal responsibility for the political failure of member states to 
remove restrictions on the movement of Turkish workers. The implementation task of the Association Council is defined as an "empty undertaking", despite the fact that the relevant provisions in the Association Agreement and the Additional Protocol clearly point to the right to free movement. Hence, the ability to take on obligations has to be questioned; it is ambitious to say the least (Engeli 1983: 116). The least successful parts of decisions of the Association Council are those concerned with social and economic rights.

\section{EC law and Turkey}

The EEC's Association Agreements with third countries have had similar effects on its bilateral agreements with Turkey. Workers from third countries are eligible for equal treatment under the same labour market conditions. However, the provisions in the Association Agreement recognize the principle of "second priority" for Turkish workers to take up employment in the member states. So, the hierarchical structure of the EEC requires a formula to allow Turkish workers to get ahead of "others". Any unfavourable conditions must be interpreted as a reaction to the dynamic effect of the Association Agreement. The EEC's preference for workers from third countries over Turkish nationals inevitably led to fierce arguments regarding the Community law.

In the early years of the EEC, some member states (notably Italy) pushed for a formal declaration of a Community priority for its workers; Italy had hoped to give "concrete expression" to preferences for Turkish workers. This legacy is still in place. It comes as little surprise that the EEC showed no enthusiasm for implementing the principle of second priority following the frozen relationship after 1979. There are still some formidable weaknesses, even though the provisions in the Association Agreement guarantee the removal of all obstacles to mobility. Although the right to employment is directly linked to the principle of the second priority of Turkish workers, after EEC nationals, among foreign nationals the priority objectives laid down in the Association Agreement are of relevance only after Turkish workers take advantage of the free movement provisions. Obviously, these objectives were not achieved, and nor was the free movement of Turkish workers because the legal instruments were ineffectual.

Under the existing rules, any shortcomings in the provisions of the bilateral treaties between Turkey and the EU are taken up by the ECJ for judicial review because the free movement rights come under the jurisdiction of the Court. The aim is to achieve a harmonious integration of Turkish workers into the EU's labour movement regime. According to the provisions of the Association Agreement, the strategy is quite simple. 
In any event, the ECJ must take legal responsibility for the political failure of the member states to remove the restrictions. However, the judgments of the ECJ are limited in their effectiveness because there is no one conception about what the member states intend to do (Uşar 1998: 81). The major task for the remaining stages of the free movement regulations is, then, to broaden their scope. Therefore, the application of a safeguard clause to labour movement is difficult to attain before any changes to the bilateral agreements.

On this basis alone, the ECJ's interpretation of the respective provisions of the Association Agreement on non-discrimination is crucial when it comes to preparing Turkey for accession. The European Commission in effect gave Turkey the amber light for the start of accession talks for membership on 3 October 2005, but EU officials counteracted the positive effect of this attempt by proposing to insert a permanent safeguard clause on labour movement. Curbing economic migration to other EU countries meant that the mainly Muslim country was being offered second-class membership. The Turkish Prime Minister, Recep Tayyip Erdoğan, demanded the same rules as for other candidate countries and criticized the conditional nature of the offer. He stated that "if negotiations are suspended, this would show a lack of respect for Turkey's democratization process and would conflict with the EU's own principles" (Gow 2004: 1). Because the Association Agreement forms the legal basis of EU-Turkey relations, the principle of second priority seems to play a vital part in Community law. Yet the situation may become somewhat analogous to the question of priority for Turks over third-country workers.

In principle, Turkish workers should enjoy relative freedom in relation to workers in the third-country category when they are granted "special treatment", and should not have stricter standards imposed on them. The policy of visa requirements for Turkish workers should be eliminated because of the agreements between the EU and Turkey (Coşkun 2006: 234). Given the deficiencies in the implementation of the provisions of the Association Agreement, there is no clear idea of how the hierarchical structure will offer active labour market measures. This is disputed for a simple reason. Differences in relative measures before and after the introduction of free movement will surely be all the more tangible for Turkish workers who are denied access to European labour markets.

Still, the question of second priority for Turkish workers remains extremely difficult to resolve because of the political sensitivity of the issues involved. The first time the EEC shed some light on this complexity was when it established Council Regulation No. 38/64/EEC, the most comprehensive international agreement dealing with labour movement, in March 1964. One of the three projected regulations was formally 
declared. Community priority was set up as follows: "Article 8 permits no discrimination between Community and national workers in replying to employment offers (except for surplus regions and professions) and Article 30 gives Member States with a labour surplus fifteen days to indicate whether they will be able to fill listed Community vacancies." For labour shortages, the member states may turn to third countries to fill their vacancies (Dahlberg 1967: 324).

As regards the supranational character of Community law, there appears to be a bargaining device used by Turkish political leaders that they were not prepared to cede. Turkish workers should come to enjoy a degree of equality of treatment, but a de facto priority over third-country nationals is not binding in nature. In the context of Directive No. 2003/ 109/EC, the Association Council provides a restrictive form of free movement. This Regulation foresees the conditions under which the right to permanent residency will be granted to third-country nationals residing in a member state legally, but the right will be suspended if the situation changes. It is realistic to assume that this Regulation is a way back into the traditional system, since it contains safeguards for the member states.

The steady flows of workers from non-EU countries have continued (Vural 1989: 62). And it is, perhaps, more than a matter of priority over third-country nationals. The concept of European citizenship, which was introduced by the Treaty of Maastricht, constitutes the basis. There is a real "deficit" in terms of the definition of the concept. The Treaty did not contain any provisions regarding third-country nationals residing permanently in the Community (Berksu 1999: 3). As a further step, the Amsterdam Treaty added a distinctive line on the complementarity of European citizenship, but it has limits for paving the way for the rights of thirdcountry nationals. Typically, the Treaty did not refer to this right being linked directly to Union citizenship under Community law.

Yet, it is possible to construct a model in which any agreement should allow EU member states to take special measures to ensure that the presence of workers from third countries does not create problems for Turkey. Additionally, when the EU Constitution comes into effect in the future, its provisions will continue to apply as a primary legal norm. Any discrimination clauses laid down in the Association Agreement will be criticized for their detrimental effect on Turkish workers' right to move, especially as regards the provisions of the Constitution. Indeed, the situation could easily get worse, with an increasing number of Turkish workers relying on the decisions of the ECJ.

\section{The economic argument}

According to integration theory, labour movement should be encouraged. The rationale for this is that migration improves economic efficiency by 
facilitating a more efficient allocation of labour across the regions, and thus reducing the marginal costs, where the productivity is greatest. The theory highlights the possible negative employment effects of increased labour migration from low-earning regions to high-earning regions. The larger labour supply lowers the wage rate of the indigenous labour force, because the low supply of labour in the emigration regions leads to higher wages. This not only means that wage differentials between regions diminish in the long run, but also leads to a better use of productive capital. By narrowing the gap in economic growth, a substantial net flow of migrants can be reduced as a result of the movement of production factors. The economic merit of migration is the key to this argument.

This is the reason Turkey is now asking for free access to the European labour markets based on its membership application. In the first place, the primary reason for Turkey's interest in joining the EU has been to find a market for its labour. Considering the restrictive measures against Turkish labour mobility in the internal market, permanent safeguard clauses may be more damaging for the member states as well, given the economic rational of integration. This may also be inconsistent with the EU's single market principles.

Nonetheless, a multitude of studies proves otherwise. The economic argument continues to justify the expulsion, or restriction, of Turkish workers on the grounds of increasing unemployment. However, Berksu (1999) has argued that migrant workers from Turkey are not only nationals of the EU but legal residents in the Union who have paid taxes and made national insurance contributions to the social policies of the member states. By doing so, they generated a Turkish community in Europe. On the one hand, the Turkish community represents a significant section of the population among all other migrant groups that coexist in the EU. On the other hand, the Turks have become a united whole in the communities in which they reside and symbolize a major economic potential whether as posted workers, employees, self-employed workers or consumers (Berksu 1999: 1).

On these grounds, Turkish workers may not crowd out national workers of the EU. Rather, they may have a positive impact on European economies by alleviating labour market shortages in certain member states or areas. Some member states (for example, the United Kingdom) have long welcomed migrants and they regularly complain that there are not enough skilled workers and urge governments to issue more work permits to migrants with the requisite skills (Seager 2004: 1). European business experts stressed in the Birmingham Post on 9 January 2002: “Turkey's growing integration into Europe's economy created a dynamic market in which small firms in the region should be exploited." From this point of view, the EU will have the opportunity to compensate for the shortages of unskilled labour by admitting Turkey into the Union. With 
Turkey's accession, the EU will gain access to efficient human resources on the basis of a blueprint and cooperation with Turkey in the long run (Özcan 2005: 102).

One pragmatic way of putting the "open door" policy into the enlargement context is the economic benefits of returning workers, who may contribute to strong and stable growth. According to this logic, the countries will benefit from a well-qualified and well-trained workforce in the hi-tech economy. Consequently, when workers return to their home country, they will have an important task in compensating for any deficiencies of the unqualified workforce (Ogan 1983: 95). For this task, Article 2(1) of the Association Agreement states:

The aim of this Agreement is to promote the continuous and balanced strengthening of trade and economic relations between the Parties, while taking full account of the need to ensure an accelerated development of the Turkish economy and to improve the level of employment and the living conditions of the Turkish people.

In such an economic environment, it is simply an illusion to talk about a serious and persistent disruption of the labour market. Article 2(1) implies that the economic justification for Turkey's request for permission for its citizens to have access to the EU is reasonable. A permanent safeguard may allow the EU member states to impose effective restrictions but cannot be an exception in serving the purpose of Article 2(1). At the very least, a worker who picks cherries is "skilled" at this trade, even if low demand for this particular skill makes him or her the "wrong kind of immigrant". The open door policy - in effect, an international version of a free labour market - should allow the EU-15 to "suck in" some of Turkey's best entrepreneurial talent (see King 2006: 3). The member states face a new challenge to attract and integrate a large number of young migrants from third countries, as they are already doing.

There is no doubt that this prevailing atmosphere served to encourage prudence as much in the political message as in the decisions that the ECJ was to take. Reinforcing this view, Article 28 of the Association Agreement states:

As soon as the operation of this Agreement advances far enough to justify full acceptance of the obligations by Turkey arising out of the Treaty establishing the Community, the Contracting Parties shall examine the possibility of the accession of Turkey to the Community.

Though circumstances may lead to a stage where Turkey abandons aspirations for full membership, joining the club has always been the ultimate goal of the Association Agreement. For some, if Turkey decides not to proceed with its membership application, it will mean a shift in 
position to a "concessionary partnership" model. According to the EU authorities, it is impossible for Turkey to rebut the claim to free movement. Turkish officials assert that only a model of "full membership minus" will leave little doubt about the question of why one of the four fundamental freedoms - laid down in these treaties - is jeopardized.

Essentially, labour movement issues are becoming an element of both parties' strategy to attempt to improve the situation. The slow progress on the issue - reaching the target step by step - does not imply abandoning the right to free movement. Rather, it should be understood that Turkey continues to insist on it, which is perfectly consistent with the spirit of the Association Agreement. In fact, Article 28 illustrates that Turkey's membership aspirations cannot be prevented by the wishes of one side, and/or it is no longer conceivable that measures in this area should be taken by only one contracting party.

\section{Conclusion}

Labour mobility is at the centre of EU-Turkey relations. Although the provisions of the Association Agreement and the Additional Protocol envisaged the eventual free movement of labour, the Treaty rules in this area have not been enforced. The Treaty's domain is limited to the acquisition of rights after accession. A gradual system of introduction in which full movement would eventually be granted in stages might have been a more realistic alternative for both parties or, indeed, could have resulted in a general suspension of Turkish labour movement rights. Much of the current ambiguity is found in the implementation of the Association Agreement and the Additional Protocol, which prevailed upon EEC members to take into consideration the political aspect of these regulations. Turkey has almost invariably sought further changes in the EU policy regimes in order to make the terms of movement better suited to its needs and interests. The prospect of removing restrictions on labour movement may still be under consideration. Nevertheless, the future possibilities are still exceptional.

The fundamental question is which factors best promoted the historical flow rates, and to what extent. As the chapter has demonstrated, Turkish labour migration since the early 1960s has invariably been linked with the social conditions and the economic, legal and political stability of both the member states and Turkey. Under the influence of globalization and information technologies, there have been fundamental shifts in employment structures. One particular aspect is that demand for low-skilled Turkish workers continues, but mostly in labour-intensive and low-paying service industries. This line of rhetoric can easily be related to the paradoxical situation where the necessary measures are primarily concerned 
with the EU's policies towards Turkish labour movement. Quite simply, Turkish migration to West European countries can be understood only within such contexts.

There is legitimate concern over labour movement in the EU, despite the fact that Turkey is not a member, and the reasons the subsequent curve developed the way it did have been the subject of intense debate. A potentially more important question is whether a candidate country will permanently be deprived of rights based on the Association Agreement and the Additional Protocol - which entailed a system of movement by progressive steps - and the decisions of the Association Council. The right to free movement is deeply rooted in these treaties and is strongly supported by the Association Council. In particular, the effect of the right of Turkish workers to move freely within the context of the social structure of the EU member states will partly depend on Association Council decisions, despite the fact that there are some complications over the implementation of the Council decisions in the member states. Essentially, Turkey should be given the right to free movement on the basis of the Association Agreement as well as the Additional Protocol.

The increasing emphasis on political considerations is accompanied by growing anxiety about the dismissal of the legal framework. Any restrictions on labour migration may undermine the proper functioning of the EU mechanism. As a further justification of Turkish workers' inclusion in the European labour markets, withdrawing from this right on a voluntary or obligatory basis is at odds with the hierarchical structure of Community law, for the most part. The fact remains that an in-depth clearing and weeding out of the EU legislative jungle should be intensified. Therefore, these restrictions must be in line with the hierarchical structure of Community law and interpreted strictly. To be sure, the EU's preference to give priority to Turkey or other countries will cause some "nuances".

It is equally important to look at the potential economic costs and benefits of Turkish labour migration. Because the embodiment of nondiscrimination is deeply rooted in the treaties, it is not legitimate to impose a permanent curb on labour movement. A somewhat more sophisticated version of the argument dispels the idea that there is a serious risk of labour market disruption in the EU member states. In an economic context, one way in which many of the market gains can accrue is if the restrictions on the movement of labour are removed. This factor is uppermost in the debate about full membership, but does not illustrate the change of attitude of the EU authorities with regard to labour mobility. Whatever the debates about how and why Turkey should be granted the right to labour movement, these considerations will inevitably force the EU to rethink its policy towards Turkey, given the entire history of relations between the EU and Turkey, from the 1960s, and the Ankara Association Agreement, to present. 


\section{Past enlargement experiences}

\section{Introduction}

In the early 1980s, anticipated labour migration caused concerns in the European Community (EC). The problem mainly arose from granting the right of free movement to workers from Greece, Spain and Portugal at the time of the accession of these countries. Factors such as income differentials, unemployment and geographical proximity, combined with a long tradition of emigration towards the West, raised an expectation of cheap labour flooding the existing nine countries of the European Community (EC-9) as soon as these countries were given member status. This led to a widespread belief that labour migration from Turkey should, at least temporarily, be avoided, as by now the EC had enough on its plate dealing with the Southern migration episode. Following the inclusion of Greece, Spain and Portugal by 1986, the movement of Turkish labour was actually prohibited and no attempt was made to fulfil the promise that had been made earlier within the EC's legal framework. The assumption that granting the right of free movement to workers would lead to massive flows from Greece, Spain and Portugal at the time of the accession of these countries to the EC may hold true, since the most significant decrease in the number of Turkish workers in the 1980s was recorded when the Southern enlargement occurred. The accession of Greece, Spain and Portugal could provide some basis for theorizing about the extent to which various receiving countries took a restrictive stand, which might, at the very least, be desirable from an economic standpoint.

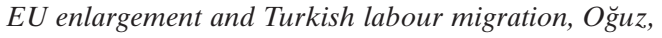

United Nations University Press, 2012, ISBN 978-92-808-1206-0 
With such considerations as background, this chapter assesses past migration trends in the Southern accession countries and examines their effect on Turkish labour migration. I first discuss the South European context of migration. Then I deal with the factors affecting Turkish migration in the 1980s in terms of a comparative analysis of indicators for Greece, Spain, Portugal and Turkey, as well as the EC-9. The final section is concerned with the implications of the Southern enlargement for Turkish labour movement.

\section{The context of migration in Southern Europe}

\section{The integration process}

The Greek and Iberian enlargements are normally considered separately, even though they share some important characteristics. First, all three countries had only just emerged from right-wing dictatorships when they applied for membership. Despite their differences, the authoritarian regimes in these countries had frozen economic, social and democratic developments. The EC presented a much-needed anchor for the young and fragile democracies. Second, decades of economic difficulties and backwardness posed a dilemma for the new political regimes and democracy, which depended on social and economic modernization in order to achieve the full support of the population and the national elite (Michalski 2006: 282).

The Southern enlargement started as early as 1962 when Greece signed an Association Agreement with the European Economic Community (EEC) that anticipated a Greek membership application by 1984 at the latest. The case of Greece illustrated the importance of political as well as economic considerations in determining membership. Although the EEC Commission had given a negative response to Greek accession on the basis of economic disparity, the political arguments - support for democracy and keeping Greece in the Western camp - outweighed these considerations (Holland 2004: 167). The Association Agreement provided for the gradual establishment of a customs union between the six EEC countries and Greece, which was completed by 1984. Greek membership of the EEC was not guaranteed automatically after the completion of the 22-year transitional period. The Agreement provided for the free movement of Greek labour, alongside a financial protocol and provisions for the export of Greek agricultural products to the EEC.

It was hoped that the Association Agreement would open new opportunities for the Greek labour market, although there were doubts about the advantages of membership politically. These issues caused the fiercest controversies during the membership negotiations over transition pe- 
riods. In fact, the Agreement was interrupted by the period of military rule from 1967 to 1974. In 1975, Greece opted for full membership one year after the collapse of the seven-year dictatorship. Eventually, Greece acceded to the EC in 1981. A five-year transition period was finally fixed for most sectors and a seven-year period was applied in the area of free movement.

Despite noteworthy efforts, controversy grew over the consequences of admitting poorer countries to the EC. The increase in Community members to 10 intensified disparities in the Community, and the necessary adjustments did not follow. The deficiencies in the overall structure of the Greek economy continued. Relatively huge resources and financial assistance had been transferred to the Community's weakest member, to aid the modernization of Greece's fragile economy as well as its administration. In similar vein, the capacity to overcome its structural problems depended on the Commission's help. The Greek economy could be mobilized only to the extent that Greece was determined to apply itself to the major task of securing the full participation of Greece in all aspects of the Community system (Walker 1983: 40).

There had, in fact, been little debate in Greece about the pros and cons of the membership. After accession, the effect of the economic recession was mainly felt when the Greek Socialist Party (PASOK) came to power in 1981, with Andreas Papandreou as prime minister. Once in government, PASOK took a stand against Greek membership. It denounced the EC as being a rich men's club and threatened that this group of monopolist capitalists would keep Greece at a peripheral level of economic development. At the same time, PASOK tried to achieve better terms, just as Spain and Portugal would do. The EC could not ignore this. So, it established the Integrated Mediterranean Programmes in the mid-1980s. This not only encouraged Greece to transform its economic structure from a heavy dependence on agriculture, but also contributed to alleviating the effects of the Spanish and Portuguese accessions on the Mediterranean region.

When the dictatorships came to an end in Spain and Portugal in the mid-1970s, a period of transition to democracy started (Guillen et al. 2003: 231) that paved the way to full membership of the EC for these countries. In 1978, the European Commission delivered favourable opinions on both countries, despite the existence of serious difficulties in relation to the free movement of workers and some other issues, for example in the agriculture, fisheries and industrial sectors. The negotiation process lasted seven years, causing a delay in the membership application, mainly owing to political instability.

In the case of Portugal, membership was impaired by the nationalization process in some important sectors of the economy, leading to the revolutionary period and the 1974 coup d'état. Bargaining over sensitive 
issues, combined with French opposition to enlargement (based particularly on concerns over the impact of Spanish agriculture), delayed the final agreement. The obstacles to accession included the free movement of workers, fisheries, the budget contribution, the British budgetary question and the Integrated Mediterranean Programmes, but these were removed in 1984-1985. In October 1984, Portuguese Prime Minister Mario Soares signed a "common declaration" affirming the integration of Portugal into the Community by the January 1986 target date. The treaties of accession were signed in 1985, and Portugal and Spain joined the EC on 1 January 1986 (Royo and Manuel 2003: 16).

For Spain, Community membership had always been a high priority. As the membership negotiations demonstrated, first, both Spain and the Community members expected to resolve a number of issues including the customs union, Euratom and capital flows, and, second, most Spaniards were in favour of wider economic integration. Other more complex issues such as agriculture and fisheries were left to be tackled at a later stage. Domestic economic interests clearly shaped Spaniards' preferences as regards political interests. However, the economic goal was rapidly set back in July 1980 when French President Valéry Giscard d'Estaing vehemently opposed the admission of another major producer of wine, olive oil and vegetables. This was condemned by Spaniards, who believed that this attitude would damage the Community's democratic credentials.

A similar logic applies to Portugal's prospective membership of the EC. In 1977, when Portugal applied for membership, diplomatic efforts were conducted along two lines. The moderate parties stressed that full membership would reinforce the stability of the democratic institutions that were established after the 1974 "carnation" revolution. None of the political parties of substance opposed the admission, with the exception of the Communist Party of Alvaro Cunhal, together with a left-wing splinter group of socialists. It was widely believed that there was no alternative but to join the industrialized countries of the West. For other supporters of accession, this could be seen as an important step towards customs union and a regional fiscal policy. Community membership was appealing in the sense that the Portuguese government could formalize a request for drought relief support. This would take the form of export facilities to compensate for further deterioration in the current account balance in farm and energy production.

The assumption of a further deterioration in the current account balance in farm and energy production appears to have been based on the calculation that an extensive "widening" of the EC would prevent its further "deepening". The widening of the EC by including Spain and Portugal was being monitored with a mixture of hope and trepidation. Hope was certainly there: at the injection of enthusiasm brought by the new 
Iberian partners; at the reinforcement of the Common market, expanding from 10 to 12 member states and from 270 million to 320 million inhabitants, as a base for economic growth; at the reaffirmation of the Community as a bastion of democracy, welcoming new members as they moved from dictatorship to genuinely free elections (Peel 1986: 28).

Some would regard the Southern enlargement as a stimulating challenge not only because it provided enormous opportunities for the more efficient producer countries once the high tariff walls came down, but also because of comparatively strong interest in EC membership, which could have a revitalizing effect. Others would argue that membership of both Spain and Portugal in the EC would have a negative effect on the $\mathrm{EC}$ in many respects. With respect to all candidates, the applications for membership were delayed on the grounds of political and economic compatibility. In particular, the European Commission was concerned mainly with the socioeconomic situation and the widening of its own policy scope. Regardless of the numbers and qualifications of labour migrants, a lack of opportunities in their labour markets might encourage migrants from those countries to make more demands on the social welfare systems of the EC and contribute less to the economies.

Increasingly it became clear that the negotiations with Portugal involved many difficulties, and they entered a critical phase. In financial matters, Spain and Portugal generally followed Greece's lead. The Iberian countries both depended heavily on access to EC markets. They were able to negotiate compensatory mechanisms in the financial framework known as the Delors I (1988-1992) and Delors II (1993-1999) budget packages through the introduction of the structural or cohesion funds. However, the Iberian economies were not included in the Integrated Mediterranean Programmes, despite an obvious need for their modernization.

Since becoming Community members, the Spanish and Portuguese economies have undergone a profound transformation in which the $a c$ quis communautaire and financial transfers from the Community have played an important part. For instance, Spain's gross domestic product (GDP) per capita relative to the EU average was 74.2 per cent in 1980 and 81.0 per cent in 2000, while for Portugal it was 55.0 per cent in 1980 and 74.0 per cent in 2000 . The structural funds contributed to this convergence by making up a substantial part of public investment, rising in 1996 to 42 per cent in Portugal and 15 per cent in Spain (Royo 2004: 33).

Overall, there would be immense economic advantages of membership for Greece. During the four-year negotiations, the EC was very much seen as an economic community, although the Greek government also looked upon it as a political bloc of the stable and privileged that Greece was going to join. At a deeper level, for all three countries, membership 
opened possibilities for migrant workers to find jobs in the EC countries. Portugal in particular was regarded as an asset to the Community in building an economic bridge to the resources of its former colonies, notably Angola and Mozambique. For the existing member states, the Southern enlargement was primarily a political step. These countries aspired to membership because they were motivated towards not merely economic modernization as a driving force but also the democratization process in the face of the ongoing Cold War. Besides, regional security was extremely highly valued.

\section{Migration flows}

The most important aspect of the EC regulations was that a great deal of emphasis was placed on governments' attitudes towards labour migration from third countries in the mid-1970s. However, their attitudes have changed since the 1980s when the issues of migration tentatively appeared on the agenda (still outside the confines of the institutions and procedures of the Community). In seeking to influence the behaviour of individual member states, it was obviously beyond the immediate power of the EC to eradicate immigration policy concerns at the Community level. At this point, the most contentious issues in the enlargement negotiations leading to the accession of Greece, Spain and Portugal were the rights of EC nationals to free movement within the Community. Full free movement rights were not conferred upon Greek citizens until 1988 or to Spanish and Portuguese citizens until 1992 (Philip 1994: 169).

The migration trends presented here are drawn from the European Commission and Eurostat data used to measure the changes in stocks of migrants from Greece, Spain and Portugal, providing a range of significant indicators. In the case of Greece, the absence of statistics for the 1985-1997 period precludes drawing conclusions about Greek emigration to the EC-9 during its transition period. Despite the lack of data, it is possible to draw a general picture of the overall magnitude of the migration flows. The available data on the stocks of Spanish and Portuguese labour in various countries are far more comprehensive.

The data indicate that in 1997 over 447,000 Greek citizens were living in the other 11 countries of the EC-12, having taken advantage of liberalized access to the European labour markets. In the last year of the transition period (1987), the total number was 345,000. An obvious point is that the number of Greek citizens rose by 102,000 over this 10 -year period - an increase of around 10,000 people per year.

This trend was reversed in Spain's case. In 1991 (the last year of its transition period) the number of Spanish citizens living in the other countries of the EC-12 was 474,000. At the time of Spanish accession to the 
EC, the number had been around 495,000, and this figure was slightly higher in 1986. Presumably, the removal of emigration barriers for people in Spain did not stimulate huge flows since the stock of Spanish immigration declined significantly during the transition period. This trend continued throughout the decade, and by 1997 the stock had decreased again, to 470,000 .

In the case of Portugal, a slightly increased trend is observed, with stocks of 825,000 at the time of its accession. In 1991 the stock was around 855,000. In 1997 the migration potential was substantial, with a marked increase to 910,000. The increase of Portuguese citizens in the EC was slightly smaller than the increase of Greek citizens, with an annual average of around 7,700 immigrants to the rest of the EC over a period of 11 years.

Figure 3.1 shows Spanish migratory flows into Germany and the United Kingdom during the period 1985-1997. The graph also indicates the employment rate in Spain relative to the German/UK average and Spain's GDP per capita as a percentage of the German/UK average. As far as labour migration from Spain to France is concerned, there are some observed underestimations regarding the true total. The number of Spanish stocks in France was largest during the period 1985-1997. However, because of the scarcity of data, France is not included in the graph. As Figure 3.1 indicates, the flows into Germany and the United Kingdom dropped from 186,000 in 1986 to 173,000 in 1992 during the transition period and further dropped to 167,000 in the following year. This decrease is in clear contrast to the changes in relative income and unemployment. Thus, the introduction of the free movement of labour does not seem to have mattered very much, as the stock series moved inversely to the relative employment rate series.

Figure 3.2 indicates the numbers of Portuguese citizens living in Germany and the United Kingdom annually between 1985 and 1997 relative to GDP per capita and employment rates. Simply by looking at the graph, it is clear that the stock of Portuguese citizens in the two countries increased between 1986 and 1992 (from 92,000 to 111,000). In the peak year of 1997, the number of arrivals of Portuguese was 153,000, a visibly increasing tendency. However, this number, which represents 5,500 citizens per year during the 11-year period, is still too small to be considered statistically significant. In Portugal's case, too, it seems that the growth of stocks is not related to relative income or employment rates. Obviously, the numbers of Portuguese citizens in Germany and the United Kingdom were not greatly influenced by the introduction of the free movement of labour.

Cavounidis (2006) provides some general insights into the labour market impact of migration. Although each country had different causes of 


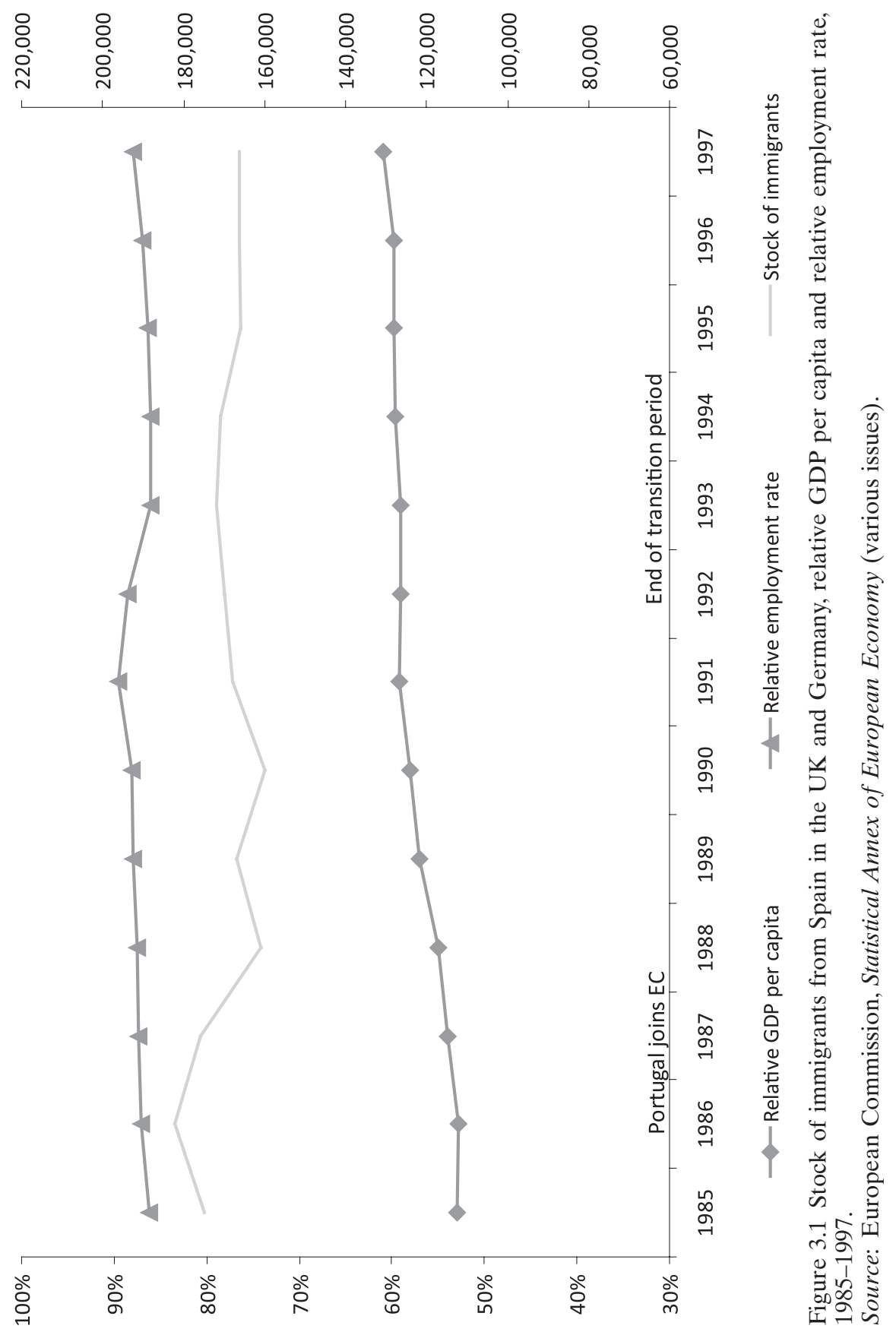




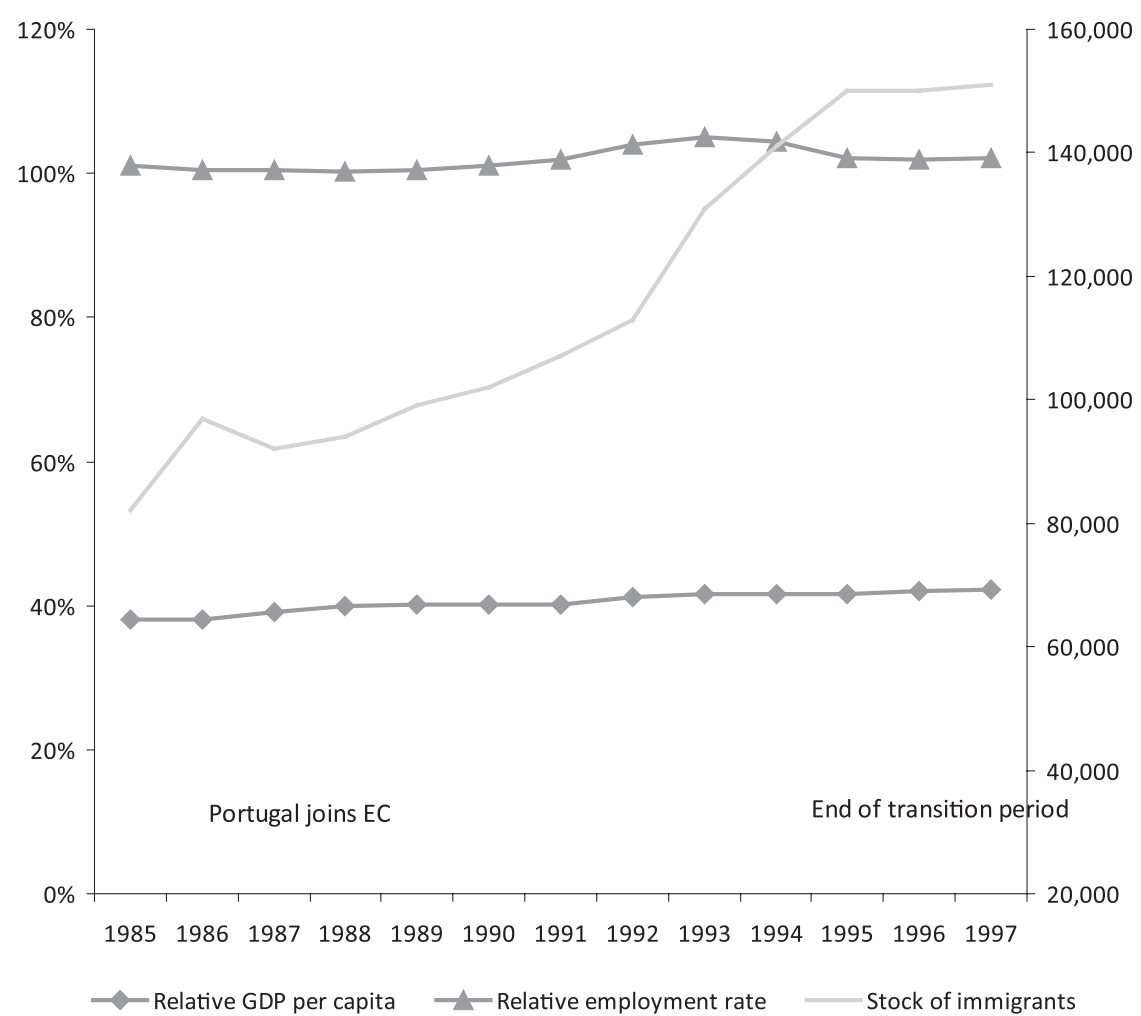

Figure 3.2 The stock of immigrants from Portugal in the UK and Germany, relative GDP per capita and relative employment rate, 1985-1997.

Source: European Commission, Statistical Annex of European Economy (various issues).

migration, essentially the policies had been the same: the economic objectives of all three countries were paramount, and a similar economic and social process seemed to underlie their transformation. In the context of the South European model of migration, the specific forms of South European economic development played an important role in terms of their transformation. In contrast to the pattern of economic development in the North of Europe, Southern Europe to some extent experienced industrialization later. In 1986, Greece, Spain and Portugal had a comparative advantage in agriculture and tourism, which constituted major economic activities. Although the number of Greeks, Spanish and Portuguese working elsewhere in the EC did grow, increases in migration following the introduction of the freedom of movement remained below the average (Cavounidis 2006: 651). Naturally, workers from the Southern accession countries used foreign earnings to set up small businesses at 
home, gradually leading to a more rapid levelling of underlying structural differences. Such transferred income invested in business in the country of origin was more attractive, because this was done when the economies of their countries were booming.

Overall, EC accession did not cause substantial cross-border movements of workers from Greece, Spain and Portugal. Indeed, a net decrease of Spanish people in Germany and the United Kingdom is evident. Thus, no consistent relationship between the relative evolution of the economic variables in the EC-9 and the stocks of migrants from these three countries can be established. More significantly, the existing transitional arrangements made no difference; the migration potential was quite low regardless of whether or not a transition period had been introduced. The free movement right was granted in full to Greece in 1987, and to Spain and Portugal in 1992, after a transition period of several years. Based on this experience, the European Commission recognized that there was no threat of large migration flows from Spain and Portugal and recommended shortening the transition periods for these countries.

\section{The basic determining factors of migration from Turkey to the EC}

\section{Socioeconomic considerations}

\section{Wages and employment}

Table 3.1 shows that the absolute gap in wage levels between the Southern countries and Turkey was generally high. Considering GDP per capita at purchasing power standard or parities (PPP), Turkey had levels of income that barely reached 34.3 per cent of the EC-10 average, ranging from 53.1 per cent for Portugal, 55.9 per cent for Greece to 72.3 per cent

Table 3.1 GDP per capita, 1985

\begin{tabular}{lcrrrr}
\hline & \multicolumn{2}{c}{ Purchasing power parities } & & \multicolumn{2}{c}{ GNP at current prices } \\
\cline { 2 - 3 } & GDP per capita & Index & & ECU & Index \\
\hline EC-10 & 12,568 & 100.0 & & 10,340 & 100.0 \\
Greece & 7,019 & 55.9 & & 4,389 & 42.5 \\
Spain & 9,089 & 72.3 & & 5,612 & 54.3 \\
Portugal & 6,689 & 53.1 & & 2,658 & 25.7 \\
Turkey & 4,311 & 34.3 & & 1,404 & 13.6 \\
\hline
\end{tabular}

Sources: Eurostat, Purchasing Power Parities and Gross Domestic Product in Real Terms, 1985 Data, EC Series, European Commission, 1988. 
Table 3.2 Unemployment rates, 1975-1987 (per cent)

\begin{tabular}{lccrr}
\hline & 1975 & 1980 & 1985 & $1987^{a}$ \\
\hline EC & 3.9 & 6.1 & 11.6 & 11.4 \\
Greece & - & - & 7.8 & 7.4 \\
Spain & 1.9 & 11.8 & 19.5 & 20.5 \\
Portugal & 2.7 & 6.7 & 7.7 & 7.2 \\
Turkey $^{b}$ & - & 14.8 & 16.3 & 15.2 \\
\hline
\end{tabular}

Sources: EEC, Annual Economic Report, 1989-1990; OECD, Economic Studies, Turkey, 1985-1987.

Notes:

${ }^{a}$ OECD statistics.

${ }^{b}$ Includes seasonal unemployment in the agricultural sector.

for Spain. We can distinguish a first subset of a more advanced country in terms of GDP per capita - Spain - and a second subset of middle-income economies - Greece and Portugal. Turkish people earned a much lower income per capita than the average of EC nationals and around half that of Spaniards.

Concerns over the possible negative employment effects of increased Turkish labour migration are found to hinge critically on whether Turkish immigrants competed with or complemented the labour force of the EC countries. In the period 1975-1987, Turkey's labour market relative to the EC was characterized by high levels of unemployment. Table 3.2 indicates the absolute gaps in the unemployment rates between the Southern accession countries and Turkey. Compared with the EC-12 (which had an unemployment rate of 11.4 per cent in 1987), the rate in Turkey was 15.2 per cent, which was twice as high as those of Greece (7.4 per cent) and Portugal (7.2 per cent). The situation in Spain, as in Turkey, was much worse than that in Greece and Portugal; its unemployment rate of 20.5 per cent remained a long way from the EC average.

In 1987, around 16 million people in Turkey (out of 32.4 million of working age) were employed in the various sectors, 750,000 were in the army and police services, and 2.2 million were unemployed. For comparison, the respective figures in the EC-12 were 123.1 million, 220.4 million, 2.9 million and 15.7 million (European Commission 1989: 32). It is not surprising that more than half of the active population in Turkey was employed in the agricultural sector, whereas only 8 per cent of total EC employment was in agriculture in 1987 (see Table 3.3). Yet employment in the agricultural sector in the Southern accession countries was also much lower than that in Turkey. This gap pointed out the differences between the EC and Turkey, posing a difficult challenge to the EC. However, a slight decrease in employment in the Turkish agricultural sector is observed in the late 1980s, while a rapid increase (5 per cent) 
Table 3.3 Characteristics of the labour market, 1987

\begin{tabular}{|c|c|c|c|c|c|}
\hline & EC-12 & Greece & Spain & Portugal & Turkey \\
\hline Population ('000) & 323,067 & 10,000 & 38,832 & 9,755 & 52,059 \\
\hline $\begin{array}{l}\text { Population aged } 15-64 \\
\text { ('000) }\end{array}$ & 220,432 & 6,323 & 25,453 & 6,556 & 32,354 \\
\hline Civilian workforce ('000) & 139,440 & 3,849 & 14,365 & 4,280 & 18,804 \\
\hline $\begin{array}{l}\text { Active population rate } \\
\text { (per cent) }\end{array}$ & 63.3 & 60.9 & 57.9 & 65.6 & 58.1 \\
\hline Civilian employment ('000) & 123,133 & 3,564 & 1,142 & 3,972 & 15,948 \\
\hline Agriculture & 1,022 & 1,016 & 1,839 & 870 & 8,757 \\
\hline Industry $^{a}$ & 41,003 & 1,001 & 3,666 & 1,354 & 2,281 \\
\hline Construction & - & - & - & - & 686 \\
\hline Services & 7,191 & 1,547 & 5,915 & 1,748 & 4,224 \\
\hline Unemployment ('000) & 15,725 & 284 & 295 & 310 & $2,256^{b}$ \\
\hline $\begin{array}{l}\text { Unemployment rate } \\
\text { (per cent) }\end{array}$ & 11.7 & 7.4 & 20.5 & 7.2 & 12.0 \\
\hline
\end{tabular}

Sources: European Commission, Economic Forecasts, June 1988; and OECD, Economic Studies, Turkey, 1988.

Notes:

${ }^{a}$ Includes the construction sector, except in Turkey.

${ }^{b}$ Excludes seasonal workers in the agricultural sector.

in employment was noticeable in services and industry. Ironically, it was only the service sector that created employment opportunities in the EC.

In the period 1980-1988, the working age population increased by 2.8 per cent per annum in Turkey. For the Community, the figure was only 1.0 per cent (European Commission 1989: 32). With no significant increase in the unemployment rate, this economic structure indicated that sustainable economic growth would be essential in the short run. Periodically, the Turkish labour market was characterized by a high degree of unemployment, as was the case in 1985 . One explanation for this was that potential migrants were returning from West European countries because of difficulties in finding jobs or accommodation. Unemployment was especially high among the young and the less educated in Turkey, despite surplus demand for highly skilled labour from some EC countries.

\section{Economic growth}

The Turkish growth record leads one back to the fundamental difficulty of judging the prospects of a country whose past performance has been so variable. Like the EC, Turkey experienced a period of relative growth through the 1960s until the first oil crisis in 1973. Table 3.4 shows the development of the Turkish economy in the period 1970-1987. We observe steady growth during the first half of the 1980s, with annual growth rates 
Table 3.4 Increase in gross domestic product, 1970-1987 (per cent)

\begin{tabular}{lccccr}
\hline & $1970-75$ & $1975-80$ & $1980-85$ & 1986 & 1987 \\
\hline EC & 3.0 & 2.6 & 1.4 & 2.6 & 2.8 \\
Greece & 5.0 & 5.1 & 0.9 & 1.3 & -0.6 \\
Spain & 5.2 & 2.1 & 1.4 & 3.5 & 5.5 \\
Portugal & 4.1 & 4.1 & 1.1 & 4.3 & 4.7 \\
Turkey $^{a}$ & 8.0 & 3.3 & 4.9 & 8.0 & 7.4 \\
\hline
\end{tabular}

Sources: Eurostat, Eurostatistics - Data for short-term analysis, Series 1B, European Commission, 1987; OECD, Economic Studies, Turkey, 1985, 1986, 1987.

Note:

${ }^{a}$ Gross national product at market prices.

up to 1.5 per cent. Over time, the differences decreased in comparison with the EC countries, but GDP growth fell to 7.4 per cent in 1987 from 8.0 per cent in 1986. Table 3.4 suggests a positive experience for Turkey in terms of GDP that is above the EC average, despite a sharp downturn in the early 1980s. By contrast, Spain (5.5 per cent growth) and Portugal (4.7 per cent growth) remained at the bottom of the EC income ladder in 1987. In the case of Greece, GDP growth (at -0.6 per cent) was far below the EC average in 1987. These GDP figures made it difficult to speculate how Turkish membership might affect the economies in the EC.

A more plausible comparison can be made by looking at the general economic outlook for Turkey and Portugal on a broad scale. The Portuguese government faced the difficult task of liberalizing the economy when accession occurred in 1986. Portugal's immediate success demonstrated its efficiency in making the transition from an economy with a huge public sector. The deep reforms of Portugal's banking and financial system involved a major programme of nationalizing large enterprises in key sectors. The consolidation of nationalizations and privatizations that had taken place within a scenario of democratic politics first began 12 years before the accession to the EC. The Turkish government was faced with similar tasks. Much immediate comment surrounded Turkey's transition from a state-managed economy to a market economy in the mid1980s. During the 1960s and 1970s, state policy was still inward-looking, excessively protective of its own industries and based on state-run companies. This led in the late 1970 s to a halt in economic growth, a contraction of industrial production and an inflation rate of over 100 per cent (Lejour et al. 2004: 17).

Given these shortcomings, it is interesting to note that, in the early 1980s, Turkey paid back a substantial amount of its foreign debt. To a certain extent, easing the balance-of-payments deficit had substantial effects on the macroeconomic disequilibrium, and marked the first serious moves 
towards a market economy. Apart from embarking on stabilization programmes, export volumes rose - Turkish trade was largely liberalized. In particular, the increased production of manufacturing goods was the outcome of sustainable development through the Turkish government's new economic policy. Structural reforms were introduced, including the banking system, fiscal policy and the exchange rate mechanism. In particular, measures to improve the convertibility of the Turkish lira and the introduction of a value-added tax were seen as two more important steps. These very substantial changes differentiated Turkey from the three Southern accession countries in the 1983-1987 period. Given this outlook, overall economic growth in Turkey was not so dire.

One conclusion must, then, be that Turkey had the potential for strong growth, but macroeconomic volatility had made sustainable growth impossible. To this end, low inflation had been one of the major policy targets pursued by all the governments of the EC during the 1980s. The doctrine of "inflation first" placed priority on the control of inflation.

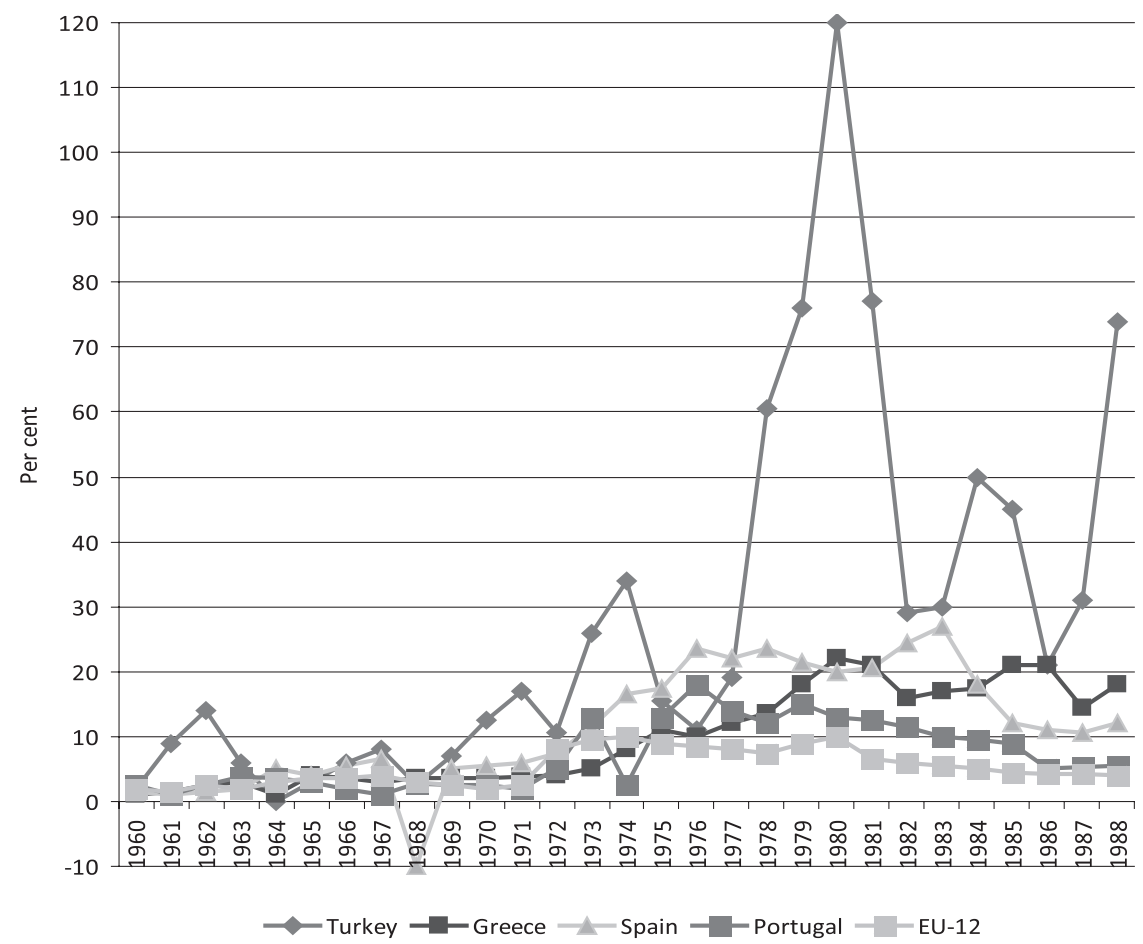

Figure 3.3 Annual inflation rates, 1960-1988 (private consumption deflators). Sources: OECD, National Accounts, 1960-1985, 1987; EEC, Annual Economic Report, 1989-1990; and OECD, Economic Studies, Turkey, 1988. 
Figure 3.3 shows inflation rates several times higher in Turkey than in Greece, Spain and Portugal. During the 1960s, the inflation rate remained below 10 per cent, while in the EC it averaged 4 per cent. Inflation in Turkey peaked at 120 per cent at the end of 1979, fell below 30 per cent in 1982, and rose again to 50 per cent in 1984 and 74 per cent in 1988. In the same period, the EC succeeded in reducing the inflation rate from 10 per cent in 1980 to 4 per cent in 1988. Relatively high inflation caused some difficulties for macroeconomic balance in Turkey, leading to very different outcomes.

In this economic situation, scepticism grew about how far Turkish industry could compete with the dynamism in the EC. Turkey's economic policy depended on external funds to restore equilibrium in the balance of payments. According to OECD statistics, in 1980 exports accounted for only 5 per cent of GDP in Turkey - much less than in Spain (10 per cent). However, after opening up its market to the rest of the world, the first set of reforms resulted in a large increase in the volume of both exports (almost 2.5 times) and imports (a doubling on average). In the EC these figures ranged between 35 and 40 per cent. The rate of export-substituting imports also increased from 44 per cent in 1980 to 80 per cent in 1988. In GDP terms, Turkish exports increased from 5.2 per cent to 16.5 per cent in the period 1980-1988. A similar increasing trend was noticeable for imports, from 11.8 per cent to 20.3 per cent. In the EC, both trends remained around 20 per cent. In 1987, Turkey's trade deficit narrowed compared with the previous year. To some extent, such counterbalancing may be closely related to export subsidies in the form of value-added tax, export loans and devaluation of the Turkish lira by 7 per cent (OECD 1988: 26).

It is also interesting to look at some of the data related to employment by sector in 1985 . Table 3.5 shows that Turkey had higher percentages of employment in agriculture than the EC average (57.4 per cent as against

Table 3.5 Employment by sector, 1985

\begin{tabular}{lcccr}
\hline & $\begin{array}{l}\text { Agriculture, } \\
\text { Forestry, } \\
\text { Fishing } \\
\text { (per cent) }\end{array}$ & $\begin{array}{l}\text { Industry (including } \\
\text { construction sector) } \\
\text { (per cent) }\end{array}$ & $\begin{array}{l}\text { Services } \\
\text { (including } \\
\text { tourism) } \\
\text { (per cent) }\end{array}$ & $\begin{array}{l}\text { Total } \\
\text { (million) }\end{array}$ \\
\hline EC-10 & 8.6 & 23.8 & 57.6 & 121.0 \\
Greece & 28.9 & 27.4 & 43.7 & 3.6 \\
Spain & 16.9 & 32.1 & 50.9 & 10.4 \\
Portugal & 23.9 & 33.9 & 42.2 & 4.1 \\
Turkey & 57.4 & 17.4 & 25.2 & 15.2 \\
\hline
\end{tabular}

Sources: Eurostat, Employment and Unemployment, European Commission, 1987; OECD, Economic Studies, Turkey, 1987. 
8.6 per cent) in 1985. In this period, the Turkish agricultural sector was largely labour intensive and thus generated relatively low productivity. Compared with Greece, Spain and Portugal, Turkey had a low share of service sector employment.

On a more positive note, Table 3.6 illustrates that Turkey specialized in transportation, which made up 10 per cent of GDP in 1985, compared with only 5.1 per cent for the EC-10, 6.7 per cent in Greece, 4.4 per cent in Spain and 7.2 per cent in Portugal. This is a crucial sign of the development of the Turkish economy. However, social services accounted for only a small share of GDP in Turkey (5.5 per cent, compared with 11.8 per cent in the EC), and the figure was 12.7 per cent in Greece and Portugal and 9.6 per cent in Spain. Apart from this, the most salient growth area was water, gas and electricity, which all accounted for over 4 per cent of GDP in Turkey, while they accounted for around 2.5 per cent in both Portugal and Greece and 3.2 per cent in Spain. For other indicators, Table 3.6 also illustrates that there were significant divergences between Turkey and the Southern accession countries.

\section{Human capital accumulation}

Human capital in Turkey was less favoured than that in Greece, Portugal and Spain because of a number of deficiencies. Education is the most

Table 3.6 Composition of GDP by sector (current prices, per cent)

\begin{tabular}{lccccc}
\hline & EC-10 & Greece & Spain & Portugal & Turkey \\
& 1985 & 1985 & 1985 & 1983 & 1985 \\
\hline Agriculture, Forestry, Fishing $^{a}$ & 3.3 & 15.3 & 6.2 & 7.9 & 17.6 \\
Mining & 1.5 & 1.9 & - & 3.4 & 2.3 \\
Manufacturing: & 25.9 & 16.3 & 27.3 & 24.5 & 25.6 \\
$\quad$ Food & 6.0 & - & - & 6.1 & 6.4 \\
$\quad$ Textiles & 2.4 & 3.9 & - & 6.5 & 2.9 \\
$\quad$ Steel & 3.0 & - & - & - & 1.6 \\
Chemicals & 2.3 & 2.1 & - & 1.8 & 1.0 \\
Metal goods & 2.5 & 1.0 & - & 1.9 & 1.0 \\
Electricity, gas \& water & 3.2 & 2.3 & 3.2 & 2.7 & 4.2 \\
Construction & 6.2 & 5.7 & 6.8 & 7.6 & 3.8 \\
Wholesale \& retail trade & 11.4 & 11.7 & 14.3 & 20.6 & 17.3 \\
Transportation \& & 5.1 & 6.7 & 4.4 & 7.2 & 10.0 \\
$\quad$ communications & & & & & \\
Banking and insurance & 8.0 & 6.9 & 13.1 & 6.9 & 7.2 \\
Social services & $11.8^{b}$ & 12.7 & 9.6 & $12.7^{b}$ & 5.5 \\
\hline
\end{tabular}

Sources: OECD, National Accounts, 1973-1985; Eurostat, National Accounts, Series 2C, uropean Commission, 1988.

Notes:

${ }^{a}$ Differing definitions.

${ }^{b}$ Non-market services. 
Table 3.7 Total expenditure on education and the proportion of the adult population with upper secondary education

\begin{tabular}{lcc}
\hline & $\begin{array}{l}\text { Total expenditure on education } \\
\text { (as per cent of GDP) }\end{array}$ & $\begin{array}{c}\text { Adult population with upper } \\
\text { secondary education (per cent) }\end{array}$ \\
\hline Turkey & 3.91 & 24.3 \\
Poland & 5.31 & 45.9 \\
Portugal & 5.69 & 19.8 \\
Greece & 3.86 & 51.4 \\
Hungary & 5.15 & 70.2 \\
\hline
\end{tabular}

Source: OECD, Education at a Glance: OECD Indicators. Education and Skills, Centre for Educational Research and Innovation, Indicators of Education Systems, 1987-1996.

striking example. Table 3.7 confirms that investment in formal schooling was relatively low in Turkey (3.91 per cent of GDP); the highest figure was in Portugal (5.69 per cent) and the lowest in Greece (3.86 per cent). Over the years, the lack of resources in state education has forced people to move into private education. This not only opened up a big gap between the two sectors, but also widened the gap in opportunities for higher education between the rich and poor in the past two decades.

Differences in the illiteracy rate are even more salient. The UNESCO Statistical Yearbook (UNESCO 1987) concluded that Turkey had a much higher illiteracy rate than the Southern accession countries - 34.4 per cent in 1981, compared with 20.6 per cent in Portugal, 9.5 per cent in Greece and 7.0 per cent in Spain. The illiteracy gap implied that Turkey needed to improve its educational standards, which set it apart from the Southern accession countries.

For a further comparison of the level of education, data from Eurostat and the Turkish Statistical Institute for 1985-1986 (CEC 1989) were broken down into rough categories of lower/medium/higher education. There was a considerably higher proportion of people with a lower level of education in Turkey (66 per cent) than in Greece (52 per cent), Spain (40 per cent) or Portugal (64 per cent). Only 5 per cent of Turkish people received higher education, whereas in Spain this figure was 10 per cent. In terms of indicators of formal education, the Southern accession countries were fairly close to the EC average. In terms of output in educational achievements and attendance at both secondary and higher educational institutions, Turkey was placed in the medium rank. In the main, Greece and Spain experienced a massive jump in educational achievements and set off from a much better starting point in the first few years of accession. In addition, compulsory education lasted for only 5 years in Turkey in the 1980s, whereas in the EC countries it varied between 9 and 12 years. 


\section{Social standards}

In the 1980s, the provisions of Turkish social policy were underdeveloped. Generally, this was because Turkey had no obligation to harmonize its social policy. This neglect occurred owing to the dominance of political and cultural issues over social trends. The burden on the EC was therefore expected to be more significant than for Greece, Portugal and Spain. Social protection expenditures both in absolute terms and as a share of GDP were lower in Turkey than in the EC countries. This gap was linked more to a specific lack of social protection than to general differences in wealth.

No formal legislation was launched to introduce changes in the 1980s, since coordination of the social security system had not been fully developed. A particular concern was the difference in employees' income levels and thus their social status. Without a decent income, they were considerably less secure. Only half of the working population made contributions to the national insurance scheme and qualified for sickness and accident insurance. The situation was thus grim for those unable to access social protection schemes (for example, unemployment and child benefits), especially for disadvantaged groups. Apparently, the nature of the social protection system in Turkey created problems for the harmonization process in the EC.

Living standards in Turkey were in fact far behind those of the EC countries. Table 3.8 highlights some social trends in Turkey and the EC. In 1985 , only 19 people in 1,000 possessed a private car, compared with 327 in the EC-10, 127 in Greece, 240 in Spain and 159 in Portugal. Annual electricity consumption was only $605 \mathrm{kWh}$ in Turkey, in contrast to 4,922 $\mathrm{kWh}$ for the EC-10. Another indicator of living standards is the infant mortality rate, which was 8.3 per cent in Turkey and 1.0 per cent in the EC-10. One further indicator of significance is that Turkish medical care standards were considerably lower, despite some changes (for example, additional expenditure on medical equipment and new hospitals) in the 1980s. These discrepancies could cause substantial social problems, eventually leading to labour migration from Turkey to the EC countries.

\section{Demographic trends}

There is clear evidence of differences in the demographic structure of Turkey and the EC. The Turkish population grew at a relatively high rate in the 1970s and 1980s owing to high fertility rates and increasing life expectancy. Table 3.9 compares the total population of Turkey and of the EC between 1970 and 1985. The Turkish population was 60.3 million, up from 35.3 million in 1970. For the EC, these figures were 322.0 and 303.4 respectively. In the period 1980-1985, the population in Turkey increased 
Table 3.8 Indicators of living standards, 1985

\begin{tabular}{|c|c|c|c|c|c|c|c|c|}
\hline & 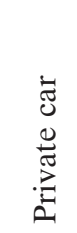 & 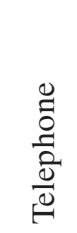 & $\begin{array}{l}\overrightarrow{0} \\
\infty \\
\vec{v}\end{array}$ & 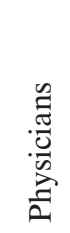 & 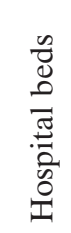 & 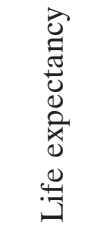 & 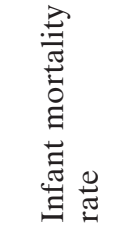 & 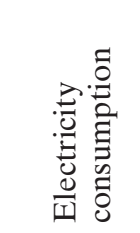 \\
\hline & \multicolumn{5}{|c|}{ Per '000 inhabitants } & Years & Per cent & $\mathrm{kWh} /$ year \\
\hline EC-10 & $327^{a}$ & $466^{b}$ & $333^{b}$ & $2.5^{a}$ & $8.9^{a}$ & $75^{a}$ & $1.0^{b}$ & 4,922 \\
\hline Greece & 127 & 375 & 272 & $2.9^{a}$ & $5.8^{a}$ & $72^{c}$ & 1.4 & 2,859 \\
\hline Spain & 240 & $352^{b}$ & $258^{b}$ & $3.3^{a}$ & $6.2^{a}$ & $73^{c}$ & $0.7^{b}$ & 3,256 \\
\hline Portugal & $159^{a}$ & $169^{b}$ & $151^{a}$ & $2.4^{a}$ & $5.4^{a}$ & $69^{c}$ & 1.8 & 2,107 \\
\hline Turkey & 19 & 45 & 151 & 2.1 & 2.0 & 65 & 8.3 & 605 \\
\hline
\end{tabular}

Sources: Eurostat, Review 1976-1985, Series 1A, European Commission; State Institute of Statistics, Statistical Year Book of Turkey, Ankara: SIS, 1987; and Eurostat, Regions, Statistical Yearbook, Series 1A, European Commission, 1987.

Notes:

${ }^{a} 1984$

${ }^{b} 1983$.

${ }^{c} 1980-85$.

Table 3.9 Population, 1970-1985 (million)

\begin{tabular}{lrrrc}
\hline & & & & $\begin{array}{l}\text { Growth 1980-1985 } \\
\text { (per cent per annum) }\end{array}$ \\
\hline EC & 1970 & 1980 & 1985 & 322.0 \\
Greece & 303.4 & 318.0 & 9.9 & 0.2 \\
Spain & 8.8 & 9.0 & 38.6 & 0.3 \\
Portugal & 33.8 & 35.5 & 10.2 & 0.5 \\
Turkey & 9.0 & 9.0 & 60.3 & 2.5 \\
\hline
\end{tabular}

Sources: Eurostat, Employment and Unemployment, Series 3C, European Commission, 1987; Eurostat, Basic Statistics of the Community, European Commission, 1987; and State Institute of Statistics, Statistical Year Book of Turkey, Ankara: SIS, 1987.

by 2.5 per cent per annum. This figure was only 0.25 per cent in the EC. The population increase in Turkey essentially stemmed from both fertility (3.2 per cent) and mortality rates ( 0.7 per cent); the figures for the EC were 1.25 per cent and 1.0 per cent. A further increase in population growth in both Turkey and the EC was anticipated in 1988, with population projected at over 70 million in Turkey and nearly 330 million in the EC. For this reason, Turkey could be seen as a typical country, implying a rising proportion of people out of work. It was precisely this feature of the Turkish labour supply and the rapid population growth that fuelled 
Table 3.10 Population by age group, 1985 (per cent of total population)

\begin{tabular}{lccc}
\hline & $0-14$ years & 15-64 years & 65 years and over \\
\hline EC-10 & 19.8 & 66.8 & 13.4 \\
Greece & 21.1 & 65.6 & 13.3 \\
Spain & 23.4 & 64.7 & 11.9 \\
Portugal & 23.8 & 64.3 & 11.9 \\
Turkey & 36.6 & 59.3 & 4.1 \\
\hline
\end{tabular}

Sources: Eurostat, Demographic and Labour Force Analysis, Series 3D, European Commission, 1987; State Institute of Statistics, Statistical Year Book of Turkey, Ankara: SIS, 1987, and State Population Organization, Structure of Turkish Populations, SPO, 1987.

considerable mobility, with a predominance of workers from the rural areas.

There were considerable differences between the age patterns in Turkey and in the EC. As Table 3.10 shows, 36.6 per cent of the Turkish population was under 15 years old (compared with 20 per cent in the EC-10) and less than 5 per cent of the population was 65 years old and above (13.4 per cent in the EC-10). Moreover, when the population is considered within the context of the country's size, the number of people per square mile was 62 in Turkey. This figure was 143 in the EC-10, 75 in both Greece and Spain and 110 in Portugal. In the eastern part of Turkey, this figure was much lower (European Commission 1989: 31), and was exceptional by European standards.

Throughout this period, Turkish demographic dynamism was characterized as a major driving force in immigration, while lower rates of population growth in the EC led to a significant shortfall in labour supply. Given the ageing population in the EC, the immigration policy, at least indirectly, supported the assumption that migrants from Turkey were a catalyst for the creation of new jobs, contributed to meeting the key labour shortages, and thus improved productivity. Indeed, the higher unemployment rates in Turkey provided a significant incentive for movement. To many, this put considerable pressure on the economies of the EC countries.

\section{Turkey's identity problem}

As far as political culture is concerned, there is a logic behind the question of whether or not the Southern countries were preferred at the expense of Turkey's accession aspiration. There had been plenty of criticism and complete rejection of the totalitarian attitudes of the Southern countries but little, if any, acknowledgement that the equally monolithic attitudes of Western democracy might have benefited from openness to 
those countries. By the end of the 1970s, the European Community had already defined democracy as a sine qua non for membership. It was the process of the Greek, Spanish and Portuguese accessions that crystallized this change (Tsoukalis 1981: 45). The emergence of a democratic regime in Greece after the demise of the Junta in 1974, the failure of the 1981 coup d'état in Spain and the revolutionary attempt in Portugal in 1974 paved the way for the successful consideration of membership applications. In this light, the magnitude of the Turkish problem should not have made it more difficult to forge a satisfactory relationship with the EC that might even lead to full membership.

That is, similar political systems in the three accession countries and in Turkey reflect the specific problems of democracy as well as its enforcement. Since 1850, Turkey has gone through the same experimentations as the three accession countries. Taking the last 50 years into consideration, Turkey experienced a pluralistic democratic system for nearly 30 years before these countries had it. Similarly, the process of democratization was put into action in each country after 1974, whereas Turkey's experience of the system of pluralistic political parties goes as far back as 1946, albeit with some short interruptions. Although democracy was fragile and in its infancy in Greece, Spain and Portugal, all three countries joined the EC. The aim was to reinforce the argument for guaranteeing democratic traditions in the difficult circumstances of the 1975-1977 period. Since 1983, Turkey has been strongly criticized by the West for the inconsistency of its democracy with European norms. However, Turkey had just emerged from an interruption and began to make some efforts to speed up the democratization process (Journal of the Economic Development Foundation 1992: 30).

Although casual observers may not readily detect the marked political similarities between the Southern accession countries and Turkey, the question of Turkish identity has attracted greater scholarly attention since the mid-1980s. Some argue that Turkey is not part of Europe: it does not share Europe's Judeo-Christian heritage and rationalist tradition, which is seen as at the root of European identity. Well-entrenched, if sometimes irrational, resentments and even fears go back to Muslim invasions of Europe in the eighth century and Ottoman occupations of the Balkans from the fourteenth century. However, others point to the fact that these Byzantine and Ottoman empires have also shaped Europe (Littoz-Monnet and Villanueva Penas 2005: 7). The issue was taken up by Mardin in 1989, arguing that the Turkish identity, that of Islam, created considerable opposition to ideas of Westernization. Radical Islamic discourse articulated the anti-Western feelings and aspirations of a provincial and bizarre population brought up on Islamic perceptions (Mardin 1989: 177). The contemporary manifestation has been a fear of massive migration from Turkey to Europe. 
During the course of the 1980s, Turkey was confronted with a widening of the EC. Although this looked a long way ahead, it seemed there might be value to be gained from the issue of Southern enlargement in terms of the possibility of Turkey's entry. Turkey's entry to the EC might have helped to frame the issue as a basic cultural difference. Therefore, redefining Turkish identity and boundaries was a crucial issue in a situation in which Turkey found itself excluded from Europe. The free movement of Turkish labour in Europe was largely stifled, with the inclusion of the Southern European countries to the EC in the 1980, and since the old pattern of Turkish labour migration (guest workers' programme) ended in 1973. The negative impact of the southern European countries inevitably created incentives for Turkey to export its surplus labour force to other countries (particularly the US). Consequently, an upward trend of Turkish labour migration in the 1989s onwards was recorded.

The same period also saw ambiguities posed by the project of Westernization. There is little doubt that, when Turkey applied to the EEC for full membership, the chances of its immediate inclusion were at their lowest. Greece's opposition to Turkish membership had a detrimental effect on Turkey's aspirations, which was a cause of concern for Turkey's governing elite. Membership and free movement of labour were seen as two advantages of Turkey's integration with the West. As circumstances deteriorated owing to Greek opposition, the chances of obtaining these two benefits diminished.

As Eralp (1992) has argued, after the inclusion of Greece, Spain and Portugal the boundaries of this newly enlarged Europe served to redefine what and who constituted its periphery. Turkey, which since the 1960s had had a special relationship with the Community, seemed to be relegated to the outside, albeit with important functions of regional mediation. This makes Turkey an interesting case to study, especially since, in many other countries outside the West, identity has largely been defined in terms of opposition to the West (Eralp 1992: 201-203).

The elite in the early Turkish Republic sought to modernize the country through an instrumental concept of reason, namely a means-end rationality that was very different from local dynamics. This highly radical undertaking involved the filtering or blocking of demands from the periphery, which was deemed to be pre-modern or backward. According to this early ideology, most of the demands from the periphery stood in the way of adopting and internalizing Western modernity, which was essential for joining the civilized world. The building of a homogeneous nationstate with a common civic culture also required the suppression of what was perceived to be peripheral (Polat 2006: 515). Turkey's attempts at modernization, led by Mustafa Kemal Atatürk, began in 1920 with the national liberation movement in Anatolia. This new era witnessed the Treaty of Lausanne following the expulsion of the Greek army from 
Anatolian soil and the Greek evacuation of Eastern Thrace. Although the outcome of the peace conference did not satisfy Turkey in relation to the conclusion of peace, Turkey adopted the ideas of the West alongside the establishment of basic Western institutions for a new Turkey. This was Mustafa Kemal's formula: it was necessary to embrace Western culture and achieve Western standards of political and economic management, while criticizing the economic backwardness of the country and its Islamic culture.

To elaborate further, Kemalism in its present-day form is the only real alternative to the modernization project. Its substance carries meaning created through the process in which the "ideology of the republic" or republicanism was forged. With its explicit and more fully developed discourse of French republicanism, Kemalism, an elitist and centralizing mind-set impervious to the demands of the periphery, often legitimized its exclusionary posture in politics. With reference to Islamism and Kurdish nationalism, its chief ideology was that the periphery should be disenfranchised for posing a threat to the unity of the nation. Kemalists have, therefore, perceived the EU's aspiration of enhancing democracy in the country as interventionism that aims at empowering the periphery and causing tension and disunity in the nation (İlhan 2002: 23).

The dilemmas in Western policy-making in terms of restrictive or cynical immigration policies were partially the consequence of the intensifying Kemalist ideology against Europe. These restrictive migration policies were largely perceived as denials of the "original" Western modernity. An upswing in sectarian identity politics (Kurdish nationalism), together with Europhobic Islamists, generated more challenging issues for the Turkish government in the 1980s. This led to an abnormal non-engagement in politics and obscured the thrust of the Kemalist argument about the security threats from the periphery - its commitment to resist greater democratization. In such a climate, there seemed to be possibilities for leaving the Kemalist project out in the cold.

Most scholars have defined Europe as "unity in diversity". By multiplying the identities constituting Europeanization, a Muslim/modern Turkey would resemble, on a larger scale, Greece and the Iberian accession countries with their distinctive cultural norms. There might be an "added value" to a European identity that is perceived as a positive effect. In a similar vein, following the landslide victory of the Motherland Party in the general elections of 1987, Prime Minister Turgut Özal repeatedly made statements such as "if Turkey catches up with the modern world, Turkey will look like Europe". This implied that, "when we look ahead, Turks will mix with the glorious European family - modern, dynamic and happy; Turkey will be reinvented" (Tekeli and Illkin 2000: 110). Although Özal did not offer any concrete explanations for how this would be done, there were ample examples of the adaptability problem. Apparently, 
some countries, especially Germany, had allowed a flood of Turkish workers in the past. By doing so, they themselves created huge problems. The various migrant groups shaped the structure of the EC in terms of customs, languages, religions and lifestyles that created many problems (Yalçın 2004a: 43). These cultural issues had been widely recognized across Europe's political spectrum as obstacles to Turkey's integration with the West and were the cause for concerns about Turkey's identity. Drawing on this experience, the most adaptive people were selected for an immigrant country, but the ultimate implications were that an emphasis on the importance of European identity might be an obstacle to Turkey's demands for labour movement. The German authorities concluded that their society was "distorted" by the existence of the Turkish/Muslim population. As a result, the gradual introduction of the free movement of workers was far from being implemented by December 1986, implying an indefinite period.

A continent with a shared history and culture can, in fact, overcome all the practical problems (that is, institutional reforms or social policy) deriving from the different economic and political structures of the Southern accession countries. For more than 500 years, Europe defined itself partially in opposition to the Ottoman Empire. Asserting a historic identity for Europe has profound implications for the question of Turkish accession (Mayer and Palmowski 2004: 575). From this viewpoint, however, it is often claimed that, although Turkey is part of Asia (because of an artificially drawn boundary), it has closer ties with European civilization. In his influential book La Turquie en Europe, Özal (1988) touched upon Turkey's Europeanness. In the context of Turkey's historic identity, Özal advocated the cultural thesis of "the Fisherman of Halicarnassus" (Cevat Şakir Kabaağaçli), an ethnographer who proclaimed Anatolia, not Greece, to be "the cradle of European civilization". Turkey has inherited the cultural legacy of successive civilizations inhabiting this region since prehistory (Tekeli and İlkin 2000: 127). These considerations, coinciding with the looming Southern enlargement, were ignored by the visionaries and ideologies of Europeanization in general.

It may be because of this that the issue of democracy and human rights practices relating to the formation of the Turkish identity often attracted Western criticism. Following a coup in 1980, Turks fled the country and applied for asylum status in some European countries. The presence of such a powerful group of émigrés in Western societies alarmed many members of democratic institutions, the lobby groups and the European Parliament. The military regime and its practices constituted the most prominent identity issues on the European political agenda, which further distanced Turkey from Europe. However, the military officers said that they had no desire to stay in government forever. They would carry on until civilians were sufficiently capable of making democracy work. 
From the European perspective, this was an indication of the incoherent structure of Turkish identity. If anything, it implied a particular challenge to those who consider a minimum level of homogeneity to be a prerequisite for the EC. Although Turkey was caught up in the logic of cultural formation, a radical change in its economic policy was largely dismissed throughout the 1980s. The degree of modernity and sophistication achievable by Özal's strategy could be seen as a positive step towards Europeanization. A shift in emphasis on economic policy or greater integration with world markets acted as a counter-argument to sustain claims about the cultural difference between the EU and Turkey. However, Turkish policy-makers contributed to changing the momentum of relations with Europe in the second half of the 1980s. These relations no longer centred on the economy.

\section{Geographical proximity}

The migration literature argues that the distance of migration makes a difference to policy orientation. Given the costs of migration, it can be assumed that the free movement of Turkish workers in the EC, which was envisaged in the treaties of 1963 and 1973, had not been addressed by 1986. Instead, the integration of Greek, Spanish and Portuguese workers became a policy objective. Consequently, the cross-border workers from those countries seemed to play a different role in their socioeconomic development.

Greece, Spain and Portugal were always regarded as belonging to the "periphery" of the EC. They enjoyed greater geographical proximity in comparison with Turkey, despite the fact that only Spain (of these three cases) shared a border with a highly developed EC member state. They were all supported to meet the challenges of migration costs. Clearly, this account confirms the significance of the distance between Turkey and the EC, which had negative implications for labour flows. Because of the transaction costs involved, restrictions on labour movement were put in place.

There is at least some evidence that the annual inflow of Turkish citizens to Germany fell continuously from 1,333 in 1978 to 17 in 1984, as reported by the Turkish Employment Institution. This can be read as a function of Germany's geographical distance from Turkey. A clue to this is that the costs of Turkish migration, including travel, information and non-financial costs, often exceeded even the substantial gains stemming from higher potential income levels.

In light of this, it was expected that large-scale migration from the Greek and Iberian enlargement would occur because of their closeness in terms of the costs involved. However, when one looks at the size of their 
populations, the share of migration from Greece, Spain and Portugal appeared to be fairly low, and it was only about 30 per cent of the total migration flows from Turkey to the EC in 1987. This implies that geographical proximity did not play a significant role in increasing migration in the 1980s, making the idea of the costs of migration irrelevant. Thus, distance appeared to be a less decisive factor in traditional migration.

As the previous section on migration flows demonstrated, the willingness of Southern Europeans to move geographically was not significantly higher on average than had been projected. Following the initial upsurge in movement, the net migration flows from these countries remained remarkably constant throughout the 1990s. After the opening of borders during the early stages of transition, considerable reductions in the rates of net in-migration were experienced in Spain, despite the low costs of movement. Although demand for migrants in some countries was complemented by the desire of workers in other countries to migrate, the main change was the transformation of the Southern accession countries, especially Portugal, from net emigration to net immigration countries. The migrants returned home and these countries became immigrant countries.

\section{The implications of the Southern enlargement for the movement of Turkish labour}

Workers from the Southern member states and Turkey (like workers from third countries) embarked on a new beginning when the European single market was put into effect in 1968. Access to the Community was already regulated by bilateral agreements under Article 238 of the EEC Treaty. Both the Athens Association Agreement of 1961 and the Ankara Association Agreement of 1963 made provisions for the gradual introduction of the free movement of labour. It soon became evident that the process concluded with the Southern enlargement of the EC without including Turkey. A particular concern in this respect was that all three countries were already integrated into the West European mainstream when Turkey applied for membership to the EC in April 1987. Thus, the virtue of the enlargement called into question the "Community approach", putting aside the previous agreements with Turkey in that the preferences granted by the EC until now to any non-candidate country would be progressively reduced.

Looking at the preliminary experiences of the Southern enlargement, it is possible to ask whether it made sense for the EC-9 countries to impose transitional measures. With regard to the strategies for the labour markets of the EC-9, the supply of workers from Greece, Spain and Por- 
tugal was cut off, which might be looked upon as a lost opportunity. However, the EC could not take any risks. Consequently, the conditions that attached to the membership of the Southern accession countries regarding free movement of their nationals included fairly long transitional periods. When the EC delayed access to its labour markets for workers from the Southern members it appeared to make sense to ignore the issue of Turkish labour movement in the 1980s.

When the Southern enlargement took place, some commentators asserted that it would have been in the EC's best interests to adopt policies that would prevent the perpetuation of unequal relations with Turkey. No matter how "hard" the measures that the Community took were, the whole process upset the very delicate balance of profits and losses for Turkey. The failure from the early days of the enlargement process to grant Turkish workers freedom to move is self-explanatory. It is precisely the fear of lower wages and higher unemployment as a result of the Southern enlargement that might be considered to be detrimental to the Community's policy towards the flows of migrants from Turkey.

Yet clearly there was some scope for justifying the EC's policy, since quite a large part of the membership negotiations with Greece and the Iberian countries related to matters that would also involve Turkey. The Southern enlargement process was the subject of political controversy across the EC. Combined with this, slow progress in the membership negotiations for Portugal and Spain was attributed to contentious bargaining over the free movement of workers. The obstacles to Iberian accession also included fisheries, the budget question and the Integrated Mediterranean Programmes. All of these issues were closely related to Turkey's aspirations, but they were all eventually removed by 1985 .

More strikingly, both the inclusion of the Southern European countries in the EC and the anticipated eventual free access of Turkish workers to European labour markets were intended to take place in 1986. Inevitably, they reinforced one another and were by no means unrelated. One may conclude that the EC authorities were reluctant to face the social and political effects of the mass recruitment of migrant workers. After 1980, Greece refused to enter into a standardization agreement with Turkey. However, its failure to comply with the provisions of the Treaty of Rome was largely ignored by the EC owing to its frozen relationship with Turkey. After intensive negotiations, an agreement was eventually signed on 1 January 1988. Although Greece's delay was based purely on political aspects, Portugal and Spain, being full members of the EC in 1986, were deeply concerned about the terms and conditions of trade with Turkey. Nevertheless, the outcome further reinforced the deepening of the Association Agreements for all three accession countries and Turkey, and provided a mechanism for adopting the EC rules and regulations. 
This development was merely a shift in Turkey's satisfaction that European officials welcomed not only the participation of Turkish workers in the European labour markets but also the strengthening of Turkey's Western orientation. From this viewpoint, it was expected that the Southern European countries would provide a powerful incentive for Turkey to consolidate its democratic process and avoid authoritarian impulses. Indeed, the inclusion of the Southern European countries within the boundaries of the EC brought in its wake a reformulation of the EC's nature.

In a broader context, the EC defined "Europeanness" as reflecting the promotion of democratic values and human rights rather than economic development. Ironically, without being a member of the industrialized Northern countries' club, Turkish policy-makers continued to rely on economic parameters, pressing their bid for membership even after the military coup in 1980, which further distanced Turkey from Europe (Birand 1985: 5). With deficiencies of the political system that were inherently similar to those of the Iberian countries, the Turks were beginning to demonstrate allegiance to European standards by adopting the acquis communautaire. From the Community perspective, these were steps towards the realization of the principle of free movement. Yet the ultimate goal continued to be to modernize society and its institutions and eventually to become a model for aspiring new entrants.

During the 1980s, the idea of the marginal effect of the accession of small countries to the EC on the political and economic balance became a real issue. In particular, there were formidable economic issues surrounding the entry of what would be the poorest members. The Southern enlargement was accompanied by prolonged problems of absorption as the original 6 EEC members became 12 and increased the Community's disparity. The enlargement led to rather acrimonious squabbling among the existing member states, which were fearful that enlargement to the South might damage their economic interests. Because the Southern European applicants were significantly poorer than the existing members of the Community, the member governments also questioned the applicants' ability to assume the obligations of membership (Cini 2004: 212). In particular, the necessary structural modifications did not happen at the time of their accession, implying that the essential conditions for their smooth integration were not met before the three countries joined the EC. They could not be met because the different structures of their economies did not support this.

In 1983, the case of Greece illustrates the scale of the problem that the EC had to face. Structural imbalances gave the Greek economy bleak prospects. Greece had a large number of small enterprises, 80 per cent of which depended on imported capital equipment. This highlighted the 
problem of a low level of investment in processing plants. A similar problem was related to agriculture. The farm population of Greece was large, accounting for around 30 per cent of the workforce, combined with an inadequate infrastructure for the marketing and processing of agricultural products. Agricultural holdings were small and greatly fragmented.

The situation in the Iberian countries was even less promising than in Greece. In Portugal, during the first six months of 1982 the balance-ofpayments deficit totalled nearly US\$2.7 billion. Although the government maintained a relatively good credit rating in gold reserves, its foreign debt was approaching US\$12 billion. Inflation was close to 24 per cent and the Portuguese had the lowest per capita incomes in Western Europe, at about US\$2,000 a year (DeYoung 1983: 4). In Spain, the public sector deficit was already over 4 per cent of GDP and this risked worsening inflation. Spain's inflation was fuelled by high wage settlements, which averaged 15 per cent in 1979-1982 and were well out of step with its international competitors. In turn, exports were losing their competitive edge and the reserves dropped as a result of support operations for the peseta (Graham 1983: 15).

As for the economic outlook in Turkey, it was highly unlikely that Turkey would be able to catch up with the EC members in economic terms. If the EC could not respond positively to the Mediterranean membership, it seemed unlikely to class itself as politically and economically competent to deal with another application, such as Turkey's. This suggests that labour movement could not take place because the EC had enough problems relating to the economic situation in these new accession countries.

Gümrükçü (1988) argued that Greece, Spain and Portugal had all been following similar economic policies since the 1970s. Moreover, the national economies of the Southern EC countries and Turkey had been closely interlinked with the EC for more than a decade. Not only did they have preferential trading relationships with the highly industrialized EC countries, but the "migratory flows" of their labour power also reflected their economic interrelationships (Gümrükçü 1988: 25). The argument was that this helped to reduce the complexity of the process of adjustment. Surely such a close relationship would have encouraged more labour flows into the European labour markets, given the socioeconomic situation in Turkey. However, no massive migration occurred in the 1980s, for the reasons outlined in Chapter 2.

Some studies have concluded that the resources that were poured into recruitment and training for workers originating from the South had an adverse effect on Turkey as a non-member state. In the context of postwar labour migration, the EC sought to maintain its export-led economic growth by drawing on unemployed workers from Southern Europe. These 
studies also indicated that South European countries benefited from the recruitment, remittances and return of migrants with precious acquired skills.

While short-lived development began to take hold in the early 1970s, at a time when the EC nations had halted recruitment in Turkey, Greek and Iberian nationals demonstrated a great capacity for commuting in border regions. Cross-border movement was more likely to occur and workers from Portugal and Spain were particularly fast to react to changes in the neighbouring countries. Moreover, proximity gave rise to specific modes of movement for countries that fell outside the strict concept of migration. In spite of low levels of movement, geographical distance usually played a positive role in migration from these countries because of the proximity of the border, but it played an opposite role for Turkey. For instance, Spanish and Portuguese children mostly stayed in the national school system, the spouse kept his/her employment and language problems were relatively minor. This explains the main incentive for movement - accession outcomes in the South European integration process certainly benefited these countries. As regards the exodus of the 1970s and 1980s in response to both the political and the economic situation, these countries contributed to the preservation of power relationships in their societies and the reduction of internal social tensions, within the bounds of the possible advantages of emigration.

Following the signing of the Additional Protocol between the EC and Turkey in 1973, the main emphasis was on preferential treatment for the Mediterranean countries. Turkey was disadvantaged politically and financially. The increase from nine member states to 12 had a dual effect on vulnerable sectors in Turkey, such as agricultural products and semiindustrial products. First, there was a reduction in trade in certain Mediterranean products, and second, there was renewed pressure to protect. The new accession countries had similar production patterns to Turkey in some sectors. This led to a worsening of Turkey's trade deficit with the EC, which amounted to 1.7 billion ECU (European currency units) in 1987. This, in turn, had serious drawbacks for the Turkish labour market. The economic consequence of adopting protectionist measures in vulnerable sectors, mainly against exports from Turkey, was higher unemployment in Turkey. This provided the incentives for additional migration. Immigrants' remittances constituted one of the main sources of income to cover Turkey's trade deficit. Put simply, there were strong economic pressures to go abroad when the population of Turkey became unemployed in large numbers at the end of the 1980s. It should also be noted that Turkey looked to other markets for its products by opening up the region to outside powers. Thus, the 1990s witnessed some attempts by Turkish political leaders to strengthen ties with their powerful northern neighbour - the Soviet Union. 
The available academic literature is critical of the way in which Community funds were largely allocated to the new accession countries at the expense of Turkey. The Southern accession countries benefited from the new opportunities and additional economically-motivated migration occurred. A comparative analysis by Büthe (2009) showed that membership brought sociopolitical and economic benefits to the new accession countries. For instance, the allocation of development funds and loans from the European Investment Bank made it difficult to envisage a satisfactory relationship between Turkey and the EC. The three accession countries increasingly relied on EU assistance. Their relative economic backwardness meant that membership in the EC signified the opening of a window of opportunity, and thus the Southern accession countries became net recipients of Community funds. For Greece alone, net profits from the Community were estimated at more than US\$800 million in 1983, which made a significant contribution to covering the balance-ofpayments deficit.

Turkey fell back on its membership application, with even larger requests for development funds. The response was negative whereas the Southern accession countries had been blessed with acceptance. Turkey needed to expand investments in education, health and nutrition (the basic elements of human development) as part of the EC membership criteria. On the whole, no progress was made in these areas. Such investments were financed by public funds, which were cut at the onset of the economic crisis. Turkey was in need of EC funds in this period given the existing state-financed labour market policy. As in the three accession countries, these funds would play a vital role in helping Turkey to catch up with the Community average for economic growth. They would also assist Turkey to modernize its labour market policies in areas such as vocational training and wage or employment subsidies.

The "Greek factor" comes into play here. Greek membership in the EC automatically raised the question of whether the Athens government might seek to employ that added clout as leverage in the controversy over Turkish immigration. This factor owes much to the historical legacy. Greece was heir to the Byzantine Empire, which had been besieged, gradually conquered and finally destroyed by the Turks from the eleventh century. This culminated initially in the conquest of Constantinople in 1453 , but was then followed by further expansion into the Balkans with the two sieges of Vienna in 1529 and 1683. Europeans supported the Greeks in their fight for independence from the Ottoman Empire from 1821 on. Apart from the old animosities, resentment against the Turks grew, most recently because of Turkish aggression, for example in Cyprus in the 1970s. Understandably, Turkey felt sidelined by the EC, partly because Greece, as a member of the Community, would stand in the way of Turkish membership. 
In fact, since 1981, Greece had used the EC institutions to harm Turkish interests. Attempts at reconciliation in early 1988 appeared to have made little progress and Greece lost no opportunity to obstruct Turkey's relations with the EC. Even at the Lisbon Summit in June 1992, although Greece lifted its previous veto on Turkey's participation in the Integrated Mediterranean Programmes, it showed no signs of dropping its opposition to the implementation of the Fourth Financial Protocol for the period 1982-1986. There had been a widespread positive response in the EC countries following the democratic elections of 1983 in Turkey, and the establishment of civilian rule with adherence to the principles of the market economy. That is why the EC as a whole and Germany in particular committed themselves to substantial aid programmes to assist the ailing Turkish economy. At this point, Greek membership might have proved to be just the spur needed to push the Turks towards the step required to make Turkey itself eligible for full membership. Nor should it be forgotten that Turkey began its Associate status with the Community about the same time as Greece did in the early 1960s.

It may seem impossible for Greece and Turkey to reach a compromise in their relationship within the EC, but it is possible to conceive of a more positive attitude on the part of Turkey in terms of cooperation with Greece. The two countries in fact have much in common despite the traditional hostility that divided them. Both Greece and Turkey took advantage of the opportunities rather than pursuing an attitude of "all or nothing". Indeed both countries sent hundreds of thousands of men and women to work in Northern Europe. By 1981, 700,000 Turks were estimated to be working in the EC countries (the bulk in Germany), or about one-twentieth of the Turkish labour force. Greek workers in the EC countries, which numbered about 175,000 , also represented close to one-twentieth of the Greek workforce (Binder 1981: 4). This apparent similarity was further reinforced by both countries' workers not only contributing the equivalent of billions of dollars in remittances to their homeland but also enriching their country by returning with newly acquired skills, albeit to a lesser extent in the case of Turkey. Remittances represented a valuable case for movement or an attempt to aid the modernization of Turkey and Greece.

\section{Conclusion}

In this chapter, the effect of the Southern enlargement on the movement of Turkish labour has been considered. What is clear from this analysis is that the hopes of increased freedom for Turkish workers who sought employment in the EC had not been realized, largely because of the chal- 
lenge to the EC of including Greece as well as the Iberian countries. Not surprisingly, EC countries that wanted to import workers found it easiest to encourage migration from the South European countries, which had a similar socioeconomic outlook and were nearby. The level of economic development of Greece, Spain and Portugal, which were integrated into the Community by 1986, diverged considerably from the average of the old EC member states, and this led to great uncertainty regarding the future shape of Turkish labour movement. As a consequence of the Southern enlargement, Turkish labour mobility became one of the unfulfilled promises of the EC.

The chapter was confined to the integration process for EC membership. In the political context, a review of the experiences of Greece, Spain and Portugal suggests that they had characteristics similar to those of Turkey in the 1980s. These countries were all under authoritarian regimes before they joined the EC. All three countries soon became liberal democracies, with widespread respect for the rule of law. As the analysis has indicated, both Spain and Portugal had had far less experience with democracy than Turkey when they became members of the EC. Therefore, it would appear that any discussion on this point should assume that the EC's response to Turkey's attempts to become a full member (and to free its labour force) would be different from its approach to the treatment of these three accession countries.

In the context of migration in Southern Europe, the chapter then presented an overall picture of flows for the period 1986-1997. The main finding from the figures is that emigration from the South European countries was negligible. The statistical portrait of Greek, Spanish and Portuguese workers in Europe shows that geographical labour mobility following the enlargement was limited. The stock of Spanish labour moving to Germany, for instance, dropped after the principle of free movement was finally granted in the early 1990s. The integration process led to limited labour flows regardless of distance; in none of the three countries did the population change their behaviour. This result is important in its implications for Turkey. It provides the best guide to what might happen with the incorporation of the Central and East European countries, especially whether the free movement principle will bring an upsurge in labour migration.

From the account of the reasons for low Turkish migration flows at those times, it is easy to see that political and socioeconomic factors distinguished the Southern accession countries from Turkey. There were significant divergences in terms of Turkey's adaptability to the EC's social model. Almost all of Turkey's socioeconomic indicators performed less well. With regard to economic efficiency, the Turkish labour market situation had long attached more weight to lower growth than the Southern 
accession countries. In many ways, Turkey resembled the least advanced of these countries, although these similarities had not always been sufficiently clear-cut. Despite labour movement being low, Greece, Spain and Portugal had the advantage of geographical proximity to and, in particular, cultural affinity with the EC-9. Perhaps the root of the problem in this particular period was not so much socioeconomic conditions or geographical distance but the question of Turkish identity, together with Turkey's political instability, which prevented the EC from pursuing a favourable policy. This is particularly relevant when a fall in labour flows was recorded in all West European countries.

The discussion of the migration implications of the Southern enlargement demonstrated considerable restrictions on Turkish labour migration. The implications were both damaging and serious. The EC did not fully appreciate the issue of Turkish labour migration following the Southern enlargement. The EC had devoted more resources to the Southern accession countries in response to its pursuit of greater European political and economic integration when it was deeply involved in establishing a single market. After all, the opening up of the market to the three countries would test the entire machinery of the EC in crucial areas. Without substantial reforms, integrating workers from Greece and the Iberian countries into EC markets might have destabilized the entire European project. While the EC was preoccupied with the flows from these countries, the issue of Turkish labour movement was treated with caution. 
4

\section{The European Union's overall strategy for the movement of labour}

\section{Introduction}

Since the inception of European integration in the 1950s, the principle of labour movement has been a cornerstone of the policies of the European Community (EC) and the European Union (EU). From these early initiatives, the opening of labour markets was a comparatively radical change. Over time, the Treaty of Rome's delimitation of the free movement of labour has been deepened, expanded and transformed by subsequent treaties. There have been problems within the EU's migration strategy so far. The main objective of this chapter is to present the problem of European labour migration and analyse the implications of policy outcomes for Turkish labour flows. I first provide the necessary background information at the European level to frame the national immigration policies. This lays the foundation for a discussion that examines the development of EU policies. I then elaborate the obstacles to EU policies by pointing out the challenges to and pressures on Turkish labour flows.

The evolution of the EU policy

Free movement for Europeans

When the Treaty of Rome established the European Economic Community (EEC) in 1957, the six signatories (Belgium, France, Germany, Italy,

EU enlargement and Turkish labour migration, $O \breve{g} u z$,

United Nations University Press, 2012, ISBN 978-92-808-1206-0 
Luxembourg and the Netherlands) were not concerned with the migration of third-country nationals. Rather the Treaty provided some competences that had as much to do with economic integration as with the migration of Community citizens for the purpose of employment. Preferences for foreign workers were ignored in the interests of national sovereignty. Article 3 touched on the abolition "of obstacles to the free movement of goods, persons, services and capital" between the member states. This Article was the blueprint for a common market, which was mostly associated with stimulating further integration.

This was a uniquely complex and challenging situation requiring the supranational principle that eventually created the freedom of establishment (Article 52) in a common market. In this regard, the most important Treaty provisions concerned the treatment of Community workers. Article 48 stipulated "freedom of movement of workers", which entailed the "abolition of any discrimination based on nationality between workers of the member states as regards employment, remuneration and other conditions of work and employment". Apart from this, Article 48 laid down the following principles:

- free access to employment;

- the right to travel for the purpose of seeking employment within the Community;

- the right to reside in the member state where the employment takes place.

It was decided that workers with an EEC passport could be allowed to move without any substantial legal restrictions from one member country to another in a manner similar to movement within their home country. Any move towards a uniform policy was necessarily associated with the realization of one of the major aims of the Community establishing the common market. At the very least, the principles had to take into account how efficiently the European labour markets could operate.

The EEC was assigned a range of objectives, based on a set of important principles. When the Council of Ministers of the EEC passed Regulation No. 38/64/EEC on 25 March 1964, they completed the most comprehensive international agreement dealing with the free movement of labour (apart from the Scandinavian and Benelux agreements) yet to be established by an EU organization. This was the second of three projected regulations designed to achieve the free movement of labour within the EEC by the established target date of 1 July 1968 (Dahlberg 1967: 311). It is worth noting that these rights originated from an economic standpoint and were aimed at enabling the flow of workers necessary for building the common market. However, significantly, the right to free movement for the families of the workers was not secured. The Treaty instituted the dualism in the regulation of migration in the EEC 
countries. Whereas the migration of EEC nationals within the EEC was regulated by Community law, the migration of third-country nationals remained within states' exclusive competence (Kicinger and Saczuk 2004: 10).

From 1958 onwards, the six original member states gradually introduced a policy of labour movement covering their joint population of 158 million people. The essential structure for ensuring the free movement of wage-earners within the six members of the EEC was in place by 1968 or settled not long afterwards. The rules that protected the right to move for work and to remain in a country subsequently gave entry rights to families and elaborated a complex system for the maintenance of social security rights. They also conformed to the right to join a trade union and to stand for office, the right of access to vocational training and the right to use the employment services. In this way, the principles of equal treatment and of ensuring non-discrimination were accepted. Broadly speaking, these rules were applied without undue difficulty. Individual cases of discrimination continue to find their way to the European Court of Justice (ECJ) - eligibility for social security benefits being a particularly complex area - but, gradually, the rules have become better understood and observed (El-Agraa 2001: 422).

\section{The guest worker programme}

The initiatives for the creation of a common market, primarily concerned with internal mobility, were important to raise the efficiency of European labour markets so that they could respond effectively to changes in demand through wage flexibility, occupational flexibility or mobility. In this economic environment, the internal free market implied formal cooperation among the member states in the sense that they would ensure a high level of economic activity. Consideration was given not only to labour movement but also to employment, which was equally regarded as one of the contentious issues.

Yet, even after the institutional implementation of the free movement and settlement of persons in 1968, intra-Community employment-related migration remained relatively small compared with the larger migration waves originating mostly from third countries (Garson and Loizillon 2003: 3). In this context, the recruitment of hundreds of thousands of Italians was not sufficient to provide the labour supply for the economies of the Northern member states, so it was natural for industrial north-west Europe to look elsewhere for labour supplies. Here, it is important to have a clear understanding of the nature of the "guest worker" phase. Building on the 1950s, the phase was viewed not only in the context of the internal economic, social and political problems raised by the large 
Table 4.1 Evolution of the EEC labour market in terms of new work permits issued

\begin{tabular}{lcccccr}
\hline & \multicolumn{2}{c}{ Community workers } & & \multicolumn{2}{c}{ Third-country workers } & \\
\cline { 2 - 3 } & No. & Per cent & & No. & Per cent $n$ & Total \\
\hline 1958 & 170,000 & 65 & & 80,000 & 35 & 250,000 \\
1959 & 150,000 & 63 & 80,000 & 37 & 230,000 \\
1960 & 260,000 & 56 & & 190,000 & 44 & 450,000 \\
1961 & 300,000 & 51 & & 290,000 & 49 & 590,000 \\
1962 & 280,000 & 42 & & 380,000 & 58 & 660,000 \\
1963 & 250,000 & 34 & & 430,000 & 66 & 680,000 \\
1964 & 250,000 & 29 & & 580,000 & 71 & 830,000 \\
1965 & 320,000 & 36 & 630,000 & 64 & 950,000 \\
\hline
\end{tabular}

Source: European Commission, Free Movement and the Labour Market in the EEC, Annex Statistics, 8162/1/II/1966/5, February 1966.

numbers of immigrants, but also in terms of its implications for, and compatibility with, the member states. Most provisions mentioned in the Treaty underlined the basic rules. For instance, it was the responsibility of any member that was committed to the creation of an internal market to implement the free movement of third-country nationals. The most important economic trend was the ever-growing number of foreign workers employed within the EEC (with the exception of Italy). This trend can be seen in Table 4.1.

The figures in Table 4.1 suggest that recruitment of foreign workers had become important for the continued growth and prosperity in much of north-west Europe. By 1973, it was estimated that the number of workers in the EEC, plus Austria, Norway, Sweden and Switzerland, was $7,500,000$. However, the Commission's statistical systems were in their infancy and there were some problems with data collection, compounded by the administrative procedures. Thus, in the "high guest worker" phase, the numbers of foreign workers were almost certainly underestimated. Nevertheless, in many cases, these systems encouraged entry, irregular recruitment and employment. Overall, the gross annual migrations in the early 1970s to and from Europe were estimated to be 2-3 million. It is important to note that the impact of the guest workers employed in West Germany cannot be underestimated, since the German economic miracle proved to have a remarkable appetite for Turkish workers in particular. In this way, Germany was able to boost its rate of economic growth. Above all, German employers were able to obtain cheap labour when they were facing problems with the country's post-war reconstruction. In subsequent years, Germany saw a steep rise in the number of Turkish workers. 


\section{Tighter rules to restrict migration}

Although the net effect of foreign labour on the Western economies was considered to be positive for the initial restructuring process, improvement in the economic situation in Northern Europe was less likely. Much changed after 1973. Starting with the 1973 recession, the relative share of the member states, in particular of Italy, in migration flows was reduced. The adverse shocks (oil shocks) led to a strong rise in unemployment. There was significant pressure on the flow of labour among countries when the EC economies moved into recession. Other reasons for this drop were the growth in the Italian economy and the reduction in intraEC wage differences. The actual path of labour migration was heavily affected by the overall situation. In 1973 the German government suddenly halted migrant entry and most European governments followed suit by 1974. It is important to note that the United Kingdom had curtailed immigration as early as 1962 .

For these reasons, policy-makers now had the encouragement to reverse the flow and started to stimulate return migration. The first important step in the development of common positions on migration in the $\mathrm{EC}$ was the adoption of the action programme in favour of migrant workers and their families in 1974. The increased interest in the question of migration in the EC was connected to the enlargement to the United Kingdom, Ireland and Denmark (Huymans 2000: 755). This made it possible to refer to the detrimental effects for the Community as a whole if a restrictive policy was not followed nationally (Brochmann 1993: 110).

To overcome these problems, some incentives were introduced in a number of West European countries in order to encourage foreign workers to return home. For instance, Germany introduced a scheme in January 1974 that entitled returning Turkish workers to receive a lump sum of subsidies. To be more specific, a number of measures were introduced:

- a return premium to the person involved;

- aid to the person involved for setting up in business;

- subsidies to the home country for professional training;

- development aid to the home country for projects.

As a result of this scheme, the migration of foreign workers dwindled, although this varied for different groups from different countries of origin, depending on the degree of integration. The theory of the guest worker system was that most migrants would leave fairly soon once recruitment stopped. In fact, many did, but others stayed on. Later, followup migration was, and still is, seen among their adult children, who might bring their marriage partner over to the country of destination (family formation) (Muus 2001: 34). "Family reunion speeded up, and settlement and ethnic minority formation became obvious to everyone (except some 
political leaders: it was not until 1998 that mainstream German political parties were willing to admit that "Germany was a country of immigration" (Castles 2006b: 743, emphasis in original). The process was described as one of the "unforced policies" adopted by the host countries. Given the existing regulations on family reunification, a substantial net flow of migrants has, since then, been taking place under this pretence.

In parallel to this development, political migration dominated the period of restrained migration. The number of illegal immigrants rose significantly (Zimmermann 1995: 47). In almost all member states, there was a widely held belief that the "stop policy" had not been a success in any of the countries in question. After the door was closed to labour migrants in the early 1970s, the only legal entry was through the asylum route. Likewise, having very little chance of succeeding through legal recruitment channels, foreign job-seekers from "peaceful" countries in the South entered through unofficial channels. Control of one gateway may consequently direct the flow on to a new track (Brochmann 1993: 108). According to the Turkish Ministry of Foreign Affairs, asylum applications by Turkish nationals arose to around 108,000 in West Germany in 1980 and 167,000 in Western Europe in 1985.

\section{Towards a comprehensive approach}

After years of retrenchment, in the early 1980s discussions and negotiations between the member states of the EC concentrated on a better and more coordinated policy. The EC redoubled its efforts to press ahead with its ambitious programme, focusing on a collectivist and Communitywide approach to social issues. Attention turned to European labour markets, which needed to be more efficient, modern and accessible to Community citizens. The adoption of the new measures (CEC 1985) improved the situation in social policy context, guaranteeing the movement of workers. Obviously, migration was mostly considered in the context of socioeconomic rights and the construction of integrated labour markets in which workers could move freely.

At the same time, it was stressed that governments should reinforce existing efforts to control their external borders. In the intergovernmental framework, the Schengen Treaty of 1985 tried to accelerate the process of extending freedom of movement from workers to all persons and removing controls at internal borders. According to Article 8, the new member states must accept the Schengen acquis in full. In this regard, the working of the Schengen system requires very strict controls at external borders as a counterbalance to free movement within and between the new member states, which is granted to both the citizens of the EU and third-country nationals (Adinolfi 2005: 470). The Treaty introduced 
measures to tighten security at the common external border, while it opened all internal borders of participating countries.

The real impulse for cooperation in labour movement issues was provided by the Single European Act (SEA) in 1986. The SEA provided a major boost to the internal market, which would embrace "an area without internal borders in which free movement of goods, persons, services and capital is ensured". The full benefits of the SEA would be realized only if checks at internal borders were to be abolished for such movements.

The Treaty on European Union (the Maastricht Treaty) of 1992 marked a new stage in the process of creating ever closer cooperation among the EC countries. The member states agreed to cooperate on asylum, refugees, immigration policy and judicial cooperation, which were covered by the third pillar of the Treaty. They now regarded immigration and asylum policy and the residence rights of third-country nationals as matters of common interest. The Treaty formalized intergovernmental cooperation by establishing an "area of freedom, security and justice" in the field of Justice and Home Affairs (JHA) policy. The Treaty also introduced the concept of European citizenship and formally recognized the need for a modest acquis in migration-related issues.

In a similar vein, an action programme to modernize the free movement arrangements began in 1997, not only with the aim of rationalizing the rules but also because the EU could now start from the principle of the right of free movement for the EU citizens, developing the minimum number of rules for special groups as required (El-Agraa 2001: 422). It was only in 1997, under the Amsterdam Treaty, that the arrangements were formally incorporated into the EU's legal framework. The Treaty increased competence in JHA policy, within which the sections of the third pillar relating to immigration, asylum and refugees were communitarized (Brinkmann 2004: 183). The aim was to maintain and develop the EU "as an area of freedom, security and justice". In this way, freedom of persons was assured in conjunction with appropriate measures with respect to external border controls, asylum, immigration and the prevention and combating of crime.

An example of another important step with regard to similar immigration policy developments can be observed in the Tampere European Council meeting in 1999. The Tampere Council urged the member states to cooperate more closely on immigration issues, including common entry, post-entry standards for asylum-seekers, the management of immigration policy and the integration of third-country nationals who had been granted access to member states. Subsequent Council meetings at Laeken (2001) and Seville (2002) reaffirmed the Tampere Council. However, the intergovernmental approach of the third pillar concerning migration- 
related issues was not contested in these Council meetings, which gained a reputation for a comprehensive role, as had been the case with the Edinburgh European Council in 1992 (where the formal phase of EU cooperation started). It should also be noted that, beyond the formal institutions built up around the national interests of each member state, there was now qualified majority voting within the policy-making process.

\section{The Eastern enlargement and transitional freedom types}

One significant difference between the 1980s and the present is the advent of EU citizenship and the concomitant rights to move freely to reside and work in all the other member states, as set out in the 1992 Maastricht Treaty (Van Selm and Tsolakis 2004: 1). The important question is, will these rights be sufficient to prompt a much larger proportion of nationals from the Central and East European countries (CEECs) to migrate, following the enlargements in 2004 and 2007, than was the case in earlier enlargements?

International migration behind the iron curtain was previously insignificant or very small between adjacent states. The advent of democracy in the former Communist states inevitably created substantial increases in flows to Western Europe. According to the official statistics of the CEECs, the flow of migrants in the early 1990s was around 850,000, compared with less than half this number in the three preceding decades. Once the Central and East Europeans started to move abroad freely, predictions were made that revolution in these countries would activate a huge migration potential in that region, with the main direction of flow being from the East to the West. Some sources foresaw that millions of people would be involved in these movements, mainly from the former USSR (Okólski 2000: 330).

To reiterate, the question of geographical labour mobility in Europe, as it was envisaged in the founding Treaty, was one of the issues at stake right from the early days of the Community. At that time, the problem was how to absorb the migrants who had been encouraged by the governments of Northern Europe to come from Southern Europe, and how to ease their access to the labour market (Vandamme 2000: 440). Nowadays, this thorny issue has fuelled the resistance of the existing member states to enlargement. Germany and Austria, in particular, have voiced fears that workers' unfettered access to the free movement provisions would cause a "flood of cheap labour" from Eastern Europe and put social cohesion at risk. To address this, there have been discussions of some sort of restriction of labour movement, more in reaction to widespread public fears. This was acknowledged by the Commission in a treaty provision that was at the basis of the accession negotiations: free movement 


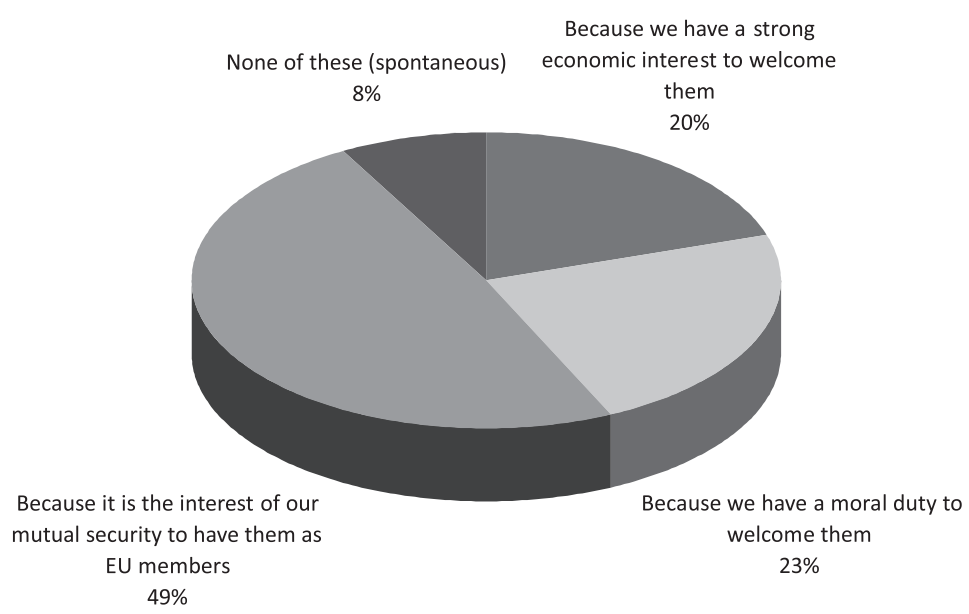

Figure 4.1 Reasons for admitting Central and East European countries.

Source: European Commission, Public Opinion in the European Community, Survey no. 441 - Fieldwork, Standard Eurobarometer 44, November-December, 1995, Fig. 38.

"cannot be achieved without a solid and coherent external border control policy" (Council of the European Union 2001: paras 1 and 7).

It may be concluded that, because of the lifting of internal border controls, any restrictions depend on the capacity of the country concerned to fulfil the necessary requirements. Therefore, full labour market integration between the old and new member states was to be achieved gradually through transitional measures in the interests of the Union, which would still have to be fully justified. Generally, it may, indeed, be beneficial for the EU to "welcome" these countries (see Figure 4.1).

Following the Commission's recommendation, the member states agreed to push for transition periods for the free movement of workers and measures relating to employment in their negotiations with the accession candidates. The accession treaties for each new member state contain provisions that allow the EU-15 to derogate from the principle of movement of workers for a period of up to seven years, during which the member states could choose to exempt themselves from the EU regulations.

Initially controversy arose over how exactly the EU-15 would regulate labour flows from the CEECs and the employment of workers during the transition periods. This reflected the particular criticism of the impact of transitional arrangements on the existing member states. A flexible system of transitional arrangements, such as those applied to Greece, Spain and Portugal, would impose a limit on the number of workers from 
various countries (Financial Times 2001: 3). Although such arrangements are essential in light of the Eastern enlargement, they would differ significantly from those that were previously introduced. This was mainly because of the large amount of discretion left to the older member states. The transitional measures are more diverse than those of the Southern enlargement.

The Treaty of Accession signed on 16 April 2003 (Act of Accession, Part IV: Temporary Provisions) allows the EU-15 member states to introduce transitional arrangements for nationals migrating from the 10 new member states (Czech Republic, Estonia, Cyprus, Latvia, Lithuania, Hungary, Malta, Poland, Slovenia, Slovakia), except for the particular cases of Cyprus and Malta. Since the date of accession, these arrangements have substantially limited the rights of workers and service providers from the CEECs to move and reside in the EU-15 countries (Carrera 2005: 706). A transitional period has been established, but it is up to the member states to decide the length and form of the transition periods. Therefore, access to some member states depends on liberal domestic immigration policies. Under the stipulations on transition periods, this goes along with various options for their approach to regulating labour movement.

As Box 4.1 shows, during the first phase (May 2004-April 2006, eight of the EU-15 countries initially applied restrictions for a period of two years - the scheme expired on 30 April 2006 - and thus kept pre-existing bilateral agreements in place. This period could be automatically extended by an additional three years for a second phase, and then by a further two years for a third phase (so that the maximum transition period amounted to seven years). Obviously, labour market demand and the economic situation of the member states determined whether they continued with, shortened or ended the transition period. Hence, the majority of the EU-15 member states used transitional periods to continue to apply ordinary or national migration legislation to workers from the new member states. Eventually, these workers will obtain access legally.

It is important to note that the transition period applied to prospective migrant workers only. It did not affect the mobility rights of workers who were already employed and legally resident in one of the EU-15. Nor did it apply to migrant students, the self-employed, service providers and all other accession nationals with sufficient and independent economic means who wished to take up a general right of residence in another member state (Stalford 2003: 2).

\section{New recruitment approaches in the post-enlargement period}

Since 2004, there has been an EU-wide approach to the admission of migrant workers. This may be a case in favour of international labour migration. A widely discussed reason for the growing support for new 
Box 4.1 An overview of the transitional period $(2+3+2)$

\begin{tabular}{|l|l|}
\hline $\begin{array}{l}\text { Phase one: } \\
\text { two years }\end{array}$ & $\begin{array}{l}\text { In the first two years after accession, the free move- } \\
\text { ment of workers does not apply to workers from the } \\
\text { EU8 wishing to work in an EU15 state. Instead, pre- } \\
\text { existing bilateral agreements continue to apply. Individ- } \\
\text { April 2006) } \\
\text { ual member states can, however, choose to introduce } \\
\text { national laws that allow greater freedom of movement. }\end{array}$ \\
$\begin{array}{l}\text { Phase two: } \\
\text { three years }\end{array}$ & $\begin{array}{l}\text { Before the end of phase one, member states that wish } \\
\text { to continue applying restrictions must notify the Euro- } \\
\text { pean Commission of their intent. During phase two, } \\
\text { any member state can decide at any time to abandon } \\
\text { April 2009) }\end{array}$ \\
\hline $\begin{array}{l}\text { Phase three: } \\
\text { workers. }\end{array}$ & $\begin{array}{l}\text { In principle, nations and allow full freedom of movement for } \\
\text { EU8 workers to the labour markets in EU15 states } \\
\text { should cease by 2009. EU15 states may, however, con- } \\
\text { tinue to apply them if there are serious disturbances or } \\
\text { threats of the same to their labour markets. EU15 } \\
\text { states that choose to allow the free movement of work- } \\
\text { ers during this phase may resort to a 'safeguard clause' } \\
\text { in the transitional agreement in order to suspend this } \\
\text { free movement, if necessary. From May 2011 onwards, } \\
\text { full freedom of movement will apply throughout the } \\
\text { European Union. }\end{array}$ \\
\hline
\end{tabular}

Source: Focus Migration, "EU Expansion and the Free Movement of Workers: Do Continued Restrictions Make Sense for Germany", Policy Brief No. 4, July 2006.

labour immigration policies has been advanced by Castles (2006a). Focusing on what he called the "flexible labour market", Castles gives two main reasons: first, the imperatives of economic liberalization and globalization on the basis of securing flexibility; second, demographic shifts, with increasing dependence on migrants, which can lead to social changes. Presumably, these factors, which are not just of theoretical interest, can be shown by reference to the economic and fiscal pressures associated with declining and ageing populations over the past decade in the EU-15 member states. In the enlarged European context, these questions are likely to be more deeply debated in the coming years.

Crucially, globalization is demonstrated in the way in which all West European countries are now engaged in migration systems that are growing in size and complexity and that are producing an increasing diversity 
of flows. Hence, employers and some governments are prepared to extend their search for skills to a global level; other governments are doing all they can to promote labour exports in return for remittances and savings (Salt 1992: 1080). The prevailing socioeconomic attitude towards a shift has resulted in polarized labour migration.

One obvious change is the selective policies of most receiving countries; the member states are increasingly and actively seeking skilled workers only. For instance, Germany's first Immigration Law (Zuwanderungsgesetz), which was introduced in 2004, focuses on an active integration policy. The law restricts new immigration and allows only temporary immigration of qualified individuals, except for immigration based on family reunification. The emphasis has now shifted principally to skilled workers. Organized labour movements are occurring with the consent of the immigration authorities in the member states. Mass immigration is no longer feasible. Indeed, it is hard to imagine that it will ever return; it is more likely to enter into an irreversible decline.

This new approach is also linked to low mobility. One trend in European labour markets is for European citizens to have a low propensity to move across EU countries and regions. In 2001, the problem was clearly summed up by Frits Bolkestein and Anna Diamantopoulou, commissioners for the Internal Market and for Employment and Social Affairs, respectively:

In spite of citizens' legal right to live and work in another member state, mobility across the EU is very low. Less than 2 per cent of people resident in Europe come from another member state. A much smaller proportion - less than 0.5 per cent - move between the member states each year. In order to achieve a healthy level of labour mobility and exploit the job potential of the single European market, governments should promote a genuinely transnational labour mobility two to three times higher than today. If Europe is to make best use of this new market, both governments and economic actors at European, national, regional and local levels need to do more to free up the barriers and hurdles hindering its development. (Financial Times 2001: 5)

Since then, this figure has remained unchanged.

With the higher level of mobility as well as employment objectives, the European Commission's interest in managed immigration shifted to the coordination of integration policies, leading to its inclusion in the Lisbon Summit conclusions in 2005 as an essential element of a comprehensive policy. Along these lines, one reasonable step forward is the Commission's proposals in the "Green Paper on an EU Approach to Managing Economic Migration" of January 2005 (CEC 2005a). The proposal was designed to "launch a process of in-depth discussion ... on the most appropriate form of the Community rules for admitting economic migrants 
and on the added value of adopting such a common framework". The Commission concluded that the EU-25's working age population would fall by 20 million between 2010 and 2030, which "will have a huge impact on the overall economic growth, the functioning of the internal market and the competitiveness of EU enterprises" (CEC 2005a: 3).

The Commission therefore suggested that it was time to revisit the restrictive immigration approaches of the past because of the absence of appropriate policies on economic migration, which may lead to increased irregular flows. It is, then, the responsibility of the member state governments to admit economic migrants. The Commission advocated "transparent and more harmonised common rules and criteria at EU level for admitting economic migrants" (CEC 2005a: 4). It seems like a rather different approach to labour migration compared with the migrant labour recruitment policies of most West European countries around 1974, when they moved towards increasingly restrictive entry rules. The roots of the current crisis lie in policies deliberately implemented in the 1950s and 1960s, when a critical shortage of labour prompted a number of European governments to encourage "temporary" labour migration (Brookes 1986: 26).

There is now a demand for temporary foreign workers in the EU, because the West European economies need more flexible labour to cope with seasonal demand. Brunson McKinley (Director General of the International Organization for Migration) highlighted the possible trends in 2004: future immigration would take place largely through regular channels of employment and work permits, and is likely to be more of a temporary nature than permanent. A consideration of selective policies is already under way by European Commission official and politicians. In fact, there has already been an introduction of temporary or seasonal migrant worker programmes in most EU-15 member states. Recently, the Commission has strengthened cooperation with several non-EU countries (China, India, Brazil and Japan) on the issue of employment and social affairs, especially with the aim of tackling long-term challenges in employment as a result of demographic ageing. Given such massive cooperation, it is perhaps not surprising that migration from third countries to countries in the EU has increased substantially in recent years, rising threefold between the mid-1990s and the early 2000s. Indeed, recent nonEU migrants who have arrived since 2000 account for almost one-third of all non-EU migrants of working age. This recent flow of third-country migrants has been notably higher (almost 2.5 times) than the recent internal movement of EU citizens between EU countries (CEC 2008f: 1).

The skill composition of workers (education, language diversity, etc.), which is no longer perceived as just one possible response to labour shortages, should be addressed in the usual terms. Hundreds of foreign-born 
doctors and nurses are currently filling the gaps in the National Health Service in the United Kingdom, and possibly in Austria and more certainly in Germany. The Commission's studies in 2008 (CEC 2008e) confirmed that, in all three economies, the need for less-qualified labour has fallen as a result of industrial slowdown and technological change. An easily adaptable labour force has now become a factor. Most migrants from the CEECs are well trained and well educated, and many speak foreign languages, which can represent an opportunity for enterprises that require flexible workers ready to adapt themselves to the required skills. However, it is still the case that the informal side of the labour market (for example in the agriculture, construction and services sectors) - where CEEC workers find employment - often needs unskilled labour. Notwithstanding the many obstacles in the way of the EU's strategy, Turkish migrants, who are predominantly young and low skilled, may become an important asset in these sectors. In these circumstances, the general expectation is that Germany will reopen its doors to Turkish workers in the services sector (for example, computer programming), and the United Kingdom may choose to import specialists from its former colony India in the same sector. Other member states, faced with the reality of shortages of skilled workers, are still considering the option seriously, even if they resist the idea (Yalçın 2004a: 47).

\section{Obstacles to the EU strategies in the context of Turkish labour movement}

\section{Conflicting views on cooperation}

Cooperation requires that the actions of separate individuals or organizations - which are not already harmonized - be brought into conformity with one another through a process of negotiation. This is often referred to as "policy coordination" (Keohane 1993: 102). The literature on the patterns of cooperation in EU immigration policy suggests that each government pursues what it perceives to be its self-interest but looks for deals that can benefit all parties, though not necessarily equally. Within this landscape, policy revolves around different opinions about migration. Disagreements will continue as long as the countries of the EU remain a destination for migrants from third countries. The United Kingdom, Denmark and Ireland opted out of Title IV of the Schengen Agreement, which was designed to assist the free movement of persons. This is a specific illustration of disparities in cooperation.

There are three reasons for the differences in members' views on cooperation: 
- governments realize the disadvantages of cooperating with other EU countries in the immigration policy area and prefer cooperate on a very loose intergovernmental basis, often on the margins of, or even outside, the EU framework;

- immigration is a highly diverse phenomenon in terms of the populations involved and their conditions of access to social provisions in a host country;

- in most countries, the pattern of immigration thinking hides different attitudes, views and policy measures towards migration between the right and left parties, and tends to have reinforcing effects along these ideological lines.

The lack of consensus and compromise by the EU authorities in making immigration policy implies that each member state is free to assess the conditions that might justify resort to derogation, possibly leading to the prohibition of Turkish workers, as well as political consideration of the issue of Turkish labour flows. Even though European politicians turned a blind eye to the free movement of Turkish workers, they had a significant effect on the real patterns of movement from Turkey. The decisions of the Association Council on conditions of entry and residence have been too controversial for a number of states. Because of concerns about a "flood of immigrants", they do not wish to forego national control over determining whether Turkish nationals are allowed to enter and stay.

In a similar vein, ECJ rulings have recently strengthened freedom of movement for Turkish workers. Therefore, one may expect Community law to demand the abolition of such limitations and implementation of the principles or decisions of the ECJ. Nevertheless, member states seem to take a very restricted approach when interpreting the Court rulings. The granting rights are confined to national legislation, implying that Turkish nationals will not automatically be able to enter the EU without being subject to the conditions outlined by each member state.

The difficulties in harmonizing divergent and legally very complex national provisions on migration procedures are one of the major causes of variations in flow rates across member states over the past two decades. To this end, "each European country allows resident foreigners to gain citizenship in different ways and at different rates, each having its own citizenship requirements based on a sometimes bewildering (and changing) combination of birth and residency requirements" (Bale 2008: 324).

A few examples are essential to illustrate this point. In Germany, naturalization is based on descent, not place of birth. Article 116 of the Basic Law provides that generations of foreign children born in Germany remain foreigners. Successive acts of parliament (the 1962 and 1968 
Commonwealth Immigrants Acts, the 1971 Immigration Act and the 1981 Nationality Act) have sought to define national citizenship. Revision of these acts has led to the introduction of a menu of varying citizenship statuses, each with a greater or lesser range of rights. For certain categories of people, there is currently simply a limitation on the fundamental right of citizenship - that of entry to the state.

In Italy, there have been changes in access to citizenship following a legislative initiative in 1992. Prior to this date, legal residence for five years was required for naturalization. The new law has changed the situation in relation to "ethnic" Italians. Specifically, it reduced the residence period to 3 years, while increasing it to 10 years for other applicants.

In France, some lack of clarity over the acquisition of citizenship remains, which seemingly puts the right to citizenship at risk. The scope of this right has been elaborated in terms of its meaning and the demands that it places on those who acquire it. Overlap occurred when the Pasqua laws were superseded by the Debré and Chevènement laws. Although the precise scope of the relevant rules on the acquisition of citizenship has changed - the automatic and irrevocable nature of French citizenship has been altered - there is still considerable room for confusion. Tensions over citizenship in these societies is likely to initiate serious debate concerning Turkish labour movement in the future.

Yet this would be a fundamentally misleading conclusion. To a certain extent, the EU system should be understood as an adequate mechanism for determining and implementing an overall policy in which the requirement of the free movement of labour is weighed and evaluated in relation to resources. It should be comprehended within the context of prevailing expectations and shared beliefs. Frequently, of course, negotiation and bargaining take place, often accompanied by other actions that are designed to induce each government to adjust its policies. In fact, the principle of flexible integration has, since the 1980s, been the attainment of the gains from pursuing complementary policies.

Despite these conflicting attitudes among the member states, Huysmans (2000) suggested that some form of cooperation exists across the EU that could provide the constituent basis for Turkish workers' movement. Policy coordination and development were institutionalized in inter-state cooperation following the Single European Act. In the mid-1990s, immigration-related questions - from the third to the first pillar - became one of the key issues for the Intergovernmental Conference reviewing the Treaty on European Union. In the Treaty of Amsterdam, the sections of the third pillar relating to immigration, asylum and refugees were communitarized (Huysmans 2000: 756). The pre-Amsterdam institutional pattern of cooperation in migration matters was structurally solid. Since then, formal rules, especially in the context of cooperation in Justice and 
Home Affairs, have coexisted with informal rules and practices of interaction.

Despite these substantial measures of progress, however, the literature on immigration policy has not produced any consensus on the likely future direction of the inclusion of Turkish labour in European labour markets. For years, cooperation in the migration field remained of no interest to the Community's institutions and its member states. The crucial reason for this might have been their migration situation, which was characterized by strong demand for foreign labour resulting from rapid economic growth (Kicinger and Saczuk 2004: 10). In the main, although the individual national migration policies of the 15 member states of the EU have remained as diverse as the history of those countries would suggest, a complex but steady process of EU cooperation has been taking place since the mid-1980s (Moraes 2003: 116).

It follows from this that the attachment of member states to the principles of the EU treaties is not compulsory. The Amsterdam Treaty constitutionalized flexibility, since the Treaty incorporated new opt-outs for Denmark, Ireland and the United Kingdom. Based on divergences in actions, a key norm should be an injunction on the member states to prevent them from creating obstacles to making and implementing the collective choice for labour movement. This is because diverse political behaviour has become comprehensible as part of a larger pattern of Turkish migration to the West. From the outset, the immigration policy process has apparently been confined to little more than occasional exchanges of ideas and information between the interested parties, and EU involvement is marginal.

\section{The impact of public opinion}

The impact of public opinion on EU immigration policy has been subject to considerable controversy. Given the evolution of the EU policy, one might think that a significant Europeanization of immigration policy has already been achieved. Even so, migration has increasingly been the subject of policy debates over the protection of public order and the preservation of domestic stability. The debates represent migration as a challenge to the welfare state and to the cultural composition of a nation.

If nothing else, since the end of 1980s the EU's policy on immigration has depended on public opinion in the member states. The fall of the Berlin Wall and the dramatic events of 1989 were initially met with celebration, which later turned into a great fear of a wave of mass migration from the East. This went far beyond what had hitherto been possible in terms of immediate labour flows. The subsequent exodus to the West 
and the use of the asylum system for immigration purposes forced the member states to be more protectionist under the influence of critical public opinion.

Following the Eastern enlargement, the debate has focused on more positive issues, including the role that Turkish immigration could play in easing the economic impacts of the declining and ageing populations of the old member states. In spite of negative perceptions regarding Turkish labour migration, there are still those who think that free movement of Turkish labour is essential for the European labour markets. Although the EU member states now require skilled labour under the selective migration policies, there is still demand for unskilled Turkish labour in some specific sectors, e.g. textiles and construction, which should stimulate a number of migration flows from Turkey to the EU.

The assumption is that the extent to which EU governments respond to public opinion depends very much on their own ideological and policy preferences. However, this may not always be the case. In the late 1980s, for instance, the UK Conservative government wished to see no extension to the Social Charter, and indeed, two-thirds of the British electorate responded positively to this opposition. Generally, there is variation in support for the EU immigration policy across the member states. In Denmark, hardly a country with a xenophobic past (and with early immigration adding barely 0.2 per cent to the population), immigration was a big issue in the March 1998 general election. In France, the centre-right is tearing itself apart over whether to form coalitions in some regions with the immigrant-bashing National Front. After decades of hospitality to asylum-seekers, Germany has more or less slammed the door. For a long time, the UK and French governments have kept immigration to a minimum (Economist 1998: 3).

This presents a challenge to Turkish workers. The Eurobarometer report on France in September 2005 (CEC 2005c) described the French governments' several attempts to deal with the issue of Turkish migration in Europe as "clumsy", despite the majority of the French population showing enthusiasm for Turkish workers' movement. The report also indicated that the German figures (50 per cent for and 50 per cent against) showed stronger opposition to Turkish entry to the EU than in other member states. The results suggested an easy way of tapping into what was mostly opposition to further enlargement or unease about Turkish immigration. Because of this, anti-Turkish sentiments in Germany, combined with low levels of support, impelled German leaders to warn that the prospect of Turkey eventually acceding to the EU was slim, as was also shown by the autumn Eurobarometer survey in 2005 (CEC 2005d). It is possible to conclude that public opinion in the EU regarding the Turkish accession is less positive in comparison with the CEECs. 
In almost all member states - even those where a large proportion of Turkish workers are themselves fearful of immigrants - there are manifest tensions over the possibility of EU decision-makers favouring a "softer style". These tensions are invoked by the fear of mass migration in the event of Turkey acceding to the EU. Fear of the undesirable economic, social and cultural impacts of labour flows should be considered in this context. There is obviously an element of exacerbation of social problems, such as criminal activity, and concerns about the burden of higher welfare outlays.

In contrast, some governments acknowledge the beneficial effects of migrant workers overall. Rather than leading to increased unemployment, migrant workers have been a major contributor to economic growth. However, public opinion doggedly refuses to believe this. In a poll in early 2007, 47 per cent of British people insisted that migration had been bad for the economy and 76 per cent wanted stricter border controls. This is a particular British response; the same poll found that Spain, which has also enjoyed strong economic growth and an influx of migrant workers, had nothing like the same suspicions (Bunting 2007: 2).

Europe's populist politicians have not been slow to pick up on - or even to help drive - these concerns, but the mainstream has had to respond to them and has had a hand in driving them too. "In the 1990s, parties of the far right or populist radical right parties scored some notable successes, especially in Western Europe. To many people, these successes are clearly related to xenophobia; in other words, the more hostile to foreigners a country is, the more likely it is to see the far right do well" (Bale 2008: 316).

Added to that, the European Parliament elections on 4-7 June 2009 were historically marked by a setback for the European left and a gain for centre-right and right-wing parties across the EU. Migration became a key issue as right-wing parties exploited workers' fears of migrants from both within and outside the EU, accusing them of taking jobs and "overloading" services. And it goes well beyond migration: European elections provided a snapshot of the campaign by right-wing parties, which was able to tap into a well of racism and hostility towards both Muslims and gypsies. To be sure, some of the fears regarding Turkish labour migration have partly been perpetuated by overtly anti-immigrant political parties, with the consequence that the free movement provisions have so far not been completely implemented. A larger proportion of the population that votes for these parties is also concerned about immigration issues. This suggests that the right-wing parties will have a significant impact on future prospects for Turkish labour flows. In the long run, Turkish workers may be beneficial for European labour markets and thus right-wing parties have to be careful not to go too far in offending Turkey. 


\section{The terrorist attacks of 11 September 2001}

The overwhelming trend across Western Europe has, since the 1990s, appeared to be increasingly negative for Muslim immigrants owing to more explicit anti-immigration rhetoric. However, such rhetoric became more prominent following the terrorist attacks on 11 September 2001 in the United States. The "9/11" attacks transformed the face of the foreigner into a prima facie face of terrorism. This has contributed to what some analysts refer to as the ongoing "securitization" of European (and, indeed, global) debates on immigration policy and minorities as well as adding yet another to the long list of negative stereotypes with which immigrants have to contend (Bale 2008: 315). The political will for closing the doors against foreigners as posing a major threat, personified by Muslims, was apparent throughout Europe. The right of individuals to protection from their state of nationality - which is central to the idea of civil liberties - is being abandoned. Although most EU anti-terrorism measures have been directed at policy and judicial cooperation rather than immigration and asylum issues as such, the extra impetus to coordinate judicial and policing provisions has a knock-on effect on aspects of immigration (Boswell 2002: 1).

On the other hand, the impact of "9/11" on the EU's developing policies on asylum, immigration and visas has been less striking than on police and judicial cooperation (Grant 2002: 147). The immediate concerns about security that are closely associated with migration have become an urgent priority. This is because the heightened worries about terrorism have contributed to the renewal of the EU's efforts to develop common policies for its external borders. From the outset, EU member states have too often not fulfilled their obligations, especially in security-related crises. Member states have sought to overcome their disappointments by continually reforming the mechanisms for conducting external relations. In this new environment, the fear that irregular migration is beginning to get out of control is echoed by the media and politicians. For instance, Jack Straw, the British Foreign Secretary, called for the introduction of qualified majority voting on asylum and immigration policy in 2002. The ambiguous character of political demands of this kind is the "hidden spring" that has continuously driven the EU leaders to "recognize their obligations" (Irish Times 2002: 3).

It was at this juncture that the Seville Summit of June 2002 approved a further drive to forge a common policy. Tangled up in this debate is a string of emotive issues, which led to calls for dealing with racism, extremist terrorism, the veil and the role of faith in secular society. With the increasing success of extreme-right and populist parties in European politics, the main security risks need to be tackled through coordinated 
action across a borderless Europe. These parties pledge to toughen asylum policy and make a link between immigration and terrorism. In its efforts to concretize the Tampere conclusions, the Seville Summit was accused of creating a "Fortress Europe". But this was something that, even if it were true, would shortly lead to successful external relations. Amid much national disagreement, the plan adopted in Seville provided for greater resources for border enforcement in front-line nations and laid the foundations for a common border policy agenda and Europewide anti-smuggling taskforces. It also proposed strategies for working with migrant-sending countries, for example repatriating captured illegal immigrants, improving cooperation and even denying generous EU economic aid to countries that failed to cooperate (Council of the European Union 2002: 7).

Establishing the significance of "9/11" for the question of Turkish labour mobility is not easy because it is difficult to know where to begin in the context of its character and antecedents. Perhaps inevitably, the event gave new significance to the visibility of the Muslim population in Europe, along with other negative stereotypes. It is claimed that, in the realm of religion, there is a real "a clash of cultures" - Islam and Christianity cannot be reconciled when minorities refuse to be assimilated in terms of adopting the customs, dress codes and ideologies of the West. As a result, a climate of anxiety has often been fuelled by the media, and populist radical right parties have thrived with literally no basis in "objective circumstances". Hostility to foreigners is everywhere, but in Europe the perception of Turks is the problem.

These tendencies can be seen in most West European countries, but there is a good case for saying that they are strongest in Germany. Attacks on Turks and their lack of rights in Germany have received much international attention in the past decade, and presumably encourage Turks to continue to protest and keep public scrutiny on Germany. The most important task for the German government and German society is to hasten the incorporation of Turks and other visible minorities into German society. Stopping xenophobic attacks is part of that process (Minorities at Risk Project: 2009: 1). After a lull in the mid-1990s, the number of violent attacks has reportedly risen and led to some fatalities. For example, nine Turkish immigrants died in a house fire in Ludwigshafen on 2 February 2008, caused by arson. The Turkish media immediately drew comparisons with the 1993 fire in Solingen, in which five Turkish women and girls were burned to death when neo-Nazis set fire to the building in which they lived (Henning 2008: 1). These and similar incidents give the impression that Turkish immigrants are, as Bale put it, "not wanted but needed" and, at the same time, have revived images of Germany's nationalist past (Bale 2008: 323). 
What has changed since " $9 / 11$ " is that EU member states' national legislation has been revised. Even countries such as Belgium and the Netherlands, which are often characterized as having more liberal immigration policies, have begun to tighten their national rules and changed their view of immigration. As an example of such changes, in the Netherlands the age at which a person can bring over a partner has been raised from 18 to 21 since 2004 and the partner residing in the Netherlands must earn 120 per cent of the legal minimum wage. Perhaps no country has experienced more dramatic changes in policy than France. Although, for a time, there appeared to be a softer stance towards immigrants, since 9/11 France has adopted more restrictive immigration policies. In 2005-2006, France more explicitly pointed the finger of blame at Islam in its discussion of immigration problems. Generally speaking, there have been shifts and fluctuations in the liberality or restrictiveness of immigration policies. Even so, policies in Spain have become increasingly strict, with more effective limitation of rights to reunite families of immigrants. Since the first law dealing with immigration was passed in 1985 (OL 7/1985), there have been several reforms and two additional laws passed that have affected immigration policies in the country. Though the United Kingdom has been subject to violent terrorist attacks by Muslim extremists, there has been little in the way of changes to immigration policies. And the Greek government, which historically has tended to neglect the problems of immigrant communities, has facilitated the creation of amnesty programmes to regularize the status of undocumented immigrants (Stoddard 2007: 1).

\section{Conclusion}

The Treaty of Rome provided the most general formulation of immigration policies in the EEC. The Treaty enforced the free movement of labour within and between the member states. The process was later embellished with references to the free movement of non-EU nationals in the guest worker phase, but, from late 1973 onwards, it brought stricter control. At the same time, immigration policies made continued migration possible because the relaxation of restrictions on family reunification stimulated further flows. This was an unforeseen consequence of the immigration standstill, because the earliest migrants residing in the EC were able to continue to sponsor the immigration of their extended families.

In anticipation of the single European market, there can be little doubt that the policy agenda has, from the mid-1980s, been dominated by the issue of an internal market as free as possible from physical, technical, fiscal and social distortions. The goal appeared to be nothing less than 
replacing restrictively managed migration by a more liberal immigration policy. In parallel with this rhetoric, new guiding principles and operating tools were incorporated into the Maastricht Treaty. This more liberal immigration policy remained unchanged in subsequent European Council meetings, up to the Treaty of Amsterdam provisions relating to citizens who live in the member states of the EU.

The accession of the CEECs to the EU has led to a resurgence of migration pressures since 2004. This has made the migration phenomenon more complex. The situation in the EU member states is that transitional periods were introduced to limit the labour flow rate. It is not particularly surprising that the EU's demand for skilled and experienced workers has become more persistent in the post-enlargement period. In particular, the EU's new approach to immigration policy, together with demographic and economic factors, appears to have wider implications for the future labour supply across the skill spectrum. The available evidence suggests that some recruitment difficulties have increased owing to the more selective policies of member states. Even with these formidable changes, there are continuing pressures of internal demand for unskilled workers.

Despite some progress towards harmonization and a common immigration policy, intergovernmental cooperation is accompanied by a resistance to the free movement of labour. Faced with diverging perspectives, one needs to stand back and clarify what is at stake in this debate on Turkish labour migration. In the process of radical enlargement, diverging perspectives are of great significance, although there is no denying that EU member states have been uniquely successful in their broad consensus on the need for restrictive policies to prevent the adverse effects of mass migration following enlargement. In the main, however, there is difficulty in arriving at a consensus on an EU migration policy.

For decades, controversies over the nature of public opinion have mainly focused on the issue of how Turkish immigrants would disrupt the social balance of the EU member states. This is based on the assumption that Turks will bring with them a culture and a religion that are fundamentally incompatible with those of the host population. Underlying these issues, the capacity of national governments or political leaders to respond to the pressures fully and effectively will probably determine the future labour flows. Being tightly constrained, EU policy has been consigned to a minor role in the issues of Turkish labour migration. The whole credibility of labour migration is more seriously at stake when a number of obstacles and tensions concerning anti-immigration rhetoric, which was intensified by the 9/11 terrorist attacks, continue to create barriers to the realization of a more comprehensive policy. On the whole, there is no reason why these trends should not dramatically affect the free movement regulations and rules for Turkish workers. 
5

\section{The impact of Central and East European accession on the movement of Turkish labour}

\section{Introduction}

There are many push and pull factors that could influence labour flows from the 10 Central and East European countries (CEEC-10) and Turkey into the European Union (EU). The first important step for assessing the possible impact of the Eastern enlargement on Turkish labour movement is to estimate East-West movements after the Central and East European countries (CEECs) joined the EU. I then consider the arguments supporting and rebutting the migration effect, and other characteristics and situations that may counteract the pull and push factors described in Chapter 1. Against this background, I also demonstrate a set of possible explanatory factors to assess the relative strength of their effects, to the extent that such factors may reflect the equilibrating forces of the migration movements themselves. Finally I look at the prospects of labour movement from Turkey to the EU in the foreseeable future, which is, in any event, debatable.

Estimates of East-West migration following the Eastern enlargement

During the first two years of membership of the CEECs in the EU, labour migration from the CEECs was characterized predominantly by East-West migration. Since the announcement of the EU's intended 
enlargement, a multitude of studies have focused on the migratory aspects of the expansion, trying to predict the size and nature of migratory flows from the CEECs to the EU. A few studies, focusing on a shorter time horizon, estimate a significantly larger migration potential, whereas others trying to estimate the size of the migration potential have arrived at very different conclusions (see Table 5.1).

These studies indicate some interesting trends, despite the different results and uncertainties concerning the basis of the calculations. First, nearly all studies concluded that the number of migrants in the EU would increase, but over a longer period of time. It was estimated that 1-4 per cent of the total population of the CEECs would move to the EU-15, accounting for 1-3 million people within two decades of the implementation of the right of free movement of labour. Secondly, there would be a shift from permanent to temporary migration and a strong preference among the nationals of the accession countries for temporary work. Taking into account the possibility of migrants returning home, it was estimated that approximately 1.75 million people in 2003 alone would be involved in these movements, representing about 0.4 per cent of the total EU-15 population. Thirdly, labour migration would be concentrated in only a few member states. In particularly, Austria and Germany would face much more substantial flows. Finally, following the initial increase in cross-border mobility between the CEECs and the EU-15, migration flows across Europe would most likely fall back to a low level, given the previous enlargement experiences of the EU. It is likely that such flows would stabilize by 2010-2020. At the lower end of these predictions, labour migration from the CEECs was not expected to be a potential burden.

Studies typically note that migration flows depend very much on the dynamics of the regional labour markets in both sending and home countries. The newly liberalized migration policies of the EU have facilitated border-crossing. It is hardly surprising that, given the primary role of labour demand in determining such flows, alongside other factors, the predictions are linked to the pace of economic development in the future. Having said this, it is not easy to estimate the relative economic gap between the CEECs and the EU-15. In 2003, migration experts revised the figures slightly downwards, mainly because of the poor performance of the German economy, which was attracting fewer immigrants. They forecast a total of 3.7 million migrants in 15 years (Wagstyl 2004: 3). Of course, an important consideration for migration decisions is not only economic conditions at a particular point in time but also future economic prospects. Migration is unlikely to take place if individuals perceive that the economic situation in their country will improve (Dustmann et al. 2003: 46). 
Table 5.1 Selected macro-analytical model-based calculations

\begin{tabular}{|c|c|c|}
\hline Author & Method & Result \\
\hline $\begin{array}{l}\text { Layard et al. } \\
\text { (1994) }\end{array}$ & $\begin{array}{l}\text { Extrapolation analysis } \\
\text { based on previous } \\
\text { South-North } \\
\text { migration in } \\
\text { Europe between } \\
1950 \text { and } 1970\end{array}$ & $\begin{array}{l}\text { Migration potential of CEECs: } 3 \text { per } \\
\text { cent of total population emigrating } \\
\text { within } 15 \text { years (around } 2.1 \\
\text { million). }\end{array}$ \\
\hline $\begin{array}{l}\text { Franzmeyer } \\
\text { and Brücker } \\
\text { (1997) }\end{array}$ & Regression analysis & $\begin{array}{l}\text { Annual East-West migration from } \\
\text { Poland, Slovakia, Slovenia, Czech } \\
\text { Republic and Hungary: } \\
\text { 340,000-680,000 people. }\end{array}$ \\
\hline $\begin{array}{l}\text { Walterskirchen } \\
\text { and Dietz } \\
\text { (1998) }\end{array}$ & $\begin{array}{l}\text { Extrapolation analysis } \\
\text { based on income } \\
\text { differentials }\end{array}$ & $\begin{array}{l}\text { Annual East-West migration from } \\
\text { Poland, Slovakia, Slovenia, Czech } \\
\text { Republic and Hungary: around } \\
220,000 \text { people. }\end{array}$ \\
\hline $\begin{array}{l}\text { Bauer and } \\
\text { Zimmermann } \\
\text { (1999) }\end{array}$ & Regression analysis & $\begin{array}{l}\text { Ultimately, at least } 3 \text { per cent of the } \\
\text { EU-10 (or around } 2.1 \text { million } \\
\text { people). }\end{array}$ \\
\hline $\begin{array}{l}\text { European } \\
\text { Commission } \\
(2000)\end{array}$ & Regression analysis & $\begin{array}{l}335,000 \text { people a year could move } \\
\text { from the } 10 \text { accession states in the } \\
\text { first } 10 \text { years following } \\
\text { enlargement. }\end{array}$ \\
\hline $\begin{array}{l}\text { Sinn et al. } \\
\quad(2000)\end{array}$ & $\begin{array}{l}\text { Macro model-based } \\
\text { calculation and } \\
\text { regression analysis }\end{array}$ & $\begin{array}{l}\text { Long-run immigration of } 6-10 \text { per } \\
\text { cent of the total population of } \\
\text { origin countries ( } 4-5 \text { million } \\
\text { people over } 15 \text { years following } \\
\text { enlargement). }\end{array}$ \\
\hline $\begin{array}{l}\text { Brücker et al. } \\
\quad(2000)\end{array}$ & Regression analysis & $\begin{array}{l}\text { Annual East-West migration from } \\
\text { the CEECs would start at the } \\
\text { level of around } 336,000 \text { people } \\
\text { and fall to } 2,400 \text { over } 30 \text { years. }\end{array}$ \\
\hline $\begin{array}{l}\text { European } \\
\text { Commission } \\
(2003)\end{array}$ & Regression analysis & $\begin{array}{l}\text { The above figure was revised } \\
\text { downward to } 286,000 \text { immigrants } \\
\text { in the first year, resulting in } \\
\text { between } 3.2 \text { million and } 4.5 \\
\text { million by } 2030 \text {. This is equivalent } \\
\text { to an increase in the population of } \\
\text { the EU-15 of } 0.7-1.2 \text { per cent. }\end{array}$ \\
\hline $\begin{array}{l}\text { Dustman et al. } \\
\text { (2003) }\end{array}$ & Survey analysis & $\begin{array}{l}2.22 \text { million temporary migrants, } \\
\text { with up to } 1.11 \text { million of these } \\
\text { possibly migrating permanently, } \\
\text { from the CEECs - no time period } \\
\text { suggested. }\end{array}$ \\
\hline
\end{tabular}

Source: Heinz and Ward-Warmedinger (2006), based on Fassmann and Münz (2002).

Notes: Layard, R., Blanchard, O., Dornbusch, R., and Krugman, P. (1994), "EastWest Migration, The Alternatives", MIT, Boston; Franzmeyer, F. and Brücker, H. (1997), "Europäische Union: Osterweiterung und Arbeitskräftemigration", DIW- 
Table 5.1 (cont.)

Berlin Wochenberichte; Walterskirchen, E. and Dietz, R. (1998), "Auswirkungen der EU-Osterweiterung auf den Österreichischen Arbeitsmarkt", WIFO, Vienna; Bauer T. and Zimmermann K. (1999), "Assessment of Possible Migration Pressure and its Labour Market Impact following EU Enlargement to Central and Eastern Europe", a study for the Department for Education and Employment (United Kingdom), Bonn; European Commission (2000), "The Impact of Eastern Enlargement on Employment and Labour Markets in the EU Member States", Report by the European Integration Consortium on behalf of the Employment and Social Affairs Directorate General of the European Commission, Berlin; Sinn, H.-W., Flaig, G., Werding, M., Munz, S., Duell, N., and Hofmann, H. (2000), "EUErweiterung and Arbeitskräftemigration: Wege zueiner schrittweisen Annäherung der Arbeitsmärkte", Federal Ministry of Labour and Social Affairs, Berlin; Brücker, H., Berlitz, H., Bornhorst, F., Edin, P., Mertig, M., Frediksson, H., Hofer, H., Hoenekopp, P., Huber, P., Kreyenfeld, M., Lundborg, P., Moebius, U., Roulstone, D., Schrettl, W., Schraepler, J., Schumacher, D., and Truebswetter, P. (2000), "Studie über die Auswirkung der EU-Erweiterung auf die Beschäftigung und die Arbeitsmärkte in den Mitgliedstaaten", Final report: Part 1: Analysis, Brussels; European Commission (2003), "Impact of Economic and Social Integration on Employment in the Context of Enlargement", Final report; Dustmann, C., Casanova, M., Fertig, M., Preston, I., and C. Schmidt (2003), "The Impact of EU Enlargement on Migration Flows", Home Office Report 25/03.

A study by the European Integration Consortium in 2000 (European Integration Consortium 2002) noted that the negative effects of migration (for example, greater competition among employees) would be visible in the field of blue-collar workers, manufacturing industry and unskilled labour services. The effects on white-collar workers, on the other hand, were said to be small or even positive regarding job creation by highly skilled migrants. Although higher levels of education are an important incentive, migration trends would be strongly influenced by economic cycles. According to an analysis by the European Commission in 2001 on the potential migration flows from the Eastern accession countries (CEC 2001b), commuting as well as the provision of services would increase significantly in both directions once the CEECs joined. Apart from this, the study suggested that the figure would remain equivalent to only 1 per cent of the EU population, but this figure would increase up to 8 per cent in border regions in the long run (CEC 2001b). The Commission concluded tentatively that labour-intensive sectors would face fierce competition.

Labour migration from the new accession countries to the EU already exists. Most of them have taken up employment in the countries that chose to open their labour markets (Heinz and Ward-Warmedinger 2006: 30). Population statistics and labour force surveys of the member states show that the average population share of the nationals of the countries 
that joined in 2004 - the initial eight CEECs plus Malta and Cyprus (the EU-10) - living in the EU-15 rose from 0.2 per cent in 2003 to 0.5 per cent by the end of 2007. During the same period, the population share of Bulgarians and Romanians living in the EU increased from 0.2 per cent to 0.5 per cent. The majority of mobile workers from the new member states that joined the EU in 2004 - mostly from Poland, Lithuania and Slovakia - went to Ireland and the United Kingdom, whereas Spain and Italy have been the main destination countries for Romanians (European Commission 2008c: 2).

The expansion has generated significant migration. Table 5.2 shows that there are already significant numbers of EU-10 workers in Germany and Austria as a proportion of the working population. Oddly enough, these are the two countries that are most keen to keep restrictions. Moreover, they have chosen to put in place transitional arrangements and appear not to have appreciably lower levels of migration. In particular, all three countries (the United Kingdom, Ireland and Sweden) that adopted an open door policy after accession reported a rise in immigration. Certainly, the rise in Spain, France and the Netherlands is also significant.

Table 5.2 CEEC employment rates in the EU-15 member states, 2005 (per cent)

\begin{tabular}{lccccc}
\hline & \multirow{2}{*}{2004} & \multicolumn{4}{c}{2005} \\
\cline { 2 - 6 } Country of & & & \multicolumn{4}{c}{ Nationality } \\
\cline { 3 - 6 } destination & EU & National & EU-15 & EU-10 & Non-EU \\
\cline { 3 - 6 } Belgium & 64 & 62 & 60 & 55 & 35 \\
Germany & - & 67 & 68 & 51 & 48 \\
Greece & 47 & 60 & 53 & 47 & 71 \\
Spain & 68 & 62 & 64 & 78 & 71 \\
France & 61 & 64 & 69 & 62 & 44 \\
Ireland & - & 67 & 69 & 85 & 57 \\
Netherlands & 63 & 74 & 76 & 64 & 41 \\
Austria & 58 & 69 & 72 & 66 & 60 \\
Finland & 67 & 69 & 67 & 55 & 45 \\
Sweden & 62 & 74 & 73 & 62 & 45 \\
UK & 72 & 72 & 69 & 75 & 58 \\
EU-15 & 59 & 57 & 68 & 62 & 55 \\
EU-10 & - & 57 & 59 & 68 & 63 \\
EU-25 & 59 & 55 & 67 & 62 & 55 \\
\hline
\end{tabular}

Source: Eurostat, Labour Force Surveys, 2004-2005Q2.

Notes: '-' data not available or not reliable owing to small sample size. Italy is excluded, since it does not disaggregate by nationality. Denmark, Luxembourg and Portugal are excluded owing to small sample size.

${ }^{a}$ EU-15 and EU-10 aggregates in 2004 based on Germany and Ireland 2005Q2 data (EU-10 = 'accession eight countries', plus Cyprus and Malta). 
This has partly been achieved by issuing workers with permits to work in specific areas for a short period of time.

Hence, full or partial opening of national labour markets to the population of the CEECs has led to East-West migration. Many workers in the new accession countries have been keen to take advantage of the new opportunities in order to earn higher wages or find jobs. However, the conclusions from the Southern enlargement suggest that one should be careful when making predictions about future migration flows based on relative differences in socioeconomic variables. The share of workers from the CEECs is still very modest in most EU-15 countries and is unlikely to be large enough to alter the observation that the stock of workers from the CEECs is low in most EU countries. It is also worth noting that forecasting the migration effect is difficult at the levels experienced in the 2000s.

\section{The impact of the enlargement}

\section{The factors supporting migration effects}

\section{Unemployment and wages}

A high level of unemployment and relatively low wages may become incentives for the population of the CEECs to migrate in order to look for better employment opportunities abroad. Comparing the average unemployment rate in 2007 between the CEECs and Turkey, the highest unemployment rate was registered in Slovakia (11.1 per cent), followed by Poland (9.6 per cent) and Turkey ( 8.5 per cent), as Table 5.3 shows. It was forecast that unemployment rates in Turkey would rise to 10.0 per cent in 2008 and fall back to 9.8 per cent in 2009, which would still be well above any of the CEECs. The average unemployment rate was 6.2 per cent in the EU-15 and 6.6 per cent in the CEEC-10. Obviously, this gap is not substantial. This might lead one to suggest that migration flows will occur between specific countries. Thus, the population of Bulgaria, Lithuania, Hungary, Poland, Romania and Slovakia will head to, mainly, Austria, the United Kingdom, Denmark, the Netherlands, Ireland and Luxembourg to find jobs. The United Kingdom has already encouraged the Polish workers who are present in much of Western Europe.

Looking at the labour market situation in Turkey, the general trend is that labour force participation rates in rural areas are consistently low. One possible explanation for this situation is migration from rural to urban areas, leaving rural areas populated more with older people and females, who are relatively less likely to participate in the labour force (Erdil 2007: 155). In rural areas, labour participation is generally in the 
Table 5.3 Unemployment rates (per cent)

\begin{tabular}{|c|c|c|c|c|c|c|}
\hline & 2004 & 2005 & 2006 & 2007 & $2008^{a}$ & $2009^{a}$ \\
\hline EU-27 & 9.0 & 8.9 & 8.2 & 7.1 & 6.8 & 6.8 \\
\hline Germany & 9.7 & 10.7 & 9.8 & 8.4 & 7.3 & 7.1 \\
\hline Austria & 4.8 & 5.2 & 4.8 & 4.4 & 4.2 & 4.3 \\
\hline Belgium & 8.4 & 8.5 & 8.3 & 7.5 & 7.3 & 7.5 \\
\hline UK & 4.7 & 4.8 & 5.4 & 5.3 & 5.4 & 5.7 \\
\hline Bulgaria & 12.1 & 10.1 & 9.0 & 6.9 & 6.0 & 5.4 \\
\hline Czech Republic & 8.3 & 7.9 & 7.2 & 5.3 & 4.5 & 4.4 \\
\hline Denmark & 5.5 & 4.8 & 3.9 & 3.8 & 3.1 & 3.2 \\
\hline Estonia & 9.7 & 7.9 & 5.9 & 4.7 & 6.0 & 6.0 \\
\hline Euro area & 8.8 & 8.9 & 8.2 & 7.4 & 7.2 & 7.3 \\
\hline Finland & 8.8 & 8.4 & 7.7 & 6.9 & 6.3 & 6.1 \\
\hline France & 9.3 & 9.2 & 9.2 & 8.3 & 8.0 & 8.1 \\
\hline Cyprus & 4.7 & 5.3 & 4.6 & 3.9 & 3.7 & 3.5 \\
\hline Netherlands & 4.6 & 4.7 & 3.9 & 3.2 & 2.9 & 2.8 \\
\hline Ireland & 4.5 & 4.4 & 4.5 & 4.7 & 5.6 & 5.8 \\
\hline Spain & 10.6 & 9.2 & 8.5 & 8.3 & 9.3 & 10.6 \\
\hline Sweden & 6.3 & 7.4 & 7.0 & 6.1 & 6.2 & 6.5 \\
\hline Italy & 8.1 & 7.7 & 6.8 & 6.1 & 6.0 & 5.9 \\
\hline Lithuania & 10.4 & 8.9 & 6.8 & 6.0 & 6.4 & 6.9 \\
\hline Latvia & 11.4 & 8.3 & 5.6 & 4.3 & 4.5 & 4.8 \\
\hline Luxembourg & 5.1 & 4.5 & 4.7 & 4.1 & 4.5 & 4.4 \\
\hline Hungary & 6.1 & 7.2 & 7.5 & 7.4 & 8.3 & 7.8 \\
\hline Malta & 7.4 & 7.3 & 7.3 & 6.4 & 6.3 & 6.2 \\
\hline Poland & 19.0 & 17.8 & 1.9 & 9.6 & 7.1 & 6.1 \\
\hline Portugal & 6.7 & 7.6 & 7.7 & 8.0 & 7.9 & 7.9 \\
\hline Romania & 8.1 & 7.2 & 7.3 & 6.4 & 6.1 & 5.9 \\
\hline Slovakia & 18.2 & 16.3 & 13.4 & 11.1 & 9.8 & 9.3 \\
\hline Slovenia & 6.3 & 6.5 & 6.0 & 4.9 & 4.7 & 4.7 \\
\hline Greece & 10.6 & 9.2 & 8.5 & 8.3 & 8.3 & 8.0 \\
\hline Croatia & 13.7 & 12.7 & 11.2 & 9.6 & 8.9 & 8.4 \\
\hline Macedonia & 37.7 & 36.7 & 36.0 & 34.6 & 33.3 & 31.8 \\
\hline Turkey & 10.3 & 10.2 & 8.4 & 8.5 & 10.0 & 9.8 \\
\hline
\end{tabular}

Source: 2004-2007 - Eurostat (2008c).

${ }^{a}$ Forecast (CEC, Economic Forecast: Spring 2008, European Economy, No. 1).

form of unpaid family workers in agricultural activities. It is possible that this internal migration will lead to an increase in international migration because Turkish migrant workers in rural areas will probably look for a source of income in countries where living conditions are relatively better.

This rural/urban divide reveals a different picture in terms of unemployment rates in Turkey. Regional discrepancies have also been the case in the CEECs since the beginning of the transition. In most CEECs, regional unemployment coexists with labour shortages elsewhere. The number of job-seekers is growing in urban areas, offering new employ- 
ment opportunities. A large component of the labour force in the CEECs was employed in agriculture. The marked decline in employment in this sector of the economy has left the underdeveloped agricultural areas of Poland (northern and north-western regions), Hungary (eastern regions), Estonia and Slovenia with high unemployment rates (European Policies Research Centre 1996: 53, 62). In contrast to the agricultural and heavy industry areas, urban areas are experiencing a rise in labour market demand. In certain areas of the Czech Republic, about 10 unemployed apply for each position, whereas in Prague there are two vacancies per job-seeker (Boeri and Scarpetta 1995: 4). The regional differences in employment, which are serious by EU standards, have increased significantly in recent years. The current regional disparities make geographical labour mobility from declining to expanding areas predictable, thus increasing labour flows to the West.

The economic literature suggests that young workers are relatively mobile. Those aged 15-24 tend to face the most difficulty in securing a job. The average unemployment rate among 15-24 year olds who are actively seeking employment is 17.2 per cent across the EU-27 as a whole. The highest rate of unemployment for this age group was in Poland, with 29.8 per cent in 2006 (Eurostat 2008c: 259). The youth unemployment rate in Turkey is generally higher than in the CEECs, accounting for 16.7 per cent in 2006 (State Planning Organization 2008: 13). The youth unemployment rate is still substantial enough to increase the migration potential in Turkey. On the one hand, this may be a sign that in the long run Turkey will enter a "golden age" similar to that experienced by the "Asian tigers" in the past, with a very high ratio of active population to total population. On the other hand, the high rate of youth unemployment in Turkey may have a serious impact on incomes and the development of human capital. It may also point to some risks of social alienation, which may even spread to EU countries.

Youth education attainment level presents a somewhat less optimistic picture in Turkey compared with the CEECs. Turkey faces the task of a major reform in its primary and secondary education systems. Oldfashioned rote learning systems are still common in schools, mainly in rural areas, which are primitive and poorly funded. A further complication of the Turkish education system lies in technical education, "which is structured inflexibly around narrow and outdated skill and job categories" (Hughes 2004: 16). Figure 5.1 shows that Turkey is placed lowest and Slovakia highest for the education attainment levels of young people aged 20-24. A particular problem is low rates of female participation rates in education. The Turkish Statistical Institute reported in 2006 that 51 per cent of women participated in education and around 12,000 unemployed females were illiterate. Yet female education attainment was 

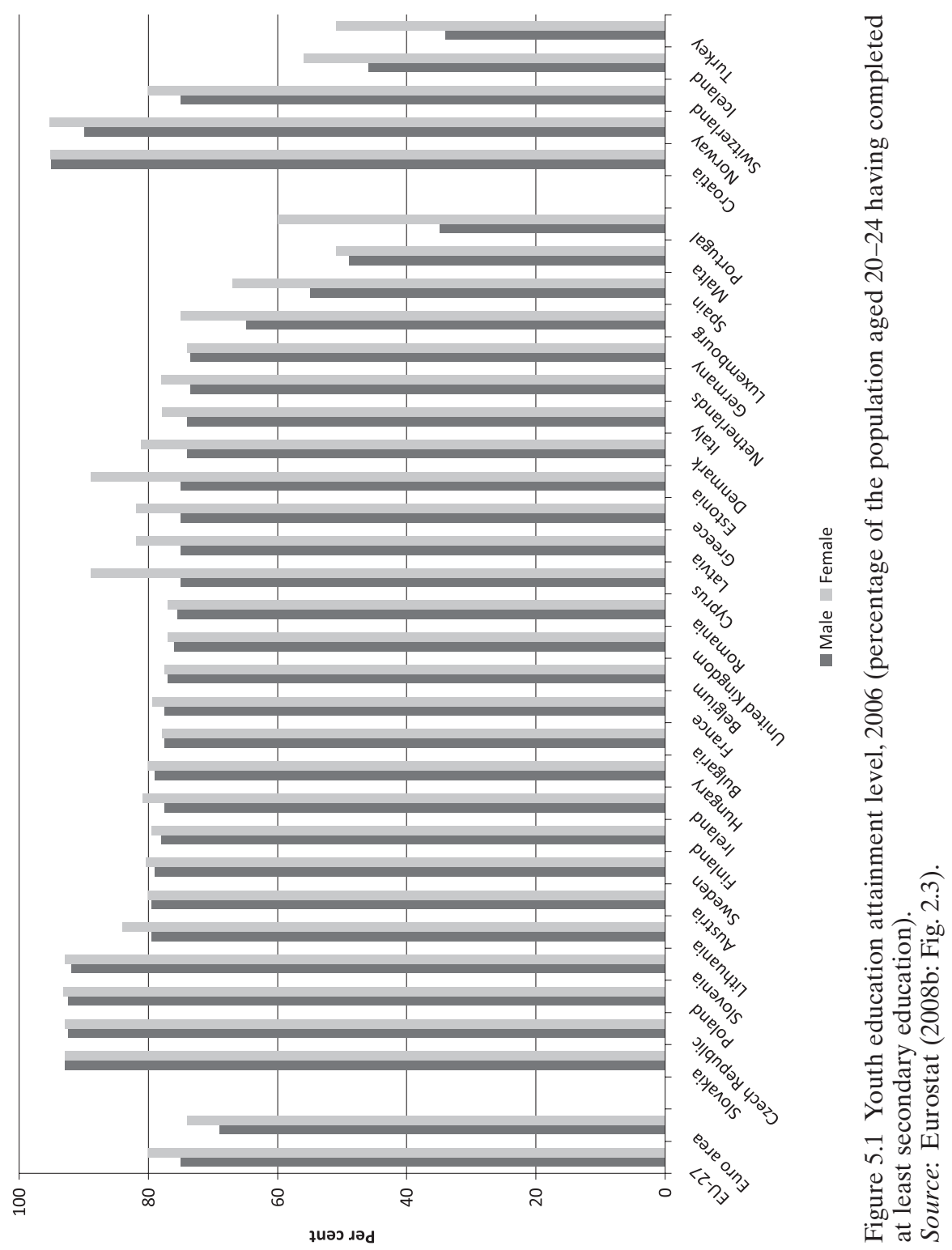
higher than that for males. The problem is even more acute in rural areas. Recently, the Turkish government launched a campaign to encourage women to take part in literacy courses under the slogan of "haydi kızlar okula" ("come on, girls, off to school"). In spite of this, it is likely that the problem will persist for a long time. This underlines the need to upgrade the quality of the labour force in order to compete with workers from the CEECs.

The available literature suggests that the economic impact on the countries of destination and the countries of origin typically depends on the skill level of the immigrants. Boeri and Brücker (2000) show that skill mismatches are characterized by a pool of low-skilled unemployed and vacancies for the relatively high-skilled, and suggest that the immigration of relatively skilled labour from the CEECs creates employment. This picture is in sharp contrast to the skill composition of Turkish migrants and should be seen as a key factor in EU policy-making when reviewing labour movement. Figure 5.2 shows that Turkey has an exceptionally high proportion of its labour force in agriculture (around one-third of the total) compared with the CEECs, with the exception of Romania. A high level of employment in the agricultural sector implies an unskilled Turkish workforce and, in turn, less employability in comparison with CEEC workers. Immigration from Turkey is likely to consist mostly of people from rural areas with low levels of education.

The gradual shift in Europe away from the primary sector and traditional manufacturing industries towards services and the knowledgeintensive economy is likely to continue (European Commission 2008e: 2). It is difficult to envisage that Turkish migrants' skill composition will improve in the long run; for some decades to come, Turkey's comparative advantage will be in lower-skill and low-wage activities in manufacturing. Compared with the CEEC-10, Turkey is, probably, significantly less endowed with human capital because of a generally much lower level of secondary and higher education. The average level of schooling for an adult is four or five years. Only recently did Turkey raise the mandatory minimum length of schooling from five to eight years (Flam 2004: 197).

Studies of the impact of the transition process on the EU have suggested that high education levels in the CEECs will give these countries a comparative advantage in high-tech products. This characteristic seems to underpin the validity of concerns that have been raised about the quality of Turkish labour (Smith 1997, in CEPR 1998: 1). In comparative studies on the quality of education, however, Boeri and Brücker (2000) found that the quality of education is generally lower in the CEECs than in the EU, and labour productivity is only about half that of the EU owing to a less-skilled labour force. In the EU countries, the expected range of 


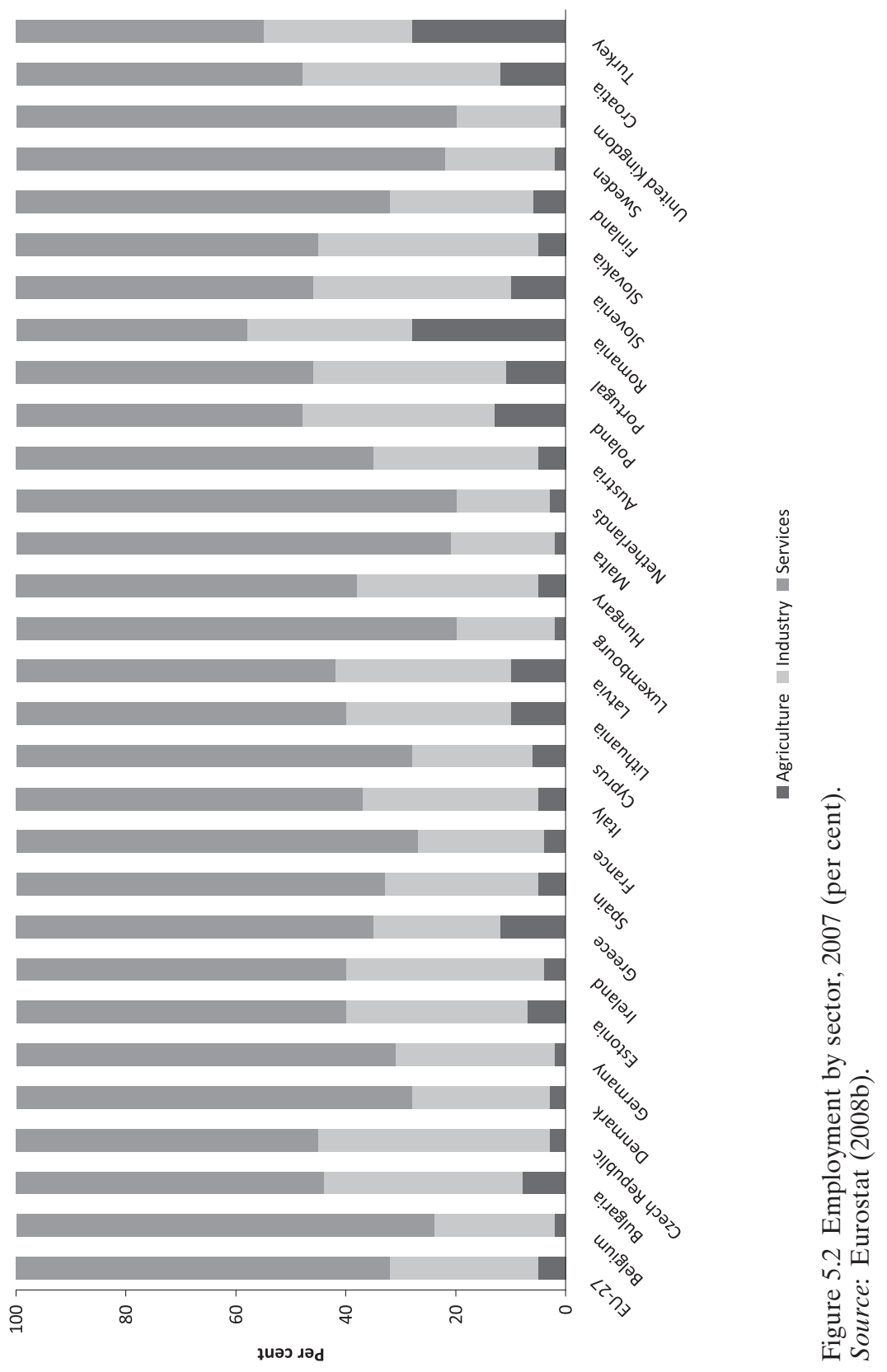


schooling is around 14-16 years, whereas in the CEEC it is about three years lower. This claim was acknowledged by Bhat (2007), who argued that the CEECs' published education statistics greatly overstate the international competitiveness of CEEC workers. Although approximately 12 per cent of those who leave Eastern Europe are in the skilled labour force, most emigrants are working-age labourers with little or no postsecondary education or college students looking to study abroad (Bhat 2007: 36). Thus, one should beware of overemphasizing the skill composition of the population in the CEECs compared with Turkish workers, even though they are well qualified and skilled.

More specifically, diminishing the importance of the chain of migration from Turkey can partly be attributed to labour market conditions in Western Europe. The large demand that prevailed in the 1960s for unskilled labour has not been maintained and only highly skilled and technical workers in the last two decades have benefited from minor job expansion. Many migrants work in the agricultural and construction sectors as well as in some fields of the service sector (for example, catering). This applies especially to seasonal workers, 90 per cent of whom were to be found in the agricultural sector and 4 per cent in the catering and restaurant sector (Kunz 2002: 19). Again, the reason for this is the skills and experiences of these individuals. In some cases, they are not transferable, applying only in their place of origin.

Considerable elements of the skill deficiencies of Turkish workers may be related to the history of the restructuring process. In the 1960s and 1970s, exports and tourism exhibited a generally low share of income. This resulted in limited sources of foreign exchange and, in turn, a reassessment of the migration policies of the Turkish government. To reiterate an important point, the goal of emigration was to alleviate the problem of high unemployment stemming from the transformation process in terms of shifting from agriculture to industrialization. For returning migrants, the skills and experience acquired in West European countries were not usable. Many workers that had returned considered starting their own companies at home, but they abandoned the idea. This was in the context of the existing economic structure in Turkey, which made it impossible for them to start, for instance, an industrial plant of their own. Although efforts have, over the years, been put into support for schemes for the unemployed in line with domestic requirements, it has proved to be impossible to provide new types of assistance because of limited training facilities combined with the traditional (or, to a greater extent, the lack of) employment services. In light of these considerations, Turkey's capacity for sending trained workers to an enlarged EU in the foreseeable future seems debatable. 
Even so, there are some grounds to suggest that skill and education levels are rising in Turkey. One piece of evidence is the dramatic rise in the number of graduates from tertiary-level education in the 20-24 age group relative to older age groups. As Table 5.4 shows, Turkey is ranked higher in terms of the number of students in tertiary education than all the CEECs with the exception of Poland, which has a similar number. In parallel with this rise, 95 new universities have been established in Turkey in recent years - virtually one in each city. Newly graduated youth are desperate for jobs, owing to the high level of unemployment among university graduates in particular. It is clear that new graduates will accelerate the rate of labour migration, given the high level of unemployment in Turkey.

As regards a profile of the characteristics of the anticipated migration from the CEECs, the workers are not all employed in occupations that fully reflect their education levels. The Accession Monitoring Report in the United Kingdom (UK Border Agency 2008) concluded that the majority of workers from the CEEC-8 were in the 25-34 age range. There were both highly educated and semi-skilled migrants in the UK, Swedish and Irish labour markets. Dobson and Sennikova (2007) argue that labour flows from the CEECs are not substantially combating the longstanding skill shortage problem. Instead, UK employers are, for instance, using CEEC labour to fill shortages in low-paid and unskilled jobs. With unemployment rising to 5.6 per cent overall, and at 11.0 per cent for 16-24 year olds, the UK labour market is clearly not functioning efficiently (Dobson and Sennikova 2007: 132). In contrast, there is already evidence that CEEC-10 nationals positively contribute in all member states to overall labour market performance by alleviating labour shortages in sectors and occupations with high labour demand that cannot be met by national workers alone (European Commission 2008c: 2). A study published by the Ernst and Young Item Club in 2007 stated that workers from the CEECs served as an "elixir" for the UK economy, contributing some US\$5 billion to UK gross domestic product (GDP). The main conclusion from the economic analysis of the migration impact by Brücker (2007) is that there exist substantial economic gains from migration within the enlarged EU, but that these gains are not - or at least not sufficiently - being exploited. The transitional periods prevent the migration potential from being fully realized, particularly in the case of the accession of Bulgaria and Romania (Brücker 2007: 23). One may still assume that workers from the CEECs are valuable for European labour markets.

Other studies confirm that the majority of CEEC workers are working in low-skilled jobs and they are likely to be over-skilled for the job they 
do. As Bhat pointed out in 2007, since Latvia's accession to the EU about 60,000 able-bodied working-age Latvians had left their homeland for better opportunities, many becoming mushroom pickers in Ireland or labourers in the UK. Although many were skilled professionals at home, they had the chance to receive higher wages abroad doing work requiring much less skill. As a result, Latvians have left their homeland in droves (Bhat 2007: 35). By contrast, studies point to the recruitment difficulties of Turkish workers who lack specific skills. A report from Migration News in 2007 indicated that Turkish immigrants in Europe were likely to underperform in school and in the labour market. Accordingly, 41 per cent of German people aged 20-26 were students in 2005, 43 per cent were employed and 16 per cent were economically inactive, while the figures for Turks in the same age group were 24 per cent, 37 per cent and 38 per cent, respectively. In the short run, although familiarity with the appropriate pools of skill may be the reason many employers in the EU-15 countries have expressed a preference for CEEC workers, they may become too expensive to employ. As regards future East-West migration, it appears that their high education levels will be twice as likely to be the reason for their immobility. For Turkey, this factor is not very influential in determining the migration potential because many will not possess the skills to find a job in the EU member states.

It is sometimes the case that the citizens of a country prefer to migrate to the country offering the highest wages. According to Boeri and Brücker (2000), enlargement would not significantly affect wages and employment in the EU. They assumed that wage differences between the EU-15 and the candidate countries would remain even after their accession, since trade and capital movements were most unlikely to equalize factor prices. The wage gap is in fact a key determinant in any labour migration forecast. In order to make reliable assumptions, the minimum wage level should be considered, together with purchasing power parities.

The level of the minimum wage in 2007 is summarized in Table 5.5. This shows that the minimum wage in Turkey was well above that in the CEECs, but much lower than in the EU-15. This is with the exception of Slovenia, whose minimum wage was the highest among the CEECs. The gap between the CEECs and the EU-15 countries is also significant, with the exception of Slovenia. It is highly likely that enlargement will lead to a new inflow of immigrants attracted by substantially higher wages in the EU-15. It is plausible to assume that the effect of the minimum wage on Turkish labour migration is limited, and European enterprises will be reluctant to employ Turkish workers. Quite simply, employers would incur high labour costs because Turkey's minimum wage level is significantly higher than that the CEECs. 


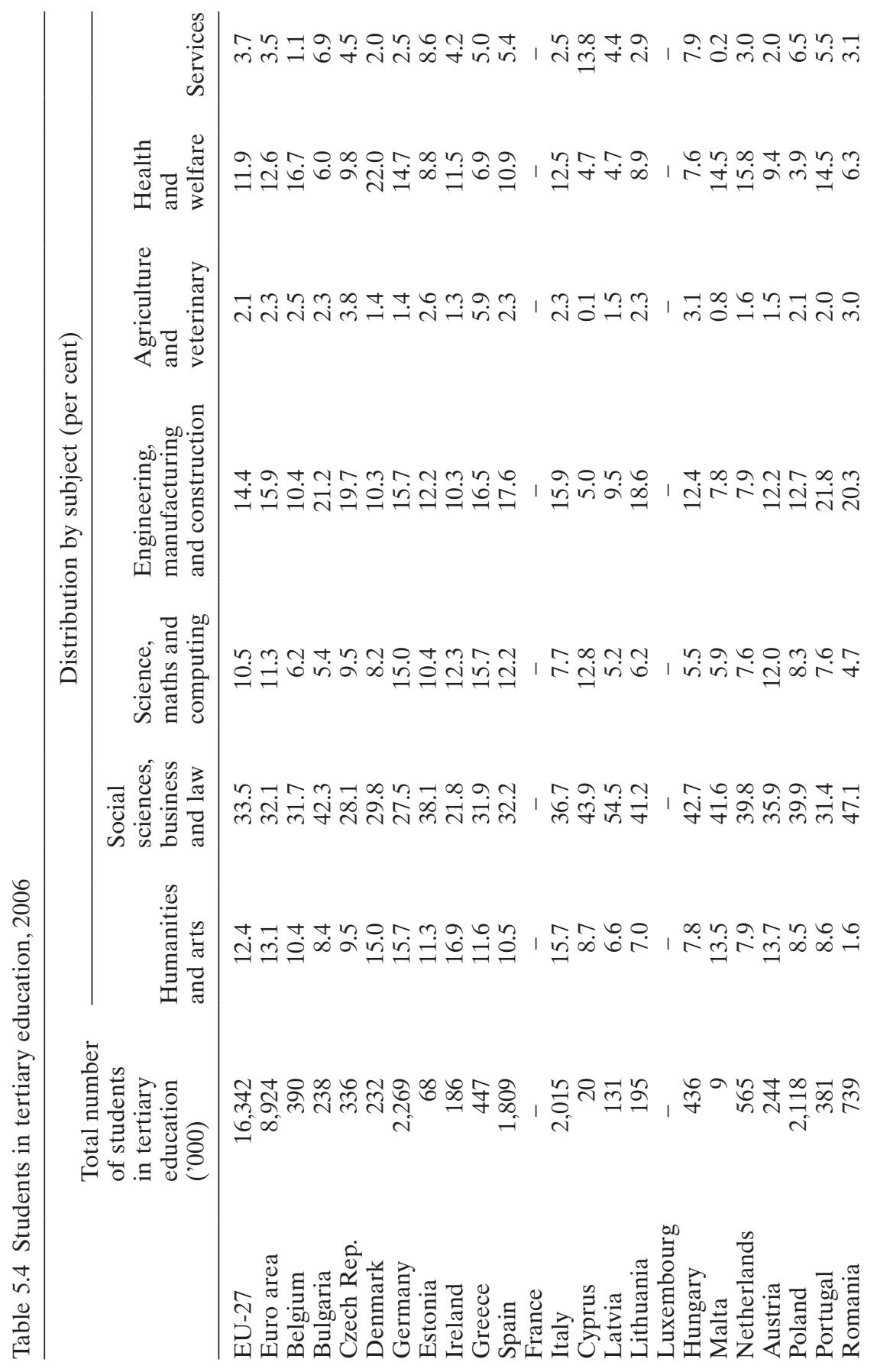




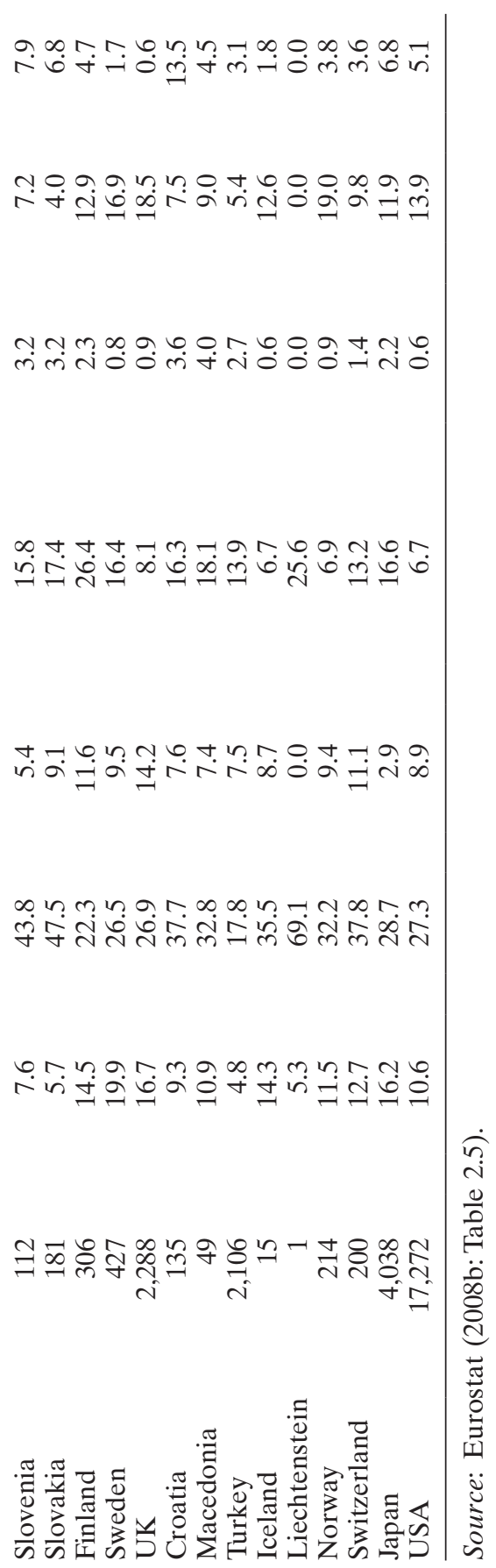


Table 5.5 The minimum wage in the EU-27 and Turkey, 2002-2007 (€)

\begin{tabular}{|c|c|c|c|c|c|c|}
\hline & 2002 & 2003 & 2004 & 2005 & 2006 & 2007 \\
\hline Belgium & 1,163 & 1,163 & 1,186 & 1,210 & 1,234 & 1,259 \\
\hline Bulgaria & 51 & 56 & 61 & 77 & 82 & 92 \\
\hline Czech Republic & - & - & - & - & - & - \\
\hline Denmark & - & - & - & - & - & - \\
\hline Germany & - & - & - & - & - & - \\
\hline Estonia & 118 & 138 & 159 & 172 & 192 & 230 \\
\hline Ireland & 1,009 & 1,073 & 1,173 & 1,183 & 1,293 & 1,462 \\
\hline Greece & 552 & 605 & 631 & 668 & 668 & 658 \\
\hline Spain & 516 & 526 & 537 & 599 & 631 & 666 \\
\hline France & 1,126 & 1,154 & 1,173 & 1,197 & 1,218 & 1,280 \\
\hline Italy & - & - & - & - & - & - \\
\hline Cyprus & - & - & - & - & - & - \\
\hline Latvia & 107 & 116 & 121 & 116 & 129 & 122 \\
\hline Lithuania & 120 & 120 & 125 & 145 & 159 & 203 \\
\hline Luxembourg & 1,290 & 1,369 & 1,403 & 1,467 & 1,503 & 1,570 \\
\hline Hungary & 202 & 212 & 189 & 232 & 247 & 262 \\
\hline Malta & 552 & 534 & 542 & 557 & 580 & 585 \\
\hline Netherlands & 1,207 & 1,249 & 1,265 & 1,265 & 1,273 & 1,317 \\
\hline Austria & - & - & - & - & - & - \\
\hline Poland & 212 & 201 & 177 & 205 & 234 & 246 \\
\hline Portugal & 406 & 416 & 426 & 437 & 450 & 470 \\
\hline Romania & 62 & 73 & 69 & 72 & 90 & 121 \\
\hline Slovenia & - & 451 & 471 & 490 & 512 & 522 \\
\hline Slovakia & 114 & 133 & 148 & 167 & 183 & 217 \\
\hline Finland & - & - & - & - & - & - \\
\hline Sweden & - & - & - & - & - & - \\
\hline UK & 1,118 & 1,106 & 1,083 & 1,197 & 1,269 & 1,356 \\
\hline Turkey & - & 189 & 240 & 240 & 331 & 330 \\
\hline USA & 1,001 & 877 & 727 & 666 & 753 & 665 \\
\hline
\end{tabular}

Source: Eurostat (2008f: Table 1.10).

\section{Income gap}

The difference in average GDP per capita between the EU-15 and the CEEC-10 is likely to increase migration pressure. Table 5.6 shows the absolute gap in GDP per capita between Turkey and the CEEC-10. Turkey has generally low GDP per capita income (€10,500 in 2007), although it is similar to Romania's $(€ 10,100)$. The gap is largest in the case of Slovenia $(€ 22,000)$ and smallest in the case of Bulgaria $(€ 9,500)$. For Turkey, GDP per capita was forecast to rise only marginally in 2008-2009. At the same time, differences in GDP per capita are even larger between the EU-15 and the CEEC-10. whose average GDP per capita is 40 per cent of that of the existing member states. As the income level of most of the CEECs is considerably below the EU-15 average, it is easy to see a trend towards an increase in the number of flows from these countries to the EU. For 
Table 5.6 GDP per capita: PPP ( $€$, at current prices)

\begin{tabular}{|c|c|c|c|c|c|c|}
\hline & 2004 & 2005 & 2006 & 2007 & $2008^{a}$ & $2009^{a}$ \\
\hline EU-27 & 21,600 & 22,400 & 23,600 & 24,800 & 25,900 & 26,800 \\
\hline Germany & 25,200 & 25,800 & 26,900 & 28,100 & 28,900 & 30,000 \\
\hline Austria & 27,400 & 28,700 & 29,900 & 31,600 & 32,500 & 33,600 \\
\hline Belgium & 26,100 & 27,100 & 28,200 & 29,300 & 30,000 & 31,000 \\
\hline UK & 26,400 & 26,700 & 27,800 & 28,700 & 29,400 & 30,300 \\
\hline Bulgaria & 7,300 & 7,900 & 8,600 & 9,500 & 10,100 & 11,000 \\
\hline Czech Rep. & 16,300 & 17,100 & 18,400 & 20,200 & 21,300 & 22,800 \\
\hline Denmark & 27,200 & 28,400 & 29,600 & 30,500 & 31,000 & 31,900 \\
\hline Estonia & 12,300 & 14,100 & 16,100 & 17,900 & 18,600 & 19,800 \\
\hline Finland & 25,200 & 25,800 & 27,500 & 29,000 & 30,000 & 31,200 \\
\hline France & 23,800 & 25,200 & 26,300 & 27,600 & 28,100 & 29,000 \\
\hline Cyprus & 19,600 & 20,800 & 21,600 & 23,000 & 23,600 & 24,500 \\
\hline Netherlands & 28,000 & 29,400 & 30,700 & 32,500 & 33,600 & 34,800 \\
\hline Ireland & 30,600 & 32,200 & 34,200 & 36,300 & 36,900 & 38,400 \\
\hline Spain & 21,900 & 23,100 & 24,700 & 26,500 & 27,000 & 27,700 \\
\hline Sweden & 27,000 & 27,700 & 29,300 & 31,300 & 32,200 & 33,400 \\
\hline Italy & 23,100 & 23,600 & 24,300 & 25,200 & 25,500 & 26,100 \\
\hline Lithuania & 9,900 & 11,200 & 12,200 & 14,400 & 15,100 & 15,900 \\
\hline Latvia & 10,900 & 11,900 & 13,200 & 15,000 & 16,100 & 17,100 \\
\hline Luxembourg & 54,700 & 59,200 & 65,700 & 68,500 & 71,000 & 74,400 \\
\hline Bulgaria & 13,700 & 14,400 & 14,300 & 15,700 & 16,200 & 17,100 \\
\hline Malta & 16,600 & 17,400 & 18,100 & 19,100 & 19,700 & 20,500 \\
\hline Poland & 11,000 & 11,500 & 12,300 & 13,300 & 14,100 & 15,200 \\
\hline Portugal & 16,100 & 16,900 & 15,500 & 18,500 & 18,900 & 19,600 \\
\hline Romania & 7,400 & 7,900 & 9,100 & 10,100 & 10,800 & 11,700 \\
\hline Slovakia & 12,400 & 13,600 & 15,000 & 17,000 & 18,300 & 19,900 \\
\hline Slovenia & 18,400 & 19,500 & 20,700 & 22,000 & 23,100 & 24,400 \\
\hline Greece & 20,300 & 21,500 & 22,900 & 24,300 & 26,500 & 26,500 \\
\hline Croatia & 10,700 & 11,300 & 13,300 & 13,900 & 14,600 & 15,700 \\
\hline Macedonia & 5,800 & 6,200 & 6,700 & 7,300 & 7,700 & 8,300 \\
\hline Turkey & 8,100 & 8,800 & 9,700 & 10,500 & 10,900 & 11,500 \\
\hline
\end{tabular}

Source: Eurostat (2008f).

${ }^{a}$ Forecast.

some countries, notably Slovenia and the Czech Republic, income levels relative to the EU-15 are higher, suggesting that their role as potential sending countries of economic migrants will be minimal.

However, medium- to long-term considerations suggest reduced labour migration incentives as the CEEC-10 catches up economically. When a catching-up economy is successful in creating the conditions for broadbased economic growth and job creation, labour migration pressure is likely to be reduced, even when larger wage differentials persist (Heinz and Ward-Warmedinger 2006: 30). This convergence is still to be achieved for the CEECs, although they are well ahead of Turkey in per capita income levels. The enlarged EU will probably face the prospect of having 
to deal with considerable disparities over a long period of time. Even the front runner CEECs are 20 years away from average EU incomes. For Turkey, catching-up will take significantly longer, possibly as much as 40 years.

Much attention has been paid to the potential financial costs of Turkish accession. In fact, GDP per capita is a good indicator of how much a country has to contribute to the EU budget. An alternative way of calculating the budgetary effects for the new member states is to estimate the contribution per capita in the EU-15 based on income per capita and to estimate the receipts per capita based on per capita Council votes and the level of development in a broader sense, as indicated by eligibility for Cohesion Fund status (Baldwin et al. 1997: 75). Since the EU-15 member states will be relatively large net contributors after the enlargement under the present rules, they will have an incentive to change the rules in order to reduce the value of the contribution from the rich to the poor member states (Flam 2004: 192). Even with rapid growth, Turkey will be a clear candidate for substantial structural and regional assistance. Undoubtedly, the new member states have the voting power to block EU funds if they feel disadvantaged, as evidenced in the Southern enlargement. Restricting these funds, which are seen as policy tools for decreasing structural and the long-term unemployment, particularly in rural areas in Turkey, would lead to substantial migration flows.

\section{Social networks and geographical distance}

Other important pull factors are the networks of migrants in the EU-15 and the geographical distances between the member states. Although economic stability and specific labour market conditions are considered to be the drivers of international migration flows, the case of the CEECs points to the importance of geographical distance and social networks in the EU countries. The EU member states are the preferred destinations for the CEECs.

That said, the current East-West migration is the result of the collapse of communist regimes in Eastern Europe in 1989, leading to large diasporas of CEEC immigrants in several West European countries (notably Austria, Germany, Belgium, France and the United Kingdom). During the Cold War, East-West migration continued, but on a limited scale, thereby increasing the immigrant populations abroad. Migration especially occurred in the first few years after the collapse of the communist structures. Since then, the traditional migration flows and the established communities in the West have introduced a new pattern for labour movement. Although some migrants have already returned, a significant proportion is still abroad. 
The existence of networks as one of the central elements of the economic determinants of migration reinforces movement, for example by Turks first to Germany and then to France. Historically, the desire of Turks to migrate to France goes back to the Ottoman legacy, despite the geographical distance. This is in contrast to other European countries, where labour migration came into existence in the 1950s and 1960s. It has been held that the Ottoman Turks living in France were kept in concentration camps in order to prevent them from spying during the First World War. The guest worker phase in the 1950s saw a spatial evolution of the migration pattern towards Western Europe, and Turkey became a major supply country over long distances. Since the standstill of 1973, the reasons for the attachment of Turks to France are family unification, waves of asylum and naturalization through marriage. It is estimated that 500,000 Turkish nationals are living in France, constituting the thirdlargest community after Moroccans and Algerians.

Hence, it can be argued that analysis of East-West migration should not concentrate exclusively on the CEECs, given Turkey's extensive previous links with West European countries. At the end of the guest worker programme, work-related migration was directed to the EC countries under the family unification scheme. Presumably this migration pattern substituted for traditional migration. Thus, networks attracted migrants mainly for labour market opportunities. At the same time, they have signalled labour market saturation or possible native social and ethnic experiences deterring Turkish migration flows over the years.

With regard to the size of the migration potential following the enlargement, the receiving countries have experienced much less dramatic flows. That is, the introduction of the free movement of labour in several EU member states has not influenced the preference of the CEECs. It may be fair to say that these possible networks are not institutionalized nor do they play a significant role in attracting labour from the CEECs. Contrary to this claim, Boeri and Brücker (2000) stressed the importance of networks within East-West migration and suggested that Austria and Germany could expect to receive a large share of labour migration from the East. Some CEECs with low living standards have a common border with highly industrialized countries. According to the 2002 Human Development Report (UNDP 2002), the average unemployment rate in the western part of Central Europe was well above the national averages in the individual countries. For this reason, labour migration flows from the regions bordering on Germany and Austria constituted a significant share of total emigration because of strong labour market distortions. Both countries already have the largest contingent of CEEC residents -1.1 per cent and 0.5 per cent respectively of the total population (Putten 
Table 5.7 The number of Turkish workers in foreign countries, 2006

\begin{tabular}{lr}
\hline Western Europe & 826,934 \\
Azerbaijan, Kazakhstan, Turkmenistan, Uzbekistan, Tajikistan and & 23,609 \\
Kyrgyzstan & \\
Middle East and African countries & 132,794 \\
Australia & 30,250 \\
United States and Canada & 143,000 \\
Russian Federation, Japan, Afghanistan and other countries & 48,919 \\
Total & $1,205,506$
\end{tabular}

Source: Turkish Ministry of Employment and Social Security, Annual Progress Report, 2006.

2002: 10). In both cases, geographical proximity seems to play a role in decreasing the costs of migration.

A quick glance at the migration history of Turkey clearly shows that the route changed radically in the early 1970s. After the standstill of 1973, the Turks migrated to the East rather than the West. Table 5.7 summarizes the distribution of the stock of Turkish migrants in foreign countries in 2006. Understandably, traditional overseas immigration countries such as Switzerland, the United States, Australia and New Zealand were generally preferred by Turkish migrants. However, the proportion of Turkish workers who emigrated to the West is still significant, reaching nearly 68 per cent in 2006. The top regions were the United States and Canada, the Middle East, and the Russian Federation, indicating that growing shares were taken by international migration movements. In particular, Russia has increasingly become a preferred destination in recent years, perhaps even more so than Germany where the Turks traditionally formed a large part of labour movements. According to statistics from the Turkish Employment Institution (2008), 12,891 Turkish nationals migrated to Russia in 2008 for employment purposes. Iraq and Saudi Arabia constituted the second group of preferred destination countries. Social and economic upheaval in rural areas, as well as the current economic crisis, have forced people to search for a new direction (Manço 2008: 2). In this vein, owing to the globalization of the world economy, Turkish workers have immigrated not only to the West but to the East as well.

If distance is seen as a crucial factor in traditional migration, this emphasis on its positive role in flows for the nationals of the CEECs and the effectiveness of maintaining links with their home country should not be undervalued. A fairly large number of people from the CEECs are already resident in the EU. Polish and Romanian groups are particularly successful in migrating to the West and have established large communities. Diaspora communities often play a role in fostering migration by providing accommodation, help with job searches and insider knowledge 
Table 5.8 Expected destinations of Turkish migrants in the EU, based on numbers in EU countries in 1999

\begin{tabular}{lcc}
\hline & No. ('000) & Per cent \\
\hline Total & 2,665 & 100 \\
Germany & 2,025 & 76 \\
France & 213 & 8 \\
UK & 53 & 2 \\
Italy & 27 & 1 \\
Netherlands & 107 & 4 \\
Rest of Europe & 240 & 9 \\
\hline
\end{tabular}

Sources: OECD (2001) for data on current destinations and Lejour et al. (2004) for calculations of expected destinations of Turkish migrants.

about how processes work. In particular, Poland is a major source of migrants because the vast majority of its emigrants live in the EU-15 and it has a relatively high population size. Existing entities (for example, Polish churches and social clubs in the United Kingdom) act as labour exchanges and advice centres, which intensifies existing movements. The close ties between the Polish community and the United Kingdom were established before the Second World War. This explains why Polish workers have an advantage in the post-2004 migration flows. In the future, Turkey may have the same experiences, since its ethnic minorities are leaving Turkey, especially for the Caucasus region.

Long before Turks migrated to the West, networks' effects were also applicable, possibly in concentrations of Turkish nationals in Germany. Migrants from Turkey are not expected to be distributed proportionally across the EU-15 countries. Table 5.8 shows how future migration flows will be distributed across EU countries. To put it another way, the choice of Germany is dictated by social networks. Germany hosts the largest proportion of Turkish immigrants (76 per cent). This implies that over 2 million Turks will migrate to Germany. France ( 8 per cent) and the Netherlands (4 per cent) also host a relatively large share of Turks and are expected to receive 213,000 and 107,000 migrants, respectively. Networks appear to be self-regulating and will continue to be active. This means that a considerable number of potential workers will continue to move even if restrictive immigration policies (for example, transitional arrangements) are abolished.

Historically, during the introduction of the free movement of workers in the previous enlargements of the EU, the labour-sending countries did not share an extended frontier with the EU immigration countries that would enable short-distance and frontier migration. Taking into account the Southern experience, however, it might be a mistake to perceive distance as being a crucial factor; the size of the flows is low, despite the 
geographical proximity of the CEECs and the EU. Analysts from the Central Statistical Office in Warsaw have claimed that, even though social ties with the EU-15 countries remained powerful, the first waves of flows since the 2004 enlargement turned out to be low in the border regions. A decreasing number of departures was observed in Poland for the period 2000-2004, but this declining trend has weakened with EU accession. As far as mobility by border is concerned, the overall decrease in departures occurred mainly on the southern and the sea borders. On the other borders, an increase in cross-border mobility of Poles was observed. One may link this increase with the appearance of inexpensive airlines that initiated their activities in Poland right after the EU enlargement. Therefore, a big increase in the number of crossings by air may be an indicator of a growing short-term or long-term labour migration by Poles (Iglicka 2002: 4). It appears that the introduction of free movement will provide a special stimulus to this trend.

A feeling of belonging and communality has been associated with this region, and a sense of "geographical identity" has patently been an important influence in shaping cross-border mobility. According to Eurostat data for 2000 (CEC 2001c), the stock of Estonian citizens living in Finland represented more than 60 per cent of Estonians living in the EU-15. Slovakia is, strictly speaking, much closer geographically to the EU core. Slovakians therefore have an advantage in terms of lower transport costs to the European labour markets. This is principally linked to a significant increase in crossings in the border regions. For instance, crossings from Slovakia (which are similar to movement from Germany) consist mainly of one-day shopping trips. The largest numbers of cheap flights are to the countries that have opened their labour markets to Eastern Europeans. As far as Turkey's geographical distance is concerned, there are apparently no tendencies towards similar movements. Unlike the border countries of Eastern Europe, flights by Turkish airlines are relatively expensive. A low level of cross-border mobility for Turkey will be highly likely, which is explained by its relative distance from West European countries.

It may be concluded that, owing to close geographical proximity, CEEC migrants will prefer to move to the EU region rather than anywhere else. Conversely, geographical distance will impair labour movement from Turkey, thereby acting as a deterrent for the social and cultural integration of Turkish migrants into Western society. Reports from the World Tourism Organization (1999) indicate increasing numbers of short trips by Turks, with the main destinations of day visits to European countries being Italy, Greece, Germany, France and the United Kingdom. As Table 5.9 shows, daily commuting by Turks to distant countries seems to be strongly deterred, and the United Kingdom and the United States were, in particular, less preferred destination countries. The Middle East is a strongly 
Table 5.9 Preferred destination countries of Turks for short trips (business or leisure)

\begin{tabular}{lcccc}
\hline Country & 1994 & 1998 & 2000 & 2003 \\
\hline Iran & 6,313 & 160,959 & - & $180,000^{a}$ \\
Saudi Arabia & - & 150,000 & 174,990 & 177,467 \\
Italy & - & 86,697 & 121,056 & 165,307 \\
Greece & 73,388 & 69,875 & 133,954 & $150,000^{a}$ \\
Russia & 101,047 & 140,157 & 103,400 & 139,252 \\
Germany & 98,858 & 113,135 & 126,926 & 135,252 \\
Jordan & 110,055 & 91,212 & 136,737 & 106,899 \\
France & - & 91,700 & 87,340 & $93,900^{a}$ \\
UK & 52,000 & 75,000 & 78,000 & 92,000 \\
USA & 33,563 & 78,219 & 106,427 & 75,227 \\
\hline
\end{tabular}

Source: World Tourism Organization (1999).

${ }^{a}$ Estimates.

preferred destination for day-trips among Turks, with Iran and Saudi Arabia being ranked top. It is important to note that cultural factors play a greater role in Turks' preferences - their trips to the Middle East are mainly for religious activities (for example, pilgrimage).

It thus appears that Turks' traditional migration pattern consists of mainly short-distance migration or frontier migration and the preferred destination is closely associated with cultural closeness. However, the large number of people who travelled to Western countries during 19942003 should not be underestimated. A significant number of day-trips is observed (although the figures are based on estimates for Greece and France). As far as the cost of migration is concerned, it is likely that long distances will act against the migration potential from Turkey.

\section{Social provision systems}

The well-developed social provision systems, which include pensions, education and healthcare, for citizens in Western Europe constitute an important pull factor. The potential consequences of the new freedom of movement have fuelled the debate over whether migrants from the new members will swamp labour markets and strain welfare systems in the EU member states. Theoretically, labour migration results from rational choices oriented to a certain system of values. A stable social context exists when people's needs are at least minimally satisfied. If those minimal needs are not fulfilled within one social context, some people will migrate to a new social context where they will find better conditions to meet their needs or will expect to suffer relatively less.

Before the 2004 enlargement, strong concerns in the EU-15 about the issue of welfare state benefits provoked much debate. This was because 
eligibility for employment support was often highly restricted in most CEECs. These countries face a daunting challenge of crippling social security systems. They also suffer from a fall in social contributions, which is especially important in the context of demographic tensions. Reduced social security with fewer young people and more pensioners will instigate a vicious circle, and thus the lower level of social protection will motivate even more young people to move abroad.

The situation regarding the social security system seems no less severe in Turkey. The state in Turkey is perceived as having a weak capacity for providing adequate social services, which have not occupied a central place within the role of the state. Instead, preserving the unitary nature of the state, national security and public order has been seen as being of primary importance. As a result, the state machinery relating to national security policies has been over-institutionalized and overdeveloped, while that relating to the provision of welfare services has remained weak and underdeveloped (Sözen and Shaw 2003: 111). However, some progress has been achieved. The most significant pillar of social security reforms, the Social Insurance and General Health Insurance Law, entered into force in October 2008. The Social Security Institution has been strengthening its capacity to deliver decentralized one-stop services for disadvantaged people. Nevertheless, there has been no development as regards new legislation on social assistance and services (CEC 2008g: $6)$.

The existence of social security benefits in the EU-15 countries has crucial consequences for potential labour migration. It ensures that an unsuccessful search for employment does not result in no income. The welfare state in the EU-15 constitutes a part of the higher standard of living that attracts migrants. Its benefits contribute to the ability of workers to trigger the labour market shortages that are the immediate condition that both stimulates and justifies migration (Freeman 1986: 57).

The risk of poverty (for people aged 65 years and over) in the CEECs and Turkey is illustrated in Figure 5.3 against the background of the EU's social provision system in 2005. For Turkey, the risk of poverty was 22 per cent. Across the new member states, the poverty rate was less than 8 per cent in the Czech Republic, Hungary, Slovakia and Poland, but it was 16-21 per cent in Latvia, Estonia, Slovenia, Lithuania and Bulgaria. A considerably higher poverty rate was evident in the EU-15, in particular in Ireland, Spain, Greece, Portugal and the United Kingdom, ranging from 31 per cent to 38 per cent. In the rest of the EU-15, this figure ranged from 5 per cent to 23 per cent. In comparison with the EU-15, the risk of poverty is, in the main, higher in most CEECs, where people thus face the risk of social exclusion. For Turkey, differences in the poverty rate may change over time when current social security reforms speed 


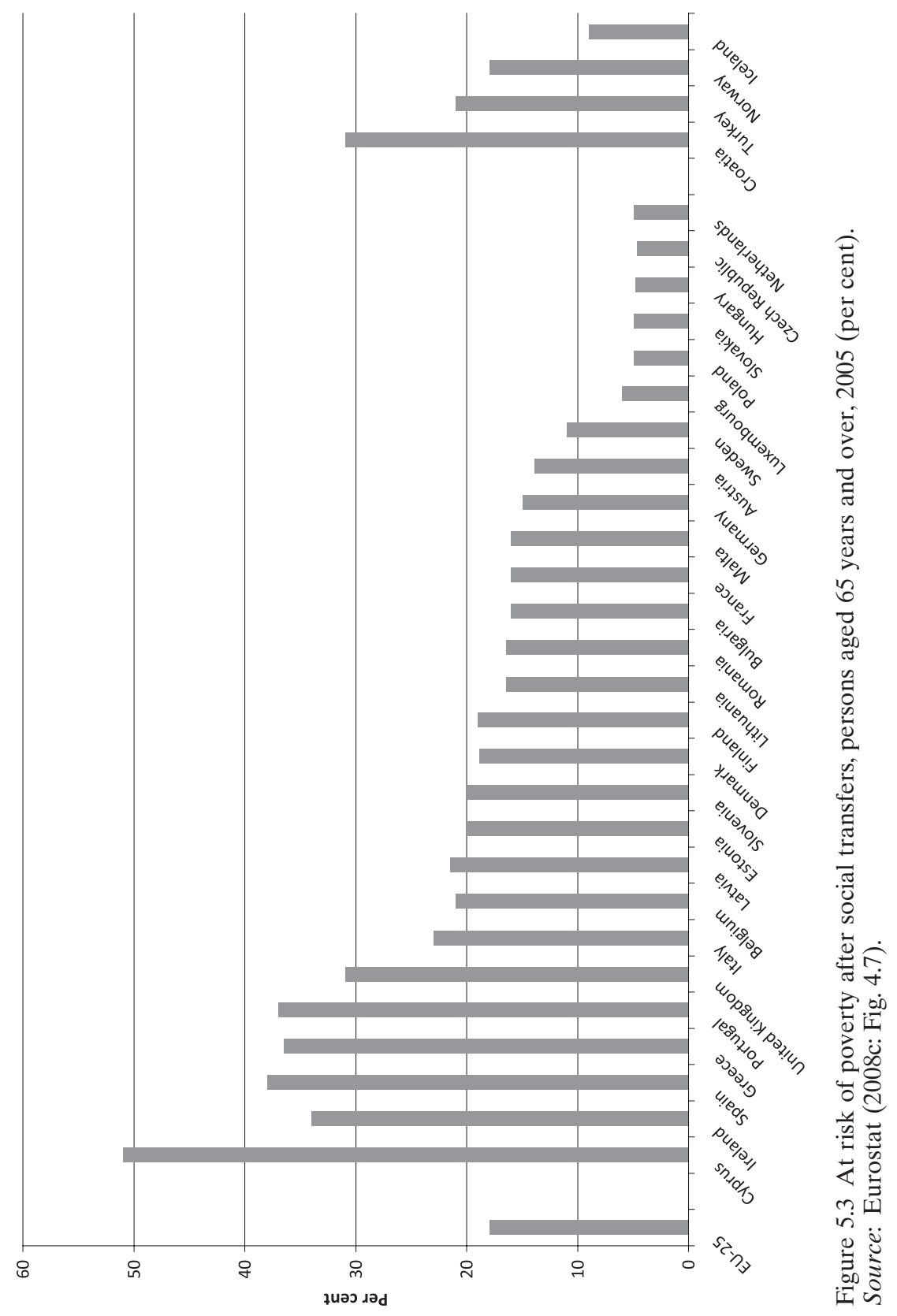


up within the accession partnership framework. Meanwhile, these differences will continue to constitute a special stimulus to migration flows from the CEECs for some time.

Several studies refer to skill level or educational attainment as being positively related to migration. Those that are left behind in the lagging regions are predominantly low-skilled workers with the worst employment prospects. This suggests that lack of education is an important barrier to mobility. As such, investments in education and training may facilitate the adjustment process, as workers acquire the necessary skills to find a job in more dynamic regions and to move away from lagging parts of the country (Paci et al. 2007: 61).

Figure 5.4 shows the difference in investment in formal schooling between the CEECs and Turkey. Public expenditure on education in the EU-27 was 5.1 per cent of GDP in 2004. Among the CEEC-10, the highest public spending on education was observed in Slovenia ( 7.0 per cent), followed by Hungary and Poland (both with 5.7 per cent), Lithuania (5.4 per cent) and Estonia (5.1 per cent). Other new members reported that public expenditure on education accounted for between 4 per cent and 5 per cent of their GDP. In the case of Romania, its proportion of public expenditure on education fell below 4 per cent of GDP. Turkey can be classified as a lower-spending country, spending 4.0 per cent of GDP on public education. Limits on education expenditure in Turkey contrast with government policy, since there has been an increasing number of higher education institutions each year without much consideration given to their maintenance. At the same time, there is a considerable expenditure gap between the EU-15 and the CEECs, which is critically important for future migration flows.

Figures 5.5 and 5.6 further illustrate this. The figures for both the number of hospital beds and the number of physicians in the CEECs were below the average of the EU-15 but above Turkey in 2005. Additionally, a Commission report in 2008 (CEC 2008h) noted that healthcare expenditure in the EU-27 exceeded 8 per cent of GDP in France, the Netherlands and Sweden, whereas it was less than 4 per cent in Poland, Lithuania and Latvia. In Turkey, health expenditure was only 3.1 per cent of GDP in 2006. Turkey clearly lags behind in all these indicators, which gives a special impetus to migration flows. Moreover, in principle, the large variation in these health indicators between the EU-15 and the CEECs creates another motive for mobility.

With a proportion of healthcare expenditure that remained the lowest by comparison, Turkey's public health situation is generally considered unsatisfactory. In recent years, there has been some progress in the area of health and safety at work, where Turkey has attained a good degree of alignment with the acquis communautaire. Nevertheless, the situation in 


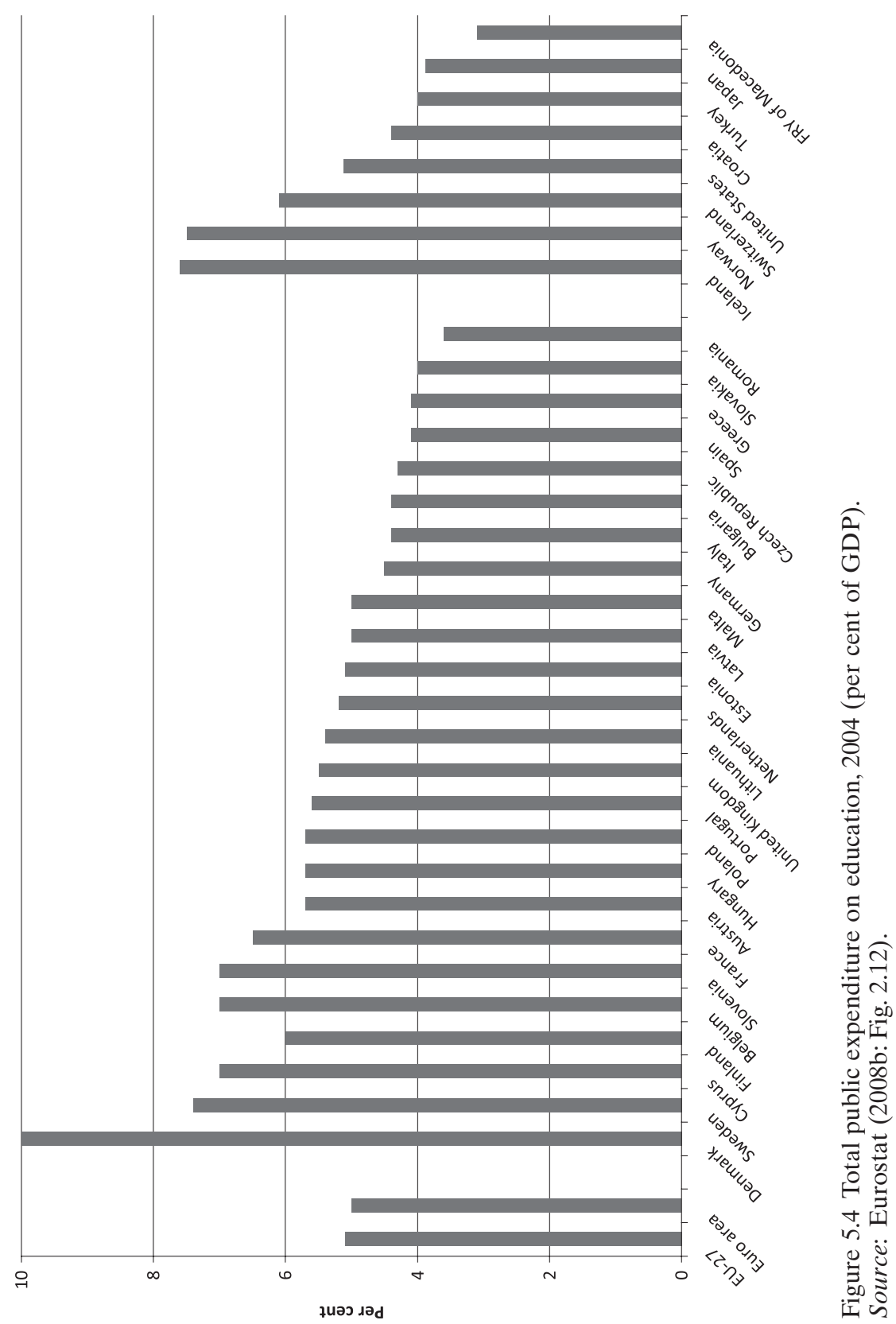




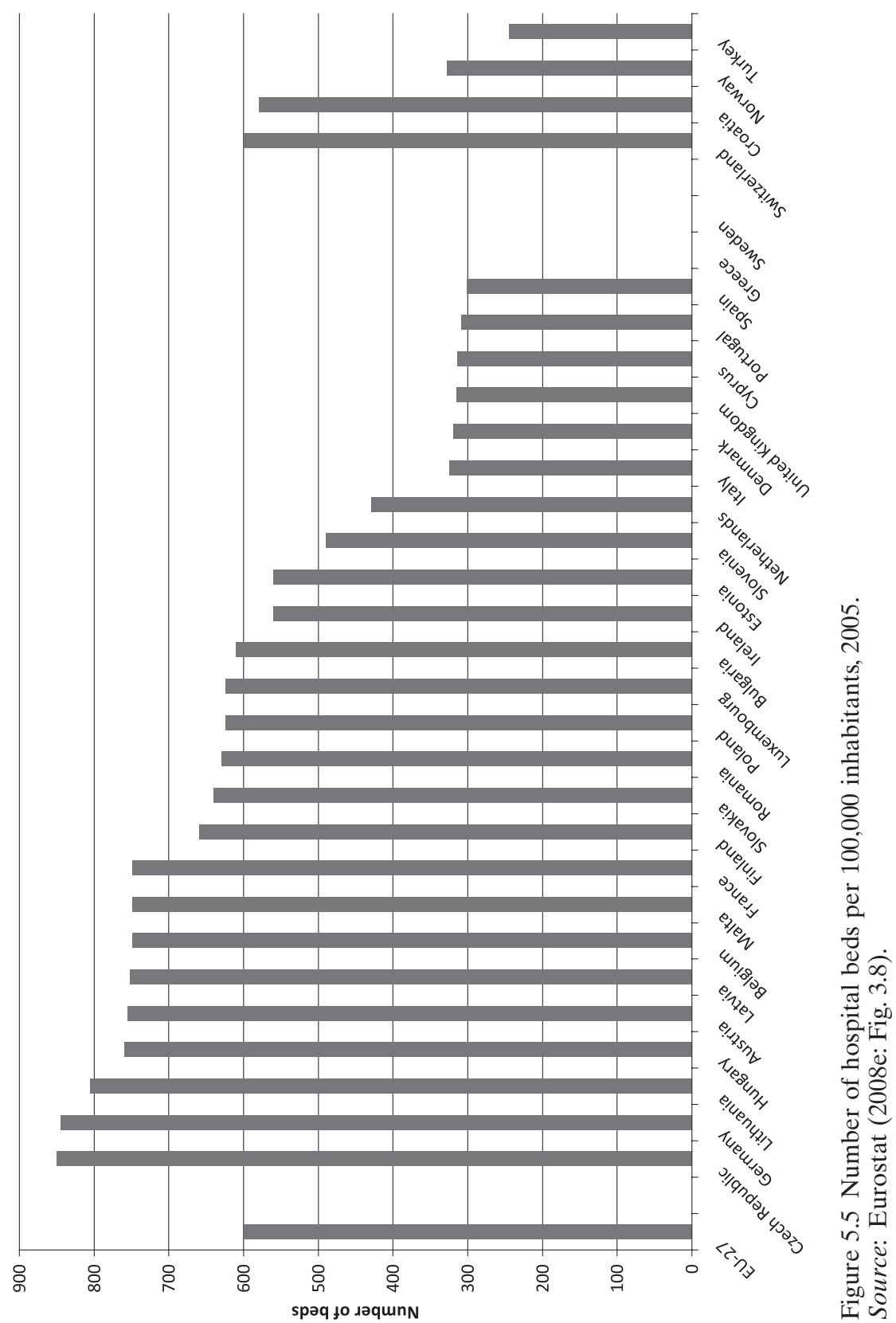




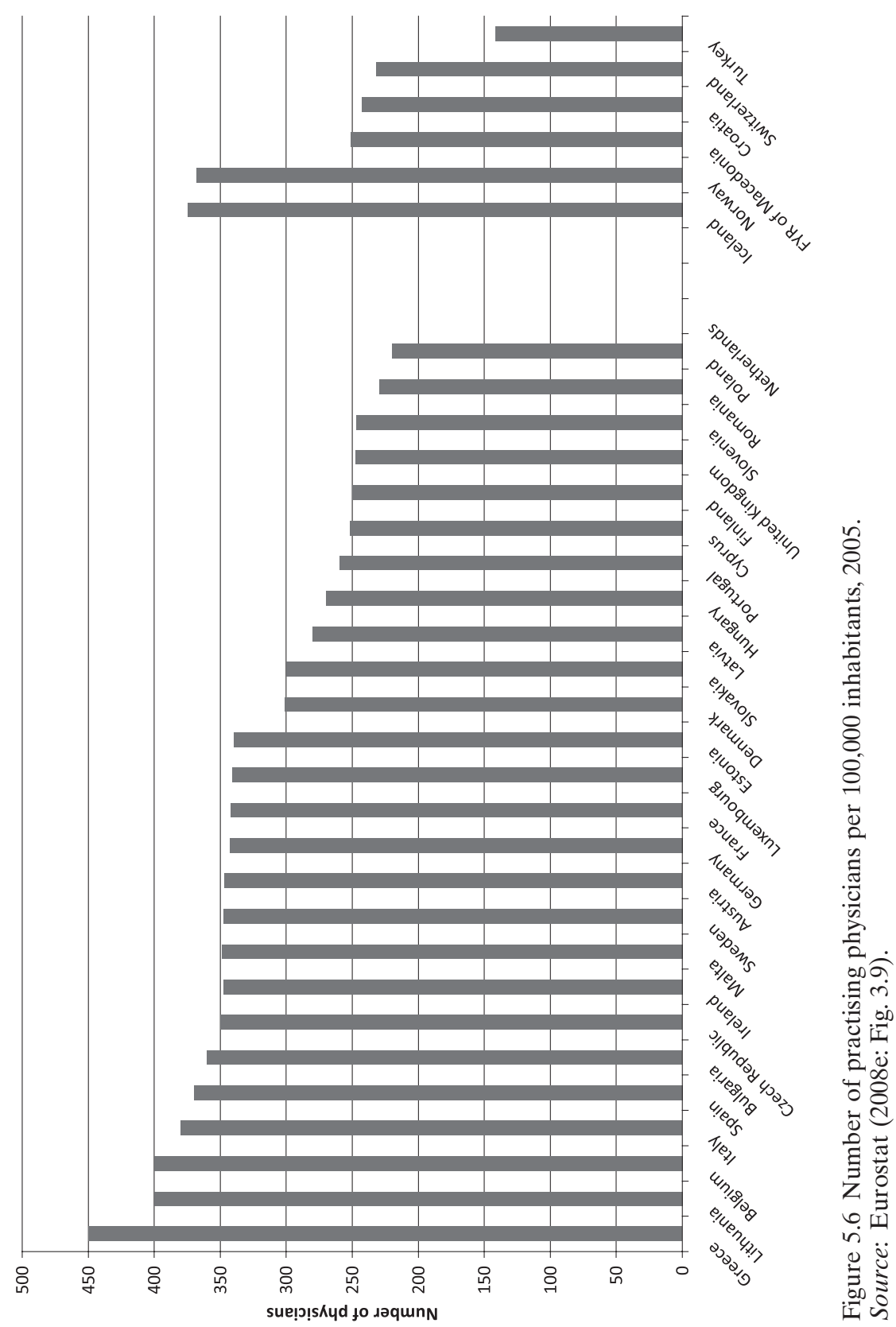


Turkey is not promising in terms of sustainable long-term development policies. Further alignment with EU standards is essential to improving the general health of the population.

It is commonly claimed that the migration of labour is a threat to the welfare state because of the very existence of an inequality in benefits between the CEECs and the EU-15. The Eastern enlargement may provide migrants with automatic access to social security benefits. At the moment, however, migrants' access to the social security systems in the United Kingdom and Ireland is restricted. Some CEEC workers are vulnerable to tough living conditions in the EU-15. For instance, when they arrive in the United Kingdom with little money, they have a very hard time. Many end up living on the streets, especially in London, and are mostly dependent on charity-run soup kitchens for food and are unable to return home (Dobson and Sennikova 2007: 130). For this reason, it is likely that many CEEC workers will limit the duration of their stay to the short term, even though the tendency to migrate is greater because of the higher social standards in the EU-15.

The social provisions in the EU-15 may have important consequences for labour movement, but some studies reject the claim that workers from the new accession countries constitute a real burden on social services. A European Commission Report in 2005 on initial statistics from the United Kingdom, Ireland and Sweden showed that the labour flow effects in a situation of no restrictions have not been as dramatic as many feared, and "workers from the new member states have not yet proven to be a 'drain' on welfare benefits systems". In particular, there were lowerthan-expected labour flows to Sweden, "where workers from the new member states boosted the active working population by a mere $0.07 \%$ between May and December 2004.... Those predicting an 'invasion of Polish plumbers' were also way off the mark" (European Report 2005: 2). In spite of this, it is still reasonable to argue that the extent to which traditional systems of social protection are inadequate (with a minimum wage below the level necessary to support a single person) will have potentially important implications for the free movement of labour in the CEECs.

Generally, migration flows from the CEEC-10 countries have already been posing some threats or challenges to the social provisions of the EU-15. Migrants appear to have a strong desire to continue to stay in the EU countries in order to be entitled to education, pensions and healthcare. This is causing downward pressure on social security standards. The EU's response could actually constitute an attempt to develop some form of collective action that aims to maintain the level of social protection via restricting labour migration. Indeed, concerns about unrestricted access to welfare lay behind the decisions of a number of EU members in early 
2004 (for example Sweden) to impose controls on migrants from the accession states, despite the earlier promise of full freedom of movement of labour. Similarly, Germany's Ifo Economic Institute has argued that this process could take 10 years and has suggested that the correct policy is to allow free movement of labour but to restrict access to some social security benefits (see Wagstyl 2004: 2).

Historically, under similar conditions, the countries of the European Community had already tried to integrate often poorly educated migrant workers from rural areas in Turkey into their labour market. During the 1960s, European countries (mainly Germany, with above-average social security expenditure) encouraged the movement of Turkish workers. Taking into account the evolution of Turkey's migration to the West, Turks may still continue to look upon the EU as a "relief centre" owing to its poverty rate.

In the meantime, educational provision in the EU continues to attract people from the CEECs. This is particularly true for students, who may seek to start or continue their education in the EU. In Poland, education is the key determinant of migration to the West: students account for a significant share of migration. It should also be noted that migration to the West for educational purposes has reached a substantial level in Turkey, as a result of active measures such as the ERASMUS programme and, to a lesser degree, programmes for staff exchange between Turkey and some member states. This will probably help to increase general acceptance of higher migration rates from Turkey regardless of the right to free movement.

\section{The factors rebutting migration fears}

\section{The effects of trade liberalization and EU funds}

In the late 1990s, when the CEECs' aspirations to EU membership became obvious, some trends started to develop, including a massive inflow of foreign direct investment (FDI), increasing international trade and payments from the structural and cohesion funds assigned by the EU. These trends seem to have generated significant economic growth, with a consequent improvement in the employment situation, while pushing convergence with the existing member states. Since one of the main motivations for migration is the search for work, the improvement of the economic situation in the CEECs has already begun to relieve the migration pressure.

In assessing the growth and convergence prospects of the CEECs, Boeri and Brücker (2000) estimated that their accession to the EU would double FDI and considerably increase capital inflows. FDI in labourintensive industries would be particularly impressive (Boeri and Brücker 
2000: 35). Boeri and Brücker's predictions have been borne out by the facts. Historically, integration of the CEECs into trade links with the EU has been significant since the beginning of the transition in 1989. The share of exports to the EU in the total exports of the CEEC-10 was 60.2 per cent in 1995 , increasing to 66.0 per cent in 2003 , and the corresponding values for imports were 61.2 per cent and 63.3 per cent, respectively. This level of trade integration with the EU market is already higher than that in the majority of the EU-15 (Crespo and Fontoura 2007: 611). The main reason for the increased trade can be attributed to the trade agreements signed between the EU and the CEECs in the early 1990s, which gave these countries preferential access to EU markets. The CEECs have experienced substantial increases in the volume of trade with the EU as a result of large investments by firms from Western Europe and elsewhere.

The inflow of foreign investments (see Figure 5.7) by mainly European investors can be seen as a sign of satisfaction with the transition process of the CEECs. For Turkey, the starting point is one of low trade volumes. According to Turkey's State Planning Organization (2008), exports to the EU accounted for only 15-16 per cent of Turkey's GDP, compared with over 20 per cent for Poland. With this sort of trade structure, a relatively small share of all FDI is invested by European companies. No significant effects from the customs union should be expected on the trade pattern in industrial goods. Trade in agricultural goods will be affected, but the major effects will be in Turkey, not in the EU, since import barriers are relatively low for Turkish agricultural exports (Flam 2004: 197). The consequences for trade policy of closer economic relations with the EU are difficult to predict. However, EU trade is not expected to change substantially as a result of full membership.

Four critical issues have contributed to the lower degree of trade integration in Turkey. First, as a result of a residual protectionist attitude on the part of the bureaucracy, the share of Turkish trade in GDP is lower than for most of the new accession countries. Secondly, corruption acts as a deterrent to investors and remains persistently high, although Turkey has recently ratified a civil law convention on corruption. Thirdly, the unstable macroeconomic environment, including high inflation rates, large fluctuations in exchange rates and problematic public finances, is a crucial impediment to investment in the Turkish economy. Finally, an equally important factor is that the geographical distribution of Turkey's foreign trade is less focused on the EU, as Turkey is much further away from the core of the EU market than most CEECs are.

A more substantial issue is that the effects of EU structural funds payments should be taken into account in the successful growth strategies of the CEECs (and Turkey). With regard to EU payments, the European 


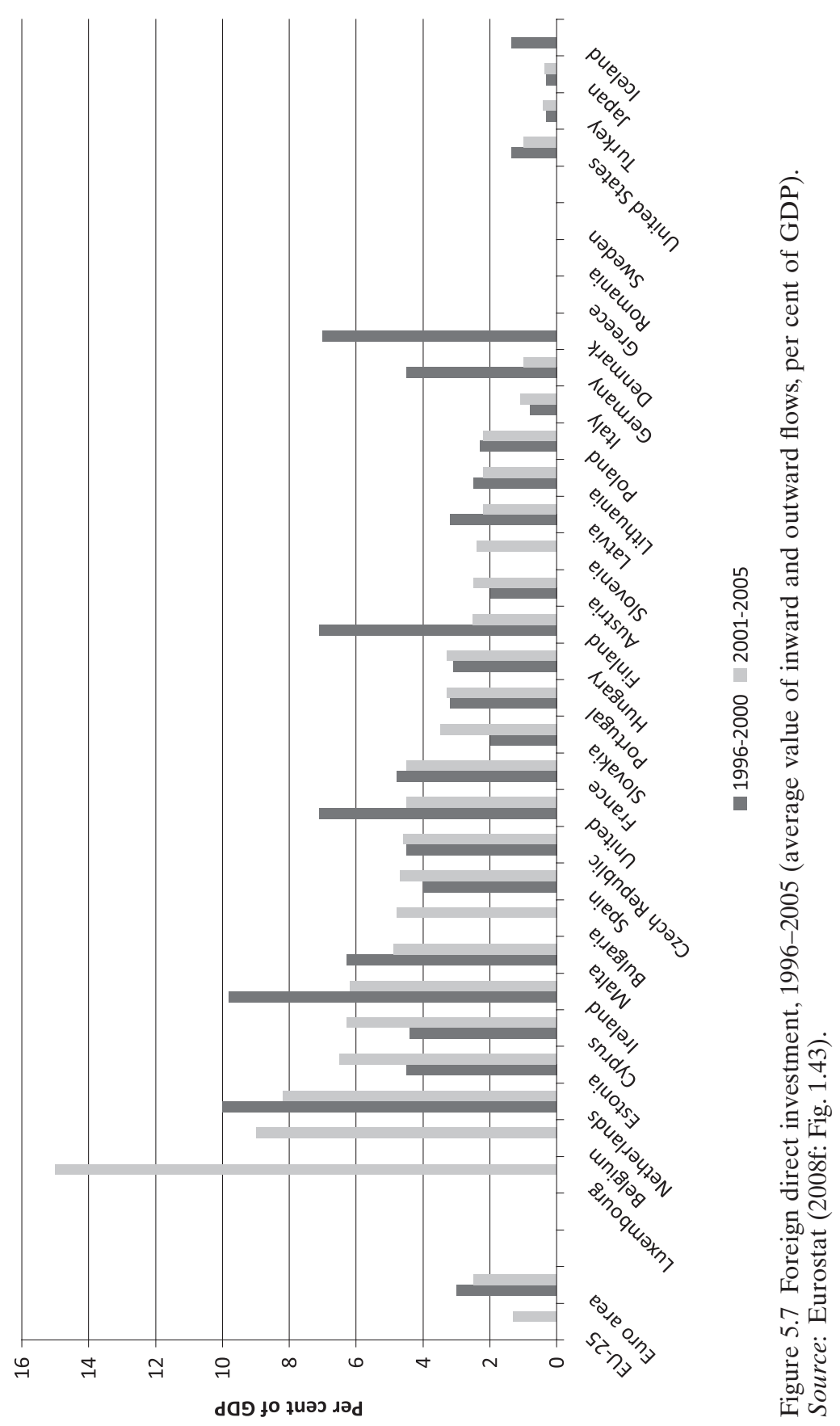


Commission itself in 2005 estimated annual growth ranging from 0.4 per cent to 1.2 per cent (CEC 2006b). Substantial transfers to the CEECs are evident, although these transfers are still ongoing. Table 5.10 shows the estimated total receipts by the 13 candidate countries in 2001 . Turkey received only a limited share of Cohesion funding, with transfers of $€ 263$ per capita. The extreme cases were Slovenia and Estonia, with transfers of $€ 1,133$ and $€ 1,548$ per capita, respectively. The smaller countries receive net transfers that are much larger per capita than those of the larger countries because of their relatively greater voting power. Given that most CEECs are small, it is likely that the potential for a dramatic increase in EU funding will be transferred to these countries.

In broad terms, assuming substantial increases in Structural Funds and rural development funding, the outlook for economic growth in the CEECs will remain bright for decades. The possibility of substantial migration flows from the CEECs have presumably led the EU incumbents to favour a gradual opening of labour markets, knowing that the ongoing convergence in living standards would make substantial migration less likely. Large-scale transformations - including financial assistance itself did actually alter the balance, as they were intended to do.

All in all, it is very likely that trade and the European Structural Funds will continue to play an important role in promoting economic growth and wage convergence in the CEECs. Such developments will contribute to welfare in the CEECs in the medium or long run, thus decreasing labour migration pressure. For Turkey, this scenario seems very unlikely. Turkey's growth prospects mostly lie in FDI inflows and European funding. A lower level of trade with Turkey implies underdevelopment. This is especially the case when Turkey is in the throes of development. If funding continues to be supplied at relatively low levels, the pressures for outmigration will persist. As a result, there will be more pressure for workers to move to the EU member states.

\section{Return migration}

Contrary to expectations, EU accession, with its resulting economic progress in the CEEC-10 countries, may motivate a return migration of people who left around a decade ago. Migration flows actually occurred during the first half of the 1990s. For this reason, most of the people motivated to migrate have already done so and the remaining pressure is very low. This process seems to be occurring in the CEEC region even at the onset of their transition periods. The CEECs are already switching from their traditional role as sending countries towards becoming substantial receivers. This issue has gained importance for Turkey. If it is reasonable to anticipate substantial return migration, anxiety should diminish. 


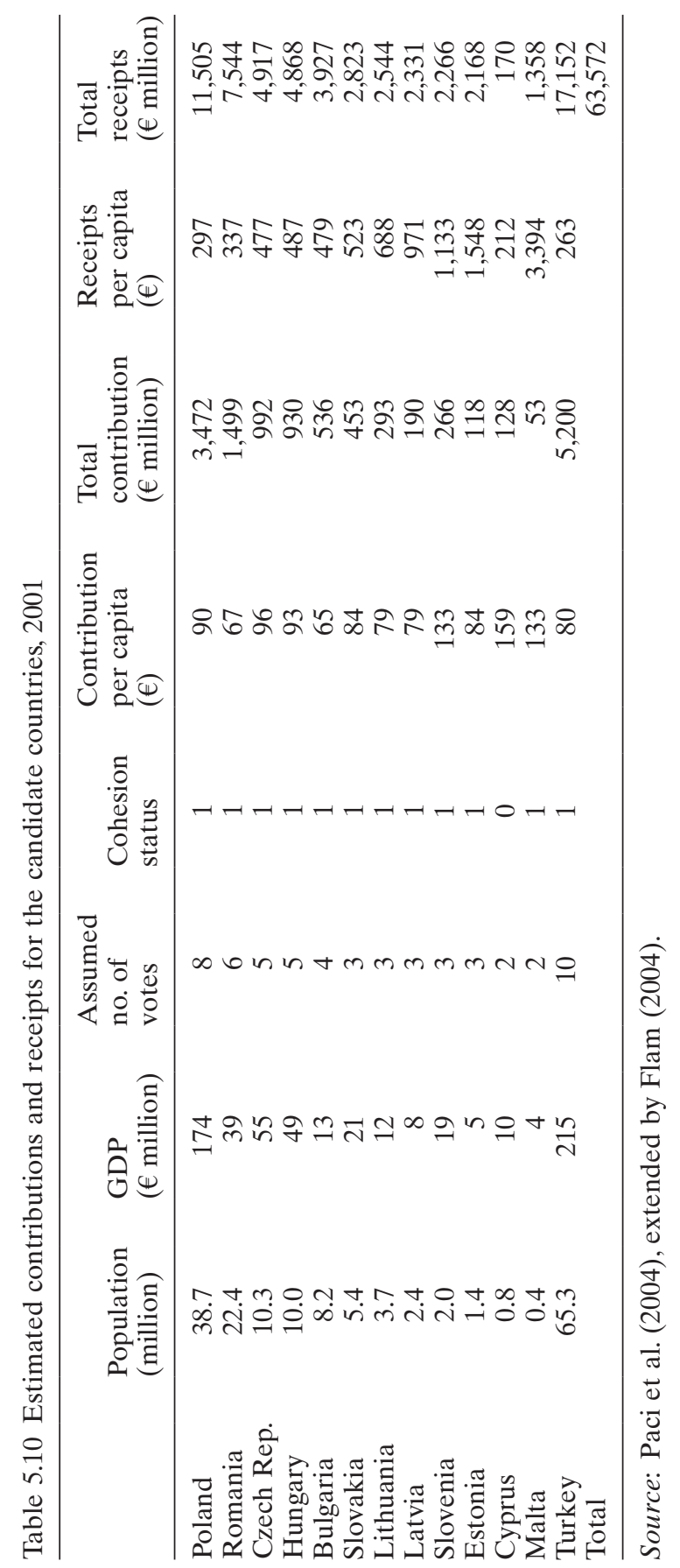


The return migration pattern predicted by Sinn and Ochel (2003) fits the reality of past EU migrations. A substantial proportion of South European guest workers, recruited to work in Germany from the late 1950s through to the early 1970 s, have returned to their home country. Observations of immigrants (from Italy, Greece, Spain, former Yugoslavia and Turkey) extracted from the German Socio-Economic Panel demonstrate that, of 3,010 immigrants surveyed in 1984, 765 (25 per cent) returned between 1984 and 1997 (Sinn and Ochel 2003: 877). In reality, the economic downturn of 1973 did not lead to a massive return of immigrants to their home country. Many immigrants decided to remain in the host country to benefit from their social rights, which were similar to those of native workers. In addition, the economic situation in the home countries was markedly worse, and, finally, many feared not being able to re-enter the host country. According to some United Nations estimates (United Nations Economic and Social Council 2009), only 10 per cent of immigrant workers returned to their country of origin in the two years following the 1973 crisis. As a result, European Community countries observed that migration was part of a process not only reflecting the needs of the labour market but also including a strong family component and a social cost linked to the presence of second generations (Garson and Loizillon 2003: 4).

This is not to deny that a substantial number of permanent migrants had changed their minds and returned to Turkey by the 1980s, thereby becoming re-migrant just as temporary migrants became permanent migrants. According to a survey conducted in 1985, 39.4 per cent of Turks in Germany had no plans to return to Turkey and 21.0 per cent considered the possibility of returning in 10 years at the earliest; thus, 60.4 per cent of Turks living in Germany wanted to remain there for more than 10 years (Martin 1991: 22). When the guest worker programme ended, the myth of return did not prevent settlement. Inherent in any such decision is an economic element, since it took migrants longer to reach their targets. In effect, the lengthening of the stay in the host country caused migrants to delay or abandon their decision to return. As time passes, this trend is likely to rise in favour of more permanent settlement. The idea of permanent migration may wane, but that will not dampen workers' enthusiasm for migration.

As regards current East-West movements, the question of whether the CEEC workers will stay permanently will be the modern version of these developments. In 2002, the results of on-line research showed that 39-88 per cent of Internet users in Latvia considered the possibility of working in one of the EU countries when these countries opened their labour markets. Depending on the underlying assumptions, the estimated number of potential movers was between 80,000 and 340,000, and only half of them had a firm intention to return to Latvia. Other things being 
equal, the following factors made the return of potential emigrants significantly less likely: higher education, young age, residence in Riga, and a preference for using Russian (rather than Latvian) on the Internet (Hazans 2003: 34).

The example of out-migration makes it evident that almost all studies take into account the improving socioeconomic conditions in the home country that might stimulate return migration. In terms of return migration, the Southern enlargement might have an important message for the likely response of the CEECs to improved economic performance. In contrast, the pressure in Turkey to migrate will continue for some decades to come. For example, Turkey is unlikely to receive the kind of Structural or Cohesion funding that the CEECs receive. These funds are seen as positive results of medium-term growth upon entering the EU. Not surprisingly, given Turkey's future demand for Structural Funds, there are those who oppose Turkish membership, assuming that Turkey's entry would put enormous strain on the EU budget because of the huge transfers necessary to bring agriculture, infrastructure and administration up to EU standards. Thus, while the CEECs are experiencing return migration as a result of accession, the prospects for Turkey's inclusion in European labour markets seem bleak following the Commission's proposed negotiation framework on Turkish membership: long transition periods, derogations, specific arrangements or permanent safeguard clauses. These instruments will limit Turkey's access to the key benefits of EU membership that are so vital for socioeconomic development. In turn, the worsening situation at home will increase the incentives for migration.

Studies on return migration in several countries show that the more skilled and successful migrants are generally better at integrating into the receiving society, and hence are less likely to return. Here, differences in qualitative potential are relevant. Turkish workers lack the skills, experience and flexibility to take advantage of new employment opportunities, particularly in the services sector or in fast-growing export industries. It is certainly true that "Europe's labour demands are not going to be the same as those of the 1960s", as stated by Gülay Aslantepe, Turkey's representative to the International Labour Organization, referring to a period of high Turkish migration to Germany and other West European countries (Elci 2005: 2). This gives us some clues to how and if Turks will be able to meet the job profiles and eventually integrate into European labour markets. Turks' increasing participation in economic - as well as political, social and educational - fields in European societies is a signal of a determination on the part of Turks to settle in the countries to which they have already migrated.

The migratory movements regulated by the provisions of the Association Agreement and the Additional Protocol are driven by labour demand. The regime of the free movement of workers allows potential 
CEEC emigrants to migrate to EU member states only if sufficient employment opportunities exist in these destination countries (Goedings 1999: 30). The availability of permanent jobs in the EU countries is limited and job creation is not fast enough to fully compensate for workers from Eastern Europe. The Commission clearly anticipates considerable return migration by the CEECs even in the short run:

In the wake of current economic developments it is likely that a possible decline in labour demand will reduce labour flows within the EU. Recent economic slowdowns in some countries have already led to a substantial reduction in new entries, in parallel to an increase in return migration. This is a sign that free labour mobility is self-regulatory by nature and provides a much needed flexibility in both directions: workers go to where there is demand for labour and many leave again when employment conditions become less favourable (CEC 2008c: 2).

Some studies point to other factors that are likely to cause return migration. Low transportation costs have contributed to return migration in the Eastern region. Return migration is also stimulated by the growing difficulty of acquiring a home in the EU-15 countries. With regard to the problem of affordable housing, most EU governments have tended to subsidize owner-occupied housing, with little effort put into the development of a rental market.

Others suggest that, at present, it is difficult to predict the impact of short-term labour migration within the East-West migration pattern, but it may become significant under conditions of free movement. What is more obvious is that East-West migration is very circular. Many CEEC citizens stay in Western Europe only briefly - to supplement the family budget, to earn money for university tuition, or to purchase expensive consumer goods - and intend to return in the future. Temporary employment, therefore, seems to suit both ends of the migratory chain perfectly: CEEC citizens improve their incomes, and West European economies often have sufficient labour to do work for which no West European citizens are available under the social and employment conditions offered (Goedings 1999: 21-31). There is reason to hope that economic conditions in the CEECs will improve. Consequently, insofar as workers are relegated to transitory employment, they will be less likely to settle permanently (Erzan and Kirişci 2004: 63). In other words, East-West migration is changing and may give rise to new forms of migration.

These expectations are now beginning to be realized. The tide of migration is turning as Polish workers return. This is happening even though the future back home is uncertain. More than 750,000 East and Central European immigrants have flocked to all parts of the UK since the accession of eight former Eastern bloc countries to the EU in 2004. However, 
the tide seems to be turning as the economies of the new EU member states strengthen. The numbers of East European immigrants approved to work in the UK dropped from 227,875 in 2006 to 206,905 in 2007, a fall of nearly 10 per cent, and the trend was expected to accelerate over the next decade. Poles, who make up two-thirds of newcomers, are understood to be returning home in greater numbers, impelled by lower salaries, job shortages and the fall in the value of the pound (Morris 2008: 1). Thus, the main motive for returning migrants is - not surprisingly - high wages and guaranteed employment. Return migration is also confirmed by research conducted for the Polish Ministry of Labour and Social Policy (2008), although finding accurate data on the scale of this return migration is virtually impossible.

Migration trends in Turkey stand out in contrast to that in the CEECs, although some Turkish immigrants might choose to return home, just as was the case with Greece, Portugal and Spain. There are different angles regarding the legal obstacles to return migration. Turks are entitled to German citizenship as permanent resident aliens only after eight years of continuous work and residence. Turkish immigrants are affected by the notion of German citizenship and face difficulty in reintegrating into Turkish society. That is why those who have returned are often referred to as "Turks in Germany, but Germans in Turkey". This is especially true for the second- and third-generation immigrants who speak German as a native language. This element clearly plays an important role in deferring return. A problem with renouncing other nationalities - as is required to qualify for German citizenship - arises because dual citizenship is prohibited. This being so, renouncing one's original citizenship in itself constitutes a drawback to return migration owing to the fact that those who renounce citizenship cannot inherit land in their home country. Additionally, the decision to defer return migration is influenced by other factors including one's residence or work permit, the children's education, the experience of disappointment by those who have already returned home (for example, economic, employment or personal circumstances).

The most obvious challenge posed for the EU by return migration will be replacing the workers who have left. As was the case at the time of the Southern accession in the mid-1980s, it should be recognized that the return of CEEC nationals provides an important opportunity for the EU to address potential future labour supply problems. If massive return flows of CEEC migrants do occur, Turkey should benefit from these returns. The key point here is not the (declining) growth rate in overall employment in Turkey but the favourable evolution of its composition, with an increasing proportion of working age (Gros 2005: 7), confirming that Turkish workers stand a good chance of finding employment in the EU if/when workers from the CEECs begin returning home. 


\section{Demographic capacity}

There is growing concern about the trend to a rapidly ageing population in the EU-15 member states and about their natural population balances, which are among the lowest in the continent. Most countries do not have the demographic capacity to support emigration without suffering important imbalances. As a consequence of joining the EU, the CEECs are expected to fill labour shortages in the EU-15, but they seem to fall short of meeting these expectations. From a demographic point of view, their accession will not drastically affect labour movement from Turkey when no mass immigration is viable.

Turkey has a larger population than any of the CEECs and makes up roughly 14 per cent of the EU-27 total (Poland, by comparison, makes up roughly 7 per cent) (see Table 5.11). Over 37 per cent of the Turkish population falls into the 25-49 age group, while the CEEC-10 demonstrate a similar proportion, ranging from 34 per cent to 38 per cent in this age group. Some 28 per cent of Turkey's population is aged less than 15 years, whereas across the CEEC-10 this age group constitutes less than 16 per cent. The number of elderly people (65 years and older) is considerable in the CEECs, accounting for between 9 per cent and 13 per cent of the total population. Population ageing tends to be less marked in Turkey, where only 5.9 per cent of the total population is over 65 years. Its working age population (15-64 years) is over 65 per cent, owing to a long-term increase in the fertility rate and a relative decline in the older age group. By contrast, a general trend towards an ageing population can be detected in most countries in the EU-27. Increasing the age of retirement in the EU will therefore inevitably lead to shortages of working-age population in Europe in the long run.

The main reason for the decline in population and in the growth rate in the CEECs is a significant fall in birth rates, together with gradually stagnating or decreasing life expectancy (especially for men), leading to higher mortality. The Bulgarian National Statistics Institute reported in 2002 that the mortality rate was over 14 per 1,000 population. Inevitably, this trend will lead to changes in the age structure and eventually to an ageing population in the country. This is even more so the case for Romania. However, the problem is not restricted to these countries. A study by the Latvian Ministry of Health (2008) predicted that by 2050 Latvia's population would be half what it is now. Similarly, John Salt's report to the Council of Europe (Salt 2006) listed Poland and Lithuania among countries with consistent population loss because of an ageing population and net emigration. There is also another potent influence at work: in almost all the CEECs the official healthcare statistics indicate that the number of deaths caused by alcohol, poisoning, homicides, suicides and traffic accidents increased nearly twofold in the 2000s, compared with the 1990s. 
A more specific reason for the change in population during the past decade is the decreasing number of arrivals simultaneously with a large number of departures from many CEECs. Since the 1990s, Estonia has experienced a remarkable outflow of the Russian-speaking population into Russia, Belarus and Ukraine. In the Czech Republic, immigration has typically exceeded emigration, making the country one of the net immigration countries, but the scale of immigration in both Romania and Bulgaria is far smaller than that of emigration. In particular, the economic and social crisis in Bulgaria after the collapse of the centrally planned economy in 1989 seriously affected demographic processes. The economic crisis has also gravely damaged access to health services (Rangelova and Zlatanov 2005: 71).

A study by Fassmann and Münz (2002) suggested that the prosperous western border regions of Slovakia, Slovenia and Hungary would face labour shortages as a result of emigration to high-wage regions of the EU. This movement, which is in line with the demographic decline and economic growth in most CEECs, would necessitate importing immigrants from third countries, as is already happening from Ukraine (Fassmann and Münz 2002: 25). Forecasts by the European Commission show that the number of inhabitants in the Baltic states, Slovakia, the Czech Republic, Hungary and Poland might fall by more than 10 per cent overall between 2005 and 2050, while the largest declines in population are projected for Bulgaria (an overall reduction of 33.8 per cent) and Romania (21.2 per cent) (Eurostat 2008a: 23). In contrast, the population of Turkey is set to rise by more than 19 million (a more than 25 per cent increase) between 2005 and 2030 (CEC 2005b: 4). However, forecasts by the Turkish Centre for Population and Health Research suggest that this trend will almost certainly be reversed in 2050 , and thus population growth will not constitute a potential threat to the EU in the long run.

For the moment, the focus should be not on the growth or decline of overall populations, but on the proportion of the working-age population. The difference in demographic patterns between the CEECs and Turkey, as well as future forecasts, suggests a migration potential for young people in Turkey that corresponds to labour shortages in the EU. Importing young and dynamic Turkish workers might help to alleviate these shortages and generate a major fiscal advantage for the ageing populations in the EU-15.

\section{Internal inequalities}

The effects of communist planning are manifest in the CEECs, where there are large internal inequalities between the capital city, small cities and the countryside in terms of wages, employment opportunities, social provision and cultural offerings. Individuals who are discontented with their current situation may not feel the need to migrate abroad. Instead, 


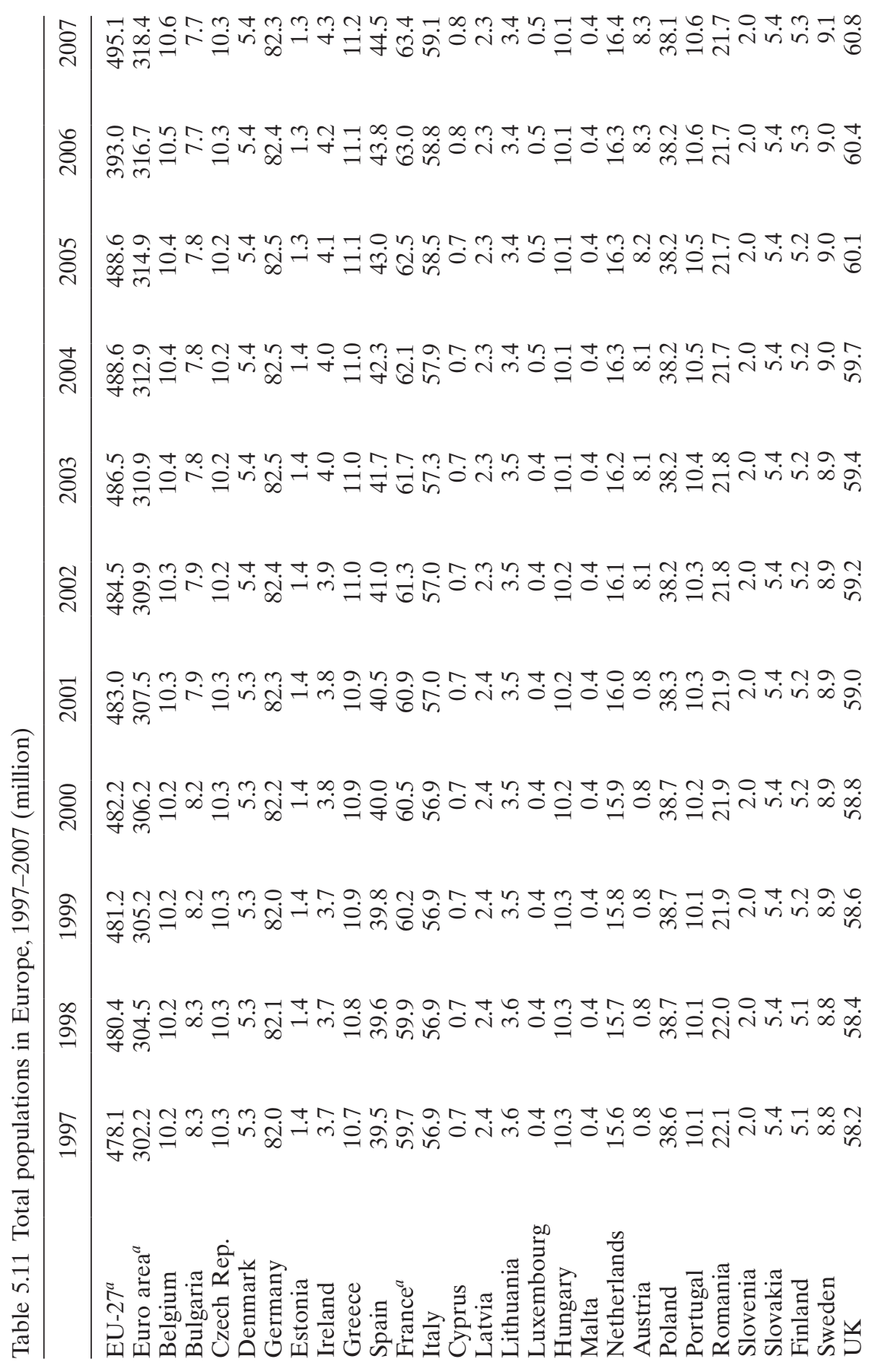




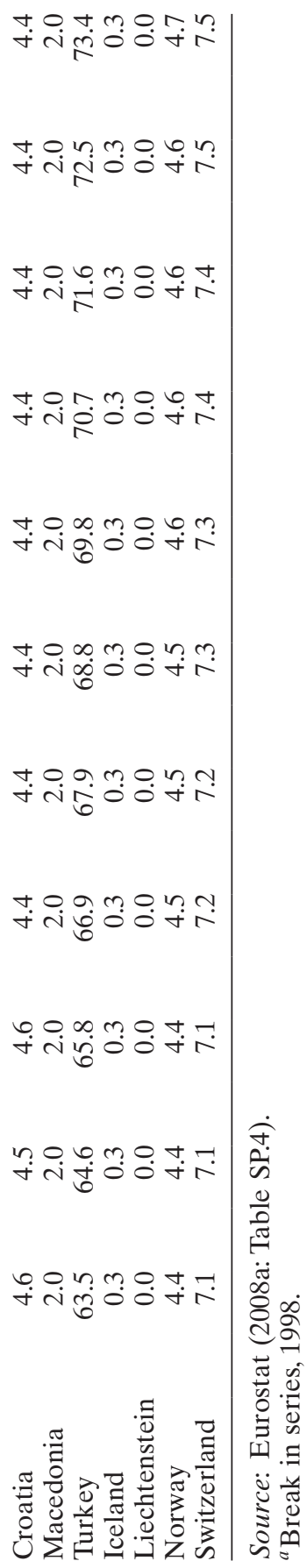


an internal rural-to-urban or urban-to-urban transfer may serve this end. This was the case in Greece, Spain and Portugal after the economic impetus of their accession to the Community, and it is very probable that this trend will be repeated in the CEECs as their development accelerates. As for Turkey, in the presence of similar inequalities, the emphasis will, instead, be on the stabilizing effect of labour migration to the EU, even though the formal benefits of labour market integration have yet to bear fruit. This demonstrates that internal migration flows are related more to push factors than to pull factors.

Some versions of immigration theory are built on the divergence between core and periphery that prevails in developed and underdeveloped countries. Within the parameters of immigration, a core/periphery situation does appear to be conceivable in the CEECs. With regard to the EU budget, different policies crucially could not meet expectations, as some sort of core/periphery is already a reality. This core/periphery device also conforms to the EU's inclination to exert influence or impose restrictions on labour movement beyond this periphery.

Obviously, this point is more relevant to Turkey than to the CEECs. The underlying theme is regional disparities. The most affluent two regions in Turkey are the Aegean region and the Marmara region. The latter region, with Istanbul as its capital city, features per capita income that exceeds the Turkish average by more than 50 per cent. The population is heavily concentrated in the Marmara region, which accounts for more than 17 million people. The (south) eastern part of Anatolia is by far the poorest region. The average per capita income in East Anatolia is less than 30 per cent of Turkey's average, and is less than one-fifth of the average in the Marmara region (Lejour et al 2004: 22). Naturally, structural and long-term unemployment is observed in these regions and unemployment affects mainly people from the various risk groups. These regional disparities imply that Turks from the poorest parts of country will flock to the West to find jobs.

What is striking is that income inequalities in Turkey may cause a high potential for labour migration, especially from eastern Anatolia, in stark contrast to the situation in the CEECs. Figure 5.8 provides a summary measure of income inequality in 2005. When compared with the EU-15 average, income inequality is noticeably higher in Lithuania, Latvia, Poland, Estonia and Romania. Other countries (Bulgaria, Hungary, Slovakia, the Czech Republic and Slovenia) show markedly less income inequality. Turkey's degree of income inequality is double that of the EU27.

The need for changes in living conditions and welfare systems in the medium term is underlined by the Commission's regular progress reports. It remains uncertain whether poverty will be reduced after accession to 


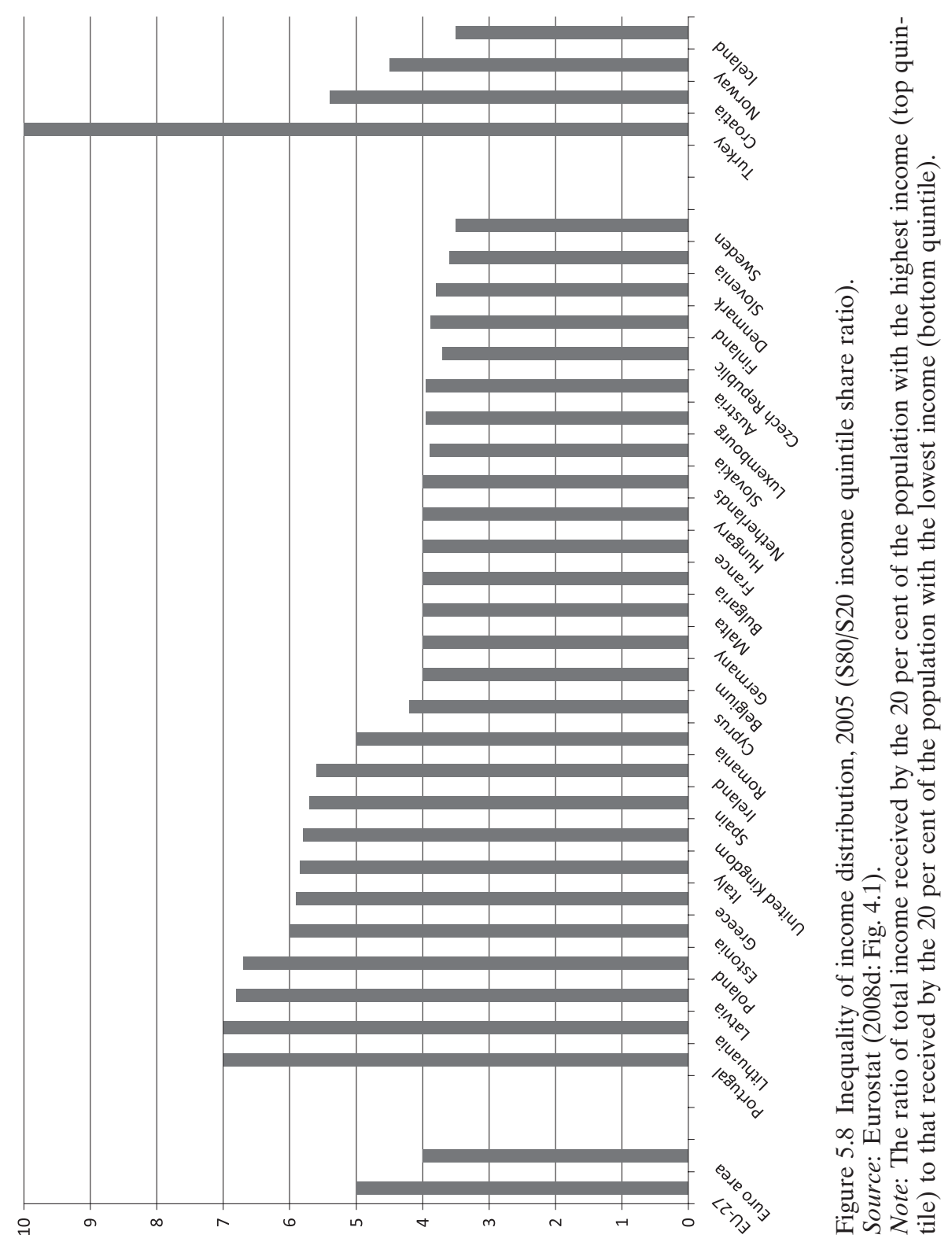


the EU. Concerning the current situation, this gap is likely to increase migration pressure in Turkey.

Migration is ultimately a matter for the individual, and the individual's decision also depends on the "advantages of staying" (Hönekopp and Werner 2000: 6). Most studies suggest that the freedom to move can be achieved only through the enhancement of competences, especially in the socioeconomic field. In the presence of income inequality in Turkey, there is an impressive willingness among many Turks to move to prosperous Western Europe. For the vast majority of East Europeans, in contrast, there are many reasons to stay, although a dramatic restructuring has taken place since the beginning of the 1990s.

First, there exists an unequal distribution of income and consumption, even if it generally lies within a fairly narrow range. With internal mobility, in almost all countries many individuals suffer from a sense of social injustice. At the same time, it is impossible to ignore a previously unfamiliar level of conspicuous wealth that has rapidly appeared, although it is not reasonable to suppose that such a system of material privilege could last forever.

Second, the dominant pattern of employment derives from the socialist economy, which built upon earlier forms of self-help using the state economy. Thus, the rules regarding certain trends in the Soviet system are set by the socialist economy. The overriding, general feature is chronic shortages (that is, labour shortages) even in the more developed CEECs. After all, economic transformation combined with recession caused a sharp decrease in economic activity and, in turn, high unemployment, which in effect traumatized society, although the rate differs from country to country.

Third, as job security disappeared, life itself became more insecure on many fronts. A useful way of drawing attention to this point is national features and how they may change. There is even a more general question of whether it is possible to discern any broad socialist trends. The socialist pattern stressed the need to bring to justice those who engaged in risky political activity. But this pattern is rather unpredictable since nothing is known in advance. Similarly, consumer prices are in a constant state of flux, which is attributed to the loss of consumer confidence in commodity prices. Free or floating exchange rates add further uncertainty to the lives of average citizens, and create conditions where they cannot make sense of interest rates or even exchange rates. Uncertainty also lies in the durability of enterprises and businesses. Formerly, a company would exist for a long period, but nowadays a company can be set up and go bankrupt from one day to the next.

Fourth, a legacy of the old regime in Eastern Europe is the outmoded phenomenon of corruption, mostly in the area of mutual favours bestowed through political or personal contacts. Most cases of corrup- 
tion continue undetected behind the scenes. Nowadays, there are varying degrees of corruption in the individual countries. It is ever-present in the myriad of transactions in the political, economic and cultural spheres. It is not difficult to see why corruption cases lead to public awareness - leaving them frustrated and angry.

Fifth, in everyday life, people are also upset about disorders in the political arena. Many regard the multi-party system as not having generated the preconditions for sound political competition, but as having created an unbridled struggle for power. The pledges of these parties are empty promises. That rendering is not at odds with the view that politicians tend to get involved in corruption by breaking the law when they are vilified by political rivals. Obviously, this legacy encourages not only an approach of economic self-help, beating the system or bending the rules but also a tradition of corrupting officials.

It turns out that large East-West population movements will not occur in the long run. Having said that, in the absence of international migration, the national governments in the CEECs will need to develop compensatory policies. This implies that new forms or types of migration flow will be promoted and facilitated to solve the problems of immobility. Indeed, other movements are evident in these countries. Migrants in search of employment form an important component of internal migration. Nearly all countries in the region are vulnerable to intra-regional movements in relation to the level of economic activities. Convergent diagnoses prepared by many research centres attest to a considerable increase in such movements in recent years. They show that about one-third of western and central Ukrainian households are involved in relocation of that kind. Recent studies of Polish households suggest that nearly half of the population has benefited from these movements at some point. Seasonal (internal) labour immigration has also appeared. It is a transitory form of spatial mobility, with its source in structural imbalances in the domestic labour markets of many of the countries in the region, in particular a relative surplus of rural population. It substitutes, in part at least, for formerly widespread commuting from the countryside to a nearby town (Okólski 2000: 322). In Latvia, substantial flows from cities to the countryside were generated by the restitution process (returning land to descendants of the former owners); these flows occurred mostly because of social welfare provisions (Hazans 2003: 11). This population loss has left entire villages in the Latvian countryside devoid of any working-age inhabitants, crippling the rural economy and limiting the government's ability to collect revenue by destroying its tax base (Bhat 2007: 35).

A similar situation prevails in the Turkish regions. In the early days of labour migration to the West, massive internal mobility occurred, owing 
much to the demographic characteristics of the Turkish workforce. A process of rapid industrialization has taken place in big cities since the 1950s. Significantly, this has given rise to seasonal internal mobility, which followed on closely from the rural exodus. A peculiarity of this phenomenon is that seasonal migrants are poor and the majority of them live in deprived provinces. These migrants, especially from the eastern regions, usually begin their journey in February and end it in December, because they cannot make a living in their place of birth. The northern and western parts of Anatolia are the target for an increasing number of economic migrants, who mostly engage in harvesting and work in the informal economy. Seasonal mobility continues to be an interesting case, since people from rural areas make up a large proportion of the unemployed. According to the Turkish Statistical Institute (2000), around 4.7 million people migrated from the eastern regions to the west. Yet, it is this aspect of internal mobility that signals to the incumbent EU-15 member states that they need to take measures in anticipation of large labour flows.

Studies confirm that people's mobility is one of the potential determinants of core-periphery structures. If people move towards the centre, the core will grow faster and faster, while the periphery will increasingly lag behind. Migration will then promote positive structural change in the immigration area and a rather negative change in the emigration area. The long-term outcome is a divergent pattern of economic growth (Hille and Straubhaar 2001: 88). The phenomenon of uneven development is not just an issue for Turkey. It is claimed that the existence of coreperiphery structures has led international migration analysts to describe the CEECs as a "new migration pole". However, the situation in the Turkish regions, as already indicated, is much worse than in these countries. The estimated number of citizens who have moved from the periphery to the centre in the CEECs seems much lower than in Turkey. This contemporary issue of uneven development in Turkey is a major cause of both internal and international migration. As long as this structure exists, Turks will continue to emigrate.

For all that, there is no real evidence that divergence has had an impact on potential migrant flows from the CEECs, as it will be unlikely to increase the incentive to migrate. Many Turks who are yet to be spared from impoverishment still have faith that the future will be better with migration to the West. The prospect of EU membership has long forced successive Turkish governments to uphold the rule of law, entrench democratic freedoms and, more importantly, pursue sensible economic policies. A strong focus on the benefits of EU membership is reasonable, on the assumption that it will provide access to scarce and often politically distributed resources that are vital for socioeconomic development. In 
the CEECs, disincentives to mobility are more long-standing, given the feelings of insecurity among most of the population.

\section{Social and cultural ties}

There are strong social and cultural ties between people in the CEECs and their home country and many are very reluctant to "pull up their roots". They may not wish to leave behind family and friends and face the prospect of establishing new social relationships in a strange country. This is probably not such an important barrier for many professional groups, because their promotion often depends upon moving to another country. The Southern enlargement showed that the removal of restrictions on Greek mobility in 1987 did not prompt a wave of intra-EC migration. Even without legal obstacles, linguistic and cultural differences remain. It seems that this problem will prevail. In particular, there are considerable pressures for deep social and cultural integration of Turks with the West. From this viewpoint, on the basis of past experience it seems unlikely that measures to restrict migration will be introduced.

The current East-West movements are not new, but have entered a new phase in approximately 150 years of modern East-West migration history (Goedings 1999: 20). What is immediately apparent for the population of the CEECs is that, for decades under the previous regime, they had no right to migrate legally - or only under very strict conditions - to EU countries. With little or no legal migration experience, the CEECs developed society-specific advantages, which could be unfamiliar with the "Western specific". These advantages usually derived from the social relationships that were built up in their local societies.

Unlike the CEECs, Turkey has a long history of legal migration. This is easily justifiable. As part of the process of governmental modernization efforts, the new constitution adopted on 27 May 1960 was characterized by a remarkable degree of liberalization of the freedom to travel. For the first time, Turkish citizens were given the right to hold a passport and to travel abroad. By the end of the 1970s, immigration to West European countries was substantial under the guest worker programme, although the tide of return migration was already strong. Family reunifications may have been both a result and a cause of prolonged stays.

The theory of integration suggests that the social consequences of immigration depend on the degree of integration achieved. Gudrun Biffl writes:

The economic and social integration of the migrants of the 1950s, 1960s and 1970s was favoured by the general economic environment of the time, i.e. the industrialization phase of economic development. In the post-industrial societies of the 1980s and 1990s, the transition from the Fordist model of production 
to the modern one of flexible specialization, decentralization of production, the increasing importance of secondary labour and the shift away from industrial production towards services have to be seen as contributory factors to the increasing difficulties migrants face in achieving economic and social integration. (Biffl 2001: 158)

Any assessment will in fact have to be based on CEEC citizens' experience of social integration in the post-enlargement period. Studies show that CEEC citizens are mostly skilled workers but even they take on manual and poorly paid jobs. Poor housing is a related problem. This is why migration will be allowed in the newly unified EU, although it is claimed that these individuals are unlikely to wish to enter the labour force (Van Selm and Tsolakis 2004). In the face of these and other abnormalities, it remains to be seen how far the CEECs will make commitments to European integration in the long run. The phenomenon of "adaptation risk" in line with Biffl's suggestion will occur when unskilled workers leave Turkey to take on jobs in the West. It will be hard to compete, because there may be fewer opportunities for an unskilled labour force. For this reason, there will be a higher propensity to prevent Turkish workers from accessing European labour markets. As a result, there will be less integration.

More recently, studies have asked why Turks continue to be "Fransa'ya Fransız" ("estranged from France"), despite longer-established ties with France than with any other European country. The best answer to this query was presented by the University of Rouen's 2007 report (Gonac'h 2008). The French sociologists claim that Turks living in a foreign homeland retain the features of an introverted society. Within this structure, the Turkish community rarely interacts with the outside world. Many second-generation immigrants opt for a local spouse from back home or from their parents' home country (although some Turkish immigrant youths in Europe prefer to marry a spouse from the host country). This is because they want to maintain closer ties among relatives in the home country where Turkish youths are desperate to get to the "promised land" of social provision and jobs. Moreover, French official statistics show that 98 per cent of the second generation of Turkish women and 92 per cent of men marry Turkish nationals back home. It is claimed that language is the main barrier to the integration of Turks into French society, with the exception of those who are born and live in France, as is the case in other European countries. With a strong sense of Turkish identity and stress on the Turkish language, Turks have great difficulty in learning French. Consequently, the need to learn French is typically ignored by migrants, and Turkish is widely spoken among family members. This is to protect the Turkish language from being "eroded". It is also important to note that 
97 per cent of families watch Turkish TV channels via satellite dishes. In addition, Turkish migrants used to visit Turkey for leisure purposes once in two or three years, but nowadays an increasing number go on a holiday trip twice a year. The situation is similar in other European societies.

A study by Hans-Christoph Steinhausen (1985) showed that migrant workers' families share a particular environment that differs significantly from that of the host country. Public policies (including restrictions on entering West Germany imposed on family members and financial incentives to return to the home country) as well as prejudice and xenophobic reactions by members of the host population jeopardize the integration of migrants (Steinhausen 1985: 15). Turks who have attained citizenship have begun to move up the political and economic ladder, but as a group they are economically disadvantaged and many continue to be employed in the low-paying jobs for which they were originally recruited (Minorities at Risk Project 2009: 1). For instance, in 1971, about 42 per cent of all Turks were employed in the iron and metal producing industry and 15 per cent in construction (Völker 1976: 49). A study of the occupations of migrants by the Turkish Employment Institution (2007) supported this finding, claiming that the phrase "unskilled workers" is used to describe the Turks. The study concluded that Turks are usually employed as builders, carpenters, bricklayers and cooks.

In the end, the debate, as always, revolves around whether or not Turkish migrants fit productively into European labour markets. In his article "Necessary But Unloved" in 1993, Thomas made the following interesting observation:

In German political and social life, no more than a handful of Turks have managed to bridge the gap between the different cultures. A few have managed to set up businesses, move from the ghettos and buy homes. But after a day's work most Turks make their way to rooms in the cities' ghettos, while their German workmates retire to their local bars or comfortable homes. (Thomas 1993: 1)

However, the problem is, in part, "one of visibility, of concentration and of an apparent 'failure' of integration or assimilation that is subjected to increasing media and political attention. Many of Europe's biggest cities (particularly in western Europe) are now multicultural. They are not, however, always 'melting-pots': different communities live alongside each other, but often share little in common" (Bale 2008: 323). According to the Christian Social Union in Germany, Turks have difficulty in adapting and have no enthusiasm to do so, despite it being over 40 years since the signing of the Association Agreement. This tendency greatly affects their integration into Germany. 
What stands out in contrast to this thinking is the contribution of Turkish immigrants to job creation, as many run their own businesses in the EU-15 member states. Self-employment began as an alternative employment path for many first-generation redundant guest workers, but it also became a significant response by second-generation youth, often assisted by parents who had in mind securing the future livelihoods of their children. An increasing number of entrepreneurs come from the ranks of the second generation, and the emerging literature on Turkish entrepreneurs points to rapid expansion across the generational spectrum (Panayiotopoulos 2008: 398). Despite the large cultural differences, the potential for Turkish self-employment in European countries is striking. In particular, in conjunction with the high Turkish population in Germany, the number of Turkish entrepreneurs is highly significant. The report from the Turkish-German Education and Scientific Research Charity (2009) showed that the total number of Turkish enterprises on the European mainland (mainly Germany) increased from 62,000 in 1997 to 108,000 in 2008, despite the economic downturn in European countries. In this period, the annual net profit of Turkish enterprises reached $€ 12$ 48 billion. This is a considerable achievement in itself, suggesting that, along with other social developments in Europe, Turkish immigrants have undergone an amazing process of assimilation. At the same time, this potential shows a shift from being a guest worker to becoming an employer in the country of residence. In addition, some Turkish nationals have actually joined the ranks of elected politicians at the local, national and European levels.

Unfortunately, this optimistic outlook does not outweigh the perception that a large number of Turkish immigrants have failed to integrate into their host communities. This has exacerbated anti-immigrant feelings in the EU member states. On the one hand, then, it is possible to assume that Turks have unskilled jobs owing to their failure to assimilate. This is likely to continue, even after the Eastern enlargement, as long as Turks hold onto their religion and culture. On the other hand, a large number of the Turks are, as already noted, unskilled labourers and the average migrant arrives with little education. This being the case, it is difficult to see how they could be good at learning about another culture.

This failure apart, empirical evidence reveals the gradual but growing integration of Turkish culture within European societies. In the face of fundamental social change associated with modernization, the Western lifestyle is favoured among young Turkish people. These young people are more integrated in Western society than those of the 1960s and 1970s. Undoubtedly, this owes much to the attractiveness of the new type of society in Europe. As Table 5.12 shows, a significant number of Turkish people $(1,350,658)$ were granted citizenship in various EU countries between 
Table 5.12 Naturalization of Turks in some EU countries

\begin{tabular}{lcr}
\hline Country & Date & Number \\
\hline Fed. Rep. Germany & $1972-2006$ & 732,524 \\
Netherlands & $1946-2005$ & 258,272 \\
Belgium & $1985-2006$ & 129,501 \\
Austria & $1983-2005$ & 111,300 \\
France & $1991-2002$ & 66,575 \\
Sweden & $1990-2006$ & 30,942 \\
Denmark & $1980-2003$ & 21,544 \\
UK & $1989-2005$ & 53,335 \\
Total & & $1,350,658$ \\
\hline
\end{tabular}

Source: Turkish Ministry of Employment and Social Security, Annual Progress Report, 2006.

1972 and 2006. In some countries in the West (especially Germany, Denmark, France and Austria), the second generation has patterns of employment similar to the rest of the country, although legal Turkish migrants suffered unemployment rates above the national average.

Although Turkish labour movement to the EU-15 since the standstill has been insignificant, a number have already experienced a glimpse of the Western way of life. Here, one can see the influence of migration networks, which have helped potential migrants of the same Turkish origin to find a job. Given the total numbers of Turkish workers employed in West European countries, the proportion of mixed marriages is rising steadily. Statistics from the Turkish Population Institution noted that the number of Turks who had contracted mixed marriages by 2002 was 24,840 and that 40 per cent of the Turks married German citizens. Similarly, a study by a Dutch government agency, Statistics Netherlands (Alders 2005), showed that marriage immigration of Turks almost doubled between 1995 and 2003, increasing from slightly less than 2,000 per year to 4,000 . The study also predicted that marriage immigration would peak by the mid-2020s. Additionally, statistics from the Turkish Ministry of Labour and Social Security indicated that Turkish immigrants in the United Kingdom totalled 52,893 in 2006 and they would soon be by far the largest immigrant group in the United Kingdom after Indians and Pakistanis. It can be assumed that these migrants will get to grips with assimilation into British culture.

The other side of the coin is that there remain considerable challenges in adequately integrating migrants into the European labour markets (CEC 2008f: 1). In almost all EU-15 countries, there is a strong tradition of racial or cultural exclusion of the CEECs, which can also be exemplified in relations between Turkey and the EU. Young people are sometimes faced with discrimination on the grounds of their age and lack of 
occupational experience, accentuated by other factors such as gender, social origin or race, all of which make it more difficult for them to integrate into economic life and society (CEC 2005b: 7). This especially leads to lower wage levels for CEEC citizens compared with the native population. Generally, they suffer from isolation, feelings of marginalization and being considered second-class residents. As has already been stated, discrimination applies in terms of expensive housing in the host countries. The inefficiency of the housing market in most EU countries, involving scarce and expensive rental housing and/or higher house prices relative to income, is a possible barrier to migration from the CEECs to the EU15. A high percentage of CEEC nationals own their own houses, and therefore are not willing to move into small and expensive apartments in other countries.

Then there is the extra complication of the complex EU relationship with Turkey as a long-standing applicant for full membership. In cultural terms, in an attempt to give a more precise picture, Wagstyl gave the following overview in the Financial Times:

While migration may be beneficial in economic terms, it can provoke political hostility. In spite of long standing efforts by most European governments to fight xenophobia, there is a growing concern in Western Europe about the scale of current immigration. While some of these worries are based on ignorance of the role of immigrants in society, other fears are real - such as concerns about the strains placed on health, education and transport services. Furthermore, those low-skilled workers who find themselves competing for jobs with immigrants, could see their wage levels pushed down. What may benefit the economy as a whole may not benefit them as individuals. (Wagstyl 2004: 2)

As such comments suggest, the debate over Turkish migration to the EU has combined not just economics but cultural issues, which have farreaching implications for the EU. Cultural restrictions on Turks mainly take the form of informal social discrimination and complaints about their public practice of Islam. This relegates the case for Turkey's European identity to a pragmatic argument that Turkey's membership will make the EU more attractive to Muslim countries outside Europe, and to some, but not all, Muslims are currently largely unrepresented in EU institutions (Brewin 2002: 25). A consequence of Turkey's new democracy and of its heightened religiosity - Anatolian peasants who move to the cities are deeply shocked by the "decadence" they find there - is that Turkey is becoming less and less secular than it was in the 1960s and 1970s and more like post-Christian Europe (Gwyn 2005: 2).

In fact, there is little disagreement about Turkey's difference from the CEECs. For decades, there has been mounting concern among European leaders about Turkish cultural issues. The most outspoken is France's 
former president, Valéry Giscard d'Estaing. He bluntly told Le Monde on 8 November 2002: "Its capital is not in Europe; 95 percent of its population live outside Europe; it is not a European country." He also said: "It has a different culture, a different way of life", and claimed that EU membership for Turkey would mean "the end of Europe" (BBC News 2002).

As Eralp (2005) has acknowledged, Turkey's rather negative image in Europe stems from two considerations. The first is the fact that the Ottoman Empire was the "enemy". Therefore, there are enduring historical prejudices. Interestingly, and conversely, the Crusades did not have such an impact on Turks. Turks are considered to be more "forgiving". The second consideration is Turkish migrant workers living in Europe. The EU and Turkey both made mistakes on this matter. First-generation migrants came from the lowest circles of the society in Turkey. The host countries did not, at that time, care about their level of education but rather focused on the workers' "muscles". Until recently, the host countries did not have a policy on integration, because migrant workers were considered to be temporary. The sending country, namely Turkey, did not have any experience of dealing with its citizens living abroad. When one looks at the second and third generations of Turks in EU countries, one can see a big difference, although the younger generations still face problems. Unfortunately, the first generation of workers left a lasting negative impression (Eralp 2005: 46).

The argument about Turkey's non-Europeanness is to some extent persuasive, but it has to be considered in conjunction with other developments in order to gain an overall picture. Turkey has been a member of NATO since 1952 and is a vital Western ally and regional power that has sought to link its destiny to Europe for more than 40 years (Strauss 2004: 1). Besides, having the second-biggest army in NATO as well as strategic reach in the Middle East, Turkey may bolster the EU's ambitions to become a key player on the world stage. There is no doubt that there has been a special relationship with the EU, which became more evident after Turkey's candidacy. In a speech in September 2005, Jack Straw, the former UK Home Secretary, said that "by welcoming Turkey we will demonstrate that Western and Islamic cultures can thrive together as partners in the modern world. Turkey's geographical position makes it of vital strategic importance in every way" (Dombey 2005: 2). This statement implies another important difference: Turkey belongs to the EU periphery, not only politically but also in geographical terms.

Studies suggest that some knowledge and skills are country-specific for the population of the CEECs and Turkey. The experience gained through education and work may be ineffectual abroad. Here, linguistic barriers play a crucial role in East-West migration. The migrant's knowledge of 
foreign languages is closely related to the choice of destination, as demonstrated by the languages that are less widely spoken in the CEECs (that is, English and French). Since German and Russian are the most widely known foreign languages in the CEECs, emigrants from this area tend to head for German-speaking countries (Fassmann and Hintermann 1997: 22). Most EU-15 countries expect migrants to integrate more quickly given that they are actually able to speak European languages. Separate language tests exist for those seeking the right of abode or citizenship in the United Kingdom, for instance. The UK government estimates that 35,000 of the 95,000 skilled migrants who had entered the United Kingdom since the 2004 enlargement would not have been able to show that they could speak the language (Wintour 2007:2). During the Cold War, East European states used to make it compulsory to study Russian as a second language. This not only resulted in resistance to Russian, but also prevented East Central Europeans from learning the languages necessary for direct access to international science, technology and entertainment. All of the states of Central Europe abandoned the Russian language policy after 1989 and immediately switched to teaching English and German (Borneman and Fowler 1997: 500).

Since 2004, this situation has changed and now most pupils have a free choice to study foreign languages. There has been a marked increase in the proportion of pupils learning English among the CEECs. Figure 5.9 shows that, despite considerable progress, the CEECs have a relatively lower proportion learning all three foreign languages (English. French and German). Many languages are spoken in Central and Eastern Europe, and people in neighbouring Slavic countries are often able to understand one another. The differences between the CEECs and Turkey are even more significant. The proportion learning foreign languages is higher in the CEECs than in Turkey, although foreign language learning - notably English - in Turkey is actively encouraged in schools, universities and adult education centres. Such a language barrier is very important for Turkish migrants who, for years, have been unable to become well integrated into Western culture.

Analysts cite a lack of language skills - indicating an absence of a natural or proven propensity to migrate - as a factor that will limit movement in the EU. For example, knowledge of German may encourage workers from Turkey. Recent immigration laws in many Western countries requires migrant workers to have a basic knowledge of the language. More specifically, from March 2006, all foreigners applying for permanent residency in the Netherlands, for example, have to pass a test on Dutch language and society. There are similar schemes in other European countries, including France, Germany and the United Kingdom. "[R] equirements are now moving beyond simply birth and/or residence 


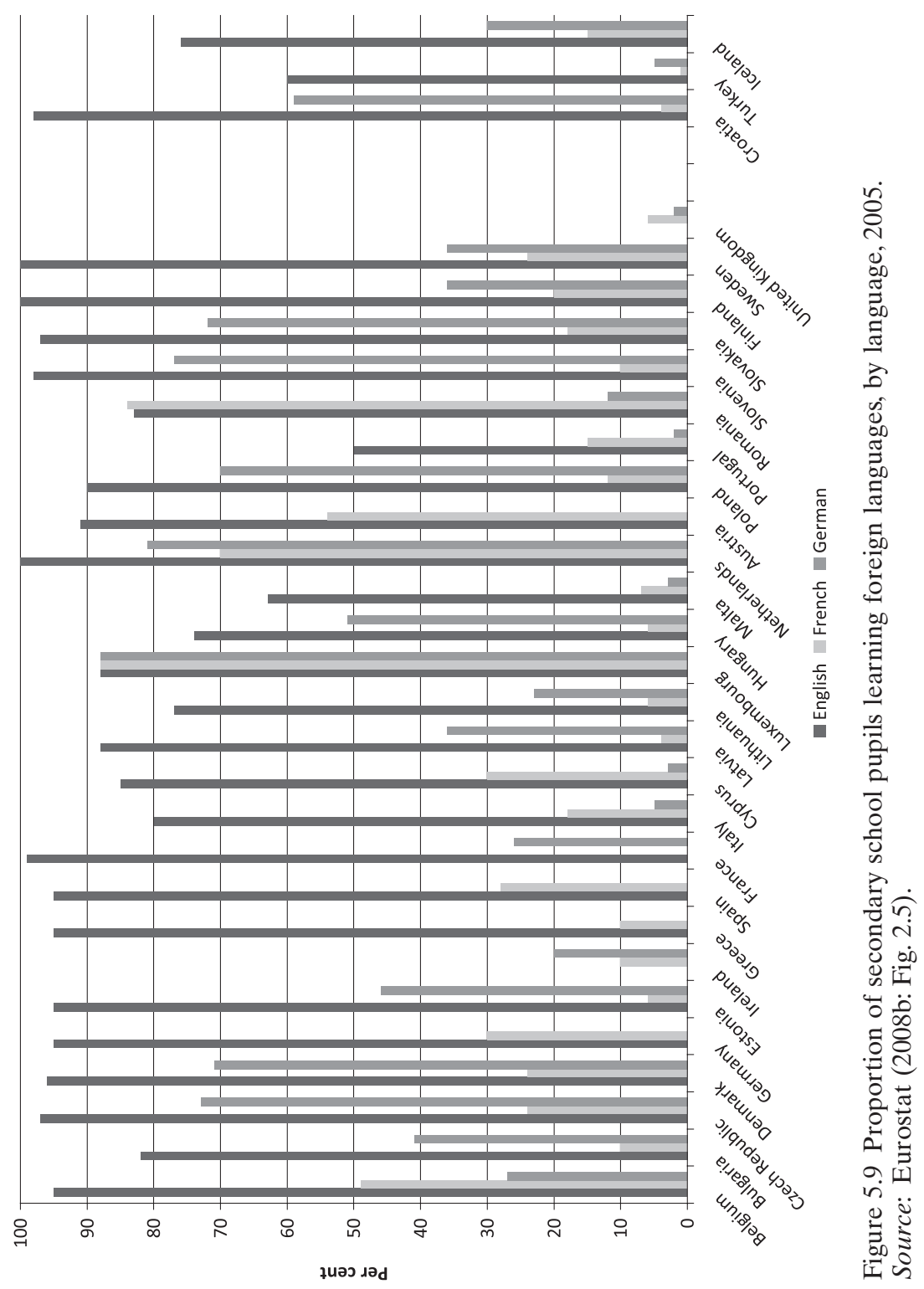


to include familiarity with the country and its language that is tested before citizenship [and even, in some cases, residency] is granted" - which could well have the (intended) knock-on effect of making immigration more difficult (Bale 2008: 324). In a cultural context, this will increase Turkey's difficulties. One possible indication of this claim is that peasant women from the Turkish province Şanliurfa are obliged to attend intensive classes to learn German in order to join their husbands (reported by Channel D on 25 January 2008). Not surprisingly, some women, being without even primary-level education or being illiterate, have difficulties in learning foreign languages, and thus they strongly criticize Germany's policy, implying that the chances to migrate to Germany are slim.

It is often claimed that immigrants are generally more likely to be unemployed than non-immigrants of working age, with some ethnic groups suffering more than others, although they are younger and tend to be economically more active than the population as a whole. In Belgium, for instance, the highest unemployment rates are for Turkish and Moroccan nationals (45 per cent for males, 56 per cent for females), compared with an unemployment rate for Belgian nationals of 10 per cent (FRA 2007: 45). It is evident that pressure from socioeconomic conditions has forced the population of the CEECs to accept jobs in the EU that in most cases do not match their educational and professional qualifications.

Similarly, the issue of the movement of skilled labour to the EU is worrying because unskilled Turkish workers may eventually be driven out of the EU labour market. Over the years, it has been especially important to enhance the job experiences and training of Turkish workers in Western European countries, but the process of integrating them into European labour markets invariably runs into problems owing to persisting divergences. There is, however, widespread recognition that Turkish students wishing to learn foreign languages in the EU countries account for a significant share of movements. These migratory movements are not a recent phenomenon: students have been oriented towards Western Europe since the early 1980s. This tendency is likely to continue in the future. This logic may not apply to nationals of the CEECs, who are well ahead of Turkey in terms of language skills.

\section{Risk aversion}

Most people normally exhibit a degree of risk aversion. They will not be willing to migrate if this represents any kind of threat. For this reason, a common attitude is one of "wait and see": if others' migration is successful, their perception of the inherent risks diminishes and they may show a motivation to migrate at that point (Chammartin and Cantú-Bazaldúa 2004: 12). If the internal situation in the CEECs improves, the actual pressure for migration is likely to disappear. It is not surprising that pol- 
itical, social and economic conditions will have the opposite role to play for Turkey.

The essence of the immigration goal is to act as a "safety valve" for the sending countries. The underlying fact is that convergence of income levels contributes to reducing the pressures on migration. This may have significantly positive economic consequences for the sending countries, with the economic growth as a key value through returning migrants, who import both professional skills and capital. The extent to which this is an issue depends on whether migrants are actually able to make a good contribution to economic development. According to migration theories, experience gained in European countries can be transferred and applied in the home country.

From an economic point of view, Turkish government policies need to be reconsidered in order to encourage the process of labour migration. Emigration was supported by successive Turkish governments because of its impact on alleviating unemployment and improving the balance of payments through workers' remittances (Şen 2003: 211). Immigrants sending back remittances can substantially reduce the severity of poverty and create educational and labour opportunities in the country to which remittances are being sent (Bhat 2007: 35). In 2006, remittances to Turkey increased markedly (more than 30 per cent) for the first time since 1998, reaching US $\$ 1.1$ billion or 0.3 per cent of GDP. This is nevertheless still well below the 1998 peak of US\$5.4 billion (OECD 2008: 282). The currently inadequate inflows of workers' remittances and savings imply lower investment, which will result in large numbers of Turks willing to migrate to Europe.

Within the optimistic catch-up scenario, almost all studies on future labour movements from the CEEC-10 countries assume that, after an initial surge, the propensity to migrate will progressively decrease and even eventually lead to a reduction in the stock of migrant workers in the EU15. This optimistic scenario is very dominant in a study commissioned by the EU (CEC 2009). The prospects of convergence of CEEC income levels towards those of the EU-15 are illustrated in Figure 5.10. The average income level in the CEECs in 2000 was only 40 per cent of the EU level. Future forecasts need to take into account economic growth in these countries in coming years. After impressive economic growth (although much lower than the EU-15 average), a lower level of migration pressure is predicted, together with a higher level of economic integration. This will totally change the expected migration flows from the CEECs in the long run.

Applying this reasoning to labour migration from Turkey is intuitively appealing, resting on the assumption that an improvement in living standards will lead to a lower probability of labour flows. 


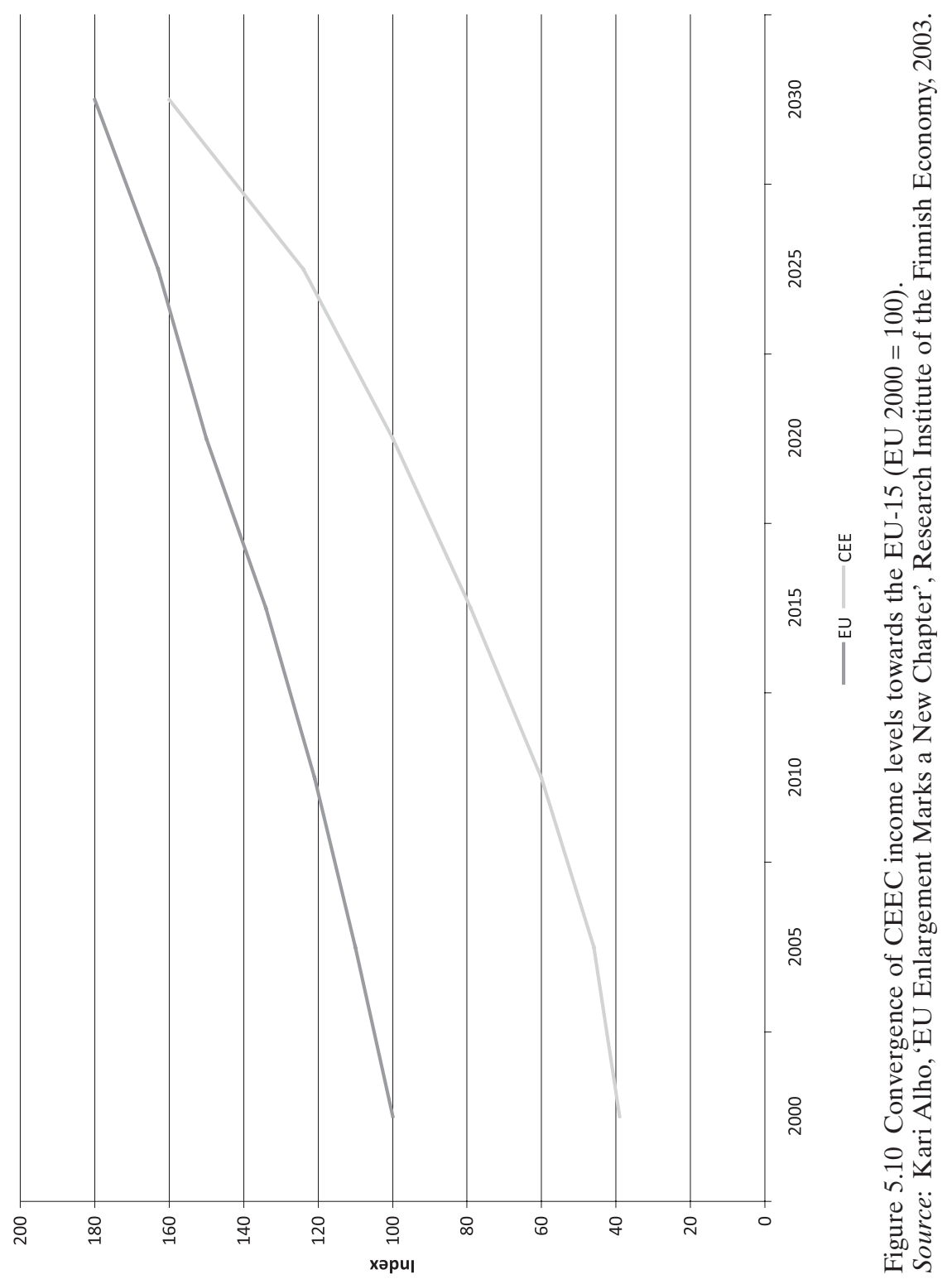


Turkey has considerable growth potential, but even on a positive scenario of average annual growth of 5 per cent through to 2015 - and EU25 growth of $2 \%$ - the Turkish economy by 2015 would only be $2.9 \%$ of EU25 GDP. This means that Turkey's economic impact on the Union and the internal market is likely to be marginal for the Union, though it could be highly positive for Turkey itself. (Hughes 2004: 10)

Obviously, one major concern on the EU side is that Turkey's GDP per capita is around 30 per cent of the EU average - similar to that of Bulgaria and Romania. Even in favourable circumstances, it will take many decades to catch up to the EU average. As noted above, Turkey has very strong regional inequalities. The large rural population is generally much poorer than the urban population. Besides, with crumbling social protection systems, most people will be unlikely to be averse to the risks of migration, despite the strange, unfamiliar culture and the difficult languages in Western Europe.

Politically, it is argued that the process of democratization in the CEEC-10, which were under communist rule for decades, will be reinforced by EU integration. Community policy should contribute to the development and consolidation of democracy and the rule of law as well as respect for human rights and fundamental freedoms. EU membership can therefore be expected to provide plentiful opportunities to build a firmer base in terms of the political process. By the time the CEECs embrace true democratic principles, the decision to migrate will be postponed and ultimately abandoned (Kraus and Schwager 2003: 169).

Actually, these democratic principles, although still discernible in comparative studies, are far more pronounced in Turkey than in the CEECs. Some progress has been made by Turkey towards meeting the Copenhagen political criteria, which require stable institutions guaranteeing democracy, the rule of law, human rights and respect for, and protection of, minorities (CEC 2008g: 6). Since October 2001, eight reform packages have been passed, mostly measures to eliminate regulations and practices that had allowed impunity for torture and ill-treatment. They included a ban on the death penalty, liberalizing the formation of associations and the right to assemble, and granting more rights to religious and ethnic minorities (for example, lifting the ban on the Kurdish language). As an example of the last measure, there are now more opportunities for minorities: a new TV channel, TRT6, was set up to broadcast in Kurdish in January 2008. As many have pointed out, this is a sign of pluralist democracy in Turkey. Despite such impressive legislative progress, Turkey continues to be criticized for human rights abuses. Restrictions on freedom of expression and religious beliefs are the most striking examples. It 
remains the case that limitations in the political arena still constitute incentives for migration in Turkey.

It is hotly debated whether Turkey is a dynamic and complex country, and its attitudes and responses present an unknown future challenge (Baykal 2005: 25). Declining confidence in the governing elites in Turkey may be part of the explanation. An investigation started in 2007 into an allegedly criminal network, known as Ergenekon, led to the arrest of a number of people, including retired army generals. The indictment against Ergenekon, presented on 14 July 2008 by the Istanbul Public Prosecutor's Office, is based on charges such as forming a terrorist organization and attempting to overthrow the government and to undermine its operations by violent means. During the course of the investigation, there were reports of insufficient safeguards for the rights of the defence and excessive detention without indictment (CEC 2008g: 6). During political turmoil of this kind, it is reasonable to expect that Turkish citizens will demand more democratic governance based on respect for human rights and personal freedoms, as they have done, especially since the military coup in September 1980. Undoubtedly, issues such as a ban on political parties or on wearing a headscarf in public places, which are still awaiting changes to the Turkish Constitution, might have serious political, social and psychological effects on the public. In the face of increasing political instability, migration to the EU is expected to rise as long as the EU is seen as a gateway to act.

Conceptual theorizing suggests that, in the short term, political and economic perturbations relating to ethnic conflict tend to conspire to produce sudden shocks to the migratory system, thus leading to large fluctuations in labour movement. Therefore, ethnic and political conflicts generate emigration rather than short-term job-related migration (CEC 2002: 395). In a democratic community, economic freedoms, especially the freedom to move, are supposed to become more effective, because migrants should be able to live with no discrimination. This explains why there are clear preferences by Turks to choose West European countries as a destination, although the main motive for migration is family bonds.

The traditional concept of immigration resulting from political conflict, which explains the redirection of Turkish workers to a "safe haven" during the Gulf War of 1991, is not a concept that fits the East European situation. The collapse of communism in the USSR was accompanied by the break-up of the old Soviet empire and the creation of 15 new independent states, several of which (including Russia) continue to be afflicted by ethnic conflict. Yugoslavia offers the most dramatic example, where ethnic conflict precipitated a full-scale war between Serbia and Croatia in 1991 and led to a civil war in Bosnia in 1992-1996 (Heywood 2007: 36), with a large number of people being displaced. For the CEECs, 
ethnic and minority conflicts may flare up, prompting a flight towards stability and safety. But such moves are, as Salt (1992) rightly pointed out, more likely among ethnic and national groups that have a mother country to return to. Thus, this factor appears to be of lesser importance in the CEECs, but could motivate specific ethnic groups, such as Kurds in the south (east) of Anatolia. Historically, most studies suggest that the major past waves of emigration were often associated with a period of political turmoil alongside economic hardship. On the face of it, a long-standing battle between the Turkish armed forces and the Kurdish guerrilla group PKK is an extreme case. Here, it is easy to make the link between migration and safety as far as the destitute population (owing to socioeconomic factors) is concerned.

Generally, migration theory demonstrates that labour migration can be seen as an investment decision, since migrants weigh the income advantages against the risks and the expenses of movement. The common "wait and see" attitude arises from a number of factors that will be likely to hold back mobility from the CEECs. First, in the macroeconomic context, unemployment still afflicts some countries in the EU or affects the particular skills required in certain jobs. This implies that CEEC workers cannot always expect to earn as much elsewhere in the EU as in their current job in the home country. Secondly, these migrants are discriminated against financially in terms of working conditions, housing and other services. Thirdly, there is the idea that culture causes "great divisions among people", which involves a certain amount of risk. If that is true, then those in the CEEC-10 wishing to work in an EU country other than their own may come up against a language barrier. Finally, on the count of the effectiveness of mobility, migrants are becoming increasingly selective. Current trends in the European labour markets suggest that labour mobility usually occurs in growth industries and in state-of-theart industries. In this respect, there is a requirement for skilled labour. Migrants from Eastern Europe are generally considered to be skilled workers. But even this does not diminish their perception of the inherent risks.

\section{The prospects of labour flows from Turkey}

The EU cannot exercise a zero migration policy even if permanent safeguards are used (Gros 2005: 9). Restrictive labour migration policies are no longer sustainable, because low-skilled workers are coming in as irregular migrants and family members. Borders are also open to tourists and asylum-seekers, which facilitates illegal migration. Without doubt, the broad claim by liberal migration theories that if there is no demand for 
migrants they will be sent back has been irrelevant and cannot be acted on either, except in wartime. Although the EC countries adopted stop policies in the 1970s, labour migration was not preventable and it even increased in magnitude from time to time (Yalçın 2004a: 36). Despite the stop on labour recruitment, 20 per cent of all Turkish nationals of working age entered Germany in 1998-2008. This is mainly the result of family reunification (about one-third of all family unification visas are granted to Turks - about 22,000 in 2003) and asylum-seeking, in which people from Turkey (mainly Kurds) have constituted one of the largest nationality groups (Liebig 2007: 15). Apart from these categories, a small proportion of the Turkish population, especially top-quality specialists and ambitious young people, often travel and spend considerable time in the EU member states (for business and training purposes).

Even under a strict movement regime for workers, there is annual net migration from Turkey to the EU-15 of over 35,000 people. Data from the OECD and SOPEMI records (İçduygu 2003) indicate that gross inflows are between 60,000 and 90,000 and gross outflows are between 30,000 and 40,000. The 2004 Impact Study by the EU Commission (CEC 2004) forecast that immigration from Turkey to the EU-15 until 2030 would range between 0.5 and 4.4 million, assuming the free mobility of labour in about a dozen of years (Erzan et al. 2004: 10).

A study at Boğaziçi University (Erzan et al. 2004) on "Growth and Immigration Scenarios for Turkey and the EU" aimed to capture the strength of potential migration by using long-term projections. Based on EU membership and the right to free movement by 2015, the econometric analysis assumed a certain analogy between the past and the Eastern enlargement. The study focused on three reference groups. The first reference group comprised Turkey and 19 European countries, in different combinations, that had migration episodes in the 1967-2001 period. The study confirmed an increase of 1.1 million migrants in 2030 on the assumption that Turkey would resemble European countries to the extent that it would have caught up with rapid growth by 2015. With the granting of the right to free movement, similar to the guest worker regimes, the stock of Turkish migrants in the EU countries was estimated to be around 1.8 million by 2030. Considering the migration experiences for the period 1986-1997 of the second reference group of countries Greece, Spain and Portugal, which resembled Turkey in terms of economic growth at the time of their accession - similar results were predicted. The study suggested that the migration flows would not exceed 1 million by 2030, with the introduction of a less flexible regime of free movement. Regarding Turkey's migration experiences as a third reference group between 1967 and 2001, the forecast for total net migration from Turkey to the EU-15 by 2030 exceeded 2.1 million. Overall, the 
total number of migrants was expected to reach more than 2.7 million by 2030. Obviously, the forecast was closely related to Turkey's high growth and the introduction of free movement by 2015. Turkey's non-membership status, coupled with a lower growth rate, was taken into account when making these predictions. Hence, the prospect of labour flows from Turkey to the EU is promising, given high unemployment and worsening socioeconomic conditions.

More important studies are based on income differentials between the EU and Turkey and population growth. For instance, the Social and Cultural Planning Office in the Netherlands estimated in 2004 that net migration from Turkey to the EU would be 2.7 million, assuming Turkey became an EU member and would thus benefit from the free movement of labour regime by 2035. For the CEECs, a migration potential of 2.9 million, 15 years after their accession, was estimated. As far as an upper limit is concerned, the Research Centre for East European Studies, University of Bremen, led by Osteuropa Institut München arrived at higher rates and estimated that Germany would have more migrants from Turkey, amounting to almost 4.4 million in the long run (Pleines 2005). With barriers to the implementation of the free movement principle and long transitional periods for Turkey, no spectacular labour migration flows are likely in the foreseeable future.

A key input in any of these predictions is the growth scenario for the EU and Turkey. GDP is expected to grow between 2000 and 2020 at an average annual rate of 2.1 per cent in the EU countries. It is also expected that 9-14 million new jobs will be created in the same period in the EU (European Parliament 2002: 5). This job creation will provide substantial gains for the new accession countries. It is not clear that the EU will generate similar gains in the case of Turkey's accession. Some member states are still hoping for a permanent restriction on Turkish labour movement to prevent mass migration, whereas others have a big need for less-skilled labour. Thus, EU accession should create more paths for legal immigration from Turkey.

The EU and Turkey have already formed a customs union in the manufacturing and services sectors. The process by which the EU establishes standards and regulations in a particular field has introduced "positive" harmonization in Turkey. Despite this positive effect, the degree of openness, the sectoral composition and the level of welfare give rough indications of how the structure of the Turkish economy differs from that of the CEECs. There is greater volatility in Turkey's economic development. Years of high growth are usually followed by years of stagnation. In the 1990s, crisis-ridden Turkey barely grew, and this was followed by the banking crisis of 2000-2001. During the 2002-2006 period, the economy grew by 7.2 per cent on average and employment increased by 0.7 per 
cent annually (State Planning Organization 2008). Arguably, this brighter growth was mainly because of the opening of negotiations with the EU for accession.

The future of labour flows to the EU-15 largely depends on long-term socioeconomic developments, political stability in Turkey and the migration policies of the EU member states. The prospect of applying safeguard clauses on labour movement that are based solely on these grounds may have a detrimental effect on political and economic stability in Turkey. As past migration experience shows, restriction may quickly trigger migration potential via family reunification or irregular migration.

Since the advent of the single European market, within which the free movement of persons was to occur, many measures have been adopted to encourage people to move within the EU. Yet people still prefer to stay at home. Similarly, as the Berlin Wall and the Soviet Union were collapsing, there was great concern and panic that millions of Russians and East Europeans were going to flood into Western Europe. It did not happen. What happened was that migration remained at manageable levels (excluding refugee movements resulting from the violence in the former Yugoslavia). In the end, approximately 1.2 million people, mostly of German and Jewish origin, emigrated in the first three years to Germany and Israel. Furthermore, most of the Russians (22-25 million) left outside Russia in the Baltic states and the former Soviet Republics stayed put too (Erzan and Kirişci 2004: 64). For Turks, the scenario of economic, social and political backwardness in Turkey may reduce their readiness to migrate to the EU, although it is not possible to exclude the fact simply the prospect of having the opportunity to move. Likewise, CEEC nationals may stay put owing to the relative strength of their country economies - a strength that contrasts with economic weaknesses in Turkey.

To some extent, migration forecasts that depend on the advantages of membership (labour movement) neglect the history of Turkish membership, which is full of stops and starts. With no prospect of accession, an increase in labour flows can be expected in the short and medium term. It is reasonable to assume that EU membership is likely to curb a large inflow of migrants from Turkey. Even in a restrictive context, immigration will continue, but the size and patterns of immigration will change. Essentially, these kinds of considerations are uppermost in the debate about Turkey's accession to the EU. Certainly, such considerations have already forced Turkey to undergo some processes of harmonization in relation to its labour market.

In fact, it is difficult to estimate labour flows from Turkey, given the uncertainty surrounding the negotiation initiatives for Turkey's accession as a candidate country and the length of the period for granting the right 
to free movement even after Turkey joins the EU. Apart from the long accession negotiation process, the attitudes of EU officials towards the free movement of labour during this process - mostly uncompromising are equally important. Such factors no doubt reflect a particular policy in some EU countries that may not be found in others.

One might even go further and be tempted to say that Turkey is a special case because it has been more than 40 years since Turkey applied for EU membership and it should be considered on its merits. Remarks by Professor Çinar Özen on the Turkish channel TRT1 on 30 January 2008 reflected a similar view:

Turkey is different and can not be comparable to the CEECs. A "special partnership" instead of full membership (with a permanent restriction on the free movement of labour) is the likely option on the basis of the current nature of Turkey-EU relations. Here, both the EU and Turkey should be assigned crucial roles as to keep this balance properly, which may be beneficial for two sides in the long run (Turkey and EU relations). (Özen 2008)

Thus, the prospect of freeing Turkey's labour force into the European market seems bleak.

Both those in favour of, and those opposed to, the free movement of labour after enlargement must adequately take into account the benefits of larger markets, possibilities for outsourcing and cheaper labour (Radeva 2004: 1). For Turkey, the situation is not so desperate. Turkey has a young population. The ratio of working adults to the total population is currently 65 per cent, and will approach 70 per cent in 2025 before starting to decline - a phenomenon called "the population window opportunity" (Erzan and Kirişci 2004: 63). As has been shown, population ageing is already a fact. The rapid ageing of Europe's population will cause a serious shortage of labour in the long run. Concerns about very low fertility and its consequences are spreading in the EU-15, and in the CEECs in particular. The CEECs are rapidly ageing and are expected to become the oldest populations in the region by 2050 , with an increasing proportion of the very old (over 80). If that is the case, then it may continue to be more rewarding to look to Turkey to alleviate labour shortages, as was the case in the post-war boom in Europe in the 1960s. Dynamic, young and relatively well-educated people from Turkey could "heal the wound" in the long run. By doing so, they could help cushion the looming pension crisis across an otherwise mostly ageing continent.

As already noted, the EU-15 member states naturally import, or have imported, foreign labour to fill skilled labour shortages where the CEECs cannot meet the labour demand of the EU-15 countries. As far as the EU's policy is concerned, continued reliance on foreign workers cannot 
be taken for granted. The costs of migration as a function of distance are probably the main motivation in the decision to migrate. In spite of this, signs are already emerging that European employers are using foreign labour to displace more expensive indigenous labour. But the employment of skilled labour was inconsistent with policy regimes back in the 1960s when European countries encouraged large-scale immigration. Countries in the Far East are undergoing periods of relatively fast development or transition and their populations are most likely to move to the European mainland. However, this option is likely to be exhausted rather quickly because importing workers from culturally different or geographically distant areas is too costly. The Turkish labour force will undoubtedly prove to be too expensive to employ.

The distinction, or lack of it in this case, between the skill composition of the labour forces of Turkey and of the CEECs can be related to EU policy-making. In this sense, one can conclude that future migration in the EU will be based on special immigration rules for highly skilled workers, especially in management and in information and communication technologies. However, some commentators suggest that any future migration will be from the unskilled and younger section of the population. As long as demand for unskilled workers in the EU and youth unemployment in Turkey remains high, this will continue to be the case. Historically, there has actually been some downgrading or diminishment in the skills of migrants, as was the case with some Turkish workers in Germany during the 1960-1973 period. In this situation, it is not just the immigrants but also the host country that failed to reap the full benefits of the available human capital (IOM 2005: 9). Given the ongoing ruralto-urban migration in Turkey, unskilled workers from the rural areas will look to EU labour markets. The experiences of the South European countries suggest this is a relevant factor.

More generally, despite the provisions for completely free movement of labour within the EU, the populations of the CEECs tend to stay put. Greece, Spain and Portugal were much poorer than the existing EC members when they joined the Community in the 1980s, but their citizens did not move en masse. By the time Turkey converges more towards the average income levels of the EU-27, this may eventually dampen migration flows in the medium term. However, this is not very likely to happen if one takes into account Turkey's overall circumstances. Perhaps this claim about the economic backwardness of Turkey will carry more weight, especially in the face of the current global economic crisis, as more businesses go bankrupt, mainly in the industrial regions of Turkey, leaving more people out of work. There are social and cultural difficulties in integrating Turkish workers into a different or even hostile society. In spite of this, Turks are unlikely to lose their desire to move. 


\section{Conclusion}

It can be concluded that no massive migration is to be expected, nor will there be substantial adverse effects on Turkish labour movement, which should contribute to calming fears. This is despite the fact that an important point of disagreement among the analysts is the predicted change in the patterns of East-West migration within the EU. The effect of the enlargement on EU migratory trends will most likely be similar to that of the accession of Greece, Spain and Portugal. The sudden freedom might induce many more nationals of the CEEC to move but, after an initial period of strong immigration, net migration flows are likely to decrease thereafter.

In any event, the weaker economies of the CEECs will certainly provide incentives for their citizens to migrate in search of work. On the one hand, based on the significant unemployment (wage) and income gap between the CEECs and Turkey, in addition to the existence of social networks, geographical distance and the problem of social provision, the Eastern accession will have a negative effect on labour movement from Turkey. The enlargement poses problems of scale and new migration flows from the CEECs may create obstacles for Turkey. Rather than resulting in substantial labour flows from Turkey, it is more likely that such flows will originate in the CEECs. Therefore, the probability of Turkish labour movement is negatively related to these key factors.

On the other hand, it is not obvious that there will be a low propensity to migrate from Turkey into the EU as a result of the Eastern enlargement. The CEECs tend to attract increasing amounts of FDI, growing foreign trade and an inflow of European funds, despite the fact that the income gap is still significant between the EU-15 and the CEECs. This will push up GDP per capita and will create employment. People have been migrating into the EU-15 since the beginning of the 1990s and the tide of return migration is already strong. Even at the onset of their transitional periods, these countries are already switching from their traditional role as sending countries. In the long run, anticipated labour flows will probably continue at a limited level, even after the restrictions are lifted, because of the drastically falling population of the CEECs. This trend suggests that sooner rather than later the drain of human resources will become a key challenge for the CEECs, if not also for the EU-15. Other factors such as large internal differences, social and cultural ties and people's risk aversion play important roles. The effect of migration from Eastern Europe will diminish, and thus these factors will reduce the potential for additional flows. All these features lead to the conclusion that factors promoting migration will be much stronger in Turkey than in the CEECs. 
The predictions for future labour flows from Turkey have been derived from the free movement experiences of some EU countries to which Turkey may follow suit, catching up with rapid growth and with no barriers to the movement of its labour by 2015 . As the studies suggest, very large labour mobility can occur for social and economic reasons, despite cultural differences. In the meantime, the factors that cause migration from Turkey will always prevail, regardless of the right to the free movement of labour. Factors such as unemployment, wage levels, GDP per capita and social standards are far more influential in reinforcing the propensity to move from Turkey regardless of its membership prospects or the completion of the accession process. As long as these factors persist in Turkey, there will be migration pressure that will significantly affect European labour markets in the medium and long term. From this point of view, the granting of the right to free movement will depend on an improvement in socioeconomic indicators. As regards fears that labour migration from Turkey will occur on a massive scale, account should be taken of the factors that trigger labour mobility from Turkey, which are likely to remain even in the absence of the right to free movement. 
6

\section{Concluding remarks}

This analysis has been undertaken with the objective of evaluating the possible impact of the Eastern enlargement of the European Union (EU) on Turkish labour movement. It is concerned with why the variation in Turkish flows over the years has occurred, given the changing volume and nature of the mobility rate since 1961 . The purpose was to explore, on the one hand, the ways in which enlargement presented challenges for Turkey, and, on the other, how changes in the legal landscape within the EU and at the national level affected Turkish migration. This necessitated an analysis of changing EU and national policies governing the principle of Turkish workers' movement, and an exploration of the political and social factors both within Turkey and the EU member states that have modified the flow rate. The Southern enlargement has been an important component of this study, which extrapolated from past experiences the various possible developments could be identified for Turkey in the migration of its workforce to European labour markets. Thus, the Southern enlargement of the European Community (EC) in the 1980s provides a benchmark for assessing the enlargement to the Central and East European countries (CEECs).

The study of the Eastern enlargement adds an important new dimension to the study and understanding of the pattern of Turkish labour migration. This is a particular challenge for Turkey. First, it draws attention to the links between the Southern accession countries and the 10 CEECs concerning population size and wage and income gaps that are greater relative to the EU than those of Spain, Greece and Portugal. While some

EU enlargement and Turkish labour migration, $O \breve{g} u z$,

United Nations University Press, 2012, ISBN 978-92-808-1206-0 
accounts still focus on the costs of migration (including the psychological costs), of major concern for Western economies are the effects on the labour markets caused by concentrated migration from the CEECs. Second, in contrast to the previous enlargement, transitional periods were introduced in 2004 in relation to the CEECs. Third, these transitional periods make it necessary to analyse the special measures for Turkey by the EU decision-makers in the form of "permanent curbs" through a concentration on the particular level of the first waves of workers from the CEECs. Rather, the study of the prolonged problems of "digestion" links with the political and socioeconomic situation in the enlarged EU, showing how little labour mobility from Turkey to West European countries has actually been taking place since the halt in migration of 1973. As with so much in European labour market trends, many of the outcomes here have still to be decided.

An overview of the history of Turkish migration demonstrated that underlying the past pattern of labour migration was European demand for Turkish workers, resulting from a phase of rapid economic development after the Second World War in Europe. Starting in the early 1960s and continuing well into the 1970s, Turkish labour migration to West European countries, particularly to West Germany, increased much more rapidly than in other periods, when mobility was permissible under bilateral recruitment agreements. Turkey's experience shows that a pattern associated with one particular constellation of economic and social conditions will not remain unchanged forever. The economic crisis of the mid-1970s caused by the increase in oil prices in 1973 brought an end to employment-related migration. Countries in the West abandoned policies of migrant labour recruitment and moved towards increasingly restrictive entry rules. In effect, whatever the outcome, demand for Turkish workers in this particular period indicated the potential need for a Turkish workforce, as European countries tried to meet the deficit of supply in their labour forces.

The trends immediately after the Association Agreement of 1963 between the Community and Turkey may be regarded as positive, but Turks seem genuinely to have been unable to grasp that benefit. With regard to the legal instruments prior to the 1980s, the critical historical factor was the provision of free movement in return for a loss of membership prospects. In the late 1980s, this rhetoric was changed, although there were still controversies regarding Turkish labour migration. Since then, the main emphasis has been on Community membership as a way of securing the principle of free movement.

The study attempted to place the patterns and trends of Turkish labour migration into a coherent framework. Turkey has, since the 1950s, experienced four major periods of movement, each associated with particular 
economic, social, political, legal and cultural factors. Since the halt in migration of 1973, there have been a few smaller but also relatively moderate periods of movement, such as the frantic labour migration of the second half of the 1970s, desperate flows resulting from human rights abuses in Turkey in the 1980s and the redirection of flows consequent upon the political conflict in the Middle East in the early 1990s. The study indicated that there has been a demand for unskilled Turkish workers in the 2000s. However, Turkey faced many difficulties in exporting its workforce abroad owing to active employment-related migration policies in the post-enlargement period. More selective policies consisting of more quotas have imposed a significant burden on the migration system. Nonetheless, Turkey is still supplying workers. When Turkish labour migration was restricted during certain periods, individual countries also had migration events, with an emphasis on racially related political violence in some West European countries in the late 1970s, ethnic conflict in Germany (the Kurdish refugee flows) in the 1990s and the labour market restructuring in Switzerland in the early 2000s.

The phases identified in this study should be regarded as mutually exclusive, although, to a certain extent, they contain a strong element of overlap. This is particularly relevant in that the aspiration of Turks to free access to European labour markets was explained mainly by economic reasons. In the early migration periods, Turks sought employment in Europe for economic gain, not because they wanted to integrate into and assimilate with the host nation culture. The 1961-2008 period displayed considerable economic migration, although political migration also occurred. To understand the magnitude of the flows to West European countries, one needs to consider Turkish migration inflows in the last decade (for example to Germany), which are large enough to increase the population significantly with regard to employment-related migration.

The analysis has shown that the restrictive policies of the Community fuelled further migration. Since the halt, family reunifications have accounted for significant inflows, although the numbers are much lower than in the 1961-1973 period. This is to say, the flow rate to the West has not been stopped, although it has been unstable or has decreased over time. Thus, Turkish nationals are taking advantage of the more limited freedom of movement rules since 1973. This markedly lower level of flows does not reflect a true fall in the number of workers, but rather is a reflection of substantial labour migration. On this evidence, the EU member states will continue to suck in many Turkish workers. There is still a tendency to employ skilled Turkish workers, regardless of changes in the migration policies of the EU member states or in perceptions of Turks in the EU. Looking at the numbers of Turkish workers in various countries, it is difficult to determine how far the block will remain in place. 
The evidence presented has shown that Turkish migration patterns are more diverse than most studies indicate. Today, the significance of Turkish labour flows varies within different geographical networks. With the halt in migration to the Community, increasingly desperate migrants changed their destination to other countries, mainly in the Middle East. In this context, one has to see cultural affiliation promoting the direction of flows. Against this background of continued labour migration to the East, the attachment to the West is likely to remain robust. It is important to realize that Turks have always been enthusiastic about labour movement. A clear trend of increasing numbers of Turkish workers in West European countries in the early 1990s is recorded, and a downward trend in the figures for annual Turkish labour migration to other countries is observed. What has changed since early 2006 is that a slight upsurge in labour migration to the West was detected, with a sharp fall in 2008. Much can be learned from a careful evaluation of recent EU-Turkey history in the context of labour migration.

There remain some reservations about how the principle of free movement is relevant to Turkey. At the same time, the structural underpinning of Turkish labour migration has been implicit throughout much of the foregoing account. Whether or not Turkish labour mobility has worked well is another matter, but the particular challenges that are addressed will depend partly on understanding the reasons for Turkey's claim to labour movement. A basic reason for including workers derives from the Association Agreement and the Additional Protocol, both of which provide Turkey with legal tools. The hierarchy of Community law and the economic argument are equally important. Assessing the decisions of the Association Council on the matter, there needs to be a swift resolution of the debate. It may then be possible to eliminate old and current perceptions. Yet, even if one is ready to admit the legitimacy of labour movement, there is little to support the implementation of the principle and the outcome of the Council's decisions. As the study shows, with a number of problems holding up agreements between the EU member states and Turkey, progress on the legal instruments for labour mobility is slower than had been hoped. The extent and impact of the various types of legislation in each member state upon migration are likely to delay the implementation of any such decisions.

More importantly, this perception also applies to the rulings of the European Court of Justice on conditions on entry and visa exemptions for employment categories of Turkish nationals. In fact, the outcome of these judgments, which should now be extended to the other EU countries, necessitates that the EU decision-makers reinterpret the term "standstill provision" in terms of allowing Turkish workers free access to European labour markets. Ideally, the right of free movement laid down in the 
Ankara Agreement and the Additional Protocol means that EU governments must allow Turkish workers to move freely to establish themselves as, for example, business persons or service providers. Basically, the disadvantageous immigration rules, especially on entry, should be reduced so that Turkish nationals are subject to more favourable treatment. If the legal means come to the fore, there will be substantial implications for the future flow rate.

The study has underscored the importance of incorporating past, current and future debates about pull migration in the European context. In this context, a review of the experiences of past EU enlargements suggests that economic pressures did not push many migrants from Greece, Spain and Portugal towards the EC countries. Although these countries faced a relatively high level of unemployment, movement occurred in very limited numbers after the introduction of the free movement of labour. Most people "stayed put" or returned home after just a few years. It is interesting to note that the probability of labour migration was negatively related to economic variables in the Southern accession countries. Consequently, the seven-year transitional period for Spain and Portugal was reduced one year before the expiry date owing to the fact that fears of a major migration wave proved to be without foundation. Obviously, all prosperous EC countries provided very high standards of living but they were not attractive destinations for immigration. The Southern experience raises the question of whether or not push migration is avoidable. This should be studied further.

Beyond the limitations raised in this study, several key variables related to the Southern accession countries and Turkey in the 1980s were discussed. With the Southern enlargement, the prospect of labour movement from Turkey, envisaged by 1986, filled the EC with dread. The EC was fully aware of the economic and social consequences of labour migration, and thus sought to put discriminatory rules in place. The emphasis was usually on the more negative externalities. Such externalities were related to the difficulties of European countries in integrating Turkey with a possibly large number of migrants - into their labour markets. The chapter looked at the debate in terms of the cultural differences between Turkey and the Southern accession countries (identity, political instability, etc.). This is the key to understanding the Community's positive approach to the inclusion of Greece, Spain and Portugal and their eligibility for labour movement because it enhanced the possibility of culturally similar workers. This last point is disputable, but the cultural argument in itself is not very helpful in explaining the important problems. Issues concerning Turkey's socioeconomic development, the nature of human capital, demographic trends and geographical proximity were all linked in an important way with Turkey's projected labour migration. 
Therefore, examining the Southern enlargement, this must have significant implications for Turkish labour flows because the EC developed a special relationship with the Southern accession countries. In the second half of the 1980s, the admission of Greece, Spain and Portugal kept Turkish migrants at a lower level than expected. The enlargement demonstrated that the conditions of past Turkish labour migration might become major issues, pointing especially to those with implications for future development.

It should be apparent from Chapter 4 that the rights to free movement were initiated in the early days of the European Economic Community with a focus on the movement of Europeans, but rights for third-country nationals were limited. However, the Community moved away from this position and introduced the notion of guest worker in the early 1960s, when the indigenous labour force failed to keep pace with economic growth. At a simple level, it was noticeable that the recruitment of foreign workers was no longer viable because of the recession at the end of the 1970s. While the EC became a more closely integrated economic area in the mid-1980s, pressure mounted to develop a comprehensive approach towards migration policy. Underpinning the policy on the temporary entry of persons, the Schengen Agreement of 1985 was designed to promote the free movement of people, more specifically concerning measures with regard to the abolition of checks at internal borders. The single market programme was linked to certain converging trends, particularly strengthening existing competence in Justice and Home Affairs and thus overcoming the obstacles to progress. With the treaties of Maastricht and Amsterdam, a steady increase in cooperation on international migration was observed in the late 1990s. These treaties were characterized as positive steps, each defining more active common policy elements. Although these treaties provided a framework for cooperation among member states, the member states have tended to follow a different structure and orientation according to their national interests.

The chapter also sketched how East-West migration resulting from the Eastern enlargement has added a new dimension to the migration policies of the EU. In particular, it was concerned with the fears that labour migration would occur en masse. To calm these fears, the accession treaties allowed for the introduction of transitional measures, similar to those in the arrangements for the Southern accession countries in the 1980s. The EU-15 member states were obliged to declare their labour markets open or keep restrictions in place until 2014. It is important in this context to see that the globalization process led to new recruitment approaches in the post-enlargement period. Obviously, the policies of the national governments have been more selective regarding active employment-related migration. Here, it is useful to consider the question 
of what category of workers or countries should supply labour in the enlarged EU.

The chapter also showed how, and in what circumstances, EU authority was divided, since the member states have demonstrated conflicting attitudes towards migration issues. It pointed out that the issue has been played down by the underlying mechanisms - the EU legal framework as well as by the impact of national governments' different policy regimes. The harmonization of immigration rules is evidently important in explaining the varying degrees of the flow rate. Turkish labour migration - and the ways in which the various policies affect it - is affected by national laws since the fluctuations were, to some extent, in line with concerns relating to divergent migration policies. The EU authorities should further question the role of harmonization in the changing patterns of immigration. The rules that have been adopted so far should establish a common EU-wide regime. As past historical flow rates have demonstrated, more restricted migration will inevitably encourage Turkish migration flows. The reason is that workers who would otherwise wish to return home for a certain period will be reluctant to do so if tightening border controls make them fear for their ability to re-enter.

Just as importantly, public attitudes towards the bulk of Turkish immigrants are, it was argued, central; at the least, they lead strong domestic opposition in most member states. Here, the claim of the challenge of Turkish labour migration is particularly appropriate. A response to this claim is mainly based on economic reasoning. It is probably more convincing to see the challenge resulting from growing domestic political pressure; the EU should now prepare to make a new offer to Turkey. This means that, although similar economic, social, political and cultural problems were predominant in the Turkish migration pattern, the old migration policy should be superseded. Theoretically, a more hard-line attitude, which was adopted in order to appear responsive to public concerns, will cause an increase in labour flows. The risk of a "spill-over effect" of restrictive measures should be avoided. However, apart from being the collective expression of attitudes about migration issues, public opinion is generally regarded as impulsive and fickle. It is difficult to follow in large and complex European societies, and thus should always be treated with some caution.

It was also argued that, to understand the EU's stance more fully, one needs to examine the ways in which migration is made visible in West European countries. The emphasis was on considerable prima facie evidence, which needs to be reconciled and rationalized given the labour shortages in the EU. The grim realities of the longer-run international migration potential (the issues of culture, religion and security) put EU decision-makers at odds because they have become more precautionary 
in terms of future flows from Turkey. In recent years, the trend has been towards a stricter stance against immigrants. The simple truth is that, under the influence of domestic politics, the situation of Turkish workers is made worse by negative dynamics. The political impact of "9/11" also affected Turkish migration; some kind of legitimate resistance by the EU to Turkish labour flows is real - albeit perhaps rather more elusive. Freedom of movement can be seen as a potent weapon, which can be used to combat the social exclusion of Turkish workers from European labour markets.

Chapter 5 demonstrated that attempts to measure East-West migration have gained in importance since the 2004 enlargement. This is because labour migration has increasingly become more prevalent at the EU level. It is possible to get a sense of the overall scale of flows and some key characteristics, even though there are problems evaluating the migration potential. The overall estimates of East-West migration presented by various studies suggest that labour migration will fall to a low level after a period of moderate increase, which is similar to the migration pattern of the Southern accession countries. These studies underestimate the level of migration because of a combination of changing trends in demand and supply, but the fear of large migration movements from the CEECs to the EU is still significant in terms of their relative socioeconomic development. Since the enlargement of 2004, there have been substantial labour flows from the new accession countries to the EU. Nevertheless, these flows are still moderate. As indicated in Chapter 5, there has been a fundamental shift from permanent labour migration to temporary migration in the EU. This is inevitable, if not always smooth.

There are many realities relating to the question of whether or not the Eastern enlargement will defer Turkish labour flows into the EU. To varying degrees, several variables appear to be restraining Turkish labour flows.

There are substantial differences in terms of unemployment rates between the CEECs and the EU-15. Because the unemployment rate varies across the CEECs and the EU member states, it might be expected that labour migration will occur between specific countries. When Turkey is compared with both the CEECs and the EU, the differences are remarkable: unemployment is a major problem for Turkey and seems likely to remain so for some time. Other concerns (themselves related to migration) are Turkey's large agricultural labour force and relatively small industrial sector. That said, Turkish workers are largely unskilled. The daunting practical obstacles relating to skills often make Turkish people significantly less mobile than the population of the CEECs. Turkey has low human capital in comparison with the CEECs, which are fairly close to the EU average. It should be noted, however, that Turkey ranked higher in terms of tertiary education graduates than most of the CEECs (with 
the exception of Poland). This evidence suggests that second-generation young Turkish people arriving in European labour markets usually have higher levels of education and training than their parents. Increasingly, young workers have engaged in employment with a "national profile" in contrast to the jobs typically held by first-generation Turkish immigrants.

Looking at it from the point of view of skill composition, future Union arrangements may use skill difference as one basis for excluding Turkish workers, because, in the post-enlargement period, mobility in the EU is increasingly becoming a migration of highly skilled workers. This acceptance of difference has been visible in Turkish communities in various old EU countries. New opportunities occur for highly qualified workers and specialists in the border areas of the CEECs, as the countries catch up in terms of human capital. The underlying trend is that a number of European countries are currently filling positions in some sectors, such as services and manufacturing, through recourse to workers from third countries, despite the migration pressure in Turkey. However, certain employers in EU countries are still ready to employ Turkish migrants, even though the relative skill composition of the reservoir of potential migrants has not changed. Naturally, there can be no question of granting special status to the best-qualified Turkish workers.

Turning to minimum wages, the picture is more promising. By comparison with the CEECs, the minimum wage is higher in Turkey (although well below that in Slovenia), suggesting little effective impact on flows. This difference between the CEECs and the EU relative to Turkey is substantial (with the exception of Slovenia). The gap in wage levels presents a sufficient stimulus for migration. Even so, there will be less tendency to employ Turkish workers by European companies because of high labour costs. Essentially, owing to the level of the minimum wage, labour migration from the CEECs is likely to occur, as those countries significantly differ from Turkey.

A higher proportion of Turkish labour migration is affected by GDP per capita. Because relative income disparities between the CEECs and the EU are significant, this measure is widely considered to be an important factor influencing the incentive to immigrate. For Turkey, the gap in this factor is even larger. A comparison of Turkey with Bulgaria and Romania, however, gives indications of a rough order of magnitude in GDP per capita. Whether growth in GDP per capita will lead to the lowest outward mobility in the CEECs as soon as they converge is an important question. It is difficult to draw any broad conclusions, but it is possible to discern differences in growth performance between the CEECs and the EU member states that seem to be still significant in the long run. Considerable interest attaches to the question of how much Turkey will contribute to the EU budget and how much funding it will receive based 
solely on its income gap. Even though Turkey is the object of targeted efforts by the EU's Structural Funds, the new accession countries are able to impose their views on how grant aid should be used owing to their voting powers. The Southern accession countries were in a similar position in the 1980s. In the future, labour migration is likely to occur in the long run to a larger extent.

Although it is not clear whether migration flows can be directly attributed to the network effect, at present social networks are well established and provide a strong link between the CEECs and the West. Within the EU, proximity in relation to the CEECs has already given rise to commuting in border regions, in comparison with migrants from more distant countries - i.e. Turkey. These modes of movement are equally relevant economically, even though they fall outside a strict interpretation of migration. Unlike Turkey, potential migrants from the CEECs have strong family connections and regional proximity. The nature of Turkish migrants' networks tends to be different from the CEEC profiles, in that the existence of prior migrants from the CEECs will encourage more migration by reducing transaction costs. Despite long-established historical ties between Turkey and the West and the existence of a significant Turkish population in the EU countries, geographical distance seems to be an additional challenge to Turkish labour mobility. Overall, a series of factors will promote labour migration from the CEECs, whereas the same factors will have a negative impact on Turkish migration.

Not surprisingly, labour mobility is limited when one sees the extent of the weak social provision system in Turkey. The EU-15 member states are disinclined to accept claims for welfare benefits by Turkish migrants, because they would place a strain on public services such as healthcare and education. The percentage of the Turkish population aged over 65 years that risks falling below the poverty line after social transfers is higher than that in the CEECs, implying a danger of social exclusion on account of material deprivation. Moreover, less public expenditure on education will become increasingly contentious. The fact that the workers from the CEECs are relatively better educated and higher skilled reduces the pressure on national governments and on firms to provide training, whereas there are limited measures, rights, entitlements and provisions in the social policy field in Turkey. In other words, the increasing similarity between the skill levels of CEEC and the EU workers compared with those of Turkish nationals means that there will be a substantial propensity to migrate from the CEECs to the EU.

Notwithstanding all these characteristics, labour flows from the CEECs to the EU are by no means structurally stable or at least regular. Although EU labour markets have become more open, in both absolute and relative terms, to workers from the CEECs in the last few years, 
these flows can frequently change form and intensity. There will certainly be labour movement from Turkey to the EU. Several variables may finally reverse the migration tendency. Six variables are especially important in stimulating Turkish labour migration.

First, the CEECs have for a long time had a greater capacity to attract foreign direct investment (FDI) and have received larger and more flexible funding from the Structural and Cohesion funds. The beneficial effect of such developments is that many people end up finding employment in the destination country, where a catching-up economy is successful in creating the conditions for broad-based economic growth and job creation regardless of wage differentials. This explanation is an important clue to why an expectation of economic growth in the CEECs is crucial in terms of deferring labour flows when one considers that they are "catching-up economies". From a dynamic perspective, accession itself can be expected to promote a more rapid convergence of the poorer new member states with the average level of the EU-15. As these countries catch up with the EU average, in principle any labour flows will be likely to decrease in the medium or long term. So, the incentive to migrate will disappear relative to the cost that migration entails. At this point, Turkey will face a considerable handicap in a "convergence race" with the CEECs. This is not entirely accidental, and this fact becomes apparent when one takes into account FDI in Turkey and the relatively small volume of trade with the EU-15, coupled with insufficient financial assistance. Overall, it is reasonable to suggest that migration pressure will continue to persist in Turkey even in the long run.

Second, it is not particularly surprising that, even after the end of the transitional arrangements in some EU member states, workers from the CEECs will return to their home country after a short stay. And these countries are bound to experience a large wave of returns in the future. Current return migration is, to a certain extent, historically determined. The intensity and volume of migration flows in the CEECs observed in the 2000s differed significantly from those in the first half of the 1990s. Labour mobility is now rather limited, in that people who had already taken the step to move out of their region in the past have no intention of moving. Economic and social factors are no less important for this migration pattern. In this sense, various concerns including tough living conditions, poor housing and low wages are particularly relevant. In fact, the main migration host countries (most notably the United Kingdom) are beginning to prove less attractive to CEEC nationals, since many workers (mainly Polish) are tending to choose to return. Past experience suggests that a more restrictive migration policy will inevitably discourage return migration. The reason is that workers who would otherwise wish to return home after a certain period will be reluctant to do so if tightening 
border controls make them fear for their ability to re-enter. No spectacular Turkish return migration is likely in the long run. For all the importance of employment, the available evidence shows that more and more Turkish immigrants are setting up companies as entrepreneurs across European countries. In conjunction with a high Turkish immigrant population, for instance in Germany, the number of Turkish entrepreneurs has more than doubled since the early 1990s. The Turks are permanently settled in European countries. Such settlements will certainly discourage return migration.

Third, future Turkish labour flows will, in part, depend on demographic change both in the EU and in the CEECs. This situation is illustrated by the trend of rapidly ageing populations in the EU and fertility decline or decreasing population size in the CEECs. These demographic trends are often identified as one of the main reasons why East-West migration is unlikely to occur in substantial numbers. In contrast to the CEECs, Turkey represents great demographic potential. On the one hand, Turkey's demographic structure should provide the EU with an opportunity to review its future enlargement policy. It will have to make the necessary policy changes in accordance with demographic trends. On the other hand, in the decision to grant Turkish workers shorter or longer transitional periods, an emphasis should be placed on demographic factors. With a low level of employment, it is likely that Turkey will accept even longer transitional periods, whereas such arrangements are seven years for the CEECs. Again, the argument should be supported by demographic variables pointing to the population potential of Turkey. For a long time, demographic dynamics will continue to be a key factor in Turkish migration trends. This leads one to conclude that the predictions of flows rate from Turkey to the EU based on demographic trends represent reliable forecasts of likely migration flows.

Fourth, it can be concluded that a series of internal inequalities in the CEECs that derive largely from communist planning will restrain labour migration. A large proportion of the population who feel resentful towards the current situation have rather negative views about the benefits of long-distance mobility. Instead, internal migration in the region has grown enormously. In this case, migration is linked to pull factors.

This conclusion cannot be applied to Turkey, although a considerable level of seasonal labour migration occurs from less developed to prosperous regions. Regional differences in Turkey are more striking than those in the CEECs. A greater degree of income inequality and a high level of unemployment in rural areas are the major concerns. The actual situation in Turkey is much more complex for the EU as far as the spectre of a massive influx of poor Anatolian migrant peasants is concerned. In short, Turkey is poor relative to the CEECs and the EU average and its econ- 
omy is more fragile. The factors relating to welfare provision suggest that the movement of Turkish workers will continue.

Fifth, potential migrants from the CEECs have family connections in destination countries and speak a foreign language. By all accounts, there has been very substantial cultural integration of the population of the CEECs. Cultural differences between Turkey and the EU are larger than in any other instance (the CEECs) and will not disappear upon Turkey's entry to the Union. Turkish migrants have already faced specific problems, such as linguistic difficulties and religious differences, that have adversely affected their social integration. From this perspective, it is doubtful how beneficial the Turkish workers will be to the EU in the long run. Against this background, the emphasis now is on the Turkish migrants currently living in the EU member states. Turks have moved to and out of Europe for decades, doing much to contribute to the social and economic well-being of European countries, given the potential of Turkish self-employment in European countries. No doubt, many of today's Turkish migrants do not look so different and are more widely integrated, if not fully assimilated; the Turkish workers' situation may be easier in the post-enlargement period in comparison with the earlier period. These experiences certainly provide us with useful lessons on how such a situation is conducive to the transfer of labour from Turkey to the EU in the foreseeable future. In the main, having emphasized that a large part of cultural integration involves a series of common attitudes and beliefs, the extent of Turkey's commitment to European values should not be underestimated.

Sixth, a common sense argument admits that the intention to move depends on socio-psychological factors, especially for longer periods of migration. For the nationals of the CEECs, desire and deeds differ considerably. Most value mobility but are too risk-averse to pursue it, because that mobility might threaten their sense of security. Apart from this, within the optimist catch-up scenario - often already having been granted the right to free movement at the end of the transitional periods - migration pressure in the CEECs will be diminished. Meanwhile, the economic and social facts concerning Turkish labour migration will continue to be drivers of migration. On the political front, Turkey is still far from meeting the Copenhagen political criteria. This is despite the fact that some positive trends are observed within the Accession Partnership framework. Deficiencies in democracy and the rule of law and the human rights record remain areas of concern. All in all, the instability of Turkey's political system will add an important dimension to future labour migration.

As was explained in Chapter 5, some studies have estimated the future potential of Turkish labour migration to the EU. Although these studies 
are more or less inconclusive, the prediction of migration from Turkey to the EU is a crucial factor that will determine Turkey's membership prospects (as well as the transitional periods) during the accession process.

Apart from anything else, the characteristics of Turkish workers who are yet to be allowed to move merits reconsideration after the enlargement. These characteristics, relating to the economic, social and political systems, seem to work against Turkish workers' mobility. Yet, Turkey's integration into European labour markets depends for its efficacy on the underlying nature of human capital; if this is not present, Turkish workers will continue to be subject to exclusion. It is difficult to know whether the EU - being bombarded with a large number of new accession countries - will again rebuff Turkey even if it meets the eligibility criteria. The EU decision-makers should review the issue of importing labour from Turkey, despite the evidence concerning restrictive immigration policies in the past.

A central question that is likely to loom large in the foreseeable future is whether countries in the European mainland will as a rule fill the gaps with workers from the new accession countries when they fall short of workers. There is in fact strong evidence that demographic factors will lead to considerable future labour demand. The problem regarding the demographic declines in the CEECs suggests that it will not be possible to meet the "shortages" from domestic labour markets. Then the EU will import workers from third countries in the medium or long term, as it is doing now. In practice, such an approach cannot be very practicable. Importing labour over long distances will increase the costs of migration and cause some recruitment difficulties. As was noted above, most of these difficulties refer to specific skill elements in the workforce (that is, adaptation and language). The choice of labour migration from non-EU countries (the Far East and Turkey) is less clear. It should not, however, be assumed, as it often is, that the EU member states will never include Turkish workers in their labour markets because of its demographic dynamics. There need to be relevant policies and instruments to ensure not only a strong contribution by the CEECs but also a contribution by Turkey to promote the effective functioning of the European labour markets. The final outcome will, as was shown, depend very much on EU decision-makers. Whatever the outcome, Turkey's exclusion from European labour markets would expose the Union as "prejudiced".

Turkey's case is placed in a theoretical framework in the sense that fearing large migration flows necessitates restrictive measures resulting from economic and social conditions in the destination countries. This trend is usually mirrored by fluctuations in the flow rate at certain times, and the push factors require careful consideration. This trend is linked to the characteristics of various policies that support mobility. The inter- 
action between restrictive policies and individuals' desperation to work abroad leads to a decision to stay in the host country because of the view that tightening border controls will prevent them from re-entering the host country. Moreover, it would appear that the eventual effect of the opening of borders during the transitional period will be a low flow following a period of moderate increase.

Finally, these complex considerations can be tackled only by a new migration policy tailored to promote and encourage continuous flows. A broad-brush interpretation of labour market trends in the EU would immediately give us an understanding that the EU achieved unprecedented growth in the context of the single market. A particularly important dynamic in such a programme is the social dimension - the jobs outlook is optimistic. Although progress has been uneven, it is continually evolving and is often examined in terms of labour movement policies. If the Lisbon objectives, designed for more active employment policies to combat the skills gap and other labour shortages, are not achieved in the long run, it is more likely that European employers will continue to import workers from various part of the world to fill shortages, especially in lowpaid and unskilled jobs. The accession of Turkey could provide an important opportunity to address potential future labour supply problems, and not just be a challenge for the EU. It is essential not to lose potential gains by imposing excessive constraints on the freedom of movement of Turkish workers, because the labour supply from the CEECs falls short of meeting the labour shortages, given the demographic factors shaping their labour markets. Conversely, the EU migration policy is designed to limit labour flows from Turkey, but unintentionally it gives rise to an even greater migration potential. If Turkey's membership application is rejected, the number of Turkish workers in the EU member states is expected to increase. What is now badly needed is a more open discussion of the real dynamics of Turkish migration, the main taboo being consideration of re-opening the question of admitting legal migrants, which is actually a matter of a political, economic and social nature and of shared interests. 


\section{References}

Adinolfi, A. (2005) "Free Movement and Access to Work of Citizens of the New Member States: The Transitional Measures", Kluwer Law International, No. 42, pp. 469-498.

Akgündüz, A. (2008) Labour Migration from Turkey to Western Europe 19601974, A Multidisciplinary Analysis, Research in Migration and Ethnic Relations Series, Aldershot: Ashgate.

Alders, M. (2005) "Forecasting the Population with a Foreign Background in the Netherlands", Statistics Netherlands Division for Social and Spatial Statistics, Department for Statistical Analysis Voorburg, Paper for the joint Eurostat-UNECE Work Session on Demographic Projections, Vienna, 21-23 September.

Aral, B. (1997) The Case of Free Movement of Workers Between Turkey and the European Union, Baltimore, MD: Johns Hopkins University Press.

Arango, J. (2000) "Explaining Migration: A Critical View", International Social Science Journal, 52, pp. 283-296.

Archick, K. and Kim, J. (2008) "European Union Enlargement", CRS Report for Congress, Congressional Research Service, US Library of Congress.

Baldwin, R. E., Francois, J. F. and Portes, R. (1997) "The Costs and Benefits of Eastern Enlargement: The Impact on the EU and Central Europe", Economic Policy, 12(24), pp. 125-176.

Bale, T. (2008) "Not Wanted But Needed: Migrants and Minorities", in T. Bale (ed.), European Politics: A Comparative Introduction, 2nd edn, Basingstoke: Palgrave Macmillan.

Bauer, T. K. and Zimmermann, K. F. (1999) "Assessment of Possible Migration Pressure and Its Labour Market Impact Following EU Enlargement to Central and Eastern Europe", IZA Research Report, No. 3, July. 
Baykal, S. (2005) "Unity in Diversity? The Challenge of Diversity for the European Political Identity, Legitimacy and Democratic Governance: Turkish Membership as the Ultimate Test Case", Jean Monnet Working Paper 09/05, NYU School of Law, New York.

BBC News (2002) “Turkey entry 'would destroy EU'”, 8 November, http://news. bbc.co.uk/1/hi/world/europe/2420697.stm.

Berksu, Ş. (1999) Rights Granted to Turkish Workers Residing in the European Union by the Association Agreement and the Rulings of European Court of Justice, Ankara: Azim Publication Ltd, No. 93.

Bhat, K. (2007) "At a Loss: The Exodus from Eastern Europe”, Harvard International Review, 28 (Winter).

Biffl, G. (2001) "Migration Policies in Western Europe and the EU-Enlargement", in OECD (ed.), Migration Policies and EU Enlargement, the Case of Central and Eastern Europe, Paris: OECD.

Binder, D. (1981) "Greek Ties", Europe, January-February.

Birand, M. A. (1985) "At the Corridor of the EEC", Milliyet Ltd, 26 March [in Turkish].

Boeri, T. and Brücker, H. (2000) The Impact of Eastern Enlargement on Employment and Labour Markets in the EU Member States, Final Report, Employment and Social Affairs Directorate General of the European Commission, Berlin and Milan.

Boeri, T. and Scarpetta, S. (1995) "Regional Dimensions of Unemployment in Central and Eastern Europe and Social Barriers to Restructuring", EUI Working Papers in Economics, No. 95/17, European University Institute, Florence.

Borjas, G. J., Freeman, R. B., and Katz, L. F. (1996) "Searching for the Effect of Immigration on the Labour Market", American Economic Review, 86(2), pp. 246-251.

Borneman, J. and Fowler, N. (1997) "Europeanization", Annual Review of Anthropology, 26, pp. 487-514.

Boswell, C. (2002) "EU Immigration and Asylum Policy: From Tampere to Laeken and Beyond", Royal Institute of International Affairs, European Programme, Briefing Paper, New Series No. 30, February.

Brewin, C. (2002) Turkey and Europe after the Nice Summit, Istanbul: TESEV Publications.

Brinkmann, G. (2004) "The Immigration and Asylum Agenda", European Law Journal, 10(2), pp. 182-199.

Brochmann, G. (1993) Control in Immigration Policies: A Closed Europe in the Making, London: Belhaven Press.

Brookes, S. (1986) "Migrant Workers Are Changing the Face of Europe", Europe: Magazine of the European Community, No. 259, pp. 26-28.

Brücker, H. (2007) Labor Mobility After the European Union's Eastern Enlargement: Who Wins, Who Loses? Washington, DC: The German Marshall Fund of the United States.

Bulgarian National Statistics Institute (2002) The Ageing Population. National Background Report for Bulgaria Statistical Codebook, Sofia. 
Bunting, M. (2007) "A Curious Irrationality Grips the British When It Comes to Migrants", Guardian, 24 September.

Büthe, T., with Gencer, Ö. and Parkash, S. (2009) "The Promise of Turkish EU Membership: A Comparative Analysis", Paper prepared for presentation to the 11th Biennial Meeting, European Union Studies Association, Los Angeles, 23-25 April, http://www.unc.edu/euce/eusa2009/papers.php.

Carrera, S. (2005) "What Does Free Movement Mean in Theory and Practice in an Enlarged EU?”, European Law Journal, 11(6), pp. 699-672.

Castles, S. (2006a) "Back to the Future? Can Europe Meet Its Labour Needs Through Temporary Migration?", Working Paper No. 1, International Migration Institute, University of Oxford.

Castles, S. (2006b) “Guest Workers in Europe: A Resurrection?" International Migration Review, 40(4), pp. 741-766.

Cavounidis, J. (2006) "Labour Market Impact of Migration: Employment Structures and the Case of Greece", International Migration Review, 40(3), pp. 635-660.

CEC [Commission of the European Communities] (1985) Completing the Internal Market. White Paper from the Commission to the European Council (Milan, 28-29 June 1985). $\operatorname{COM(85)~final,~Brussels,~} 14$ June.

CEC [Commission of the European Communities] (1989) The Turkish Economy: Structure and Developments, SEC (89) 2290 Final, Brussels, 18 December.

CEC [Commission of the European Communities] (1995) Standard Eurobarometer 44, European Commission.

CEC [Commission of the European Communities] (2000) "Europe's Agenda 2000: Strengthening and Widening the European Union", Draft of Commission information brochure for the general public on Agenda 2000, Priority Publications Programme 1999, X/D/5, Final version 31.8.

CEC [Commission of the European Communities] (2001a) The Economic Impact of Enlargement, Directorate General for Economic and Financial Affairs, Enlargement Papers No. 4, June, http://ec.europa.eu/economy_finance/ publications/publication1583_en.pdf.

CEC [Commission of the European Communities] (2001b) The Free Movement of Workers in the Context of Enlargement, Information Note, 6 March.

CEC [Commission of the European Communities] (2001c) Documentation of Eurostat's Database on International Migration: Population by Country of Birth, 3/2000/E/n ${ }^{\circ}$, Luxembourg: Office for Official Publications of the European Communities.

CEC [Commission of the European Communities] (2002) "European Commission on Factors Influencing Labour Movements", Population and Development Review, 27(2), pp. 391-394.

CEC [Commission of the European Communities] (2004) Issues Arising from Turkey's Membership Perspective, COM (2004) 656 final, Brussels, 6 October.

CEC [Commission of the European Communities] (2005a) "Green Paper on an EU Approach to Managing Economic Migration”, COM(2004) 811 final, Brussels, 11 January.

CEC [Commission of the European Communities] (2005b) Green Paper "Con- 
fronting Demographic Change: A New Solidarity Between the Generations", Communication from the Commission, COM(2005) 94 final, Brussels, 16 March. CEC [Commission of the European Communities] (2005c) Eurobarometer 64: Public Opinion in the European Union - Autumn 2005. National Report France, European Commission.

CEC [Commission of the European Communities] (2005d) Eurobarometer 64: Public Opinion in the European Union - Autumn, European Commission.

CEC [Commission of the European Communities] (2006a) Enlargement Strategy and Main Challenges 2006-2007. Including annexed special report on the EU's capacity to integrate new members, Communication from the Commission to the European Parliament and the Council, COM(2006) 649 final, Brussels, 8 November.

CEC [Commission of the European Communities] (2006b) Report from the Commission: 17th Annual Report on Implementation of Structural Funds (2005), $\operatorname{COM}(2006) 638$ final, Brussels, 27 October.

CEC [Commission of the European Communities (2008a) "Commission Report on Transitional Arrangements Regarding Free Movement of Workers", MEMO/08/718, Brussels, 18 November.

CEC [Commission of the European Communities (2008b) "EU Leaders and Social Partners Debate Next Steps for Growth and Jobs", IP/08/441, Brussels, 13 March.

CEC [Commission of the European Communities (2008c) "Free Movement of Workers Is Good for Europe's Economy", IP/08/1729, Brussels, 18 November.

CEC [Commission of the European Communities (2008d) "Modernisation of the European Labour Market", 16 February.

CEC [Commission of the European Communities (2008e) "New Skills for New Jobs: Anticipating and Matching Labour Market and Skills Needs", MEMO/ 08/791, Brussels, 16 December.

CEC [Commission of the European Communities. (2008f) "What Is the Employment in Europe Report?", MEMO/08/719, Brussels, 18 November.

CEC [Commission of the European Communities] (2008g) Turkey 2008 Progress Report, Commission Staff Working Document, SEC(2008) 2699, Brussels, 5 November.

CEC [Commission of the European Communities] (2008h) Modernisation of the European Labour Market, Directorate-General for Employment and Social Affairs, 16 February.

CEC [Commission of the European Communities] (2009) Five Years of an Enlarged EU: Economic Achievements and Challenges, Directorate-General for Economic and Financial Affairs, European Economy No. 1/2009.

CEPR [Centre for Economic Policy Research] (1998) "EU Enlargement: Implications for East-West Trade", CEPR Bulletin, No. 71, Summer.

Chammartin, G. M.-F. and Cantú-Bazaldúa, F. (2004) "Migration Prospects after the 2004 Enlargement of the European Union", International Migration Papers No. 73, International Labour Office, Geneva.

Çiçekli, B. (1999) "The Rights of Turkish Migrants in Europe under International Law and EU Law”, International Migration Review, 33(2), pp. 468-483. 
Cini, M., ed. (2004) European Union Politics, Oxford: Oxford University Press.

Coşkun, G. (2006) "Free Movement of Turkish Workers and Their Family Members in the EU from Ankara Association Agreement to Present", Institute of Social Sciences, Gazi University, Ankara.

Council of the European Union (2001) "Accession Negotiations - Information Note, Schengen and Enlargement; Chapter 24: Cooperation in the Fields of Justice and Home Affairs", 10876/01, Brussels, 12 July 2001.

Council of the European Union (2002) EU Enlargement, 5 April.

Council of the European Union (2005) "Brussels European Council, 16/17 December, 2004: Presidency Conclusions", 16238/04 REV 1, CONCLUSION 4, Brussels, 1 February.

Crespo, N. and Fontoura, M. P. (2007) "Integration of CEECs into EU Market: Structural Change and Convergence", Journal of Common Market Studies, 45(3), pp. 611-632.

Dahlberg, K. A. (1967) "The EEC Commission and the Politics of the Free Movement of Labour", Journal of Common Market Studies, 6(4), pp. 310-333.

DeYoung, K. (1983) "Portugal”, Europe, January-February.

Dobson, J. R. and Sennikova, I. (2007) "From Fundamental Freedom to Political and Economic 'Hot Potato' in 50 Years: Labour Mobility and Migration Within the EU", Journal of Business Economics and Management, 8(2), pp. 123-136.

Dombey, D. (2005) "EU Voters Uneasy over Turkey’s Membership Quest", Financial Times, 27 September.

Duran, H. (2006) "Evaluating Turkish Migration to the EU: Past, Present and Future Trends in the Context of Free Movement of Workers", Master's thesis, İzmir University of Economics, October.

Dustmann, C., Casanova, M., Fertig, M., Preston, I and Schmidt, C. M. (2003) The Impact of EU Enlargement on Migration Flows, Home Office Online Report 25/03.

Economist (1998) "Millions Want to Come", 2 April.

El-Agraa, A. (2001) The European Union: Economics and Policies, Harlow: Prentice-Hall.

Elci, Z. (2005) "Interview: EU Economy Seen Needing Turkish Labour in Future", Reuters News, 21 September.

Emek, U. (2004) Understanding Structural Reforms in Turkey, Istanbul: Bilgi University Press, December.

Engeli, E. (1983) European Commission Report, Ankara: State Planning Organization, Publication No. 1871.

Eralp, A. (1992) "Turkey and European Community: Forging New Identities along Old Lines", New Perspectives on Turkey, Fall, pp. 199-211.

Eralp, Y. (2005) "Cultural and Political Dialogue between Turkey and the EU: Overcoming Difficulties", Turkish Policy Quarterly, 4(3).

Erdil, E. (2007) "Poverty and Turkish Labor Markets", METU Studies in Development, 34, pp. 137-172.

Ernst and Young Item Club (2007) "Special Report: Migration and the UK Economy", December. 
Erzan, R. and Kirişçi, K. (2004) "Turkish Immigrants: Their Integration within the EU and Migration to Turkey”, Turkish Policy Quarterly, 3(3), pp. 61-68.

Erzan, R., Kuzubaş, U., and Yıldız, N. (2004) "Growth and Immigration Scenarios for Turkey and the EU", EU-Turkey Working Paper, No. 13/December, Boğaziçi University.

European Committee on Migration (1996) Temporary Migration for Employment and Training Purposes, CDMG (96) 18, Council of Europe, Strasbourg, 9 October.

European Integration Consortium (2002) Labour Mobility within the EU in the Context of Enlargement and the Functioning of the Transitional Arrangements Country Studies, Employment, Social Affairs and Equal Opportunities Directorate General of the European Commission.

European Parliament (2002) Report on the Human Rights Situation in the European Union (2001), 2001/2014(INI), 12 December, <http://www.europarl.europa. eu/sides/getDoc.do?pubRef=-//EP//TEXT+REPORT+A5-2002-0451+0+DOC+ $\mathrm{XML}+\mathrm{V} 0 / / \mathrm{EN}>$.

European Policies Research Centre (1996) The Impact on Cohesion of EU Enlargement. (Study Area 3) Draft Final Report to the European Commission (DG $X V I)$, Glasgow, Rheinisch-Westfälisches Institut für Wirtschaftsforschung (Essen) (a.o.), July.

European Report (2005) "Free Movement of Workers: Spidla Hosts First HighLevel Group Gathering”, 17 September.

Eurostat (2008a) "In the Spotlight - Demographic Change: Challenge or Opportunity?", in Europe in Figures - Eurostat Yearbook 2008, Luxembourg: Office for Official Publications of the European Communities.

Eurostat (2008b) "Education", in Europe in Figures - Eurostat Yearbook 2008, Luxembourg: Office for Official Publications of the European Communities.

Eurostat (2008c) "Labour Market", in Europe in Figures - Eurostat Yearbook 2008, Luxembourg: Office for Official Publications of the European Communities.

Eurostat (2008d) "Living Conditions and Welfare", in Europe in Figures Eurostat Yearbook 2008, Luxembourg: Office for Official Publications of the European Communities.

Eurostat (2008e) "Health", in Europe in Figures - Eurostat Yearbook 2008, Luxembourg: Office for Official Publications of the European Communities.

Eurostat (2008f) "Economy", in Europe in Figures - Eurostat Yearbook 2008, Luxembourg: Office for Official Publications of the European Communities.

Fassmann, H. and Hintermann, C. (1998) "Potential East-West Migration, Demographic Structure, Motives and Intentions", Czech Sociological Review, 6(1), pp. 59-72.

Fassmann, H. and Münz, R., eds (2002) Ost-West Wanderung in Europa, Vienna/ Cologne/Weimar: Boehlau-Verlag.

Fertig, M. and Schmidt, C. (2002) "Mobility within Europe - What Do We (Still Not) Know", IZA Discussion Paper No. 447.

Financial Times (2001) "Workers Without Frontiers", 6 March. 
Flam, H. (2004) "Turkey and the EU: Politics and Economics of Accession", CESifo Economic Studies, 50(1), pp. 171-210.

FRA [European Union Agency for Fundamental Rights] (2007) Annual Report 2007: Report on Racism and Xenophobia in the Member States of the EU, http:/l www.fra.europa.eu/fraWebsite/attachments/ar07p2_en.pdf.

Freeman, G. P. (1986) "Migration and the Political Economy of the Welfare State", Annals of the American Academy of Political and Social Science, 485, May.

Garson, J.-P. and Loizillon, A. (2003) "Changes and Challenges: Europe and Migration from 1950 to Present", paper presented at the conference "The Economic and Social Aspects of Migration", jointly organized by the European Commission and the OECD. Brussels, 21-22 January.

Goedings, S. (1999) EU Enlargement to the East and Labour Migration to the West, IISG Research Paper 36, International Institute of Social History, Amsterdam.

Gonac'h, J. (2008) "Bilingualism and Biliteracy among Second-Generation Immigrant Youth: The Case of Turkish Pupils and Students in France and England”, University of Rouen, France [in French].

Gow, D. (2004) "UK Resists EU Curb on Turkey", Guardian, 6 October.

Gow, D. (2006) "Germany Threatens Enlargement Timetable", Guardian, 23 August.

Graham, R. (1983) “Spain”, Europe, January-February.

Grant, C. (2002) "The Eleventh of September and Beyond: The Impact on the European Union", Political Quarterly, 73, pp. 135-153.

Groenendijk, K. (2004) "Legal Concepts of Integration in EU Migration Law", European Journal of Migration and Law 6(2), pp. 111-126.

Gros, D. (2005) "Economic Aspects of Turkey's Quest for EU Membership", CEPS Policy Briefs, No. 69, Centre for European Policy Studies, Brussels, April.

Guild, E. (2007) “Turkish Self-Employed: The European Court of Justice Applies the 1973 Rules Strictly", European Immigration Lawyers Network, press release, 20 September.

Guillen, A., Alvarez, S., and Adao e Silva, P. (2003) "Redesigning the Spanish and Portuguese Welfare States: The Impact of Accession into the European Union", in S. Royo and P. C. Manuel (eds) Spain and Portugal in the European Union: The First Fifteen Years, London: Frank Cass, pp. 231-268.

Gülçiçek, A. R. (2006) The Turkish Presence in Europe: Migrant Workers and New, European citizens, Report, Committee on Migration, Refugees and Population, Rapporteur, Parliamentary Assembly, 19 October.

Gümrükçü, H. (1988) "Demography and the Labour Force in Turkey", Perspectives for Migration and the Free Movement of Labour, Hamburg University.

Gwyn, R. (2005) "A Democratic Decision on Turkey", Guelph Mercury.

Hazans, M. (2003) "Potential Emigration of Latvian Labour Force after Joining the EU and Its Impact on Latvian Labour Market", BICEPS Working Paper, Baltic International Centre for Economic Policy Studies, Latvia. 
Heinz, F.-F. and Ward-Warmedinger, M. E. (2006) "Cross-Border Labour Mobility within an Enlarged EU”, European Central Bank, Occasional Paper Series No. 52 , October.

Henning, D. (2008) "Germany: Nine Turkish Immigrants Die in House Fire", World Socialist Web Site, 12 February, http://www.wsws.org/articles/2008/ feb2008/fire-f12.shtml.

Heywood, A. (2007) Politics, 3rd edn, Basingstoke: Palgrave Macmillan.

Hille, H. and Straubhaar, T. (2001) "The Impact of the EU Enlargement on Migration Movements and Economic Integration: Results of Recent Studies", in Migration Policies and EU Enlargement, Paris: OECD, pp. 79-100.

Holland, M. (2004) Future Enlargement: Challenges and Opportunities, London: Pinter Publishers.

Hönekopp, E. and Werner, H. (2000) "Is the EU's Labour Market Threatened by a Wave of Immigration?”, Intereconomics, January-February, pp. 3-8.

Hughes, K. (2004) "Turkey and the European Union: Just Another Enlargement? Exploring the Implications of Turkish Accession", Friends of Europe Working Paper, Brussels.

Huymans, J. (2000) "The European Union and the Securitization of Migration", JCMS: Journal of Common Market Studies, 38(5), pp. 751-777.

İçduygu, A. (2003) "SOPEMI Report for TURKEY (period from 2002 to the early 2003)", For the Continuous Reporting System on Migration (SOPEMI) of the Organisation for Economic Cooperation and Development (OECD), Istanbul.

Iglicka, K. (2002) "Shaping a Harmonised Migration Policy for an Enlarged Europe", Perspectives on European Politics and Society, 3(2), pp. 325-334.

İlhan, S. (2002) Avrupa Birliğine Neden Hayır [Why No to the European Union], Vol. 2. İstanbul: Ötüken Yayınları.

IOM [International Organization for Migration] (2005) World Migration Report 2005: Costs and Benefits of International Migration. Geneva: IOM.

Irish Times (2002) "Immigration and the Nice Treaty", 22 August.

Journal of the Economic Development Foundation (1992) Reports on Turkey, No. 102, April.

Karluk, R. (2003) Avrupa Birliği ve Türkiye [The European Union and Turkey]. Istanbul: Beta Publication.

Kelly, M. (2003) "Ageing Scotland Needs the Migrants", Scotsman, 19 December.

Keohane, R. O. (1993) "Sovereignty, Interdependence and International Institutions", in L. Miller and M. Smith (eds), Ideas and Ideals: Essays on Politics in Honor of Stanley Hoffmann, Boulder, CO: Westview.

Kicinger, A. and Saczuk, K. (2004) Migration Policy in the European Perspective - Development and Future Trends, Working Paper 1/2004, Central European Forum for Migration Research, Warsaw.

King, S. (2006) "This Land of Opportunity Must Not Close Doors to Migrant Labour", Independent, 30 October.

Kirişçi, K. (2003) "Turkey: A Transformation from Emigration to Immigration", Center for European Studies, Boğaziçi University, Migration Information Source, Country Profiles, November. 
Koray, S. (1999) Study on Migrations: the Case of Turkey, Working Paper No. 73, Economic and Social Committee of the European Communities, Essen.

Kraus, M. and Schwager, R. (2003) "EU Enlargement and Immigration”, Journal of Common Market Studies, 42(2), pp. 165-181.

Kunz, J. (2002) Labour Mobility and EU Enlargement - A Review of Current Trends and Debates, Discussion and Working Paper 2002.02.01, European Trade Union Institute, Brussels.

Lee, E. S. (1966) “A Theory of Migration”, Demography, 3(1), pp. 47-57.

Lejour, A. M., de Mooij, R. A., and Capel, C. H. (2004) "Assessing the Economic Implications of Turkish Accession to the EU", Netherlands Bureau for Economic Policy Analysis, CPB Document No. 56.

Lichtenberg, H. (2000) Summary Report, European Commission, Directorate General for Employment and Social Affairs, Unit D4.

Liebig, T. (2007) The Labour Market Integration of Immigrants in Germany, OECD Directorate for Employment, Labour and Social Affairs, Social, Employment and Migration Working Papers No. 47, 1 February.

Littoz-Monnet, A. and Villanueva Penas, B. (2006) "Turkey and the European Union: The Implications of a Specific Enlargement", Egmont European Affairs Paper, April.

McKinley, B. (2004) "Statement by Mr. Brunson McKinley, Director General of the International Organization for Migration (IOM) at Symposium on CrossBorder Movement of Natural Persons: Economic Partnership Agreement (EPA) and Acceptance of Foreign Workers", Organized by Ministry of Foreign Affairs, Government of Japan \& IOM. Tokyo, 27 July.

Manço, A. (2008) "The Turks Changed the Route", Istanbul News Office, Cumhuriyet Ltd, 2 September.

Mardin, Ş. (1989) Religion and Social Change in Modern Turkey, Albany, NY: SUNY Press.

Mardin, S.., ed. (1994) Cultural Transitions in the Middle East, Leiden: Brill.

Martin, P. L. (1991) The Unfinished Story: Turkish Labour Migration to Western Europe, Geneva: ILO.

Mayer, F. C. and Palmowski, J. (2004) "European Identities and the EU: The Ties that Bind the Peoples of Europe", Journal of Common Market Studies, 42(3), pp. 573-598.

Michalski, A. (2006) "The Enlarging European Union”, in D. Dinan, ed., Origins and Evolution of the European Union, Oxford: Oxford University Press, pp. 271-293.

Migration News (2007) "Inventory of Existing National Measures Combating Discrimination outside Employment and their Impact", October 22.

Ministry of Health (2008) "Challenges and Strategic Plans for Development of the Latvian Health Care System", Latvia.

Ministry of Labour and Social Policy (2008) Annual Report of EURES Network Activity in Poland, 1 April 2007-31 March 2008: part II, Warsaw, June.

Minorities at Risk Project (2009) "Assessment for Turks in Germany", Center for International Development and Conflict Management, University of Maryland, http://www.cidcm.umd.edu/mar/assessment.asp?groupId=25501. 
Moraes, C. (2003) "The Politics of European Union Migration Policy", Political Quarterly, 74, pp. 116-131.

Morris, N. (2008) "A Different Picture Emerges: Tide of Migration Turns as Polish Workers Return", The Independent, 27 February.

Murat, S. (2004) "Immigrant Turks and Their Socio-Economic Structure in European Countries", C.Ü. Journal for Economics and Administrative Sciences, 2(1), pp. 25-46.

Muus, P. (2001) "International Migration and the European Union: Trends and Consequences", European Journal on Criminal Policy and Research 9, pp. 31-49.

Narlı, N. (2002) "Migration to Turkey and Human Trafficking”, Bianet News, 16 July.

OECD [Organisation for Economic Co-operation and Development] (1988) Economic Surveys: Turkey, 1987-1988, Paris: OECD Publishing.

OECD [Organisation for Economic Co-operation and Development] (2001) Trends in International Migration: Continuous Reporting System on Migration. Annual Report 2001 edition, Paris: OECD Publishing.

OECD [Organisation for Economic Co-operation and Development] (2008) International Migration Outlook 2008, Paris: OECD Publishing.

Ogan, S. (1983) "Turkish Labour Movement in the EEC Countries and Problems", Institute of Social Sciences, Gazi University, Ankara.

Okólski, M. (2000) "Recent Trends and Major Issues in International Migration: Central and East European Perspectives", International Social Science Journal, 52, pp. 329-341.

Özal, T. (1988) La Turquie en Europe, Paris: Plon.

Özcan, M. (2005) “Turkey's Possible Influences on the Internal Security of the European Union: The Issue of Illegal Migration", in S. Laciner, M. Ozcan and I. Bal (eds) European Union with Turkey, Ankara: ISRO, April.

Özen, Ç. (2008) "Turkey and EU Relations”, TRT1, 30 January.

Paci, P., Tiongson, E. R., Walewski., M., Liwínski, J. and Stoilkova, M. M. (2007) Internal Labor Mobility in Central Europe and the Baltic Region, Washington DC: World Bank.

Panayiotopoulos, P. I. (2008) "Turkish Immigrant Entrepreneurs in the European Union: A Political-Institutional Approach", International Journal of Entrepreneurial Behaviour \& Research, 14(6), pp. 395-413.

Peel, Q. E. C. (1986) "Enlargement Brings New Hopes and New Problems", Europe, April.

Philip, A. B. (1994) "European Union Immigration Policy: Phantom, Fantasy or Fact?", West European Politics, 17(2), pp. 168-191.

Pleines, H. (2005) "Participation of Civil Society in New Modes of Governance. The Case of the New EU Member States, Part 1: The State of Civil Society", Research Centre for East European Studies, University of Bremen, No. 67, May.

Polat, N. (2006) "Identity Politics and the Domestic Context of Turkey's European Union Accession", Government and Opposition, 41(4), pp. 512-533.

Putten, R. V. D. (2002) "The Effects of EU Enlargement on Product and Labour Market", Conjuncture, July-August. 
Radeva, M. (2004) "East-West Migration in the Context of an Enlarging European Union: New Opportunities and New Challenges", Open Society Institute, New York.

Raines, P. (1996) Labour Market Regulation and Foreign Direct Investment, Regional and Industrial Policy Research Paper No. 22, Glasgow: European Policies Research Centre.

Rangelova, R. and Zlatanov, S. (2005) "Ageing and Health Status of the Bulgarian Population", SEER - South-East Europe Review for Labour and Social Affairs, Issue No. 02, pp. 71-93. http://www.ceeol.com/.

Reuters News (1998) “Turkey Says It Was Right to Reject EU Invitation”, 12 March.

Royo, S. (2004) "From Authoritarianism to the European Union: The Europeanization of Portugal", Mediterranean Quarterly, Summer, pp. 95-129.

Royo, S. and Manuel, P.C. (2003) Spain and Portugal in the European Union: The First Fifteen Years, London: Frank Cass.

Salt, J. (1992) “The Future of International Labor Migration”, International Migration Review, 26(4), pp. 1077-1111.

Salt, J. (2006) Current Trends in International Migration in Europe, Consultant's Report to the Council of Europe, CDMG (2006) 22e, Strasbourg, March, [Migration \CDMG2006\51e réunion\docs\11f].

Seager, A. (2004) "Immigrants Seen as Economic Benefit to Britain", Reuters News, 23 February.

Şen, F. (1994) "Racism in Germany and Its Impact on the Turkish Minority", Turkish Yearbook of International Relations, 24, pp. 1-10.

Şen, F. (2003) "The Historical Situation of Turkish Migrants in Germany", Immigrants \& Minorities, 22(2-3), pp. 208-227.

Sinn, H.-W. and Ochel, W. (2003) "Social Union, Convergence and Migration", Journal of Common Market Studies, 41(5), pp. 869-896.

Social and Cultural Planning Office of the Netherlands (2004) Migration Estimates, The Hague: Statistics Netherlands, September.

Sözen, S. and Shaw, I. (2003) "Turkey and the European Union: Modernizing a Traditional State?", Social Policy \& Administration, 37(2), pp. 108-120.

Stalford, H. (2003) "Free Movement Post Accession - Transition Arrangements in Poland and Bulgaria", Symposium on Science Policy, Mobility and Brain Drain in the EU and Candidate Countries, 27-29 July.

State Planning Organization (2008) Economic Growth in the Member States and Candidate Countries, Secretariat General for European Union Affairs, Ankara, August.

Steinhausen, H.-C. E. (1985) "The Environment and Psychosocial Functioning of Migrant Workers' Children in West Germany", Children's Environments Quarterly, 2(1), pp. 12-15.

Stoddard, A. (2007) "Immigration and Islam in Europe", News and Analysis on Islam in Europe and North America, Euro Islam Info.

Strauss, D. (2004) “Turkey's Ottoman Mission”, Financial Times, 23 November.

Teitelbaum, M. S. and Martin, P. L. (2003) "Is Turkey Ready for Europe?", Foreign Affairs, 82(3), pp. 96-111. 
Tekeli, I. and İlkin, S. (2000) Türkiye ve Avrupa Birliği [Turkey and the European Union], Ankara: Ümit Yayıncılık.

Thomas, B. R. (1993) "Necessary But Unloved: Turkish Immigrants in Germany", Green Left, 10 February.

Tisdall, S. (2002) “The Big Invitation”, The Guardian, 21 November.

Tsoukalis, L. (1981) The European Community and Its Mediterranean Enlargement, London: Allen \& Unwin.

Turkish Employment Institution (2007) Annual Report, Ankara [in Turkish].

Turkish Employment Institution (2008) "Migration to the West".

Turkish-German Education and Scientific Research Charity (2009) "Numerical Power of Turks in the EU", Lider Forex, 8 April [in Turkish].

Turkish Statistical Institute (2000) Census of Population 2000: Migration Statistics, Ankara: Prime Ministry, Republic of Turkey.

Turkish Statistical Institute (2006) "Household Labour Force Survey Results", Prime Ministry, Republic of Turkey, October.

UK Border Agency (2008) Accession Monitoring Report, May 2004-June 2008: A8 Countries, Home Office.

UNESCO (1987) Statistical Yearbook 1986/Annuaire Statistique/Anuario Estadistico/U1552 (Unesco Statistical Yearbook), Paris: United Nations Educational.

UNDP [United Nations Development Programme] (2002) Human Development Report (2002), Deepening Democracy in a Fragmented World, New York: Oxford University Press.

United Nations Economic and Social Council (2009) "Report: Regional Workshop on International Migration Statistics. Cairo 30 June-3 July 2009", E/ESCWA/SD/2009/9, Economic and Social Commission for Western Asia (ESCWA), 10 December.

Uşar, A. S. (1998) "Free Movement of Labour in the Context of EU-Turkey Relations and Harmonization", Institute of Social Sciences, Gazi University, Ankara.

Van Selm, J. and Tsolakis, E. (2004) "EU Enlargement and the Limits of Freedom", Migration Information Source, Migration Policy Institute, May.

Vandamme, F. (2000) "Labour Mobility within the European Union: Findings, Stakes and Prospects", International Labour Review, 139(4), pp. 437-455.

Vaughan-Whitehead, D. (2003) EU Enlargement versus Social Europe? The Uncertain Future of the European Social Model, Cheltenham: Edward Elgar.

Völker, G. E. (1976) "Turkish Labour Migration to Germany: Impact on Both Economies", Middle Eastern Studies, 12(1).

Vural, S. (1989) "Free Movement in the European Community and in the Relations between Community and Turkey", Institute of Social Sciences, Gazi University, Ankara.

Wagstyl, S. (2004) "Movement Curbs Cause Bureaucratic Tangle", Financial Times, 27 April.

Walker, V. (1983) "Stabilizing the Economy", Europe No. 240.

Wintour, P. (2007) "Brown Plans New Migrant Controls to Get Unskilled Britons Back to Work", The Guardian, 10 September. 
World Tourism Organization (1999) Yearbook of Tourism Statistics. Geneva.

Xuereb, P. G. and Pace, R., eds (1996) The European Union, the IGC and the Mediterranean, University of Malta.

Yalçın, C. (2004a) Göç Teorileri [Migration Theories], Ankara: Bynı Publications, October.

Yalçın, C. (2004b) Göç Sosyolojisi [The Sociology of Migration], Ankara: Anı, October.

Zimmermann, F. (1995) “Tackling the European Migration Problem”, Journal of Economic Perspectives, 9(2), pp. 45-62. 


\section{Index}

absorption capacity, 9-10, 33

Accession Monitoring Report (UK Border

Agency, 2008), 128

accession partnership framework, 142, 199

acquis communautaire, $11,63,86,142$

adaptation risk phenomenon, 166

Additional Protocol (1973), 2, 27, 38, 45-47,

$50,52,57-58,88,155,190-191$

admission policies, 6

advantages of staying (migration decisions), 162

adverse shocks (oil shocks), 97

Aegean region, 160

ageing population, 103, 110, 156, 157, 198

agricultural sector, 69-70, 74, 125, 127, 186

Amsterdam Treaty, 54, 99, 109

Anatolia, 80-82

Anatolian peasants, 170

East Anatolia, 160

annual growth rates, 70

anti-terrorism measures, 112

anti-Turkish sentiment, 110

assimilation, 167

association agreements, 2, 52, 85

asylum-seekers, 99, 110, 179

authoritarian regimes, 66, 91

balance of payment deficits, 87

Baltic states, 157, 182
Berlin wall, 26, 109, 182

best-qualified Turkish workers, 195

"Big Bang" enlargement, 9

blue-collar workers, 119

borderless Europe, 113

catch-up scenario, 175, 199

causes of migration, 4, 34, 65-67

Central and East European countries, 1, 33,

91, 100-101, 116, 187

centrally-planned economy [Bulgaria], 157

Christianity, 113

civic culture, 80

civil law, 148

clash of cultures, 113

cohesion funds, 63, 147, 197

common external borders, 99

common market, 3, 26, 63, 94-95

common rules, 105

Commonwealth Immigration Acts (1962 and 1968), 107-108

Communist states (former), 100

Community. See European Community (EC)

commuting, 3, 7, 88, 119, 139, 163, 196

comprehensive policy, 104, 115

concessionary partnership, 57

consolidation of democracy, 177

conspicuous wealth, 162 
cooperation, 90, 95, 99, 100, 105-106, 108-109, 112-113, 115, 192

coordinated policy, 98

Copenhagen political criteria, 177

core/periphery, 160

corruption, 148, 162

Council of Ministers (EEC), 94

coup d'état, 39, 61, 79

culture

cultural affiliation, 190

cultural differences, 4, 7, 12-13, 165, 168, 186, 191, 199

customs union, $31,60,62,148,181$

Debré and Chevènement laws, 108

democracy

democratic deficit, 29

democratic freedoms, 164

democratic values, 86

democratization process, 53, 64, 79

liberal democracies, 91

lynchpin of liberal democracy, 35

right-wing parties, 111

demographics

demographic capacity, 156

demographic structure, 76, 147, 198

diaspora communities, 136

discrepancies, 76, 122, 147

discrimination, 38, 46-47, 50, 53-54, 94-95, 169-170, 178

anti-Turkish sentiment, 110

racism, 39-40, 111-112

distance, 5, 7, 22-23, 82-84, 86, 88, 91-92, 134-39, 184-85, 196, 198, 200

domestic stability, 109

dualism, 94

Dutch language and society, 172

East Anatolia, 160

Eastern Thrace, 81

East-West population movement, 163

economy

Asian tigers, 123

capital inflows, 147

capital movements, 129

economic backwardness, 184

economic disparity, 60

economic growth, 20, 34-35, 37, 55, 63,

70-72, 87, 89, 96, 105, 109, 111, 133, 147,

150, 157, 164, 175, 180, 186, 192, 197

economic liberalization, 103 economic migration, 105, 189

economic miracle, 26, 96

economic refugees, 28

economic situation, $12,37,40,63,73$, 87-88, 97, 102, 117, 147, 152, 188

fiscal advantage, 157

foreign direct investment, 147, 149, 197

GDP, 32, 41, 63, 65-69, 71, 73-76, 87, 128, 132-133, 142-143, 148, 151, 175, 177, 181-182, 185-186, 195

"Green Paper on an EU Approach to Managing Economic Migration" (2005), 104

inflation, 72-73, 87, 148

integrated labour markets, 98

internal market, 105, 114, 177

macroeconomic disequilibrium, 71

market economy, 7, 37, 72, 90, 186

single European market, 2, 29, 104, 114, 182

Turkish economy, 56, 70, 74, 90, 148, 177, 181,186

education, 6, 19, 42-43, 46, 48-51, 74-75, 89, $105,119,123-25,127-30,139,142-43$, 146-47, 153, 155, 168, 170-75, 194-96

11 September 2001, 112

elixir, 128

emigration, 127, 135, 156-157, 164, 175, 178-179. See also migration

barriers, 65

large-scale, 33

employment. See also labour

employment opportunities, 70, 121, 153-154, 157, 186

employment-related migration, 36, 43, 95, 188-189, 192

entrepreneurs, 198

Ergenekon (criminal investigation), 178

ethnic conflict, 179

ethnic minority formation, 97

Europe. See also European Union (EU)

agreements, 1

borderless, 113

Central and East European countries, 1, 33, 91, 100-101, 116, 187

citizenship, 54, 99

Eastern Europe, 19, 32, 100, 119, 138, 154, $162,172,179,185$

Employment and Social Affairs Directorate General of the European Commission, 104, 119 
Eurobarometer survey, 110

European Commission, 96, 103, 105-106, 118-20, 125, 128, 146, 157

European Court of Justice (ECJ), 30, 95, 190

European Integration Consortium, 119

European Investment Bank, 89

European Parliament, 38, 82, 111, 181

European project, 92

Europeanization, 12, 81, 83, 109

European Economic Community (EEC), 2, 25-26, 60, 93, 192

labour markets, $1,32,34,41,50,53,55,58$, 64, 85-87, 94-95, 98, 104, 109-11, 128, 138, 153, 166-67, 169, 174, 179, 186-87, 189-90, 194-95, 200

North of Europe, 67

Northern member states, 95

north-west Europe, 95-96

post-Christian Europe, 170

single European market, 2, 29, 104, 114, 182

Southern Europe, 34, 60, 67, 80, 84-87, 91, 100

standards, 78, 86, 147

West European countries, 2, 12-13, 16, 21, 26-27, 28, 34-36, 39-40, 58, 70, 92, 97, $103,105,113,127,134-135,138,153$, $165,169,178,188-90,193$

Western Europe, 13, 16, 19, 26-28, 34, 39-40, 45, 57, 98, 100, 111-112, 121, 127, 135-136, 139, 148, 154, 162, 167, 170, $174,177,182$

European Community (EC)

approach, 84

average for economic growth, 89

countries of, 59

intra-Community, 11, 95

intra-EC migration, 165

law, 45-47, 52-54, 58, 95, 107, 190

nationals, 42, 52, 64, 69, 95, 155, 170, 182, 186, 197

rules and regulations, $29,38,52,85$

European Union (EU)

"Big Bang" enlargement, 9

citizens, 1, 99-100, 105

Eastern enlargement, 2, 6-8, 11, 19, 21, 32, 41-42, 100, 102, 110, 116, 119, 146, 168, 180, 185, 187, 192, 194

enlargement fatigue, 9

funds, 22, 134, 147
Greek membership application, 60

Iberian enlargements, 60

post-enlargement period, 9, 45, 102, 115, 166, 189, 192, 195, 199

Southern accession countries, 60, 67, 69, $72,75,79,82,84-85,89,91-92,96,187$, 191-192, 194, 196

Southern enlargement, 1, 59-60, 63-64, 82, 84-86, 90-92, 102, 121, 134, 153, 165, 187,191

standards, 123, 146, 153

Turkish membership, 9, 30, 33, 71, 80, 89, $153,182,186$

visa-free access, 48

exports, $30,60,72-73,87-88,148$

faith, 29, 112, 164

family

bonds, 178

extended families, 114

reunification, 11, 16, 36, 98, 104, 114, 165, $180,182,189$

Far East, 184, 200

fertility rates, 76, 147

flexible integration, 108

foreign direct investment, 147, 149, 197

"Fortress Europe" (created at the Seville Summit), 11, 113

Fourth Financial Protocol [Greece], 90

free movement of labour, $8,33,57,65,80$, 84, 93-94, 108, 114-115, 117, 135, 146-147, 181, 183-184, 186, 191

frozen relationships, $29,38,52,85$

fundamental freedoms, 177

GDP, 32, 41, 63, 65-69, 71, 73-76, 87, 128, 132-133, 142-143, 148, 151, 175, 177, 181-182, 185-186, 195

geography

identity, 138

proximity, 5, 23, 59, 83-84, 92, 136, 138, 191

Germany

Berlin wall, 26, 109, 182

citizenship, 155

irreversible decline, 104

Research Centre for East European

Studies [University of Bremen], 181

Globalization, 57, 103, 136, 192

golden age, 123 


\section{Greece}

Fourth Financial Protocol, 90

Greek factor, 89

Greek membership application, 60

Greek opposition, 80

"Green Paper on an EU Approach to Managing Economic Migration" (2005), 104

Gulf War, 178

healthcare expenditure, 142

highly-skilled labour, 43, 70, 186

high-tech products, 125

hostility, 40, 90, 111, 113, 170

human capital, 74, 123, 125, 184, 191, 194-195, 200

human rights, $29,35,37-38,82,86,177-178$, 189, 199

Iberian enlargements, 60

identity, 12, 19, 78-83, 92, 138, 166, 170, 182

illiteracy gap, 75

immigration. See also emigration, migrant, migration

anti-immigration rhetoric, 115

gap, 7, 132, 185, 187, 196

immigrant-bashing National Front

[France], 110

income differentials, 7, 59, 118, 181

law, 104, 172

theory, 160

industrial slowdown, 106

industrialized countries, 135

inflation, 72-73, 87, 148

Integrated Mediterranean Programmes, $61-63,85,90$

integration process, 2,91

intergovernmental approach, 99

internal borders, 98-99, 192

internal inequalities, 22, 157, 198

internal market, 105, 114, 177

International Labour Organization, 153

inter-state cooperation, 108

Islam, 79, 81, 113-114, 170-171

Islamic discourse, 79

Istanbul Public Prosecutor's Office, 178

job. See also labour

creation, 37, 119, 133, 154, 168, 181, 197

foreign job-seekers, 98

over-skilled, 128 permanent, 154

profiles, 153

unskilled, 128, 168, 201

Judeo-Christian heritage, 79

Junta, 79

Justice and Home Affairs, 99, 192

Kemalist project, 81

Kurdish nationalism, 81

labour

best-qualified Turkish workers, 195

blue-collar workers, 119

employment opportunities, 70, 121, 153-154, 157, 186

employment-related migration, 36, 43, 95, 188-189, 192

entrepreneurs, 198

flexible labour market, 103

flood of cheap, 100

foreign job-seekers, 98

frantic labour migration, 189

free movement of, $8,33,57,65,80,84$, 93-94, 108, 114-115, 117, 135, 146-147, 181, 183-184, 186, 191

highly-skilled, 43, 70, 186

integrated labour markets, 98

less-qualified, 106

low wages activities, 125

low-paying service industries, 45

low-skilled, 37, 45, 142, 170, 179

low-tech sectors, 42

market demand, 102, 123

minimum wage, 114, 129, 132, 146, 195

new recruitment approaches, 102, 192

non-Community workers, 51

outdated skill, 123

over-skilled jobs, 128

participation, 121

permanent jobs, 154

polarized labour migration, 104

productivity, 125

recruitment stop, 27, 36, 97

seasonal migrant worker programme, 105 sending countries, 2,137

shortages, 2, 10, 26, 33, 42, 54, 78, 105, 122, $128,156-157,162,183,193,201$

skilled, 42-43, 70, 106, 110, 119, 125, 127,

$166,168,174,179,181,183,184$

surplus, $30,37,80$

temporary labour migration, 105 
unskilled, 128, 168, 201

vocational training, 43, 51, 89, 95

wages, 3-5, 21-22, 31-32, 37, 55, 68, 85, 95, 121, 129, 155, 157, 182, 197

working population, 76, 120, 146

working-age, 127

work-related migration, 135

language

foreign languages, 4, 106, 172, 174

linguistic barriers, 171

law

European Community law, 45-47, 52-54, $58,95,107,190$

legal framework, 22, 46-48, 58-59, 99, 193

legal instruments, 2, 8, 27, 30, 52, 101, 190

legislation, 29, 102, 107, 114, 140, 190

rule of law, 177

liberal democracies, 91

Lisbon Summit, 90, 104

living standards, 28, 38, 40, 76-77, 135, 150, 175

Maastricht Treaty, 99, 100, 115. See also

Treaty on European Union

marginalization, 170

Marmara region, 160

Mediterranean

region, 61

membership, 87

Middle East, 16, 28, 39, 136, 138-139, 171, 189-190

migrant. See also migration

asylum-seekers, 99, 110, 179

diaspora communities, 136

first-generation, 171

influx of workers, 9, 111

naturalization, 107-108, 135, 169

non-EU, 105

remittances, 88

seasonal worker programme, 105

semi-skilled, 128

undocumented immigrants, 114

migration. See also emigration, immigration, migrant

advantages of staying, 162

anti-immigration rhetoric, 115

assimilation, 167

asylum-seekers, 99, 110, 179

causes of, 4, 34, 65-67

costs of, 5, 83-84, 136, 184, 188, 200

country of origin, $3-5,68,152$ cross-border movement, 8, 68, 88

destination country, 4, 43-44, 197

effects, 22, 24, 116, 121

employment-related, 36, 43, 95, 188-189, 192

flood of immigrants, 90, 107

flows, 2, 4, 10, 16, 18, 25-26, 34-35, 37, 42, $64,68,84,91,97,110,117,119,121$,

134-135, 137, 142, 146, 150, 160, 175,

180-181, 184-185, 193, 196-98, 200

frantic labour, 189

frontier, 2, 137, 139

future East-West, 129

"Green Paper on an EU Approach to Managing Economic Migration"

(2005), 104

intra-EC, 165

international labour, 2, 18, 102

irregular, 112, 182

management of, 42

mass, 11-12, 28, 43, 109, 111, 115, 181

massive, 34, 79, 87, 185

networks, 4, 169

new economics of, 5

potential, 20-21, 35, 65, 68, 100, 117-118,

123, 128-129, 135, 139, 157, 181-182

pressure, 9, 16, 19, 34, 37, 39, 115, 119,

132-133, 147, 150, 162, 175, 186, 195,

197,199

theory, 4, 160, 179

naturalization, 107-108, 135, 169

new entrants, 2, 38, 86

new migration pole, 164

open door policy, 56,120

period of restrained, 98

polarized labour, 104

preferred destination countries, 138

pull and push factors, 24, 116

return, 22, 97, 150, 152-55, 165, 185, 197-198

rural-to-urban (Turkey), 184

selective policies, 41, 43, 110

Southern, 59

temporary labour, 105

tide of, 154

traditional, 84, 135-136, 139

wave of mass, 109

military

coup, 39, 86, 178

rule, 61

minimum wage, 114, 129, 132, 146, 195 
mixed marriages, 169

mortality rates, 77,147

multicultural cities, 167

national profile, 195

national provisions, 107

national security, 140

national sovereignty, 94

naturalization, 107-108, 135, 169

negative stereotypes, 112

neo-Nazis, 113

9/11. See 11 September 2001

North of Europe, 67

Northern member states, 95

north-west Europe, 95-96

obstacles, 3, 6, 11, 20, 24, 36, 39, 49-50, 52, 62, 82, 85, 93-94, 106, 109, 115, 155, 165, $185,192,194$

open door policy, 56, 120

Ottoman Empire, 79, 82, 89, 171

Ottoman legacy, 135

outdated skill, 123

over-skilled jobs, 128

owner-occupied housing, 154

Pasqua laws, 108

perception of Turks, 113

period of restrained migration, 98

periphery, 80-81, 83, 160, 164, 171

permanent curbs, 8-9, 188

polarized labour migration, 104

police and judicial cooperation, 112

policy coordination, 106, 108

Poland

plumbers, 9, 146

Polish community, 137

Polish Ministry of Labour and Social

Policy, 155

political instability, 39, 61, 92, 178, 191

post-Christian Europe, 170

posted workers, 55

post-enlargement period, 9, 45, 102, 115, 166, 189, 192, 195, 199

post-war boom, 183

poverty, 140-141, 147, 160, 175, 196

prejudice, 167

prima facie face of terrorism (foreign faces as), 112

principle of second priority, 29, 52-53

psychological costs, 5, 188 public opinion, 8, 12, 101, 109-11, 115, 193

public order, 140

public scrutiny, 113

racism, 39-40, 111-112. See also discrimination

recruitment stop, 27, 36, 97

regional discrepancies, 122

relief centre, 147

religious activities, 139

Research Centre for East European Studies [University of Bremen], 181

restructuring process, 97,127

resurgence, 9,115

return migration, 22 , 97, 150, 152-55, 165, 185, 197-198

revitalizing effect, 63

right-wing parties, 111

risk aversion, 22, 174, 185

rule of law, 177

rural/urban divide [Turkey], 122

rural-to-urban migration [Turkey], 184

Russian language policy, 172

Russian-speaking population, 157

safeguard measures, 9

Schengen acquis, 98

Schengen visa, 47

seasonal migrant worker programme, 105

Second World War, 137, 188

second-class residents, 170

second-generation youth, 168

secular society, 112

security-related crises, 112

Seville Summit, 112-113

Single European Act (SEA), 29, 99, 108

single European market, 2, 29, 104, 114, 182

skill

composition, 42, 105, 125, 127, 184, 195

mismatches, 125

skilled labour, 42-43, 70, 106, 110, 119, 125, 127, 166, 168, 174, 179, 181, 183, 184

spectrum, 115

social alienation, 123

Social and Cultural Planning Office

[Netherlands], 182

Social Charter [UK], 110

social cohesion, 100

social distortions, 114

social exclusion, 140, 194, 196 
social model, 31, 91

social networks, 22, 134, 137, 185, 196

social policy, 20, 22, 27, 29-31, 47-48, 50, 76, $82,98,155,196$

social protection expenditures, 76

social provision, 11, 22, 40, 107, 139-140, $146,157,166,185,196$

social security benefits, $27,95,140,146-147$

social services, 74, 140, 146

social welfare system, 63

socioeconomic outlook, 91

socioeconomic variables, 121

Southern accession countries, 60, 67, 69, 72, $75,79,82,84-85,89,91-92,96,187$, 191-192, 194, 196

Southern enlargement, 1, 59-60, 63-64, 82, 84-86, 90-92, 102, 121, 134, 153, 165, 187,191

Southern Europe, 34, 60, 67, 80, 84-87, 91, 100

Southern migration episode, 59

Soviet Union, 88, 182

Russian language policy, 172

Russian-speaking population, 157

spill-over effect, 193

standstill clauses, 46

standstill provision, 190

State Planning Organization, 23, 123, 148, 182

stop policy, 98

structural funds, 63, 148, 150, 153, 196

structural imbalances, 86,163

structural reforms, 72

surplus labour, 30, 37, 80

Tampere European Council, 99

technological change, 106

temporary labour migration, 105

terrorist attacks, 112, 114-115. See also 11 September 2001

tertiary education, 128, 130, 194

theory of integration, 165

third country nationals, 44, 48, 54, 94-96, 98-99, 192

trade deficit, 73,88

trade liberalization, 22, 147

transformations, 150

transitional freedom, 100

transitional measures, 84, 101, 192

transport cost, 5, 138

traumatized society, 162
Treaty of Lausanne, 80

Treaty of Rome (establishment of the European Economic Community, 1957), 85, 93, 114

Treaty on European Union, 99, 108. See also Maastricht Treaty

Turkey

best-qualified workers, 195

Channel TRT1, 183

Constitution, 35, 178

economy, 56, 70, 74, 90, 148, 177, 181, 186

enterprises on the European mainland, 168

membership of the EU, 9, 30, 33, 71, 80, $89,153,182,186$

Ottoman Empire, 79, 82, 89, 171

Ottoman legacy, 135

perception of Turks, 113

rural/urban divide, 122

rural-to-urban migration, 184

trade, 72,148

Turkish Population Institution, 169

Turkish Statistical Institute, 75, 123, 164

Turkish-German Education and

Scientific Research Charity, 168

24 January 1980 Decisions, 39

unpaid family workers, 122

24 January 1980 Decisions [Turkey], 39

undocumented immigrants, 114

unity in diversity, 81

University of Rouen, 166

unpaid family workers [rural Turkey], 122

unskilled jobs, 128, 168, 201

violent attacks, 113

visa-free access to EU countries, 48

visible minorities, 113

vocation. See labour

vocational training, 43, 51, 89, 95

wages, 3-5, 21-22, 31-32, 37, 55, 68, 85, 95, 121, 129, 155, 157, 182, 197. See also labour

welfare outlays, 111

welfare systems, $63,139,160$

West European countries, 2, 12-13, 16, 21, 26-27, 28, 34-36, 39-40, 58, 70, 92, 97, 
$103,105,113,127,134-135,138,153, \quad$ work. See also labour

$165,169,178,188-90,193$

workers' muscles, 171

Western Europe, 13, 16, 19, 26-28, 34, 39-40, working population, 76, 120, 146

$45,57,98,100,111-112,121,127$

135-136, 139, 148, 154, 162, 167, 170,

working-age labourers, 127

$174,177,182$

Westernization, 79-80

work-related migration, 135

xenophobia, 110, 113, 182 